\title{
Ballet Pointe Shoe Discomfort: an exploration through the use of real-time assessments while performing en pointe movements
}

By

\author{
Christel Ayoub
}

A thesis submitted to the Faculty of Graduate and Postdoctoral Affairs in partial fulfillment of the requirements for the degree of

Master of Design

In

Industrial Design

Carleton University

Ottawa, Ontario

(C) 2021, Christel Ayoub 


\begin{abstract}
Despite the advancement in technology, the ballet pointe shoe remains largely unchanged and few research studies have investigated it. The pointe shoe is still in use today and poses many disadvantages to the ballet dancer's foot health. This research aims to uncover ballet dancers' feet discomfort while dancing en pointe, in the hopes of contributing to the improvement of the future design of pointe shoes. This research brought together a human-centred approach in order to comprehend and gain different perspectives on the topic in a real-time setting. Real-time assessments were obtained using questionnaires, a 3-D apparatus of feet en pointe and thermographic imaging in a simulated ballet laboratory. Ten ballet participants currently practicing pointe work with at least two years of pointe work experience took part in the study. During the study, participants completed a pre-test questionnaire, three pointe work movements, followed by real-time discomfort assessments, thermographic imaging sessions and a post-test questionnaire. Through data triangulation, the great toe area was found to be the most frequently assessed by participants with the highest average discomfort intensity and average temperature variation. Increased temperature areas found to be a predictor for discomfort intensity, in complex movements like bourrée. Results demonstrated the relationship of the various methods used and their contribution on examining real-time pointe shoe discomfort and pointe shoe design recommendations.
\end{abstract}

Keywords: human-centered approach, discomfort, en pointe, real-time assessments, pointe shoes 


\section{ACKNOWLEDGEMENTS}

In memory of my cousin Imad, for always reminding us to do what makes us happy.

I wish to express my deepest gratitude to my family and friends. To my parents, Joseph and Hélène thank you for your unconditional love, support and allowing me to follow my dreams. To my sisters, my musketeers, Lizbeth and Cosette thank you for always encouraging me, guiding me and supporting me no matter the distance. To the Zeadey's, Faith and Mary Ann, thank you for your unmeasurable support to our family and for inspiring us from a very young age to pursue a higher education. And, to my friends, Amina, Lana, Libby, Kizi and Samiyah, thank you for always being there, listening, and encouraging me.

I wish to express my sincere appreciation to my supervisor, Stephen Field. Thank you for your invaluable support, patience, encouragement and helping me be the designer that I am today. To my co-supervisor, Dr. Adrian Chan, thank you for your patience, expertise and guidance within an unfamiliar field of study. Thank you to Dr. Lois Frankel and Dr. Audrey Girouard for allowing me to enrich my knowledge and career in User Experience, through CLUE - NSERC.

I wish to extend a special thank you to the lab technicians at The School of Industrial Design, Walter Zanetti, Paul Durocher, Anthony Dewar and my lab assistants Amina Balaa and Kayla Daigle. Many thanks to Kathryn Burke and fellow colleagues at IRCC for allowing me to step away from my professional role to finalize my graduate degree. Finally, thank you to the ten participants that gave their valuable time and insights and made this research possible. 


\section{TABLE OF CONTENTS}

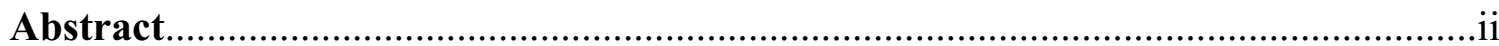

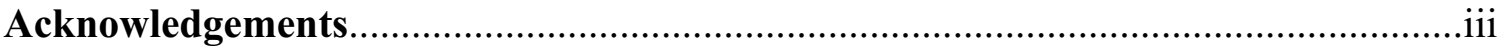

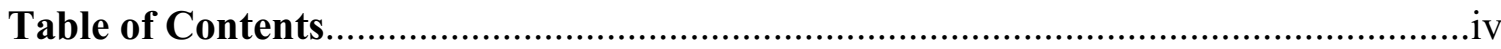

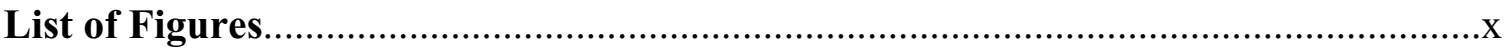

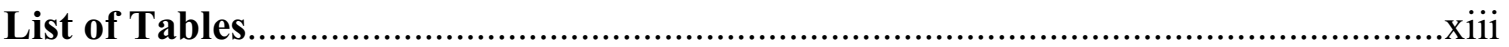

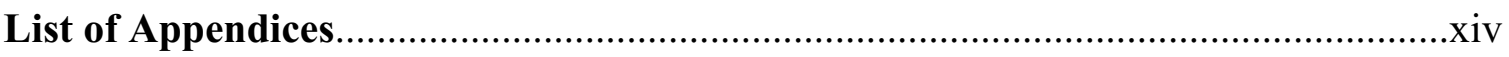

Preface

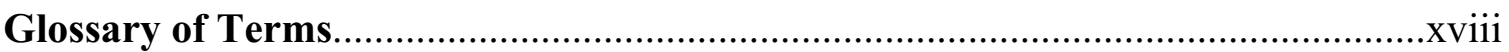

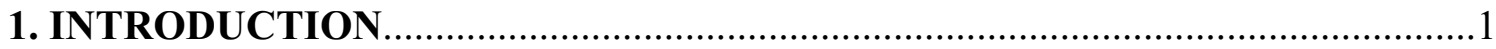

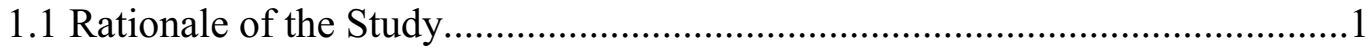

1.2 Research Questions.............................................................................2

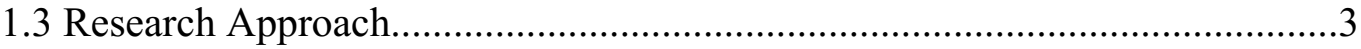

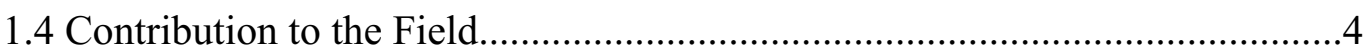

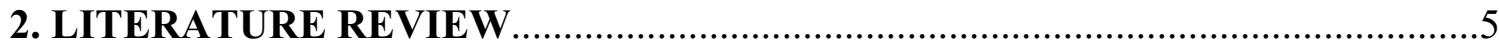

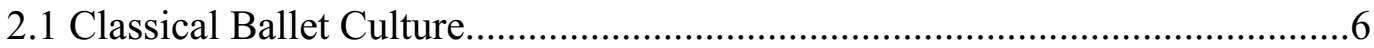

2.1.1 The Ideal Ballerina.................................................................6

2.1.2 Traditional Ballet Pedagogy, Hierarchy and Body Image................. 7

2.1.3 Pain Tolerance and its Risks....................................................

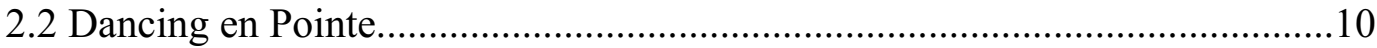

2.2.1 Pointe Work Readiness and Technique.......................................11

2.2.2 The Role of the Foot and Pointe Work Related Injuries..................12

2.3 Pointe Shoe Designs and its Current Advancements...................................13 


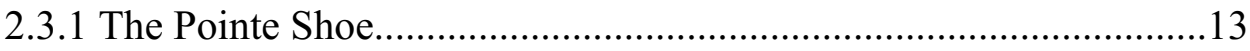

2.3.2 Pointe Shoe Intricacies...................................................................16

2.3.3 Pointe Shoe Advancements.............................................................17

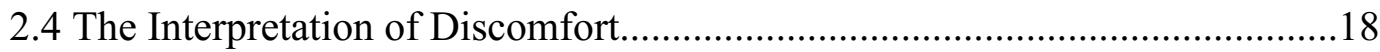

2.4.1 Real-time Assessment Rating Scales................................................19

2.4.2 Infrared Thermographic Imaging as an Assessment Tool.................20

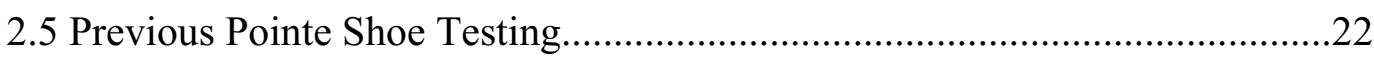

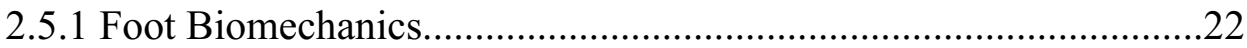

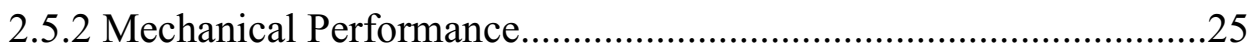

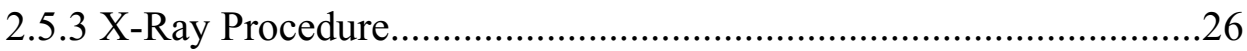

2.5.4 Magnetic Resonance Imaging......................................................26

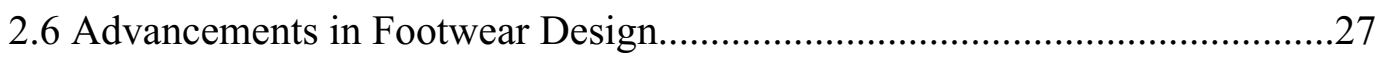

2.6.1 Customization in Footwear for Comfort and Fit..............................28

2.6.2 Athletic Footwear Testing Procedure..............................................28

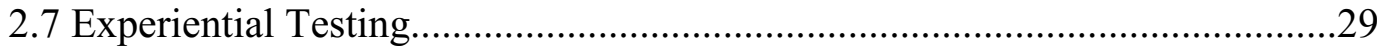

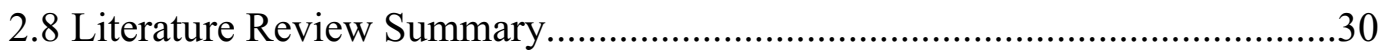

3. METHODS

3.1 Research Approach..................................................................................

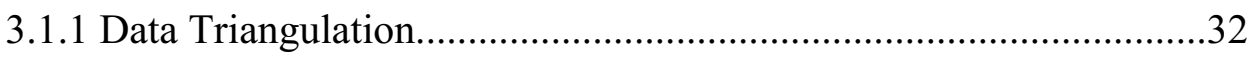

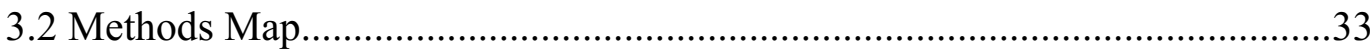

3.3 Participant Prerequisites and Recruitment.......................................................34

3.4 The Ballet Studio Laboratory Design....................................35

3.4.1 Zone 1 Questionnaires........................................... 
3.4.2 Zone 2 Real-time Discomfort Assessments...........................38

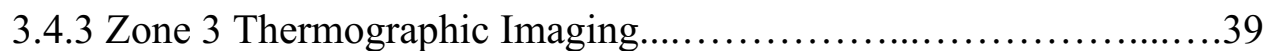

3.5 Pre-Test Questionnaire Design..........................................40

3.6 Real-time Discomfort Assessment Design...................................41

3.6.1 Questionnaire and Real-time Discomfort Scale Design....................44

3.6.2 3-D Printed Feet Assessment Apparatus Design................................46

3.6.3 Real-time Discomfort Assessment Procedure.....................................50

3.6.4 Real-time Discomfort Assessment Collection Method.....................51

3.7 Thermographic Imaging Protocol Design...................................52

3.7.1 Equipment, Tools and Space Planning.............................................52

3.7.2 Imaging Sessions Procedure............................................................54

3.7.3 Image Collection Method...............................................................56

3.8 Post-Test Questionnaire Design.......................................57

3.9 Test Session Procedures..................................................58

3.9.1 Pre-Test Session................................................................................59

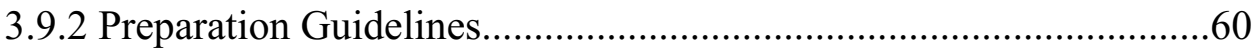

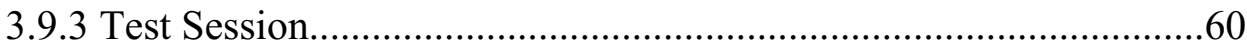

3.9.3.1 Introductory Questionnaire................................................61

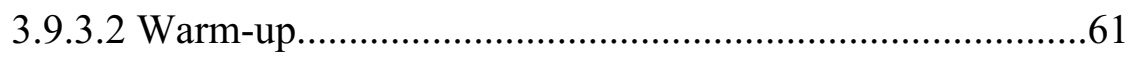

3.9.3.3 Real-time Discomfort Assessment 1..................................62

3.9.3.4 Real-time Discomfort Assessment 2................................62

3.9.3.5 Real-time Discomfort Assessment 3..................................63

3.9.3.6 Closing Questionnaire..........................................................64 


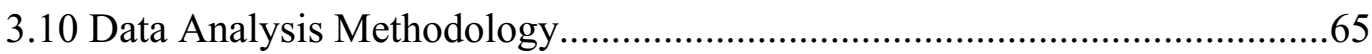

3.11 Participant Questionnaire Response Analysis........................................65

3.12 Real-time Discomfort Assessment Analysis..............................................66

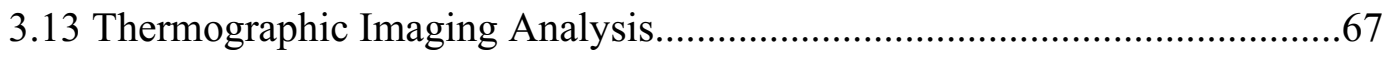

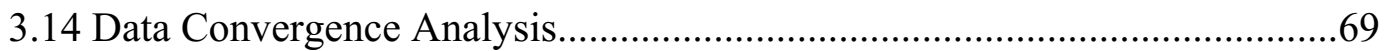

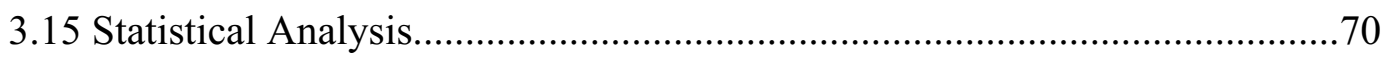

3.15.1 Average Delta T and Discomfort Area Ratings Differences for Movement $(1,2,3)$............................................................................ 71

3.15.2 Relationship Between Average Delta T and Discomfort Area

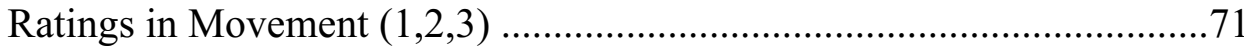

3.15.3 Relationship Between Average Delta Temperatures and Average

Discomfort Ratings of the Great Toe in Movement $(1,2,3)$...................72

3.15.4 Overall Discomfort Intensity.............................................. 72

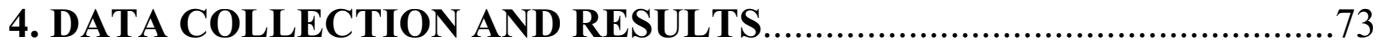

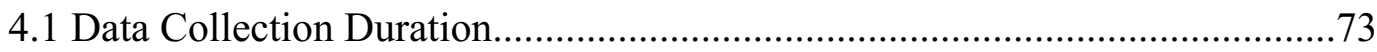

4.2 Zone 1 Pre-test Questionnaire Results ......................................................74

4.2.1 Participant Background............................................................ 74

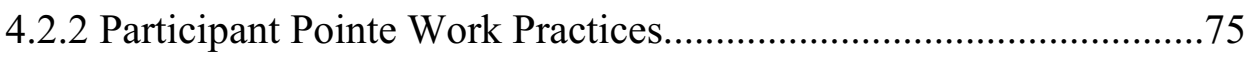

4.2.3 Participant Pointe Shoes........................................................... 75

4.2.4 Participant Usual Discomfort.................................................. 76

4.3 Zone 2 Real-time Discomfort Assessments Results.....................................77

4.3.1 Pointe Work Movement 1 Échappé..............................................77 
4.3.2 Pointe Work Movement 2 Sissonne Simple.......................................78

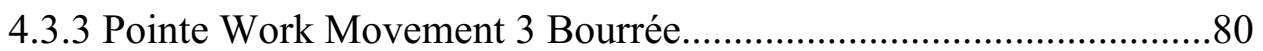

4.4 Zone 3 Thermographic Imaging Results ....................................................

4.4.1 Pointe Work Movement 1 Échappé......................................................81

4.4.2 Pointe Work Movement 2 Sissonne Simple.....................................82

4.4.3 Pointe Work Movement 3 Bourrée.....................................................83

4.5 Zone 1 Post-test Questionnaire Results ………………………….................83

4.5.1 Participant Post-test Discomfort.......................................................84

4.5.2 Participant Previous Pointe Injuries..................................................84

4.5.3 Participant Testing Experience..........................................................85

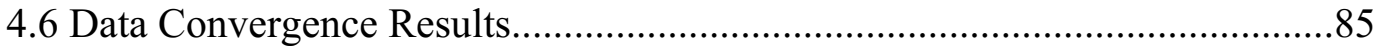

4.7 Average Delta T and Discomfort Intensity Differences for

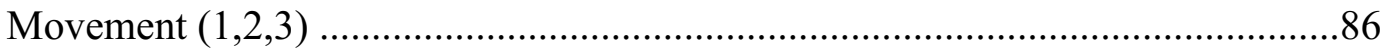

4.8 Relationship Between Average Delta T and Discomfort Area Ratings in

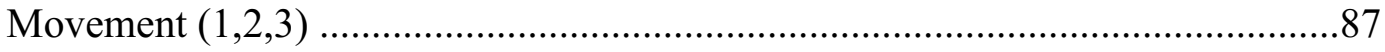

4.9 Relationship Between Average Delta Temperatures and Discomfort Ratings of

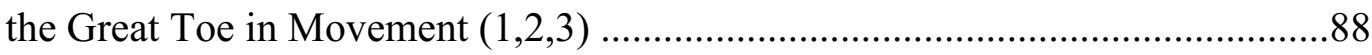

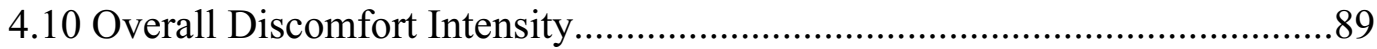

5. DISCUSSION

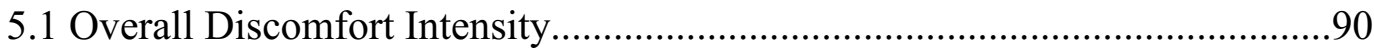

5.2 Real-time Discomfort Assessments..............................................................91

5.2.1 Feet Discomfort in Questionnaires and Movement $(1,2,3)$..............91

5.2.2 Feet Discomfort Areas Assessed in Movement $(1,2,3)$...................92 


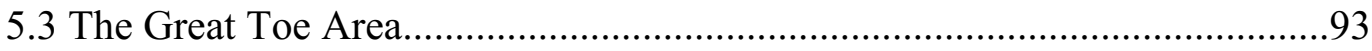

5.4 Pointe Shoe Design Recommendations.........................................................95

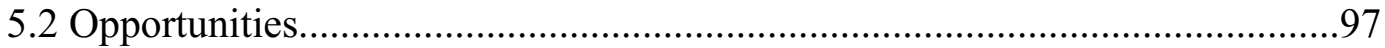

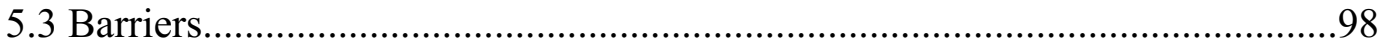

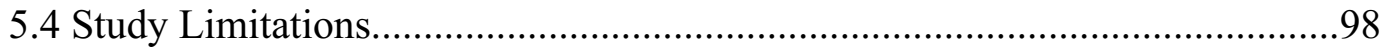

6. CONCLUSION

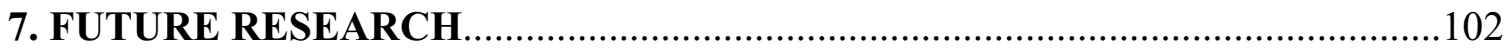

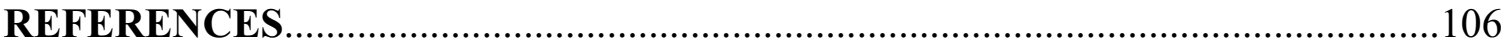

APPENDICES 


\section{LIST OF FIGURES}

Figure 1. Illustration of the literature review map.......................................................

Figure 2. Interpretation of Balanchine's re-creation of the ideal ballerina...........................

Figure 3. Ballet teacher correcting a ballet dancer during class (O’Connor, 2020) ...........8

Figure 4. Side view of ballet dancer's feet when en pointe (Freepik, 2020) .....................10

Figure 5. Illustration of the pointe shoe's toe box, shank and platform.............................14

Figure 6. The traditional satin pointe shoe (DFS, 2021) and a cut-away of its traditional

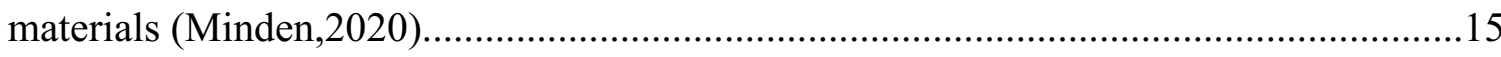

Figure 7. The Verbal descriptor Scale (VDS), the Numeric Rating Scale (NRS) and the

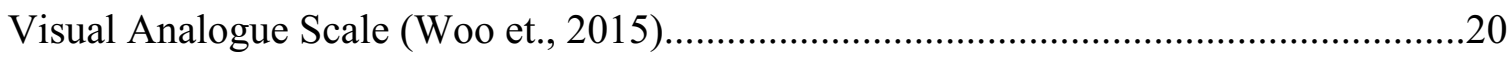

Figure 8. Thermographic imaging used for detecting body temperature (FLIR, 2020)....21

Figure 9. Illustration of data triangulation used for this study..........................................32

Figure 10. Illustration of the methods map used during the preliminary stages of this

study

Figure 11. Illustration of the ballet studio laboratory floor plan.........................................36

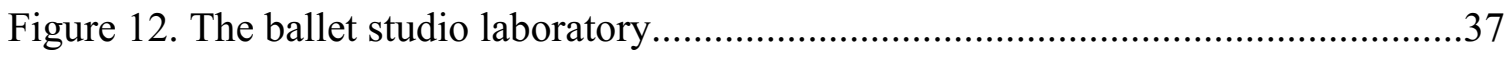

Figure 13. Zone 1: pre-test and post-test questionnaires................................................38

Figure 14. Zone 2: warmup, pointe movements and real-time discomfort assessments...39

Figure 15. Zone 3: thermographic imaging sessions....................................................40

Figure 16. Real-time discomfort assessment areas on the 3-D apparatus.........................42

Figure 17. Movement 1 performed for 1 minute by alternating the front foot when springing to go en pointe.

Figure 18. Movement 2 performed for 1 minute by alternating the left and right foot en

pointe 
Figure 19. Movement 3 performed for 1 minute by rapidly alternating the weight on the left and right foot when en pointe

Figure 20. Real-time discomfort scale design..........................................................45

Figure 21. Real-time discomfort scale used during testing.......................................45

Figure 22. 3-D printed apparatus of feet en pointe used for all real-time discomfort assessments 46

Figure 23. 3-D scanning procedure of a ballet dancer's foot en pointe.............................48

Figure 24. 3-D printed feet en pointe apparatus used for all real-time assessments.........49

Figure 25. Equipment used during the thermographic imaging sessions.........................53

Figure 26. Setup of the secluded thermographic imaging area....................................54

Figure 27. Tool designed to capture the plantar view of the feet..................................54

Figure 28. Feet positions for each sequence and its correspondent thermal map.

Figure 29. Illustration of the data collection map for each test session. .59

Figure 30. Illustration process for real-time discomfort used as visual reference............66

Figure 31. Illustration process for thermal areas used as visual reference.....................68

Figure 32. Illustration of the statistical analysis map used during the analysis stage of this study. .70

Figure 33. Movement 1 real-time discomfort assessment areas results. .78

Figure 34. Movement 2 real-time discomfort assessment areas results.........................79

Figure 35. Movement 3 real-time discomfort assessment areas results.........................80

Figure 36. Significant differences of (a) discomfort level and (b) delta T (a).................87

Figure 37. Relationship between the average delta $\mathrm{T}$ of the great toe and average real-time discomfort intensity for movement 3 .88 
Figure 38. Differences between overall discomfort intensity before, during and after

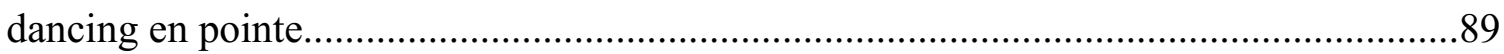

Figure 39 . The great toe area localized most frequently by participants in real-time

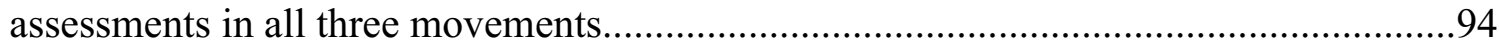

Figure 40. Illustration of the area of recommendation, the pointe shoe's toe box...........95 


\section{LIST OF TABLES}

Table 1. Movement 1 real-time discomfort assessment results.......................................78

Table 2. Movement 2 real-time discomfort assessment results....................................79

Table 3. Movement 3 real-time discomfort assessment results......................................80

Table 4. Movement 1 average delta T for all real-time discomfort areas assessed...........82

Table 5. Movement 2 average delta T for all real-time discomfort areas assessed..........82

Table 6. Movement 3 average delta $\mathrm{T}$ for all real-time discomfort areas assessed...........83 


\section{LIST OF APPENDICES}

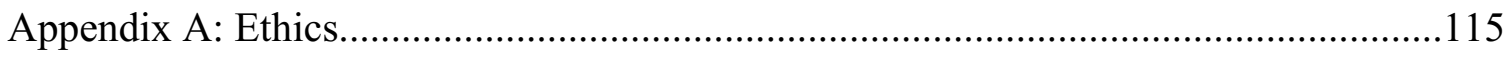

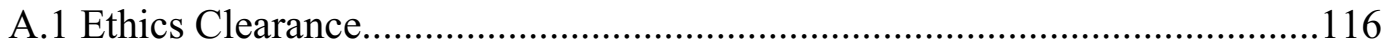

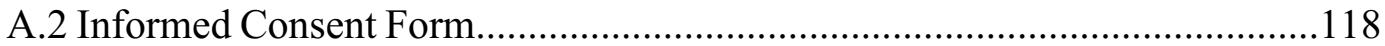

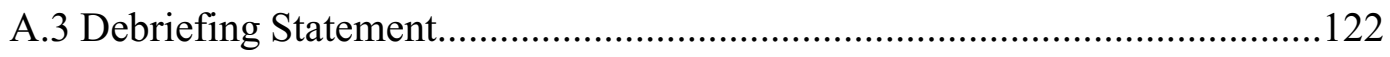

Appendix B: Recruitment ........................................................................................125

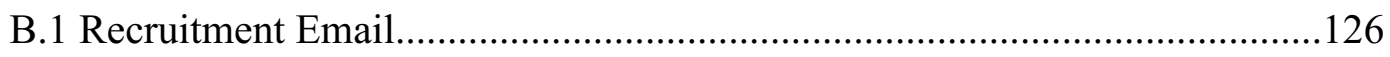

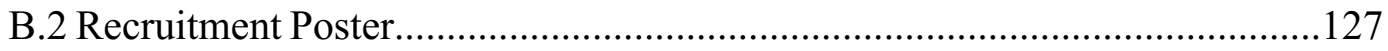

Appendix C: The Ballet Studio Laboratory...............................................................128

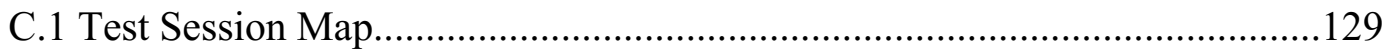

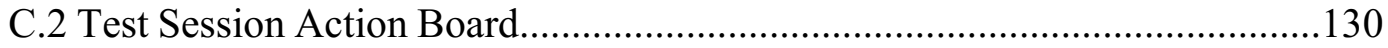

Appendix D: Zone 1 Questionnaires.........................................................................133

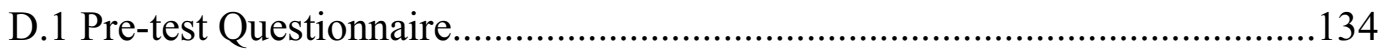

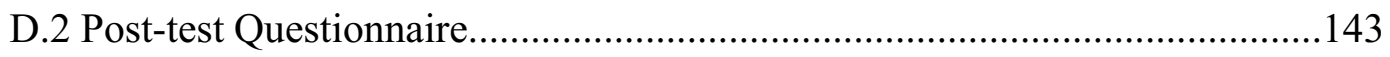

Appendix E: Zone 2 Real-time Discomfort Assessments...............................................148

E.1 Fundamental Pointe Work Movements.......................................................149

E.2 Real-time Discomfort Assessment Questions................................................152

E.3 Guidance Steps for Data Collection.............................................................153

E.4 Feet Positions for Real-time Discomfort Assessment Movement $(1,2,3)$......154

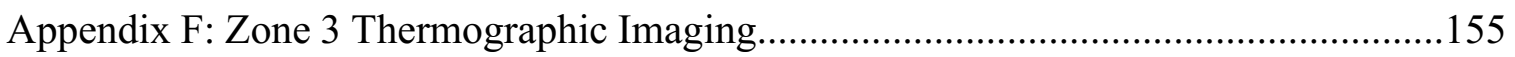

F.1 Thermographic Imaging Setup Design ......................................................156

F.2 Thermographic Imaging Feet Positions Test Sessions.....................................157

F.3 Thermographic Imaging Preparation Checklist for Participants......................158 
Appendix H: Data Analysis Methodology

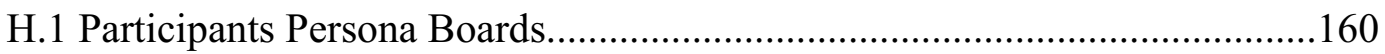

H.2 Average Discomfort Intensity of Both Feet for Movement $(1,2,3)$................165

H.3 Reference Material used for Thermographic Imaging Analysis.......................166

H.4 Thermographic Imaging Analysis Report...................................................175

H.5 Average Delta T and Average Discomfort Rating Results..............................189

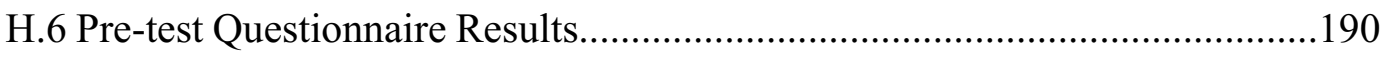

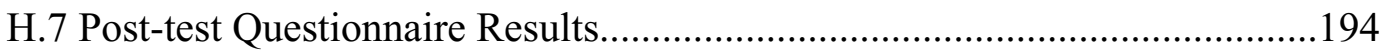

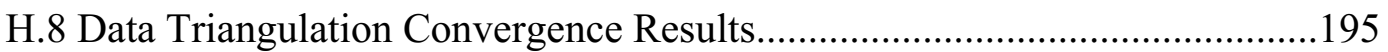




\section{PREFACE}

Ever since I was a child, I had one dream: to become a professional ballet dancer. I imagined myself dancing on a big stage, applauded by thousands of people. However, my journey to make this dream come true was as painful as it was magical. I dedicated myself to over 14 years of dancing and choreographing classical ballet. Despite the challenging nature of this career path, I was ready to persevere through hours and hours of practice and countless blisters and painful feet. However, life had other plans and I came to the realization that pursuing ballet as a professional career was not for me at the time. This resulted in exploring a different creative avenue, my undergraduate, and higher education in Industrial Design.

While studying Industrial Design at Carleton, ballet continuously influenced all parts of my study and served as creative inspiration: The moving lines and shapes which dancing creates ignited my imagination towards better product design; The discipline and perfectionism I gained from years of dancing, inspired me to be diligent in terms of quality, aesthetics, and functionality. Merging the world of ballet and design together, I advanced my studies and decided to use my experience and passion for both design and ballet to help address the issues around the painful journey that ballet dancers have to experience, specifically in regard to pointe shoe discomfort.

Being a graduate student at The School of Industrial Design has given me the opportunity to explore the world of ballet and pain from an interdisciplinary perspective. This approach allowed me to research and analyze the subject from different fields of expertise, resulting in an enhanced delivery and communication of the study. In addition, 
my professional work experience in user experience research and design has allowed me to understand the importance of a user's experience, which greatly contributed to this study. I am hoping that my passion for the craft of ballet, and my love for design will help to improve the ballet dancer's experience, so they can continue to enrich our world with their art. 


\section{GLOSSARY OF TERMS}

Bourrée: also known as "bourrée en couru" or "pas couru", is an advanced pointe movement done en pointe, moving in a straight line or diagonally across the floor. It entails small quick steps in the $5^{\text {th }}$ ballet position (en pointe), keeping no space between the feet. The front foot bears most of the ballet dancer's body weight and the foot placed behind is in charge of the travelling movement. The knees must only bend enough to allow the movement to occur.

Breaking in process: also known as "softening" pointe shoes, is a technique used by ballet dancers to mold the pointe shoe according to the shape of their foot. It involves various techniques targeting the toe box and the shank of the shoe primarily due to their stiffness properties.

Cecchetti technique: an Italian ballet technique which is one of the main training techniques of classical ballet developed by Enrico Cecchetti. This technique is known for its strict training regimen. A ballet dancer training in Cecchetti moves as an instrument does, where the arms and legs are all one working entity. It is not as soft and romantic like the French and Russian technique.

Coup-de-pied: a position of the non-working foot and not a pointe movement. It is when the foot that is not en pointe (the non-working foot) is placed on the other leg between the base of the calf muscle and the top of the ankle.

Dancing en pointe: also known as "pointe work", classical ballet technique that involves dancing on the tips of the toes with the help of the pointe shoe. 
Demi-pointe: when a ballet dancer stands on the ball of one foot or both feet with the heels off the ground.

Demi-pointe shoe: a shoe-like slipper worn by ballet dancers from their initial ballet class until their last. This is also a transition shoe before graduating to the pointe shoes. Its composition is made of canvas or leather, depending on the brand, and has a flexible shank (midsole part of the shoe).

Échappé: a fundamental pointe movement, performed en pointe, pushing off with the heels from the $5^{\text {th }}$ ballet position, while springing into $2^{\text {nd }}$ position en pointe, and alternating the feet. The body weight is distributed on both feet.

En pointe: a position in ballet also known as "sur les pointes" where the dancer executes ballet movements on the tip of the toes, either on one or both feet, with the help of the pointe shoe.

Fifth ballet position: also known as " $5^{\text {th }}$ position", where the ballet dancer stands with the feet turned out in order for the front foot's heel touches the back of the foot's toe.

French technique: one of the main training techniques of classical ballet developed by Rudolf Nureyev. The French technique was influenced by the Russian ballet method. This technique is known to be one of the most fluid methods of ballet, although it is not practiced outside of L'Opéra de Paris ballet school. A ballet dancer training in this technique is known to have musicality, while portraying an ethereal look and executing complex movements with precision. 
Platform: a flat area located at the tip of the pointe shoe. When en pointe, it enables the dancer to balance due to its flat surface.

Pointe shoe: a shoe-like slipper worn by ballet dancers which enables them to do pointe work; executing ballet movements on the tip of the toes. Depending on the brand, the front of the shoe (toe box) is traditionally constructed of densely packed layers of fabric, cardboard, and/or paper which is hardened by glue. The other parts of the shoe are made of leather, cotton and satin. The Traditional shoe is handmade by a pointe shoemaker.

Pointe technique: an extension of ballet technique, using the same terminologies. There are three pointe techniques when rising en pointe: the French technique, the Cecchetti technique, and the Vaganova technique.

Rélevé: a fundamental ballet movement performed either en pointe or demi-pointe by raising one of both feet into position. The body weight is distributed on both feet.

Shank: midsole part of the pointe shoe, providing support to dancer's foot arch while balancing on their toes, due to its stiffness properties.

Sissonne Simple: a fundamental pointe movement performed en pointe, pushing off with the heels starting in $5^{\text {th }}$ position, while springing onto one foot at a time and raising the other leg into a coup-de-pied and alternating the feet. The body weight is distributed on one foot at a time.

Toe box: front part of the pointe shoe that holds the toes, which is the stiffest part of the shoe. Depending on the brand, the traditional toe box is made of strips of burlap, canvas, 
or newspaper saturated with glue and layered like papier-mâché. To accommodate different shaped feet, they come in different shapes and different amounts of coverage of the forefoot.

Turnout: when rotating the hips which causes the feet to turn outward, away from the front of the leg.

Vaganova technique: a Russian ballet technique developed by Agrippina Vaganova. The Russian technique is a fusion of the French ballet style and the Italian ballet style, with traditional Russian character dancing. This technique is known for having precise movements with clean lines yet performed with a softness. A ballet dancer trained in the Vaganova technique is known to be very strong, while executing precise movements performed effortlessly. 


\section{INTRODUCTION}

The hardships of a ballet dancer are prominent as pain and injuries are part of the culture (Hoogsteyns, 2013; Wulff, 2001). The ballet pedagogy demands the female ballet dancer years of training to be able to dance en pointe (Aalten, 1997) with a shoe failing to protect the foot (Tuckman, Werner, James, \& Bayley, 1991). Despite modern advancements, the ballet pointe shoe remains unchanged since its early creations and female ballet dancers are still performing pointe work on cardboard hardened with glue (Colucci \& Klein, 2008). This research aims to uncover real-time discomfort by allowing ballet dancers to voice and localize the discomfort experienced while dancing en pointe, within a safe and secluded environment. An interdisciplinary approach is used to investigate pointe shoe discomfort through the use of real-time assessments, while performing pointe work movements within a ballet studio laboratory in the hopes of contributing to a future pointe shoe design.

\subsection{Rationale of the Study}

While ballet is considered a traditional dance performance, modern researchers view it as an extreme sport, only second to football (Martin, 1997). However, little research has investigated the equipment used by ballet dancers to perform their sport. The pointe shoe has not evolved since its early creation two hundred years ago (Colucci \& Klein, 2008). As such, research has shown that the pointe shoe design still causes discomfort, foot deformation, and chronic injuries (Anderson, Ng, Benwood, \& Walter Jr., 2015; Colucci \& Klein, 2008; Khan et al., 1995; Spilken, 1990; Turner \& Wainwright, 2003) which eventually hinders the dancers' career. It is mentioned that, in the ballet industry, ballet 
dancers are voiceless and are expected to be silent regarding the discomfort they experience, (Kelly, 2012), as it is a necessity to endure pain and discomfort during their training and careers (Wulff, 2001). A review of literature on the subject has revealed no academic work about real-time discomfort assessments when en pointe. The use of realtime data allows sampling moments from the user's experience more precisely than traditional means of assessment, reducing memory and other biases associated with recall of experience (Stone \& Broderick, 2007). As such investigating areas of real-time discomfort while performing pointe work movements will open the door for future improved designs of the ballet shoe.

\subsection{Research Questions}

Studies have indicated that the experience of dancing en pointe remains "elusive" (Barringer \& Schlesinger, 2012, p. 315). This research aims to unravel the ballet dancers' experiences of discomfort when dancing en pointe, in the hopes of contributing to advancements in the future design of pointe shoes, by using questionnaires, thermographic imaging, and discomfort assessments in a real-time setting.

The principal question of this thesis asks: How can real-time discomfort assessments help identify the main areas of foot discomfort when dancing en pointe, using ethnographic assessments, thermographic imaging, and a 3-dimensional assessment tool?

To explore this question, the study examines ballet dancers' real-time discomfort when en pointe, seeking to answer the following: 
- What are the prevalent areas of real-time discomfort of the feet and is there a correlation between the thermographic imaging and discomfort assessment outcomes identified by ballet participants when en pointe?

- How does discomfort intensity change overtime, before dancing en pointe, while dancing en pointe, and after dancing en pointe?

- What are the benefits and barriers of using real-time discomfort assessments in investigating the ballet dancers' experience when performing pointe work movements?

- Can real-time discomfort assessments be utilized to develop a design guideline for future pointe shoe design?

\subsection{Research Approach}

This study begins with a literature review to assess the current data collected regarding pointe shoes and their effects on the ballerina's health within the ballet culture. The review further explores the current advancements in pointe shoe design and testing while examining how real-time assessments and experiential testing can benefit the accuracy of data collection of in-the-moment experiences. Furthermore, this study's human-centered approach, explored through data triangulation, is described. Three distinct measures of data collection, conducted in a simulated ballet studio environment using both qualitative and quantitative research methods: questionnaires, real-time discomfort assessments, and thermographic imaging sessions. This study is based on objective and not subjective measures of experienced discomfort. Each test session included: an introductory questionnaire, three fundamental en pointe movements followed by real-time discomfort assessments, thermographic imaging sessions, and a closing questionnaire. After the 
sessions were completed, the results were synthesized through data triangulation and statistical analysis using data visualization as a point of reference. Finally, recommendations for future design and research development of pointe shoes are proposed for future investigative research.

\subsection{Contribution to the Field}

Our research contributes to pointe shoe designers, researchers, and the larger ballet industry. It aims to bridge the gap between the industries of ballet, design, and academia, allowing for an opportunity to apply the technological advancements of research for the benefit of the ballet dancer. First, we provide real-time data, from a multidisciplinary approach, to benefit the design of a customizable product, "the pointe shoe", based on user's, “the ballerina's", insights. Second, we provide integrative methodologies for future researchers to approach a design problem using self-report metrics and thermographic imaging. Third, these approaches will create a bridge between ballet and design for the possibility of advancing the ballet pointe shoe. Most importantly, we propose that our findings could enhance the ballet dancer's experience when dancing en pointe through the design and development of an improved pointe shoe. 


\section{LITERATURE REVIEW}

The ballet pointe shoe has been researched in a multitude of disciplines including, but not limited to cultural studies, sociology, anthropology, biomechanics, medicine and psychology. However, research on the pointe shoe in design is scarce. Given that very few studies have yet to explore real-time discomfort assessments when dancing in pointe shoes, this research focuses on unravelling the female ballet dancers' foot discomfort areas while dancing en pointe, in the hopes of contributing to the improvement of pointe shoes design. The following sections outline the risks of classical ballet culture, pointe work and pointe shoes on the ballerina's feet health. In parallel with, the interpretation of discomfort, real-time assessments and experiential testing. The literature study revealed how real-time assessments, specifically applying user experience research principles in a testing environment, captures real-life experience data. Figure 1, illustrates the mapping of the literature review, including key elements and influencing factors to this research.

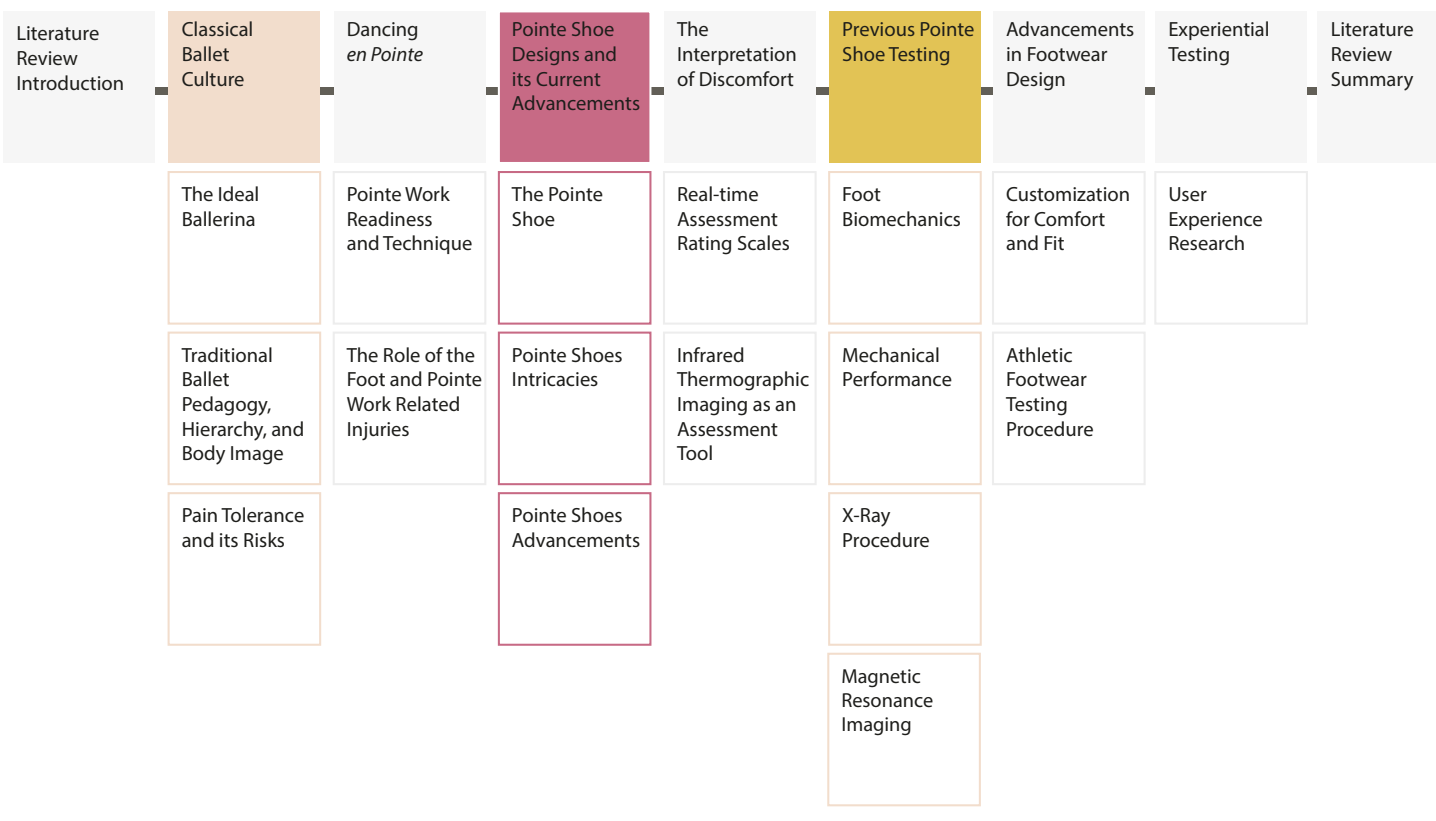

Figure 1. Illustration of the literature review map. 


\subsection{Classical Ballet Culture}

"The ballet world is an intense, closed, highly specialized community...", explained Wulff (2001) when shadowing the international renowned ballet companies (p.18). The distinct culture of ballet differs from dance genres and dance culture, dues to its traditions and hierarchy (Wulff, 2001). Numerous authors discuss the risks and effects of its traditional pedagogy and hierarchal influences on the health of the ballerina. However, the experience of pain and discomfort when dancing en pointe, is yet to be investigated, as it is known to be kept silent. In order to comprehend the cultural barriers that it implements on the ballerina's experience, it is crucial to identify the degree of its traditional pedagogy, hierarchy, body work, pain tolerance, and its risks.

\subsubsection{The Ideal Ballerina}

Having an ideal aesthetic plays a significant role in the experience of the ballet dancer. The iconic look of the ballerina was re-created by George Balanchine “... according to his own idea of what the ideal female dancer should look like: tall, with long legs, highly arched and flexible feet, narrow hips, long arms, and a small head” (p.131) (Martins, 1997)(see Figure 2). George Balanchine was a renowned and influential choreographer in the ballet industry. He looked for perfect dancers Martins (1997) explains, he said “proportion is everything. That's all that matters. Even the neck has to be perfect" (p.9). Additionally, the choreographer felt no shame in describing his ideal female body as "like toothpick", extreme thinness (Kelly, 2012, p.137). His creation of the ideal ballerina heavily influenced ballet training, pressuring the female ballet dancer to maintain a strict body image, while achieving high performance. In particular, the ideal ballerina's feet 
should be highly arched and flexible, while moving at a fast, graceful pace. This is achieved and maintained through rigorous training by ballet teachers.

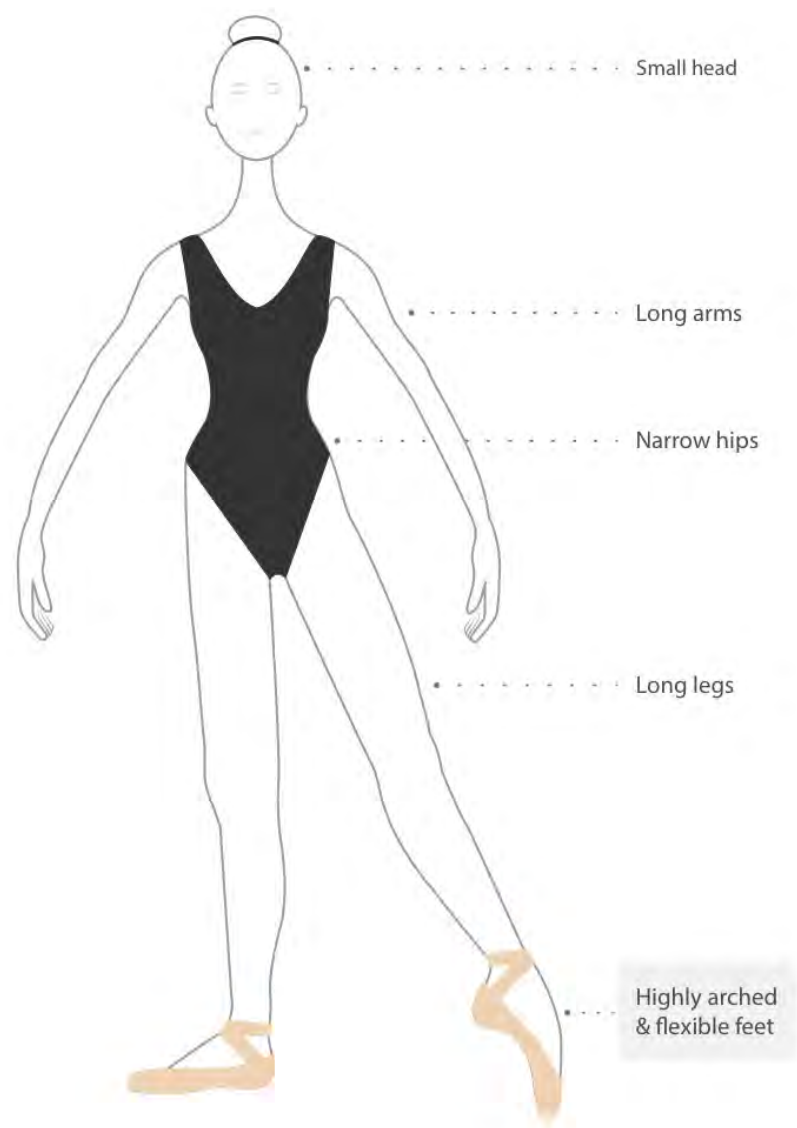

Figure 2. Interpretation of Balanchine's re-creation of the ideal ballerina.

\subsubsection{Traditional Ballet Pedagogy, Hierarchy and Body Work}

Ballet pedagogy is a strict regime and plays an integral role in the physique and psychology of the dancer's training and performances. According to Wulff's research, ballet companies still hold to this day a pyramidal hierarchy, dismissing dancers from exploring personal experiences (2001, p.34). A standard ballet class carries the same structure for beginners as for professionals, starting with the ballet barre for warmup and the centre to dance (Minden, 2005). Although it carries the same structure, Kirstein \& 
Stuart (2004, p.10) emphasize how during a ballet class, there is no room for improvisation, experiment, or doubt. In such, the dancer submits to the ballet discipline which will shape her body's anatomy in time for stage performance (Kirstein \& Stuart, 2004)(see Figure 3).

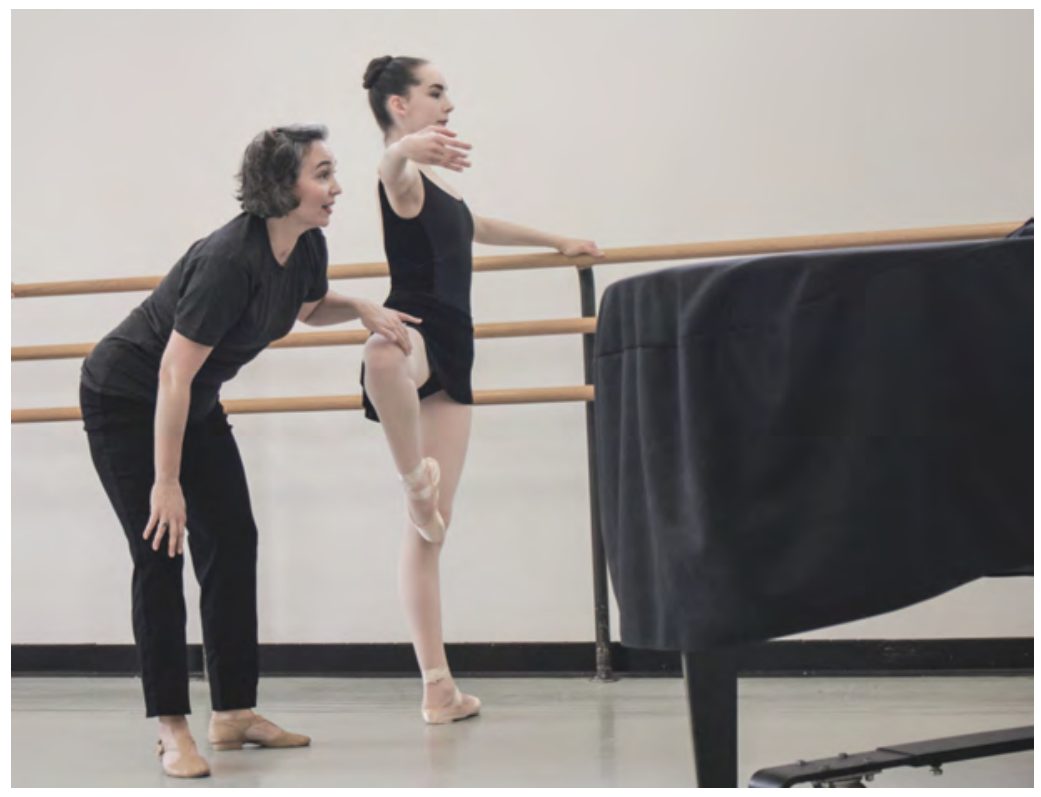

Figure 3. Ballet teacher correcting a ballet dancer during class (O’Connor, 2020).

Mandated by ballet tradition, female ballet dancers are constantly seeking perfection towards body image and ballet techniques (Wulff, 2001; Aalten, 2007). Therefore, it is essential that dancers continuously monitor, manage, maintain, and discipline their body (O’Brien, 2014, p.7). Ballet dancers train in a competitive atmosphere where they seek perfection, leading them to a culture of risk (McEwen and Young, 2011). In order to achieve the role, they always dreamed of, dancers depend on their body and its performance, since they are constantly striving to perfect their art (Wulff, 2001). While the audience is watching the ballerina dancing with her pristine satin shoes on the outside, little do they know what is kept on the inside of her shoe (Fisher, 2007). 


\subsubsection{Pain Tolerance and its Risks}

Ballet dancers experience pain and discomfort, but they are trained to tolerate it (Aalten, 2001, 2007). This leads to acute and chronic injuries and shorter career spans. Research investigating pain experience is limited (Encarnacion, Meyers, Ryan, \& Pease, 1999). Current literature investigates mainly professional ballet dancers' overall pain perception, influencers and its risks on their health and careers. However, recreational female ballet dancer's feet discomfort when dancing en pointe, is yet to be elucidated.

In a study using multidimensional measures of pain on 105 subjects, ballet dancers were found to have significant higher pain thresholds and pain tolerance than non-dancers, similar to athletes (Tajet-Foxell \& Rose, 1995). Tajet-Foxell \& Rose found that this phenomenon is most likely due to greater exposure to physical training and ballet dancers' increased fitness, but also psychological factors which ballet dancers experienced in coping with pain (1995). Most importantly, ballet dancers can ignore pain and physical problems, as it is an inevitable part of their career (Aalten, 2005, 2007; Wulff, 2001; McEwen \& Young, 2011). The daily experience of female ballet dancers, consists of pain in their toes as they are being forced into pointe shoes and onto the tip of their toes, defying human principles, (Aalten, 2005, 2007). Blisters, bunions, and ingrown toenails are all part of the painful experience disclosed by ballet dancers (Fisher, 2007). Although, pain is not discussed when training or performing, it is often welcomed by the dancer as it can be a sign of hardship and physical improvement (Wulff, 2001). "There was this little note in the dressings room saying: "Blood is good, no pain no gain", explained by a dancer in Aalten's study (2007, p.116). Research has shown that most ballet-related injuries are a result of ignoring pain and not seeking medical advice in 
order to maintain status among the pyramidal hierarchy, resulting in acute injuries (Encarnacion, Meyers, Ryan, \& Pease, 2000). Although, it is believed that pointe work technique is a cause of injury risks (Khan et al., 1995).

\subsection{Dancing en Pointe}

Dancing en pointe entails to dance on the extreme tips of all toes of the foot, where the arch is extended (Vaganova, 1969, p.109)(see Figure 4, Freepik 2020). The ballerina is required by ballet traditions, to create the illusion of lightweight fluidity. Ballet experts and podiatry specialists discuss the risks and effects of dancing en pointe on the ballerina's foot health, specifically how improper technique can lead to discomfort, pain and prolong injuries. In order to comprehend the ballerina's journey, it is important to elucidate the effort it takes to commence pointe work, its different techniques, the role of the foot and its related injuries due to pointe work practice.

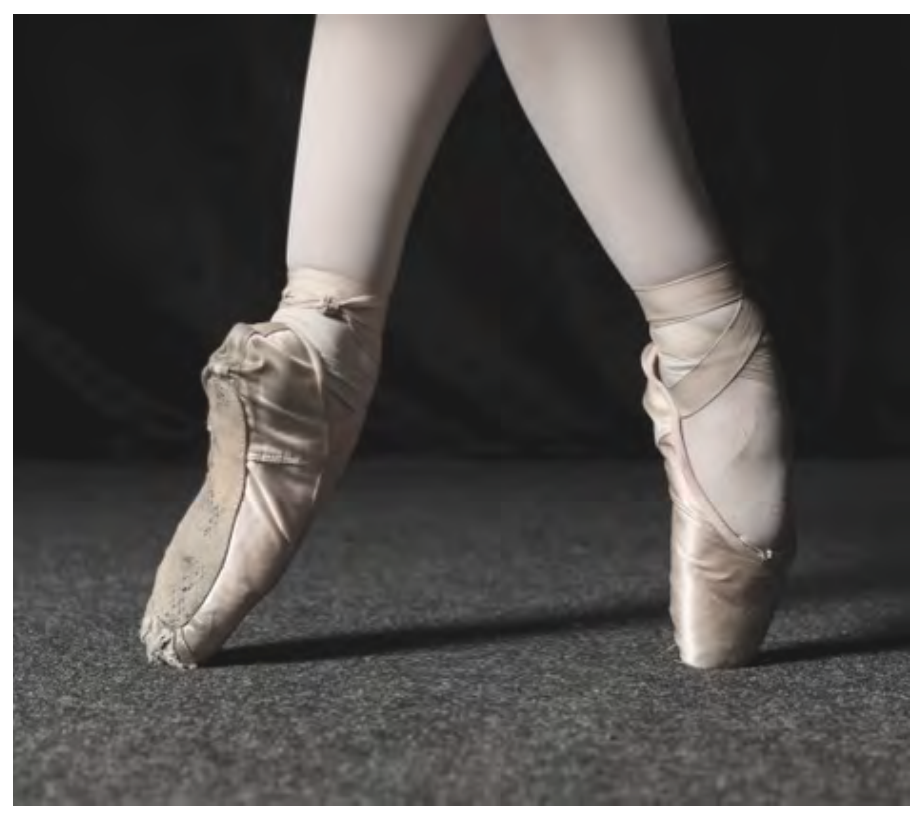

Figure 4. Side view of ballet dancer's feet when en pointe (Freepik, 2020). 


\subsubsection{Pointe Work Readiness and Technique}

Dancing en pointe requires years of training and rigorous practice (Aalten, 1997). Pointe work starts approximately at the age of 11 or 12 (Shah, 2009) with at least 3 years of continuous daily ballet training (Kirstein \& Stuart, 2004). Ballet teachers determine if a dancer is ready to start pointe work (Shah, 2009). According to Shah, there are no standard measurements for pointe work readiness, although the teacher determines a dancer's readiness by assessing and validating: proper ballet technique, flexibility in the foot and ankle, alignment, proprioception, postural control and strength (2009, p.298). Students may never be ready to go en pointe, but some schools and teachers may recommend dancers to start, resulting in beginning pointe work when their feet and bodies are not ready (Shah, 2009).

Pointe technique is an extension to ballet technique, as it uses the same terminologies and movements (Minden, 2005). A standard ballet class carries the same structure for all levels, from beginners to professionals, with the ballet barre to warmup and the centre of the studio to dance across the floor (Minden, 2005). No matter the pointe class level, fundamental exercises must always be performed at the beginning of each class to prepare the muscles for complex movements, while facing the ballet barre (Kirstein \& Stuart, 2004). These fundamental pointe movements are: relevés, échappés, glissade, assemblé soutenu, sissonne simple, sissonne passer la jambe, pas de bourrée (Kirstein \& Stuart, 2004). Not all dancers are trained to rise en pointe the same, there are different techniques. The Cecchetti (the Italian technique) and Vaganova (the Russian technique), teaches the dancer to rise en pointe with a little spring, pushing off the floor (Vaganova, 1969). While The French technique teaches the dancer to rise up en pointe smoothly, and 
come down smoothly (Vaganova, 1969). Vaganova, emphasizes that under no circumstances should the dancer "jump" en pointe before the feet are strengthened $(1969$, p.110).

\subsubsection{The Role of the Foot and Pointe Work Related Injuries}

The foot plays an important role when performing pointe work. Pointe work requires the ballerina to have strong feet, supple and as sensitive as the hands (Barringer \& Schlesinger, 2012). It necessitates the dancer to have a great turn-out, for the foot to be supported by as many toes as possible, while not resting its full weight on the big toe only (Vaganova, 1969, p.109). The most comfortable foot shape when dancing en pointe is a foot where all toes are equal, with a low arch and a strong ankle (Vaganova, 1969, p.109). This square foot shape allows the dancer's weight to be distributed equally on all toes and not just the great toe. Although, this may limit pointe shoe design, as not all dancers have an ideal foot shape.

Dr. Spilken, a podiatrist with extensive experience treating ballet dancers states, "during ballet the dancer's foot receives four times the weight", causing repetitive impact to the foot leading to injury (Spilken, 1990, p.4). The most common injuries affecting the foot are: blisters; sprained ankles; tendonitis; bone bruises and fractures; heel spurs; and plantar fasciitis (Spilken, 1990, p.3). In addition, dancers lack of knowledge on how forces affect the foot has led to an increased number of ballet related-injuries (Spilken, 1990).

Improper pointe work technique or pointe shoes not fitted well, are the lead causes to discomfort, pain and injuries (Spilken, 1990). Through extensive research from medical 
experts, Barringer \& Schlesinger, also agree with these findings while adding that pointe work related injuries, is also a result of body types and feet not suited for ballet (2012). Not to mention, structural properties in pointe shoes, rigorous hours training of dancing and poor placement caused by tired muscles, may also be a cause (Barringer \& Schlesinger, 2012). After all, Dr. Spilken explains that dancers dread injuries and fear doctors who might tell them that they should never dance again, therefore they do not seek proper medical attention (1990, p.53). As such, concerted effort in redesigning the pointe shoe by investigating its structure and material selection could perhaps prevent foot injuries and improve the ballerina's experience while dancing.

\subsection{Pointe Shoes Design \& its Current Advancements}

The appearance of the pointe shoe enabled ballet dancers to rise on their toes and to expand the ballet technique while still being able to create the illusion of weightlessness (Barringer \& Schlesinger, 2012). Researchers discuss that the traditional pointe shoe has remained unchanged for at least two decades, and "ballerinas are still dancing on a piece of cardboard hardened with glue" which leaves the ballerina vulnerable to injuries (Colucci \& Klein, 2008, p.6). In order to comprehend the phenomenon behind the unchanged design, it is crucial to discern the anatomy of the pointe shoe, its intricacies and its current design advancement.

\subsubsection{The Pointe Shoe}

The pointe shoe supports the ballet dancer's feet by enabling them to balance and dance en pointe (Barringer \& Schlesinger, 2012; Hoogsteyns, 2013). It supports the ballet dancer's weight with its toe box and shank, transferring the body's load on the tip of the 
toe box, called the platform (Cunningham, DiStefano, Kirjanov, Levine, \& Schon, 1998; Minden, 2005). In fact, the toe box area protects and supports the forefoot and the toes (Cunningham et al., 1998). Figure 5 illustrates the pointe shoe's toe box area, shank and platform.
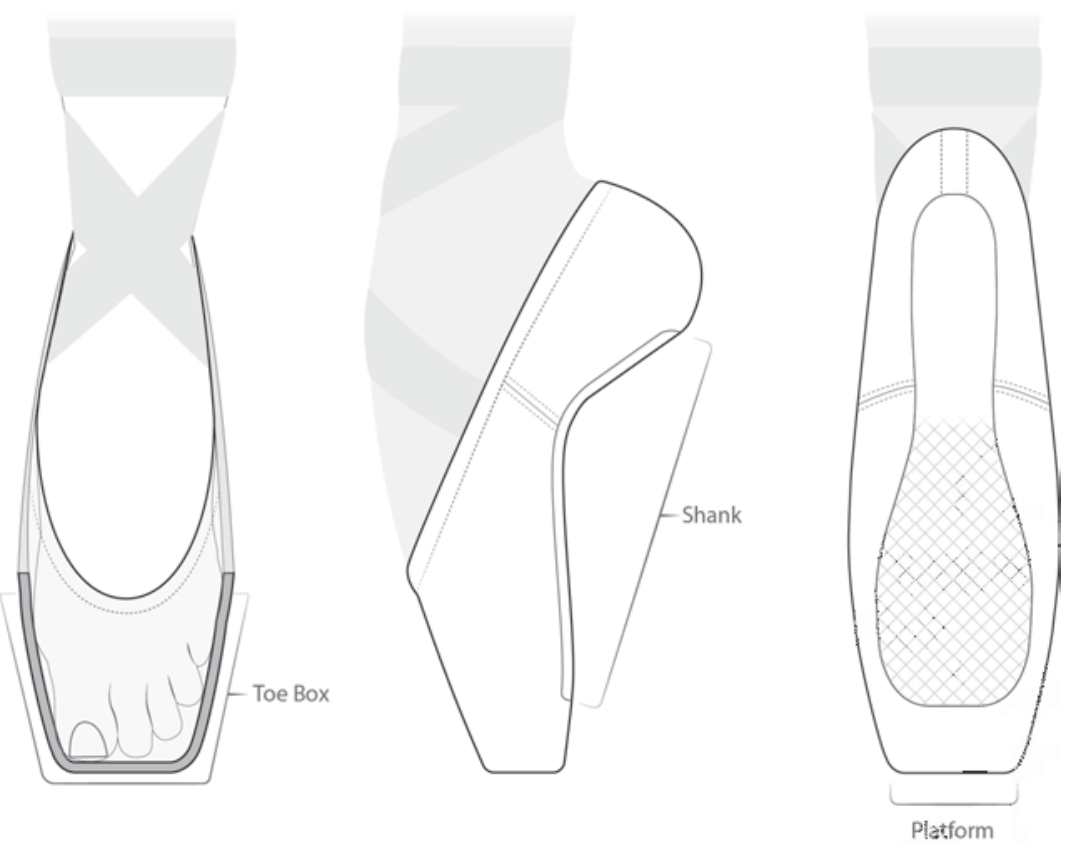

Figure 5. Illustration of the pointe shoe's toe box, shank and platform.

Pointe shoes are made in different sizes, various shapes and material strength in order to support and accommodate the ballet dancer's foot (Barringer \& Schlesinger, 2012). Compared to regular footwear, pointe shoes, have no right or left, allowing the dancer to alternate their shoes from one foot to the other (Barringer \& Schlesinger, 2012). Although, feet shapes and toe lengths that are not similar to the one another, will make it more challenging to the dancer to alternate her shoes (Barringer \& Schlesinger, 2012).

The outside shell of the pointe shoe is made of satin, and the inside of the shoe is composed of canvas (Minden, 2005). The toe box is the stiffest part of the pointe shoe, 
made of dense layers of 'Hessian', a woven fabric usually made from the skin of the jute plant, shaped and dipped with water soluble glue, giving the shoe its wooden appearance (Barringer \& Schlesinger, 2012; Spilken, 1990). The shank sits underneath the dancer's foot supporting the arch, made of thin layers of rigid material: fiberboard, cardboard and sometimes treated paper (Minden, 2005). The traditional materials of the pointe shoe degrade quickly with heat and perspiration, in return failing to provide impact absorption and support, leaving the ballet dancer's foot unprotected and vulnerable to injury (Anderson, Ng, Benwood, \& Walter Jr., 2015, p.1). Figure 6 illustrates the traditional pointe shoe and a cute away of the its main materials.

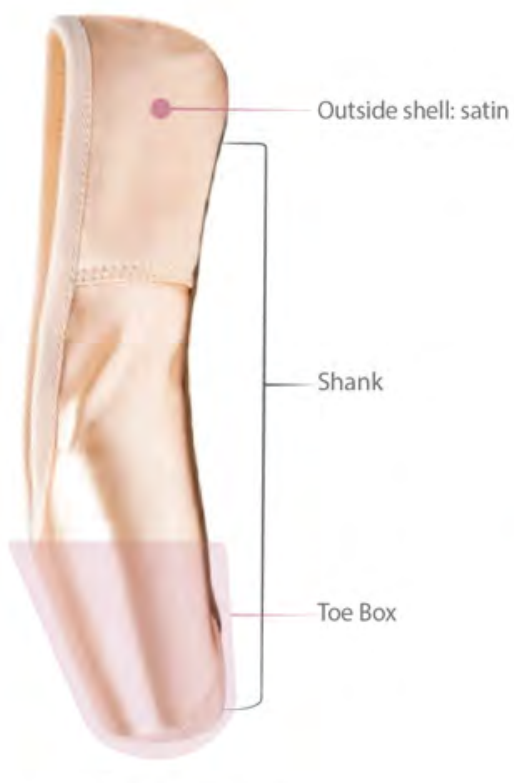

Side view

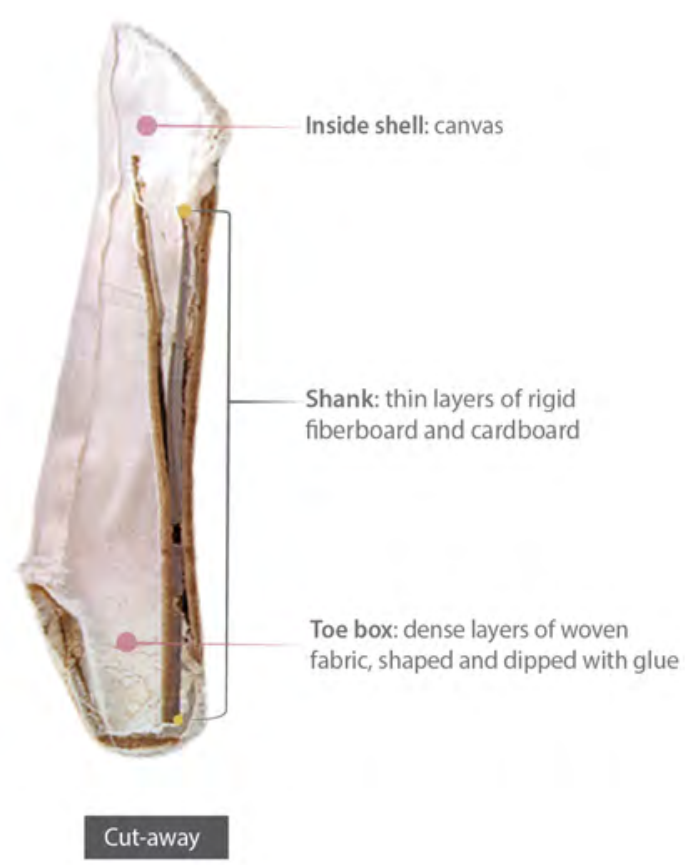

Figure 6. The traditional satin pointe shoe (DFS, 2021) and a cut-away of its traditional materials (Minden,2020).

Most pointe shoes are handmade, having a short life span and are costly. The traditional pointe shoe is made by a pointe shoemaker through the turn shoe process: placed on a foot-shaped form, similar to a shoe last, sewn inside out to then turn the shoe's right side 
out for shaping, drying and finishing (Barringer \& Schlesinger, 2012, p.16). Depending on the pointe shoe's features and manufacturer, a pair of pointe shoe can cost up to 180 Canadian dollars (Dancewear Centre, 2021). Ballet dancers often replace their pointe shoes, as the shoe loses structure and inhibits the dancer's abilities to go en pointe. Pointe shoes break down quickly due to its material properties, making dancing en pointe expensive (Barringer \& Schlesinger, 2012). Pointe shoes should fit snug, therefore not allowing the younger dancer to grow into a larger shoe, which can play a factor in the cost, as they need to need to be fitted often (Spilken, 1990). Also, shoe replacement is costly, for example, a well-known ballet company such as the New York City Ballet goes through 12, 000 pairs of pointe shoes each year, costing more than half a million American dollars (Martins, 1997, p.39).

\subsubsection{Pointe Shoe Intricacies}

A ballet dancer's ultimate goal is to merge with her shoes while dancing, as the pointe shoe is found to be an extension of her foot (Hoogsteyns, 2013; Mandradjieff, 2016). Pointe shoes are difficult to fit and choosing the correct pointe shoe and proper fitting is important for the ballet dancer's feet, as it can cause severe injuries in the future (Spilken, 1990). In order for the pointe shoe to perform at its full functionality, the fit should be ‘snug', allowing slight toe movement (Spilken, 1990). There are two influencers to the fitting process, the pointe shoe fitter and the ballet teacher (Barringer \& Schlesinger, 2012; Spilken, 1990). A pointe shoe fitter assesses the dancer's foot when trying on various pointe shoe models while the ballet teacher validates if the pointe shoe fits right, as they know their student's foot (Barringer \& Schlesinger, 2012; Spilken, 1990). In his 
book, Dr. Spilken explains the importance of getting a proper fitting for a pointe shoe, as most shoe fitters are not always fully trained to select the proper pointe shoe (1990).

Custom work can be done prior to every new pair of pointe shoe, to avoid discomfort and foot problems, by adding padding to the shoe (Spilken, 1990). Dancers use the breaking in process, prior to dancing in a new pair of pointe shoes. Breaking in a pair of pointe shoes entails, to mold the shoe to the dancer's foot, in order to make it more comfortable while dancing en pointe (Barringer \& Schlesinger, 2012). Every dancer spends a great amount of time customizing their shoe such as: softening the toe box, darning the platform, bending the shank, as well as sewing on ribbons and elastics (Harris, 2003). Breaking in the shoe is taking a risk, as it can interchange the mechanics of the shoe, over softening of the toe box and the risk of breaking the shank (Barringer \& Schlesinger, 2012).

\subsubsection{Pointe Shoe Advancements}

In the early twentieth century, the first pointe shoe documented was made of soft satin slipper, with a flexible sole and ribbons, which did not permit the ballet dancer to have proper alignment when going en pointe as there was no support in the toe box area (Minden, 2005). In that era, dancers were strengthening their feet to be able to stand en pointe without shoes (Barringer \& Schlesinger, 2012). As pointe work evolved, the pointe shoes' toe box became harder to accommodate the technical demands of the dancer's foot (Barringer \& Schlesinger, 2012). In addition, pointe shoes designs developed into different shapes and styles, but even today most pointe shoes are being handmade (Minden, 2005). 
Eliza Minden, was the first designer to revolutionize the world of ballet by viewing the ballet dancer as an athlete (Hoogsteyns, 2013). Thermoplastic elastomers and urethane foams were introduced in the late twentieth century, into pointe shoe design, for the toe box and the shank (Minden, 2005). The Minden pointe shoe design focuses on durability and flexibility, as the shoes do not have to be broken in (Hoogsteyns, 2013). Although, in a survey of 200 ballet dancers about pointe shoe manufacturers and preferences, it was found that proper fit and comfort were preferred over a pointe shoes' durability (Cunningham et al., 1998).

Colucci and Klein, remain amongst the only scholars that have studied the pointe shoe from a design perspective; exploring ergonomics, user needs, material properties and prototyping (2008). Results lead, to create a pointe shoe prototype where the elastic part of the shoe covered the entire foot (called the boot shoe), the shank was combined with the toe box as one piece and lined with memory foam, and the platform was inclined by 90 degrees (Colucci \& Klein, 2008). Non-scholarly published data explored 3-D printing as a means of customizing pointe shoes, to accommodate comfort. The pointe shoe still remains the same, yet self-reports from ballet dancer's experience have not been taken into account in the design process.

\subsection{The Interpretation of Discomfort}

Researchers have yet to find a clear definition of discomfort. Although, in a literature study done on differentiating pain from discomfort, it has been found that discomfort is defined as "a negative physical and/or emotional state, causing unpleasant feelings or sensations" (Ashkenazy \& DeKeyser Ganz, 2019, p.561). Ashkenazy \& DeKeyser Ganz, 
explain the definition does not include tissue damage, one mechanism to distinguish discomfort from pain (2019). The definition of pain according to the International Association for the Study of Pain is "An unpleasant sensory and emotional experience associated with, or resembling that associated with, actual or potential tissue damage" (Raja et al., 2020, p.1977). In particular, Tenenbaum et al., states how athletes avoid describing what they feel as 'painful'. They prefer the term 'discomfort' to describe their ongoing efforts, demanding physical and physiological exertion, and emotional and cognitive experiences, rather than pain. (1999, p.184). In this study, discomfort was chosen as a measurement to unravel the ballet dancer's feet discomfort areas when dancing en pointe.

\subsubsection{Real-time Assessment Rating Scales}

Discomfort is a subjective measurement and assessment is through self-report. Real-time assessments, captures a person's immediate experience, minimizing the need to recall and rate past experiences (Stone \& Broderick, 2007). Self-report real-time assessment rating scales are used to quantify the level of discomfort intensity. A previous study has used a discomfort rating scale in a real-time setting to identify their foot discomfort intensity in tennis athletes (Llana, Brizuela, Durá, \& García, 2002). Other self-assessment scales are commonly used such as the Numeric Rating Scale (NRS), the Visual Analogue Scale (VAS) and the Verbal Rating/Descriptor Scale (VRS/VDS), commonly used for pain assessments (Karcioglu, Topacoglu, Dikme, \& Dikme, 2018, p.708)(see Figure 7, Woo et al., 2015). 

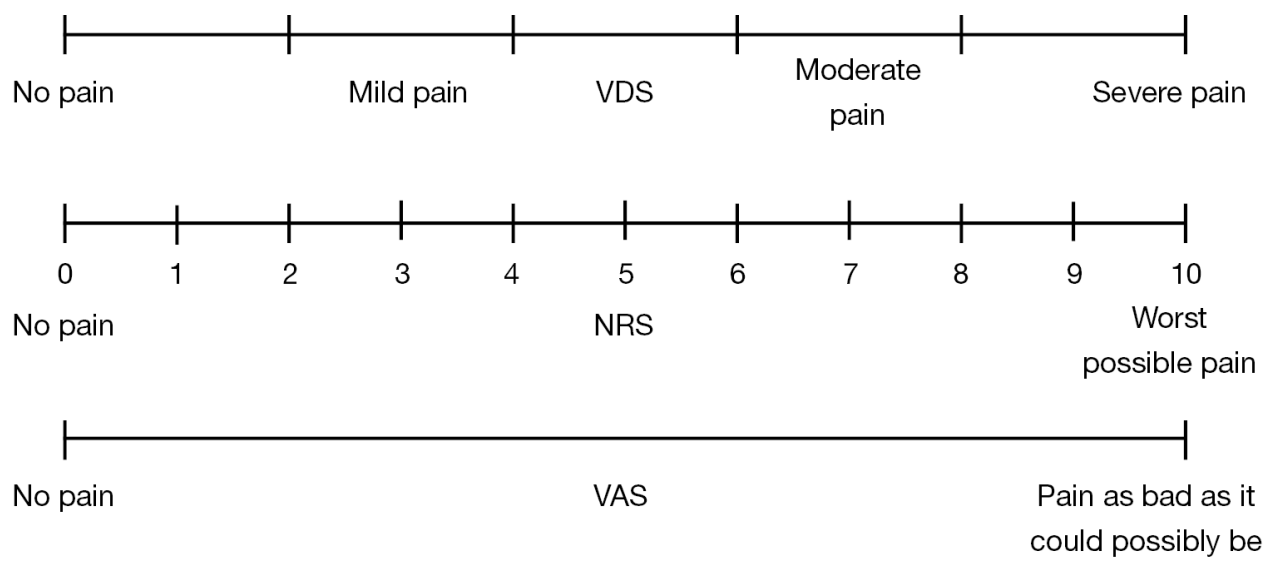

Figure 7. The Verbal descriptor Scale (VDS), the Numeric Rating Scale (NRS) and the Visual Analogue Scale (Woo et al., 2015).

\subsubsection{Infrared Thermographic Imaging as an Assessment Tool}

Infrared thermographic imaging is a non-invasive method that captures the body's heat distribution through an infrared camera which is then processed as a digital thermal map (Jones, 1998)(see Figure 8, FLIR 2020). The use of thermographic cameras, allows the researcher to conduct experiments in a variety of environments as they are compact and portable (Jones, 1998). Thermal imaging has been used in the medical field for diagnostic purposes as it is contactless and does not produce radiation to the human body (Jones, 1998). It can detect abnormalities, such as inflammation, infection or malignancies caused by increases in temperature, which are represented as hot spots or asymmetrical patterns in a thermal image (Jones, 1998). Although, quantitative analysis must be performed as irregular temperature distribution of the human body might not be an indication of the presence of abnormalities (Herry \& Frize, 2002). In parallel, thermal imaging has been found to assess pain, although, pain is a subjective experience and cannot be quantified using solely by thermal imaging (Herry \& Frize, 2002). They show that an increase in temperature does not necessarily mean that the individual is feeling 
pain, suggesting that self-report is necessary to establish a relationship between imaging and what the individual is sensing. Injured feet showed areas of increased heat, and weight-bearing pressure areas on the feet also showed increased heat temperature even without conducting self-report assessment (DiBenedetto, Yoshida, Sharp, \& Jones, 2002).

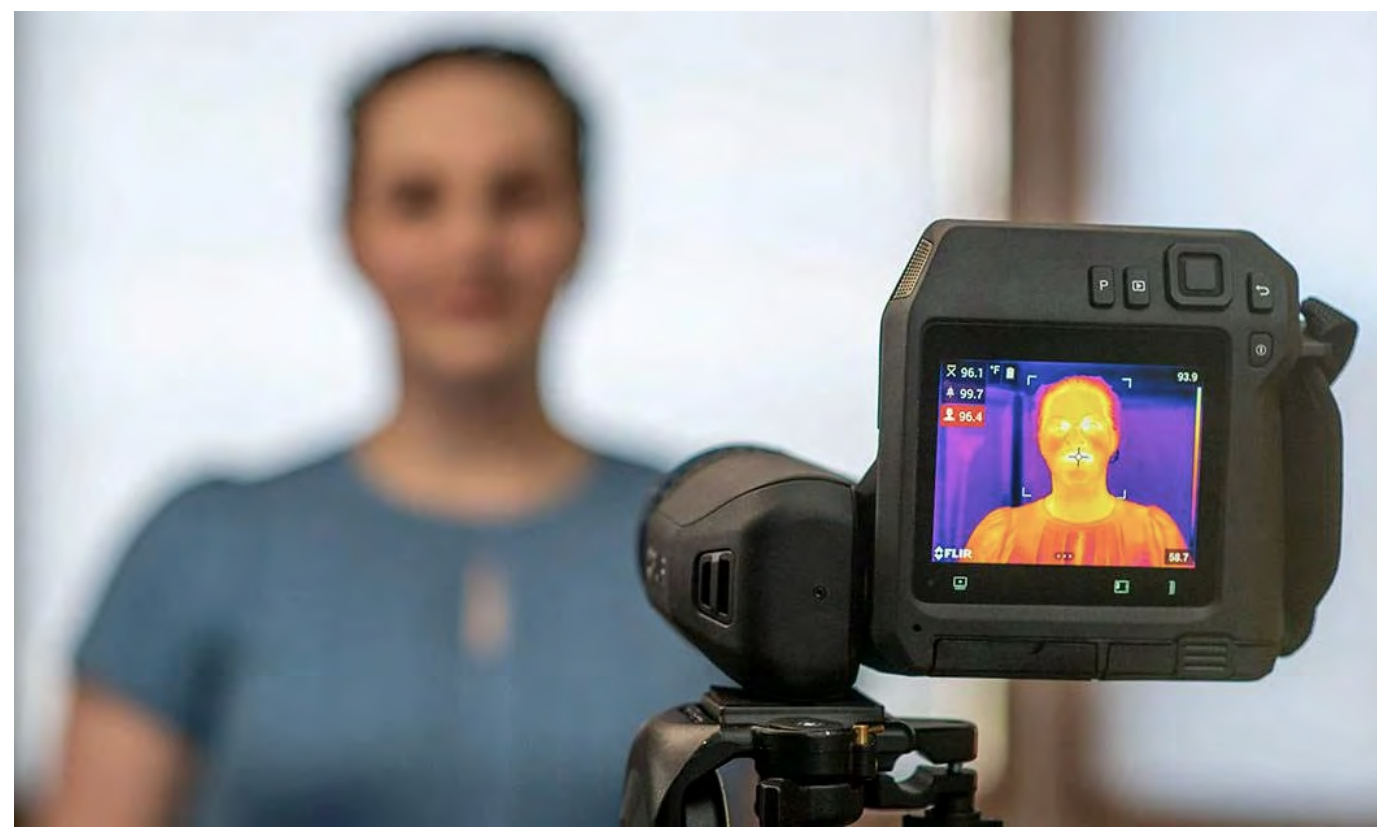

Figure 8. Thermographic imaging used for detecting body temperature (FLIR, 2020).

A strict controlled protocol must be followed for the testing environment and the participant when comparing thermal images (Jones \& Plassmann, 2002). The room temperature should be controlled and direct sunlight should be avoided (F. J. Ring, 1995). Preparing the person that is being imaged is crucial as eating, drinking, smoking, physical activity, sun exposure, drinking alcohol or caffeine can affect body temperature (E. F. J. Ring \& Ammer, 2015; F. J. Ring, 1995). When quantitative measurements from the thermal imaging is required, subjects must be imaged at the same distance from the camera, to cover the same number of detector elements (Jones \& Plassmann, 2002). In 
addition, utilizing low emissivity surfaces allows for high contrasting imaging when capturing temperature body areas (Jones \& Plassmann, 2002). As such using an appropriate thermographic protocol can help identify areas on the foot where there is presence of temperature increase. Coupled with a self-report discomfort assessment which has not been performed yet in ballerinas, these two assessments could pin-point where there is discomfort form the pointe shoe and how we can improve its design.

\subsection{Previous Pointe Shoe Testing}

In a review on dance footwear and its effects on dancers, the pointe shoe was found to be the most extensively researched and analyzed dance shoe (Yan, Hiller, Smith, \& Vanwanseele, 2011). Over the years, pointe shoe testing has covered foot biomechanics, X-ray procedure and magnetic resonance imaging studies evaluated solely acute and chronic injuries when en pointe, and others evaluated the pointe shoe's mechanical performance only. However, experiencing discomfort when dancing en pointe, has yet to be systematically investigated.

\subsubsection{Foot Biomechanics}

Foot and ankle biomechanics remain amongst the most reoccurring testing performed, specifically investigating pressure zones when en pointe. It has been found challenging to measure pressure at the pointe shoe interface, since the shoe fits tightly and the loading of the surface is not flat (Torba \& Rice, 1993). In a study using sensors, results have shown that peak pressure was higher than other areas over the forefoot (the front of the foot's smaller bones) when standing en pointe for 8 seconds (Picon, Lobo da Costa, De Sousa, De C.N.Sacco, \& Amadio, 1985). According to Picon et al., findings of their study 
showed that the toes and metatarsals were the most compressed areas, when standing en pointe (1985). As stated by Picon et al., “...the ballet dancer is submitted to very high external loads when wearing the pointe shoe" (1985, p.4). Despite the results obtained, Picon et al., presented results of only one subject (1985).

Teitz, Harrington \& Wiley designed a study to investigate the pressure of dancers' first and second toe and first metatarsophalangeal joints ( MTP), where bunions occur while performing relevé en pointe (1985). The researchers concentrated on the variations of the forefoot pressure in variation with toe length, foot positioning when rising en pointe and padding in the shoes (Teitz et al., 1985). Data collection was performed using a force plate and very small sensors placed directly on the participants' toes: the first and second toe, as well as the MTP joint (Teitz et al., 1985). Teitz et al. proved that the great toe receives the most pressure, whereas the second toe varied as a function of toe length and padding. Additionally, the researchers discovered that performing relevés with everted feet increased the pressure on the first MTP joint (great toe joint) and might contribute to bunion formation (1985). Dancers who have a short great toe, evert the foot when going en pointe, causing difficulty to balance and increases pressures on the toe, which will lead to deformity and generative joint disease (Teitz et al., 1985). Conclusively, Teitz et al. suggests that carefully designed padding may redistribute pressure equally (Teitz et al., 1985).

A study by Tuckman, Werner, James, \& Bayley, in 1991 analyzed the forefoot when en pointe for 1 minute with nine ballet dancers. The researchers investigated the pressure placed on the forefoot through alginate powder placed in their pointe shoes and a 
questionnaire on their subjective feelings when dancing en pointe. The researchers found that in all molds, significant pressure was apparent on the great toe's, where flattened tissues were visible on the great toe's medial edge (Tuckman et al., 1991). In addition to Teitz et al., the pressure on the toes did not vary with the toe length. As one of the only studies to question discomfort when dancing en pointe, six categorized as "uncomfortable" and one as "painful" (Tuckman et al., 1991, p.145).

In addition, Torba \& Rice, used sensors and plaster casts were used to investigate the forefoot's point of contact (toeprints) in the toe box, while en pointe one foot at a time (1993). The researchers found that the pressure on the forefoot when en pointe, is not distributed evenly, which may be responsible for acute and chronic conditions: blisters, bunions, bruised toenails, tendinitis and degenerative joint disease (Torba \& Rice, 1993). Results showed that areas contacting the inner shoe wall has the highest pressure, primarily the ends of the toes and joints (Torba \& Rice, 1993). Although, the stronger bones and joints of the tarsus (bone structure of ankle and heel) are nearly load free (Torba \& Rice, 1993).

In a recent study by Pearson \& Whitaker, the researchers explored the relationship between dance shoe type and foot pressure, using a scan pressure platform and questionnaire with ballet dancers from university dance degree programs (2012). The protocol included, performing fundamental ballet movements (including movements that were not en pointe as well) on the pressure platform in barefoot and different ballet footwear including the pointe shoe (2012). The researchers discovered that pointe shoes vary significantly in the plantar pressures that they impose on the foot compared to 
barefoot and the other ballet shoes (Pearson \& Whitaker, 2012). Additionally, results from the questionnaire showed that dancers who wear demi-pointe shoes prior to starting pointe were found to be less likely to have a ballet-related injury (Pearson \& Whitaker, 2012). Conclusively, Pearson \& Whitaker, discuss how integration of appropriate footwear prior to pointe work in adolescent dancers may help reduce injury and promote more accurate technique (2012).

\subsubsection{Mechanical Performance}

Very few scholars have performed mechanical testing on the pointe shoe itself.

A study conducted a comparative mechanical analysis of pointe shoes' toe box properties with five brands: Capezio, Freed, Gaynor Minden, Leo's and Grishko (Cunningham et al., 1998). Cunningham et al. aimed to assess the mechanical performance of the toe box's stiffness, strength and fatigue in relation with the needs of the ballet dancer (1998). In order to replicate the load of when a dancer is en pointe and demi-pointe, Cunningham et al., applied both axial and vertical loads to the toe box, to investigate the stiffness, strength and fatigue of the toe box using a servo hydraulic device. Testing results showed that all shoes were significantly stiffer and stronger at the tip of the toe box when going en pointe, than going en demi-pointe (Cunningham et al., 1998). Conclusively, Gaynor Minden's pointe shoe toe box, constructed of high density polymers, showed the highest fatigue life, approximately 10 times higher than the other brands (Cunningham et al., 1998). Contrary to the Gaynor Minden shoe, the other brands use burlap, cardboard, paper and glue, which can result in permanent shoe deformation (Cunningham et al., 1998). Despite the results from the mechanical testing, the ideal pointe shoe is one that 
fits and is comfortable, "not necessarily the strongest or most durable", based on the 200 participants that completed the study's questionnaire (Cunningham et al., 1998).

\subsubsection{X-ray Procedure}

Experts in the medical field performed X-ray superimposition technique using graphics software, in order to understand the ankle and foot joints in motion when the female dancer is en demi-pointe and en pointe (Russell, Shave, Kruse, Koutedakis, \& Wyon, 2011). A superimposition technique was used where the $\mathrm{x}$-ray images were placed in Adobe Illustrator layered, magnified and increased in transparency. In order to evaluate the change in positions of the bones, the images were adjusted until they all aligned with the ankle. Results showed that the talocrural joint (ankle joint) contributed the most motion when the participants attended to go en demi-pointe and en pointe (Russell et al., 2011). Russell et al. found that this technique is useful to analyze and quantify bone motions in the ankle, which in the end will allow a ballet dancer to attain the positions required in demi-pointe and en pointe (2011). Researchers Russell et al., mention that quantification of motion analysis of the foot may prove helpful in analyzing the causes of symptoms in ballet dancers experiencing foot and ankle pain (2011). Despite the results obtained, Russell \& et al. discovered variability in the movements of the foot, since the sample size consisted solely of seven participants (2011).

\subsubsection{Magnetic Resonance Imaging}

It has been found that current high field strength magnetic resonance imaging limits capturing the weight bearing effects that en pointe positioning creates on the ballet dancer's ankle (Russell \& Yoshioka, 2015). According to Russell \& Yoshioka, this 
phenomenon is due to the difficulty of balancing en pointe without moving for an extended period of time, resulting in reduced quality MRI scans (2015). Despite these challenges, Russell \& Yoshioka established an assessment to capture MRI of the ankle, using a non-weight bearing en pointe position (where no weight was placed on the foot when en pointe). The research aimed to visually assess the orientation of the bones, cartilage, and soft tissues in the participants' ankles and verifying the correlation between the level of pain experienced by the participants and the MRI findings, when en pointe. Russell \& Yoshioka conducted the round of imaging, by capturing one foot at a time (pointing the foot and not going en pointe) stabilizing the leg and ankle with a wooden rod wrapped against the medial and lateral leg and foot (2015). Due to the constraints of the study, MRI results showed that the ankle joint in the en pointe position may have higher risk of cartilage wearing than other joints. Correlation results showed that pain assessments by the dancers using the visual analogue scale showed minimal or no pain in their imaged ankle, and did not relate to the MRI findings (Russell \& Yoshioka, 2015). Despite the results, Russell \& Yoshioka's limitations were a small sample size, imaging only 6 participants and not being able to replicate the weight bearing en pointe position (2015).

\subsection{Advancements in Footwear Design}

Footwear with improper fit has been found to be the leading cause of discomfort, pain and foot problems (Zhang, Rout, Zhang, Khandual, \& Luximon, 2010). Researchers and designers have been exploring 3-D foot scanning as a means of customizing a shoe last that meets the shape and size of a user's foot biometrics, ensuring comfort and proper fit. 
In parallel, athletic footwear testing procedures are utilized to ensure comfort and many more footwear properties through a controlled laboratory setting.

\subsubsection{Customization in Footwear for Comfort and Fit}

Scholars have reported the importance of comfort in footwear design since a shoe is meant to protect the foot without causing damages (Cheng \& Perng, 1999; Di Roma, 2017; Zhang et al., 2010). A study by Zhang et al., explored how 3-D scanning measurements of the foot can later be used to create a custom shoe last, shaped exactly to the user's foot accommodating for comfort and proper fit when designing footwear (2010). The use of a 3-D scanner enables to capture optimal measurements of a body part's skin surface, providing accurate and fast results (Royo \& Panyella, 2014). A shoe last is essential in footwear design processes. It is a 3-dimensional model representation of the human's foot, usually made out of wood, metal or polymers on which shoes are shaped (Cheng \& Perng, 1999). The shoe last should be designed in accordance to the foot shape, as it is a subordinate to the foot (Cheng \& Perng, 1999). Although, a traditional shoe last is fitted to influence the style of the shoes and does not prioritize foot comfort (Di Roma, 2017). Di Roma, explored the comparison of shoe last processes with a: traditional, 3-D scanned and re-modeled using a virtual environment. Interestingly, this approach was taken to prioritize and explore ergonomics and shoe comfort for the future

of footwear design, by remodeling the 3-D foot scan in virtual modeling environments to replicate the natural shape of the user's foot. 


\subsubsection{Athletic Footwear Testing Procedure}

There is no published data currently available on athletic footwear testing procedures within controlled laboratory settings which might be due to high level companies' integrity. However, Gromer (2001) reveals the fundamental research that partakes in Nike's Sports Research Laboratory for athletic footwear, using a particular basketball shoe model as an example. All stakeholders are involved in designing the testing procedure of the basketball shoe. The players and coaches are key to determine the specific basketball movements that should be investigated and the team doctors to stress the prominent foot injuries that occur when playing on the field (Gromer, 2001). Gomer explains that testing is performed in a real-time setting, through a simulated basketball flooring section at the laboratory. Simultaneous real-time data collection methods were applied: motion analysis, pressure sensors, reflectors, and infrared thermographic imaging (2001). The laboratory procedures at Nike show the involvement of the user, although no self-reports methods were utilized.

\subsection{Experiential Testing}

User experience design and user experience research are emerging fields, yet their definition is debatable. The term user experience has been regarded as an individual and unique experience in a particular interaction. The term experience has been seen as an individual's reaction relating to contextual and social aspects (Arhippainen, 2003, p.3). User experience researchers study users and their experience with a product or service (Travis \& Hodgson, 2019, p.7). User Experience research allows a user to indicate what they are experiencing in a particular moment during their journey. Travis and Hodgson emphasize the importance of including the user when conducting research, as it can 
provide actionable and testable insights into user's needs (2019). A way to measure how the user will interact with a product or system is to observe them in a real-time setting. If a real-setting is not available, it can be re-created with realistic elements and scenarios (simulating a real-setting environment for testing procedures) (Travis \& Hodgson, 2019). For example, this is seen inside Nike's Research Laboratory where an area is dedicated to real environments when testing footwear (Gromer, 2001). Incorporating user experience research into product design is an important step for the user as it can improve their experience.

\subsection{Literature Review Summary}

In summary, this literature reviewed the risks and effects of ballet culture, pointe work and the pointe shoe on the ballerina's feet health, the advancements of pointe shoe designs and its intricacies. The interpretation of discomfort, real-time assessments and thermographic imaging as a means of capturing thermal mapping of the body. The use of modern technologies highlighting the importance of comfort in footwear through shoe customization and controlled testing environments. The exploration of user experience research and how user's honest behavior can be accounted for during testing. Findings from the literature review lead to the principal question of this thesis: How can real-time discomfort assessments help identify the main areas of foot discomfort when dancing en pointe, using ethnographic assessments, thermographic imaging, and a 3-dimensional assessment tool? 


\section{METHODS}

The primary means of examining real-time discomfort of foot areas when en pointe was investigated through a mixed-method approach, drawing from both qualitative and quantitative data collection methods using three distinct measurements: 1) questionnaires, 2) real-time discomfort assessments, and 3) thermographic imaging sessions. The data collection was divided into three phases conducted and repeated consistently during each testing session. All phases of the research were conducted in a simulated ballet studio laboratory. Each session included: a pre-test questionnaire, three fundamental en pointe movements followed by real-time discomfort assessments of foot areas, thermographic imaging sessions of the feet, and a post-test questionnaire. A total of 10 recreational ballet participants were recruited for this study, varying in age, pointe work experience, and pointe work technique.

\subsection{Research Approach}

The research approach for this study centralizes around the principle of human-centered design, recognized as knowing the people that one is designing for. As Kumar explains, knowing people well is an "indispensable phase of the design process" as it enriches it by gaining empathic understanding of the people's thoughts, feelings, and needs (2013, p. 87). This approach can be applied by listening, observing, interacting, and analyzing the user (Kumar, 2013, p. 88). To address the research question, this study allows recreational ballet dancers to express and localize their immediate experienced discomfort when performing fundamental movements en pointe. This is an important development in research for ballet dancers, as current testing and research has solely 
examined professional ballet dancers and have not explored using real-time assessments when dancers are en pointe.

\subsubsection{Data Triangulation}

As Martin and Hannington explain, data triangulation is performed by comparing and verifying the findings of the study and overlapping the common results (2012). The goal of utilizing triangulation in complex subjects is to form an area of convergence where the collected information overlaps. In addition, this convergence is considered to be the most accurate representation of the truth, see Figure 9 below (Martin \& Hanington, 2012).

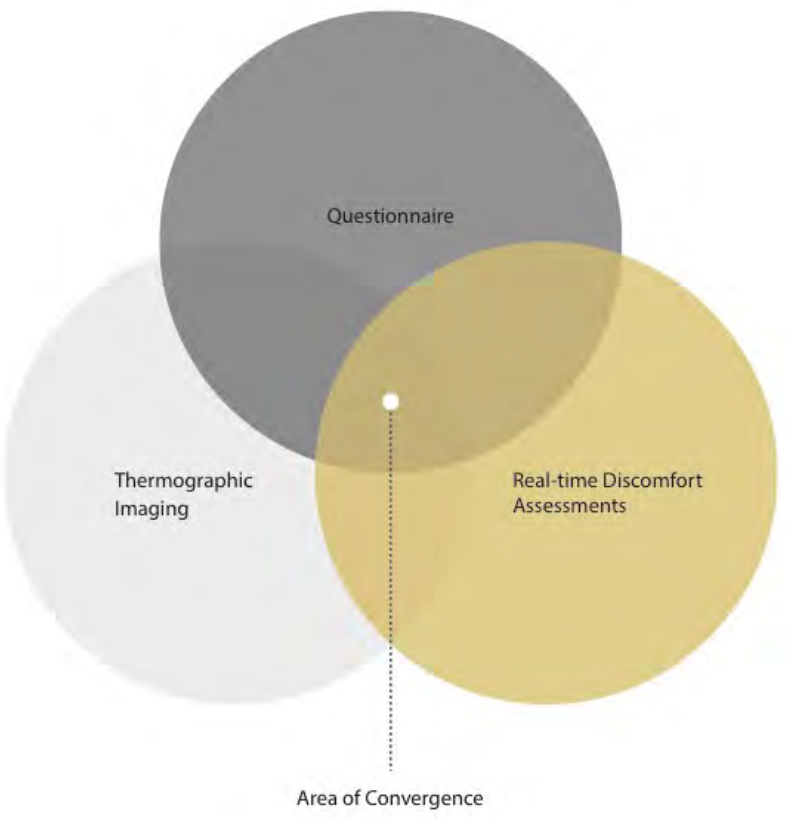

Figure 9. Illustration of data triangulation used for this study.

For an in-depth understanding of foot discomfort when en pointe, data triangulation design and a mixed-method approach were utilized through: i) questionnaires, ii) realtime discomfort assessments, and iii) thermographic imaging sessions. Therefore, by applying data triangulation through multiple methods, data convergences can be utilized 
to give a better perspective on the experience of real-time discomfort when dancing en pointe.

The primary reason for using this approach is to ensure the accuracy of information by combining sources and eliminating the weaknesses of any single method: this will either increase confidence in the results or suggest a limitation of the design (Martin \& Hanington, 2012). The study uses one method to make up for the limitations of another, which is one of the main benefits of triangulation. Curedale discusses, in his book of design research methods, that this method is useful for; quantitative and qualitative research, overcoming bias of a single method, and also may help the credibility of research conclusions (2013). Additionally, using three methods in combination can result in collecting a rich depth of information, contributing to a deeper understanding of the topic area, which can improve the credibility of research conclusions (Curedale, 2013; Martin \& Hanington, 2012). The use of the triangulation through the distinct three data collection means (questionnaires, thermographic imaging, and discomfort assessments) will explore the participants' experience with real-time foot discomfort and gain different perspectives on the topic, using each method to build a more comprehensive picture of what is being studied.

\subsection{Methods Map}

A map is a tool that enables viewing and illustration of each stage of a project within a specific context, as well as the relationships between each stages, their activities, their influences, and their goals (Curedale, 2013). For this study, the use of a methods map was designed in order to identify the links between each research stage and their required 
activities. The methods map illustrated below (Figure 10) presents the prevalent stages of this study in logical order. This map was a key tool throughout the stages of the study, as it assisted in visualizing and categorizing the test methods and key activities that were conducted.

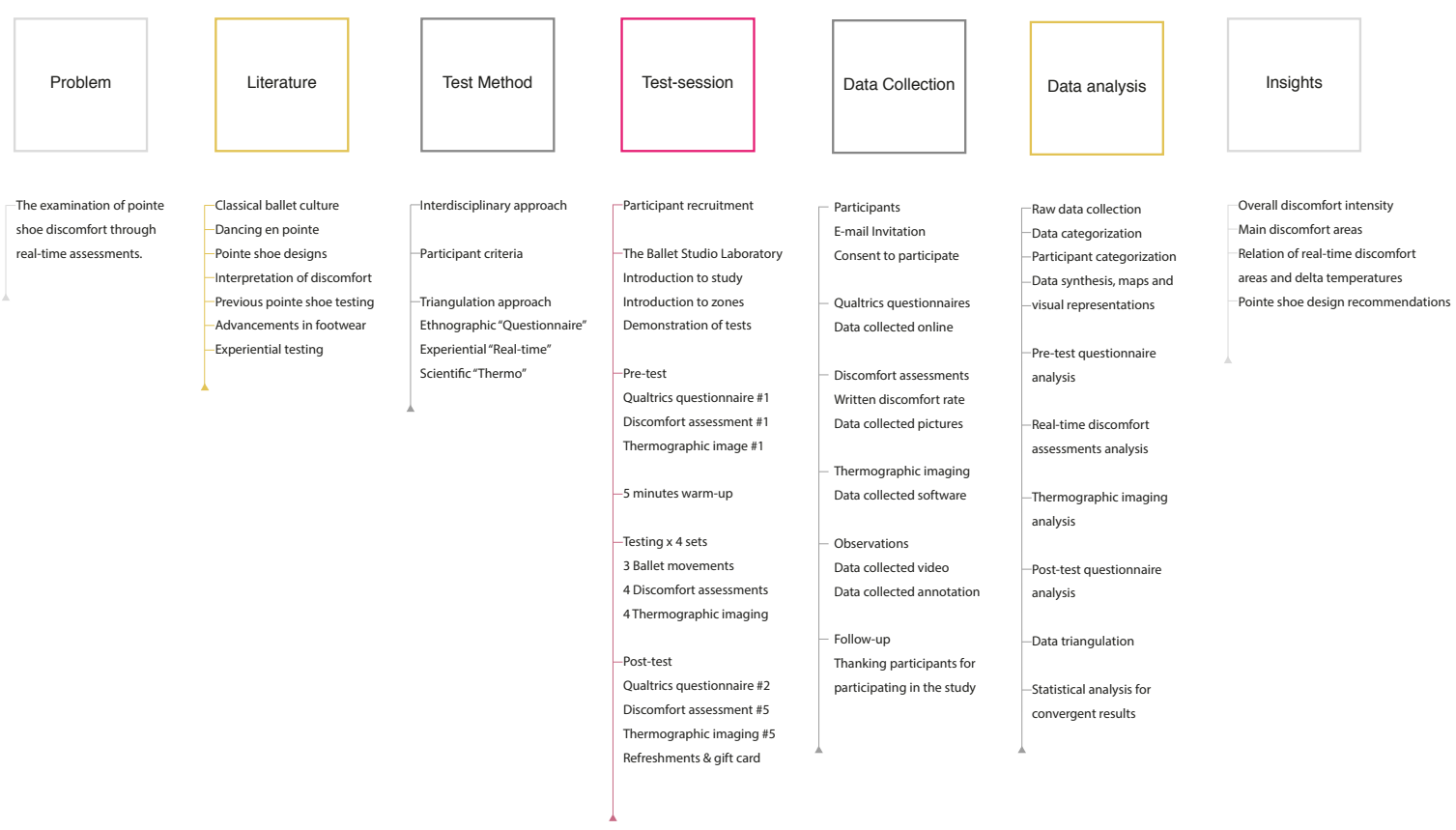

Figure 10. Illustration of the methods map used during the preliminary stages of this study.

\subsection{Participant Prerequisites and Recruitment}

Ethics clearance was obtained in July 2019 (Project clearance \# 111156), as illustrated in Appendix A.1. The research protocol followed ethical measures of participant interaction and recruitment, as illustrated in Appendices A.2, B.1 and B.2. Ballet participants had to meet the following prerequisites:

- Female dancers currently practicing recreational ballet pointe work.

- Have a minimum of two years of experience in pointe work. 
- Able to dance and balance en pointe without the support of a dance barre.

- All participants must be a minimum age of 16 years and a maximum age of 30 .

Participants were not allowed to partake in the study if they currently have injuries related to the ankle and the foot. Participants' prerequisites were validated through email. A total of 10 participants were recruited, between the ages 16 to 27 years, who were currently registered and practicing pointe work with 3 to 16 years of en pointe dancing experience varying in Vaganova and Royal Academy of Dance (RAD) ballet techniques. Participants that met the prerequisites received a copy of the consent form and information letters stating the goal of the research and highlighting the protocol and procedures, described in Appendices A.2 \& A.3. Participants were advised to bring and solely use their own pair of pointe shoes, since ballet dancers go through a lengthy trialand-error shoe fitting process in order to pick a shoe that fits them like a glove, offers support, and prevents injuries (Barringer \& Schlesinger, 2012, p. 23). Consent forms were signed by the participants prior to the beginning of the test session, see Appendix A.2. Schedules for the sessions were based on the participants' availability. All sessions were conducted between 9:00 am and 5:00 pm, during natural daylight.

\subsection{The Ballet Studio Laboratory Design}

The test sessions were conducted in a simulated ballet studio environment, which was created in the Carleton School of Industrial Design's gallery, see Figure 12. The gallery exhibits natural lighting and open unobstructed space, which allowed privacy for the sessions. Testing was done with one participant at a time to eliminate "peer pressure" that usually occurs in a ballet studio environment (McEwen \& Young, 2011). The consistency of the testing procedure was crucial, as uncontrolled testing environments, specifically 
the temperature of the environment can affect the data collection when capturing thermal imaging (Jones \& Plassmann, 2002). The experiment needed to be consistent, repeatable, and controlled for all sessions, as controlled conditions, eliminates errors and avoids biases (Travis \& Hodgson, 2019). To maintain accuracy, each zone had visual representations of the testing plan, schedule, and methods performed, which guided the researcher and the participant (Appendix C.1). The laboratory was divided into three major zones in order to accommodate the different data collection phases and guide the participants into the proper zones, see Figure 11 for the detailed floorplan.

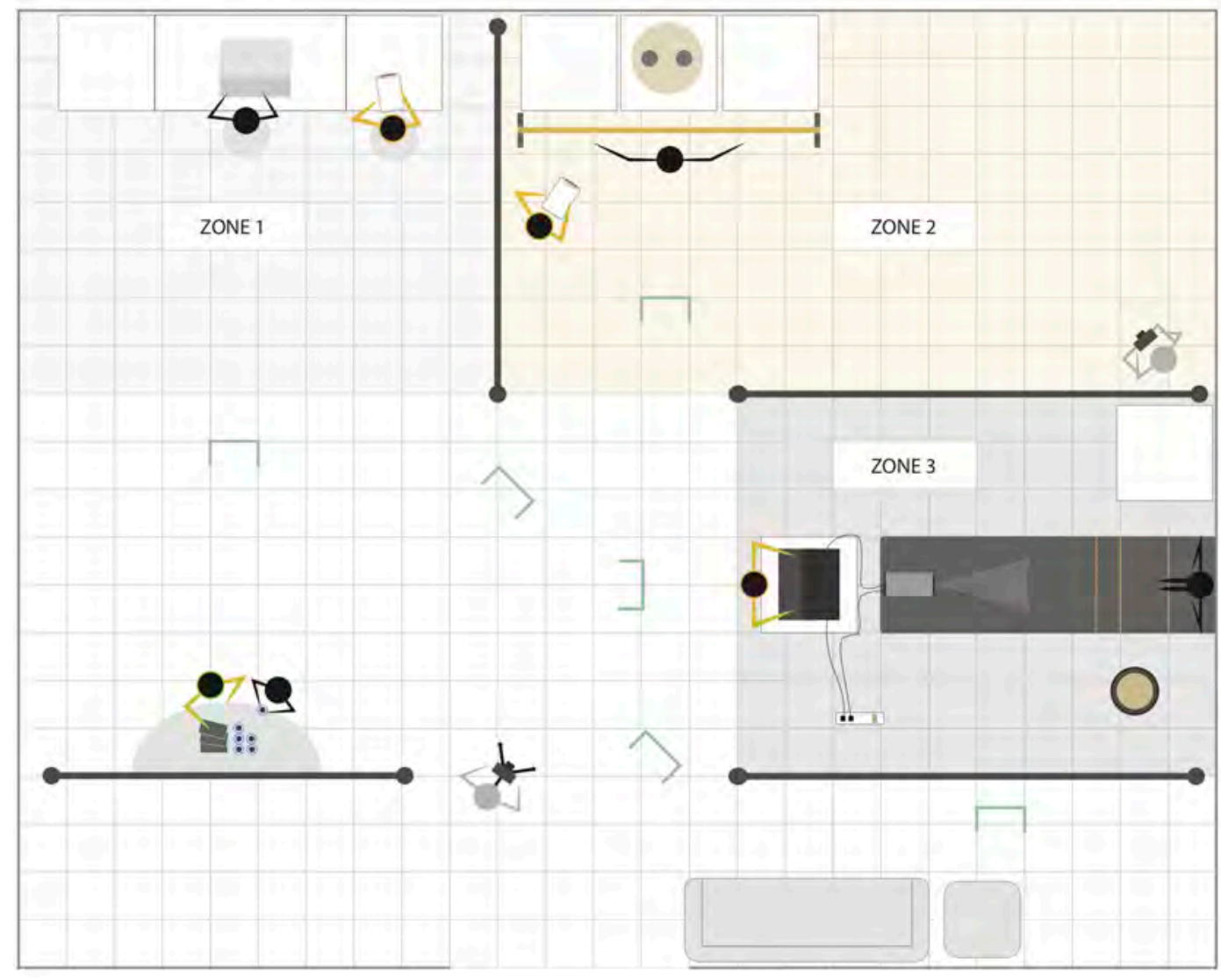

Logend Symbols

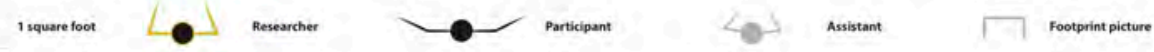

Figure 11. Illustration of the ballet studio laboratory floor plan. 


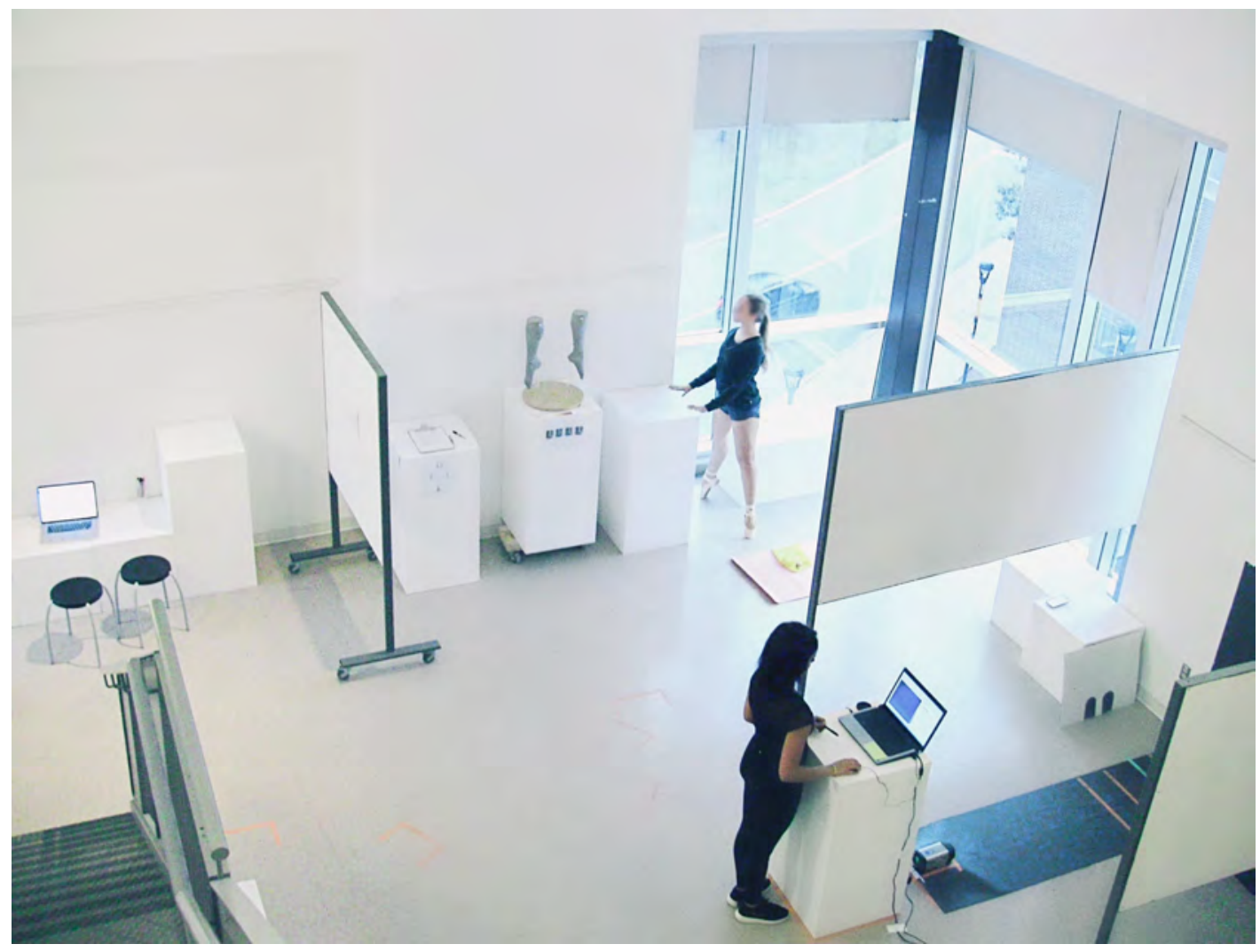

Figure 12. The ballet studio laboratory.

\subsubsection{Zone 1 Questionnaires}

The first zone was appointed for filling out the pre-test and post-test questionnaires. It included a surface with a seating area to accommodate writing, concentration, and seclusion (Figure 13). Additionally, the zone was intended to allow the participant's skin to stabilize to the room temperature for 10 minutes before being imaged while the participant signed the consent form, received debriefing, and completed the questionnaires. 


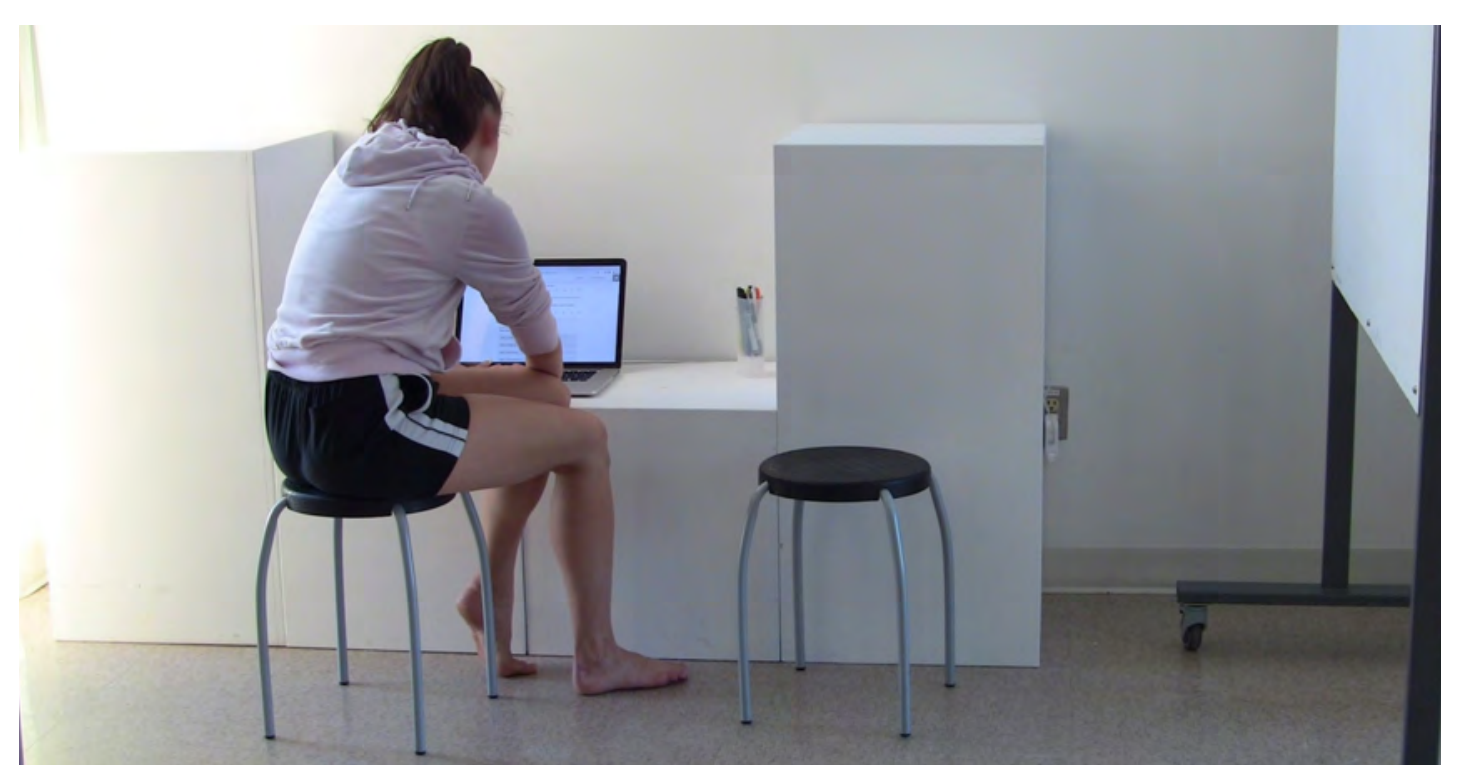

Figure 13. Zone 1: pre-test and post-test questionnaires.

\subsubsection{Zone 2 Real-Time Discomfort Assessments}

The second zone was created to reflect a ballet studio setting to accommodate warming up, followed by performing the pointe work movements and the real-time discomfort assessments using the 3-D apparatus of feet en pointe (Figure 14). Support was included in case the participant needed to balance while performing the ballet movements and assessing the discomfort areas on the 3-D printed apparatus. On the other hand, mirrors were not included in this area, as the intent was to focus on executing the pointe movements without perfecting them. This allowed participants to focus on the accuracy of the assessments. Additionally, in ballet training, mirrors are known as the primary source of fixation and influence on perfectionism (Wulff, 2001), which we wanted to avoid. 


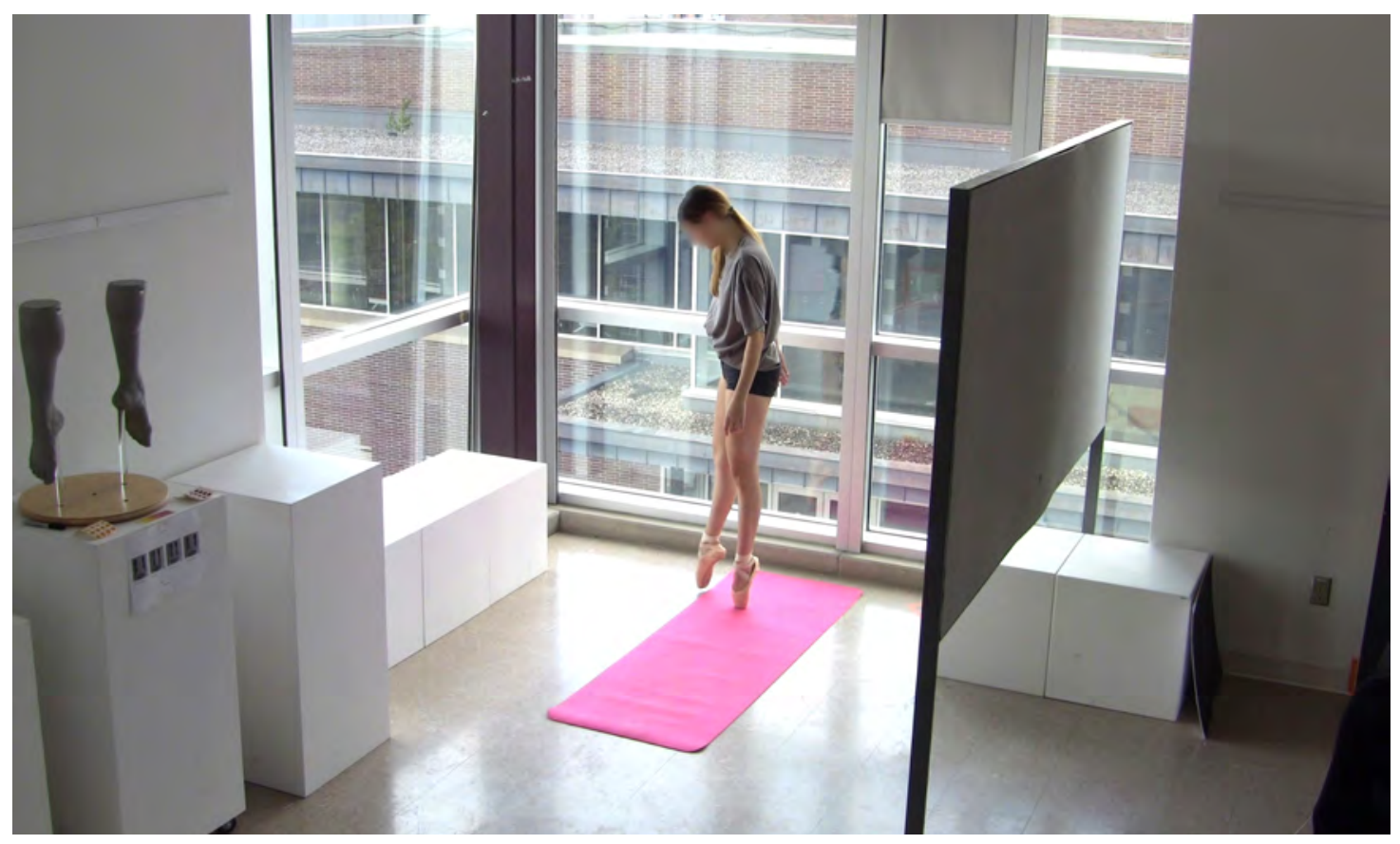

Figure 14. Zone 2: warmup, pointe movements and real-time discomfort assessments.

\subsubsection{Zone 3 Thermographic Imaging}

The third zone in the laboratory was secluded and controlled in order to accommodate consistent and accurate thermographic images for all the participants (Figure 15). This section included the thermographic imaging camera equipment and rubber-like mats and accessories to avoid high emissivity when imaging sessions were being done. This section followed thermographic imaging protocols (see Appendix F.1). Participants in this zone were imaged at the same distance from the camera, and lighting and temperature were kept consistent while utilizing surfaces with low emissivity (Jones \& Plassmann, 2002). The participant was guided by visuals and the moderator of foot positions when being photographed (Appendix F.2). Additional areas in the laboratory were designated to accommodate participants who needed parents with them while being tested. 


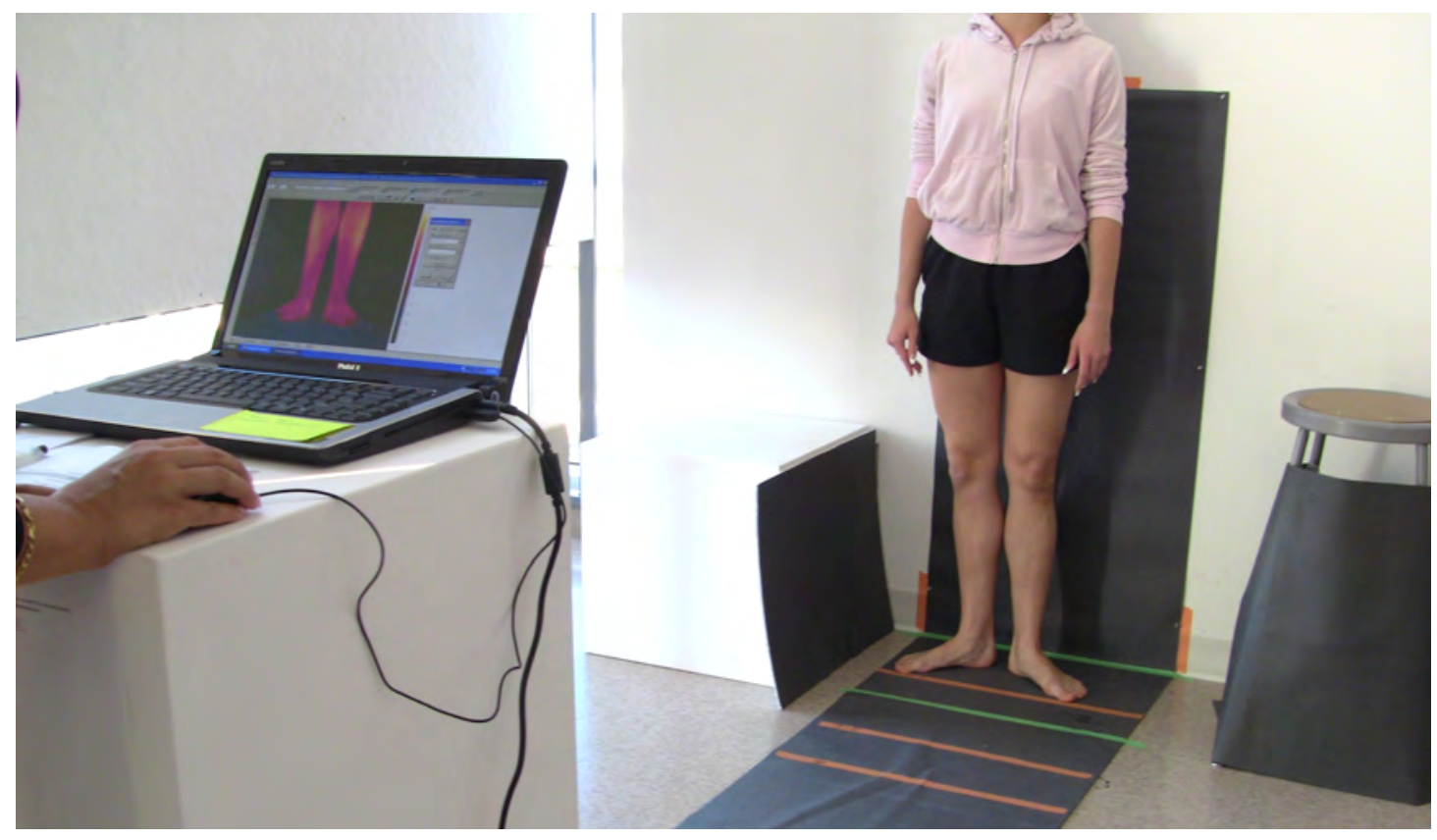

Figure 15. Zone 3: thermographic imaging sessions.

\subsection{Pre-Test Questionnaire Design}

The introductory questionnaire was the first stage of data collection during the testing session. Prior to each test, the table illustrated in Appendix C.2 was photographed before capturing any data, in order to keep track of the method used, assessment, movement, and participant code, while maintaining participant anonymity. The questionnaire (Appendix D.1) was done via Qualtrics ${ }^{\mathrm{TM}}$ on a computer provided by the researcher, covering the following sections: i) background in pointe work, ii) pointe work practice, iii) pointe shoe condition and brand, and iv) usual discomfort experience when dancing en pointe. It consisted of close-ended questions with multiple choices and scales, allowing the questionnaire's results to be quantified, which can eliminate data ambiguity (Travis \& Hodgson, 2019). 
In the questionnaire, the first section "Background", which gathered data about the participant's background information and experience with pointe work, from the age they started practicing ballet up to the ballet style they're currently practicing. The second section of the questionnaire, "Practice", collected data about the participant's pointe work practicing style, from knowing their pointe work readiness to their strongest foot when en pointe. The third section of the questionnaire, "Pointe Shoes", gathered background information in regard to the pointe shoe brand the participant would be using, the fitting process conducted for their shoes, and the current condition of the shoe. The last section of the questionnaire, "Discomfort", collected data on usual discomfort intensity, location, frequency and coping styles of the participant when dancing en pointe. The discomfort assessment questions were repeated five times, at the beginning, during and at the end of each test session to assess variation that occurs in perceiving and experiencing discomfort.

\subsection{Real-Time Discomfort Assessment Design}

The second phase of data collection involved participants assessing their real-time foot discomfort immediately after performing pointe work movements and before thermographic imaging sessions. A design problem process was utilized in order to carefully create the procedure, tools and protocols of the real-time assessment's methods, as it is a new means of measuring discomfort. A 3-D printed real-life representation of a ballet dancer's feet when en pointe was created. It was accompanied by four (4) discomfort assessment questions, allowing participants to assess their immediate discomfort location while en pointe. A set of requirements that will be explained in 
section 3.6.2 were established, enabling to design and develop an apparatus that ballet participants could easily relate to.

Participants assessed their discomfort by holding the last en pointe position and vocalizing the intensity of discomfort while indicating it on the 3-D apparatus (see Figure 16). Real-time data, allows the user to assess their immediate experience, minimizing the need to recall past experiences (Stone \& Broderick, 2007). When developing the design of the real-time discomfort assessment, research identified in the literature review, on current real-time pain scales and questionnaire led to design the scale and the apparatus.

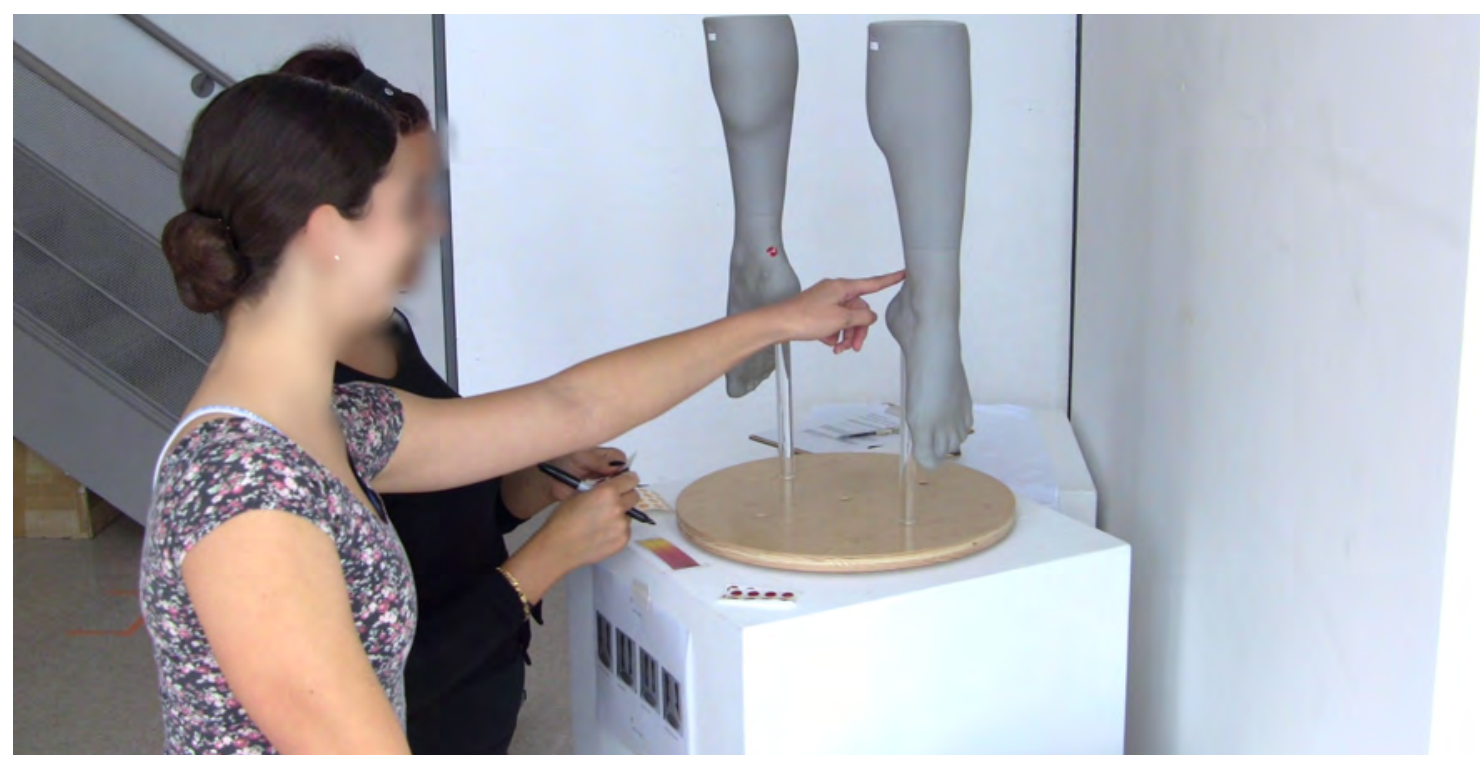

Figure 16. Real-time discomfort assessment areas on the 3-D apparatus.

Ballet steps were chosen based on fundamental pointe movements, familiar for all levels of pointe work: i) échappé, ii) sissonne simple, and iii) bourrée (see Appendix E.1 for further details). All participants were asked to complete the movements, within a oneminute time frame, guided with 8 counts of 8 to keep track of the beat and tempo of the ballet steps. The first movement is called échappé, it involves the dancer springing from a 
fifth ballet position to two feet en pointe, by alternating the front foot (see Figure 17). The last en pointe position, is illustrated as the third image in Figure 17, called relevé.
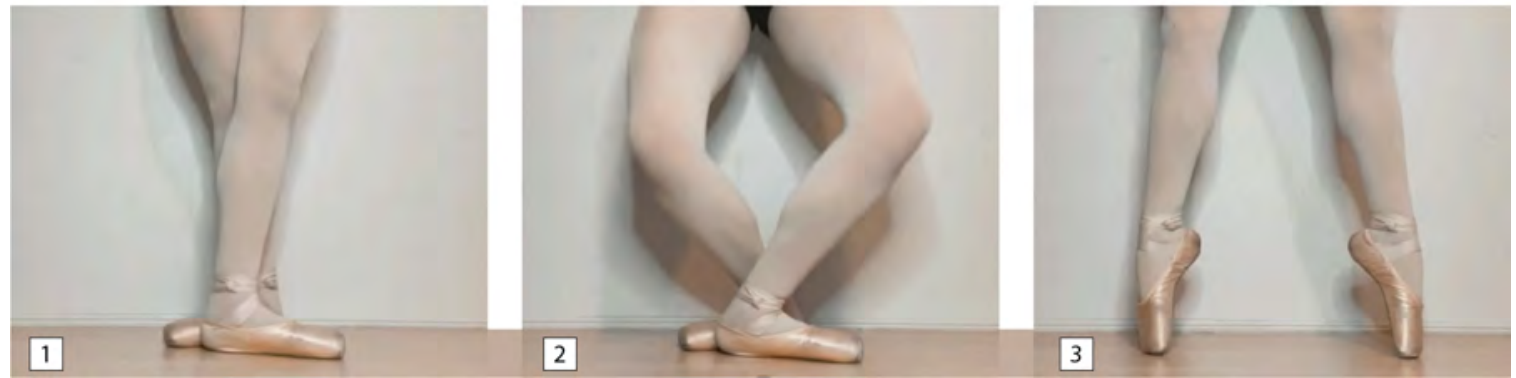

Figure 17. Movement 1 performed for 1 minute by alternating the front foot when springing to go en pointe.

The second movement is a weight bearing movement called sissonne simple, it consists of springing from a fifth ballet position to one foot en pointe, by interchanging both left and right foot when en pointe (see Figure 18). The last en pointe position, is illustrated as the third image in Figure 18, called coupé relevé. This movement required two assessments, as the movement involves alternating weight en pointe, one foot at a time.

M2 Mouvement 2: Sissonne Simple

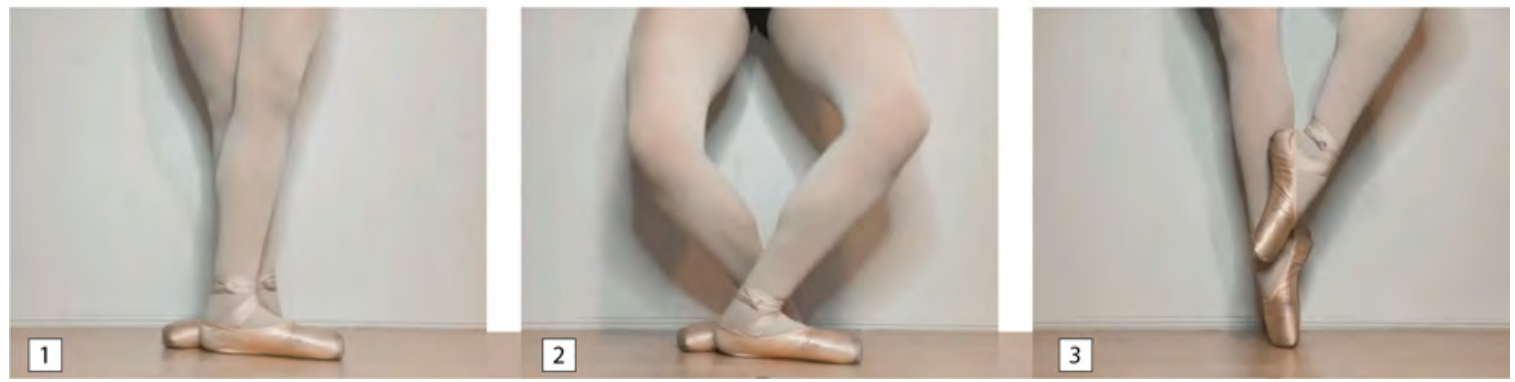

Figure 18. Movement 2 performed for 1 minute by alternating the left and right foot en pointe. 
The third movement is also a weight bearing movement called bourrée, it entails small quick steps in the fifth ballet position en pointe, keeping no space between the feet (see Figure 19). The front foot bears most of the ballet dancer's body weight. The last en pointe position, is illustrated as the third image in Figure 19, which is a fifth ballet position en pointe.

M3 Mouvement 3: Bourrée
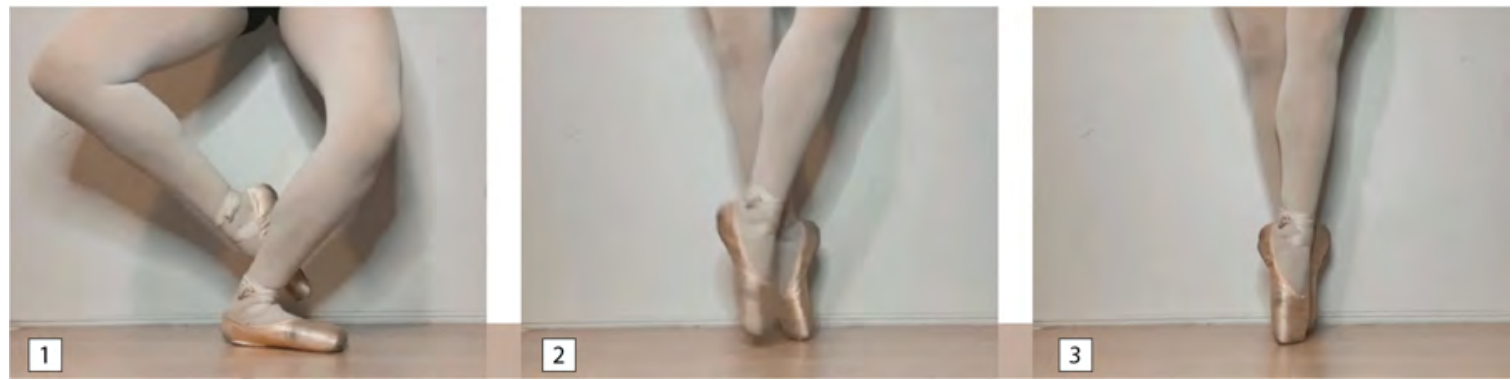

Figure 19. Movement 3 performed for 1 minute by rapidly alternating the weight on the left and right foot when en pointe.

\subsubsection{Questionnaire and Real-Time Discomfort Scale Design}

Four preliminary assessment questions (Appendix E.2) were asked to the participants, after completing pointe movements $(1,2,3)$ and holding the last en pointe position of each movement. The questions were accompanied by a discomfort scale from $0-10$ (see Figure 20), with 0 representing no discomfort and 10 representing most discomfort imaginable. A gradient from yellow to red was used allowing participants to differentiate discomfort felt immediately (see Figure 21). All participants responded verbally while holding the last en pointe position of each movement:

- First, verbalizing if discomfort was experienced in the left, right, or both feet. 
- Second, rating the overall discomfort on a scale of 0-10 using the discomfort scale presented in front of them.

- Third, localizing and rating their most felt discomfort on a scale of 0-10 with the help of the moderator using red stickers while rating each point on the 3-D model.

- Fourth, localizing rating their least felt discomfort on a scale of 0-10 with the help of the moderator using yellow stickers while rating each point on the 3-D model.

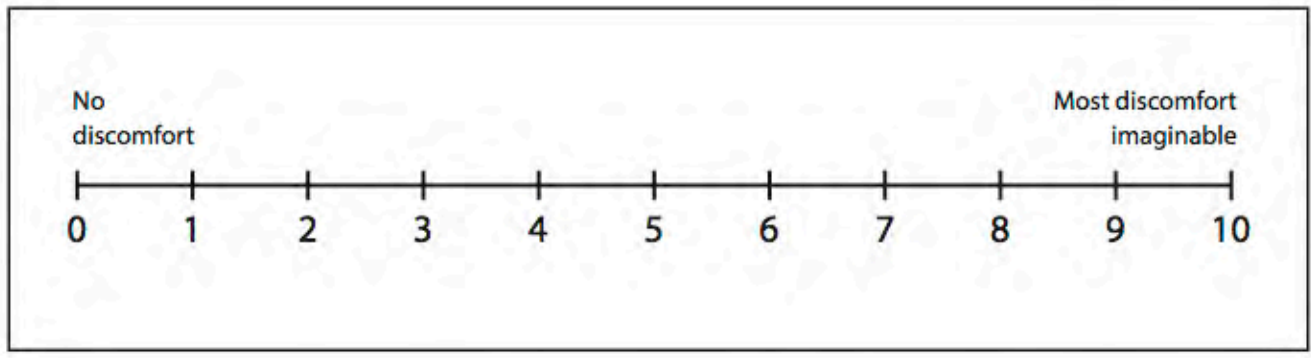

Figure 20. Real-time discomfort scale design.

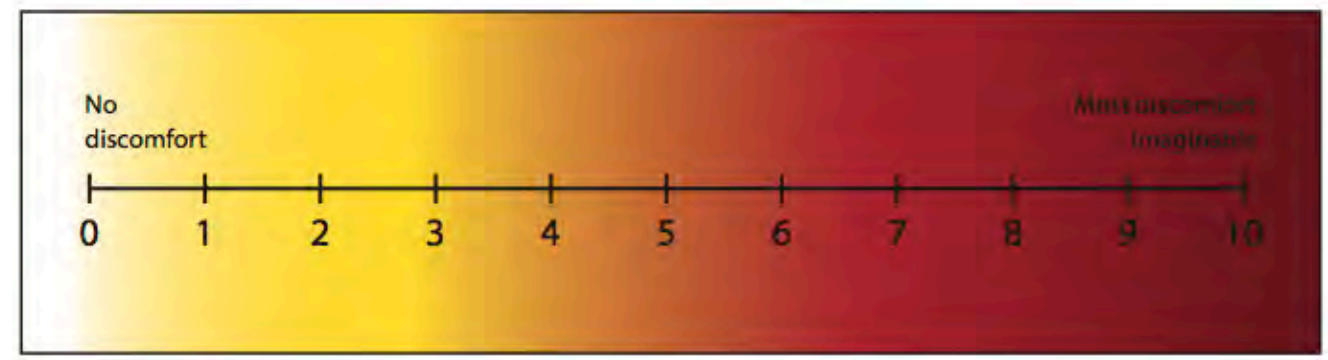

Figure 21. Real-time discomfort scale used during testing.

The questions consisted of close-ended questions on discomfort location and discomfort scale ratings. The data collected in this phase allowed the primary researcher to establish the main areas of discomfort and their intensity levels while en pointe. As some pointe work movements involve supporting the weight on one foot more than the other, the goal 
was to observe the variation in discomfort ratings and areas of convergence on the 3-D feet apparatus. In particular, a goal was to investigate the variations in the discomfort areas as the level of movements' complexity increases. The discomfort areas and their ratings were then compared with the delta temperature of the thermographic images for that specific movement. The procedure of the real-time discomfort assessments was identical for each pointe work movement.

\subsubsection{3-D Printed Feet Assessment Apparatus Design}

For the first time, a 3-D printed assessment apparatus of feet en pointe was designed, allowing ballet participants to assess their discomfort when holding an en pointe position (see Figure 22). Multiple processes and iterative explorations led to the final design of the apparatus. Requirements and design criteria were established to accommodate assessments from any angle and area of the foot while prioritizing the accuracy of the assessments as timing was key for data collection.

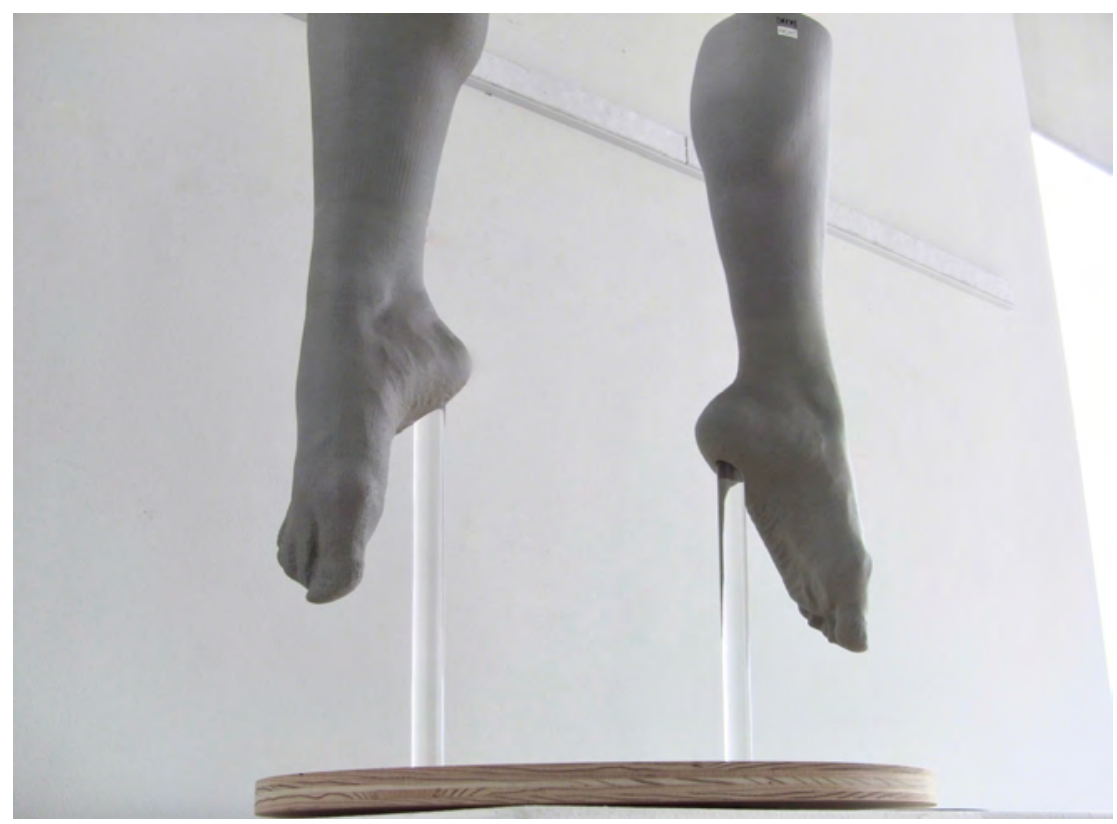

Figure 22. 3-D printed feet en pointe apparatus used for all real-time discomfort assessments. 
Three-dimensional scanning and printing were utilized for the apparatus design to best replicate the realism of a ballet dancer's bare feet when en pointe. In particular, 3-D scanning allows generating and recording data from a surface of any object without contact (Kus, Unver, \& Taylor, 2009), including human body parts, as it is known for its non-invasive properties while maintaining, speed, quality, and detail (Royo \& Panyella, 2014). The apparatus design allowed the researcher to use it with ease while manipulating it under pressure during testing. In addition, the 3-D model allowed re-creation of the last en pointe positions obtained by the participant, due to its design features (see Appendix E.4 for all possible positions). The placement of the apparatus and discomfort scale were carefully studied in order to allow for easy access when en pointe and assessing their discomfort.

The 3-D assessment model was placed directly in front of the participant and raised on a plinth at reach level. The apparatus was composed of grey PLA 3-D printed feet, held by clear acrylic rods and a supported plywood base. 3-D modeling scanning enabled recreation an accurate representation of a ballet dancer's feet when en pointe. To recreate such representation, an expert in the field of Industrial Design at Carleton University's School of Industrial Design scanned a ballet dancer's pointed foot using "Go! Scan 50", a handheld 3-D scanner (see Figure 23). 


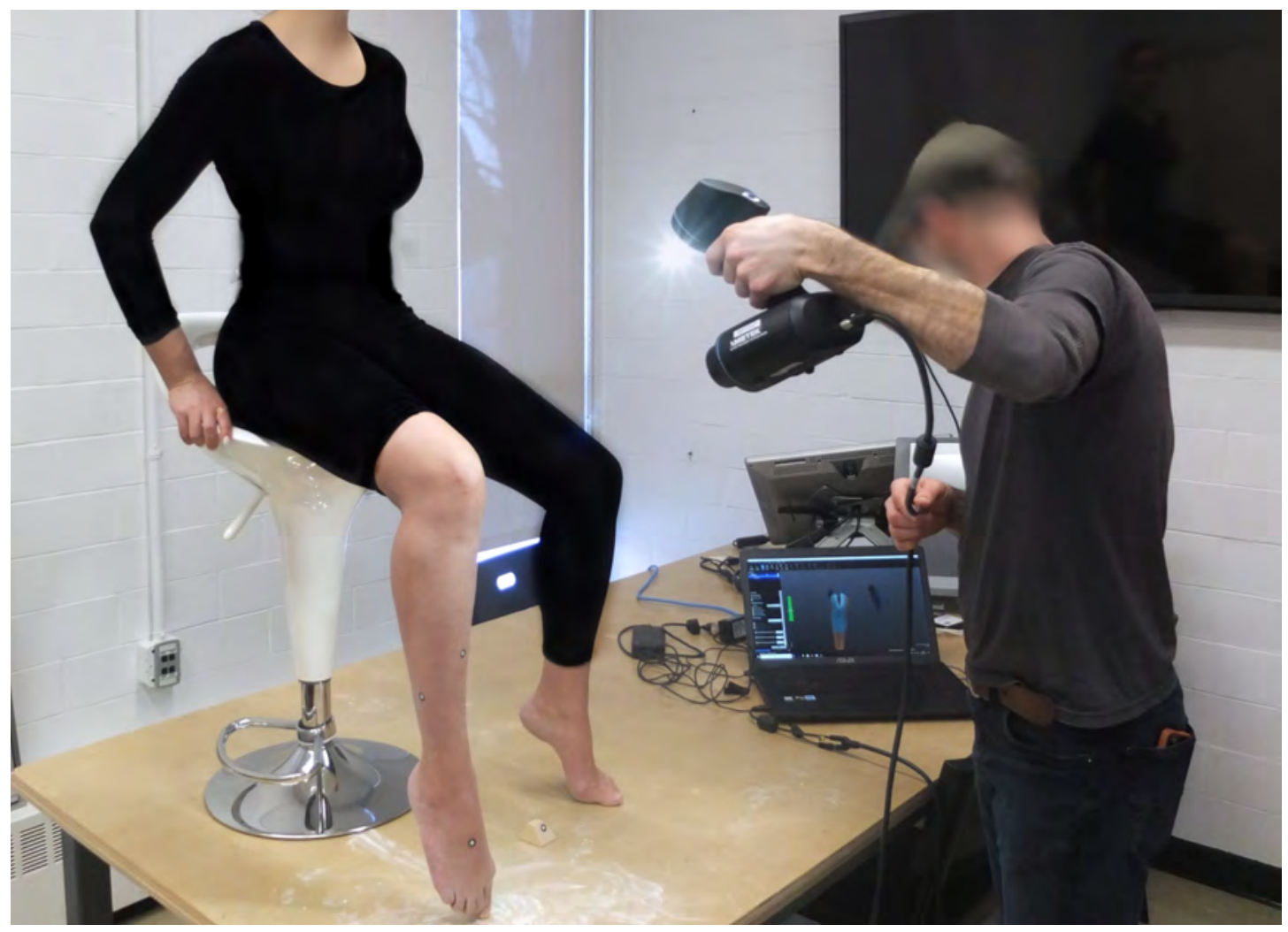

Figure 23. 3-D scanning procedure of a ballet dancer's foot en pointe.

The dancer held a stable position for at least one hour, while pointing the strongest foot for scanning. Following the scanning process, the CAD file was manipulated and edited using Solidworks ${ }^{\circledR}$ in order to prepare for 3-D printing, conducted by an expert in the field of Industrial Design at Carleton University’s School of Industrial Design. The following steps were taken before 3-D printing:

- Extruding a hole in the heel of the foot, in order to fit the clear acrylic rod.

- Increasing wall thickness for proper 3-D printing quality.

- Separating the foot into two parts, to allow for printing.

- Extruding a female and male connection, enabling assembly with precision.

- Creating two files for the left and right foot by reflecting the parts using the vertical axis. 
- 3-D printing both feet using a rapid prototyping machine.

- Sand blasting the 3-D printed feet for a matte finish to replicate the appearance of human skin.

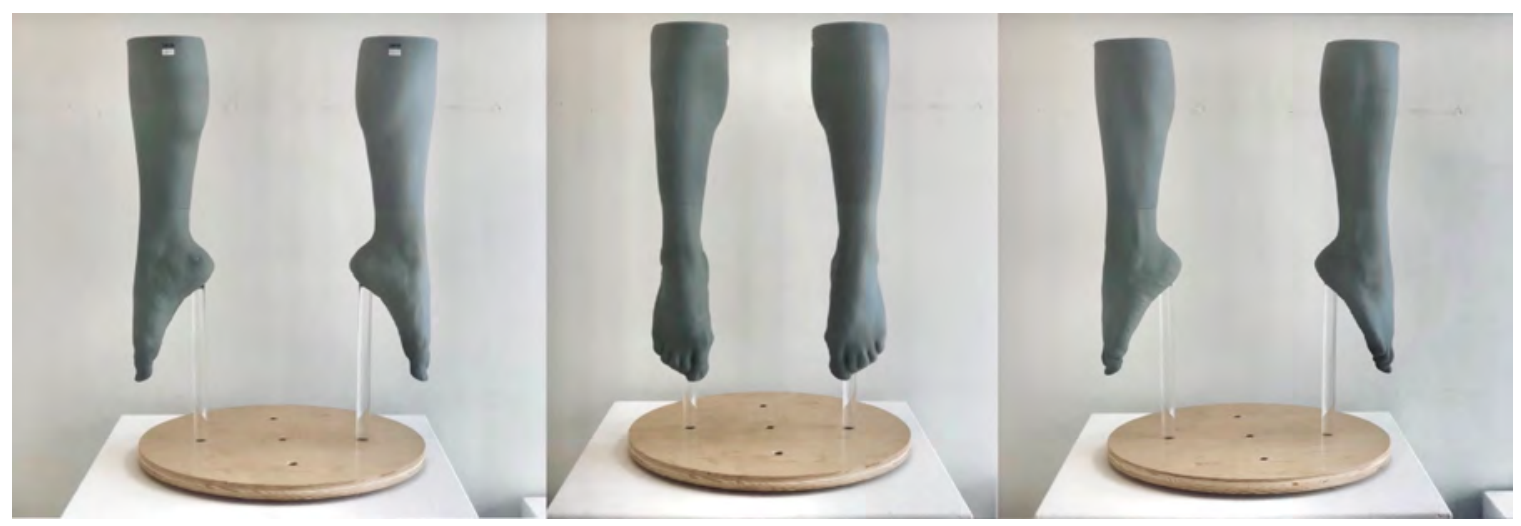

Figure 24. 3-D printed feet en pointe apparatus used for all real-time discomfort assessments.

Prior to the fabrication of the apparatus, concept drawings of the model were developed in parallel by consultations with manufacturing experts in the field of Industrial Design at Carleton University's School of Industrial Design's laboratory shops. The key features of the 3-D printed feet en pointe apparatus (see Figure 24) are as follows:

- Drilled openings to accommodate 4 different ballet positions, $1^{s t}$ position, $2^{\text {nd }}$ position, $5^{\text {th }}$ position and releve position, to allow the researcher for positioning the feet in the last en pointe position during assessments (see Appendix E.4);

- Levitated feet and turntable platform to allow assessments from all angles, including the bottom of the feet;

- Turntable platform to accommodate data collection being photographed and repeated in a systematic and consistent matter; 
- Non-adhesive plastic surface, allowing for easy peeling of stickers when assessment is completed;

- Sand blasted surface to replicate texture of skin for accurate representation;

- Grey colour PLA filament to portray skin tone neutrality encouraging inclusivity;

- Wooden platform to replicate the aesthetics of a ballet studio's dancefloor;

- Vinyl labeling to differentiate the left and right foot when collecting data.

\subsubsection{Real-Time Discomfort Assessment Procedure}

Real-time discomfort assessments occurred after each pointe work movement performed and before each thermographic imaging session. Prior to dancing en pointe, participants were allocated a timed 5-minute warmup. In order to capture consistent data, each movement was explained and demonstrated by the moderator. In addition, instructional visuals of each movement were printed and showcased on the wall, to allow for guidance, efficiency, and confidence (Appendix E.1). All participants were instructed to use the barre when needed and stop dancing at any time if they felt tired or experienced pain and discomfort. During each assessment, the moderator assisted the participants when assessing their discomfort on the 3-D model. The participants assessed their real-time discomfort and were asked to do the following for all assessments:

- Hold their last en pointe position while holding on to the barre;

- Vocalize if they are experiencing discomfort in the left, right, or both feet;

- Rate their current overall discomfort using the discomfort scale in front of them;

- Indicate their current most experienced discomfort, using the red vinyl stickers on the 3-D model and vocalizing the intensity of it; 
- Indicate their current least experienced discomfort, using the yellow vinyl stickers on the 3-D model and vocalizing the intensity of it.

\subsubsection{Real-Time Discomfort Assessment Collection Method}

Consistency and repeatability were key, when collecting data during this stage, as many different methods were happening simultaneously. For each ballet movement, the moderator transcribed the data using a printed sheet of the preliminary questions, coded accordingly to the participant and exercise performed (Appendix E.2). Data was transferred electronically in a table using Excel, for analysis. An area in the laboratory was allocated using neon tape, for photographing the data collected on the 3-D model using a camera, from the same distance. The discomfort areas collected using the 3-D model were photographed in the same positions as the thermographic images, with the help of a laboratory assistant during testing, to keep consistency when analyzing the data. Data on the specific areas of the feet were then illustrated and transferred digitally using illustrator. A plinth was placed next to the 3-D assessment apparatus, in order to have a surface to place the 3-D printed feet when capturing data of one foot. The positions and order of necessary photographs were illustrated on a printed paper taped on the plinth for reference (Appendix E.3). Following data collected, the laboratory assistant removed all stickers from the 3-D model in order to prepare for the next set of assessments. Photographs of the top, bottom, inside, and outside of the 3-D printed feet were collected during the assessments, as shown in Appendix E.3. 


\subsection{Thermographic Imaging Protocol Design}

The thermographic imaging protocol and its area were designed to allow for consistency and repeatability during the data collection. The equipment used allowed capturing of real-time images, while the area allowed the researcher and participant to circulate with ease without interfering with any equipment or the placement of the tools. Throughout each imaging session, the participant was guided by the researcher and assisted by illustrations of the distinctive feet imaging positions facing the participant.

\subsubsection{Equipment, Tools, and Space Planning}

Each imaging session utilized FLIR ThermoVision ${ }^{\mathrm{TM}}$ A40M infrared camera to capture temperature and heat patterns through thermal images. The camera is able to measure temperature from $-20^{\circ}$ to $120^{\circ}$ Celsius and from $0^{\circ}$ to $350^{\circ}$ Celsius (see Figure 25). The camera allows detection of temperature variations of $0.08^{\circ}$ Celsius at $30^{\circ}$ Celsius with a reading accuracy of $\pm 2^{\circ}$ Celsius. Additionally, the minimum focus distance is 0.3 meters. Each thermal image has a pixel resolution of 320x420 for monochrome images and 640x480 for colored images, which are sampled at a refresh rate of 50 to $60 \mathrm{~Hz}$ (times per second). 


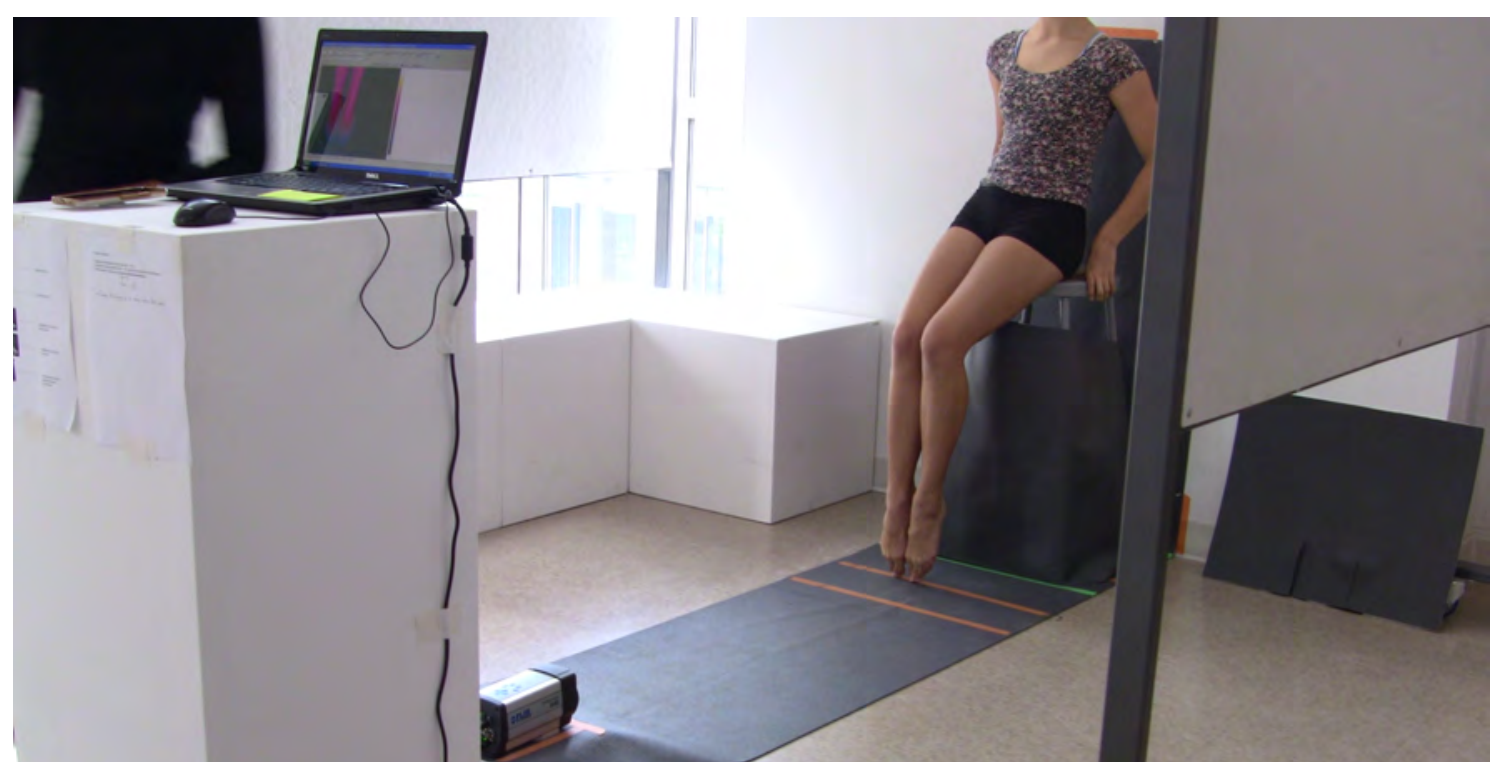

Figure 25. Equipment used during the thermographic imaging sessions.

The imaging was done in a secluded controlled area, following repeatable thermographic imaging protocols, in terms of consistent distance of the participant's feet and the camera, lighting consistency, temperature consistency, and surface reflectivity and emissivity (Figure 26). The photographic area, the area of preparation and tools were covered with rubber-like mats in order to avoid emissivity, and allow for high contrast imaging when capturing the temperature body areas (Jones \& Plassmann, 2002). In addition, a rubberlike board was designed to isolate the feet from the rest of the body when capturing the plantar view of the feet, allowing to easily isolate the background when analyzed the images, see Figure 27. All the equipment's electronic cables were secured to the floor with electrical tape for security measures when circulating during testing. 


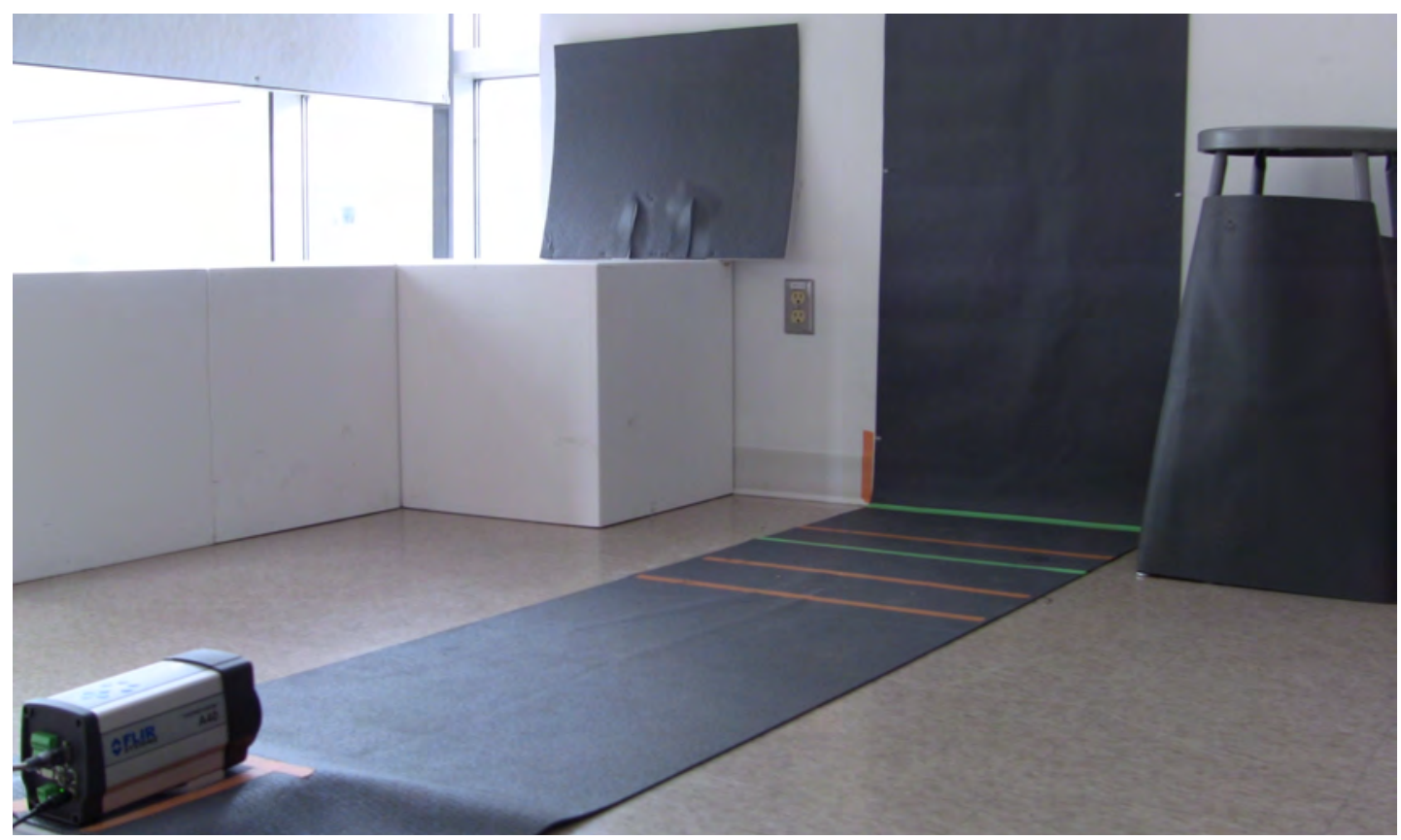

Figure 26. Setup of the secluded thermographic imaging area.

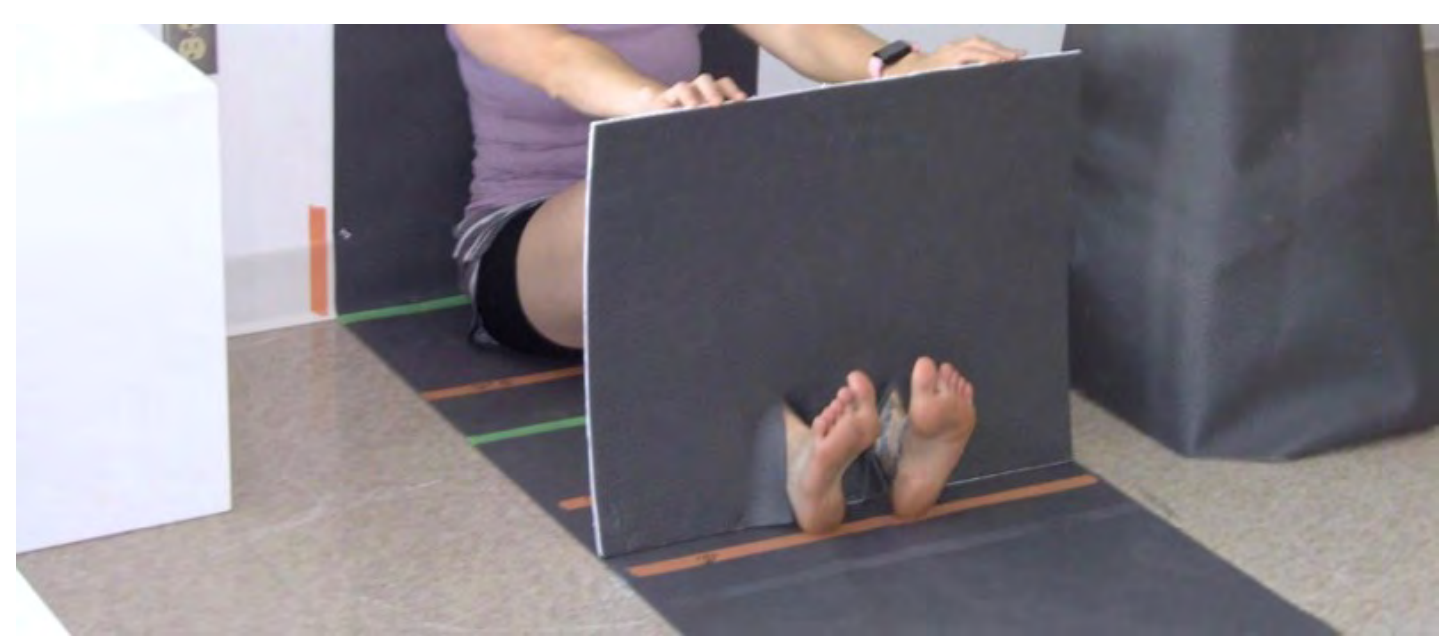

Figure 27. Tool designed to capture the plantar view of the feet.

\subsubsection{Imaging Sessions Procedure}

For each participant, five sets of image sequences were captured, before and after performing pointe movements, see Appendix C.1 for a map of the detailed occurrence.

For the purpose of this study, each set of video sequences contained five different frames, 
allowing to select the best representation of heat patterns when en pointe. In order to capture consistent thermographic images, each position was measured and marked with a neon coloured tape on the rubber mat, coded with the position, as seen in Figure 28. In addition, instructional visuals were printed and placed facing the participant, to allow for guidance, efficiency, and confidence in case they forgot what positions to hold (Appendix F.2). The room temperature and humidity settings for the images collected were controlled through each imaging session. The room temperature was kept at $15^{\circ}$ Celsius.

Prior to the imaging sessions, participants were asked to sit for 10 minutes while completing the introductory questionnaire, allowing the skin's temperature to stabilize. The first stage of image collection served as a baseline, evaluating the temperature of the feet before lacing pointe shoes and dancing en pointe. During the second, third, and fourth stages of image collection, the participant was instructed to perform fundamental pointe movements for one minute each, respectively: i) échappé, ii) sissonne simple, and iii) bourrée (Appendix E.1). The sequences were captured immediately after completing each movement. Participants were instructed to unlace their pointe shoes on the rubber matte, in order not to alter temperature change of the feet. Here, we wanted to observe the change in feet temperature as the exercises got harder and dancing en pointe became more physically demanding, as some movements are more weightbearing than others. The fifth and last stage of image collection took place 10 minutes after dancing en pointe and while the participant was completing the closing questionnaire. The intent was to observe temperature variation when the feet were resting in pointe shoes after completing all pointe movements. 


\subsubsection{Image Collection Method}

The camera was connected directly to a laptop via Firewire display port, for real-time image display and recording, through ThermaCAM Researcher obtained from FLIR systems. The software captures 60 frames per second and allows to view real-time thermal sequences and statistics, record a sequence of images, and store the sequence. The images were captured through recording sequences, which were later divided into individual frames for image analysis. The sequences' order was tracked using a sheet, coding the identification of each participant in regard to their session. During the test sessions, the temperature scale was set to measure temperature between $21^{\circ}$ Celsius to $37^{\circ}$ Celsius, since that range was successful in isolating the foot regions from the background for most participants' images. The emissivity parameter was set at 0.95 , which is appropriate to measure skin temperature. The participants were imaged at a distance of one meter to two meters depending on the positions and were asked to do the following for all sequences, see Figure 28:

- For the first set of sequences, to sit on the stool and hold a sixth ballet position, pointing the feet facing the top of the feet to the camera

- For the second set of sequences, to sit on the stool and hold a sixth ballet position, pointing the feet heels facing the camera.

- For the third set of sequences, to stand up in first ballet position, while separating the feet so the calves do not touch, with insides of the feet facing the camera.

- For the fourth set of sequences, to stand up in first ballet position, while separating the feet so the calves do not touch, with outsides of the feet facing the camera. 
- For the fifth set of sequences, to sit on the rubber mat with feet closed in sixth ballet position, while flexing the feet towards the sealing while holding the rubber board, bottoms of the feet facing the camera.
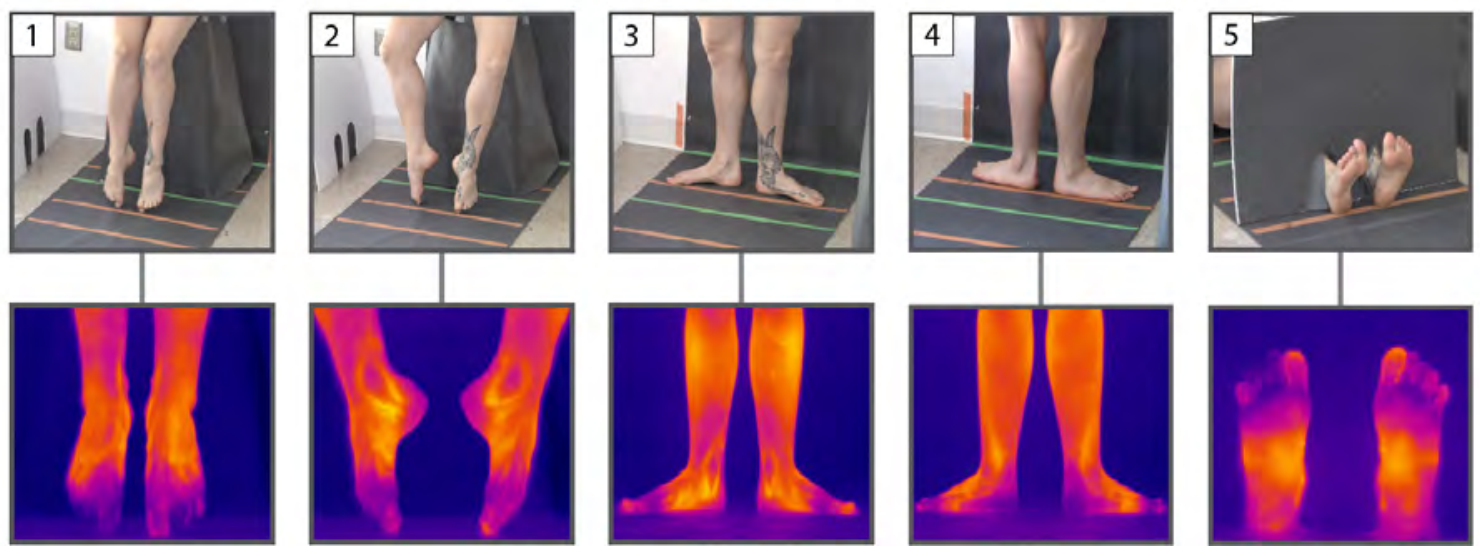

Figure 28. Feet positions for each sequence and its correspondent thermal map.

\subsection{Post-Test Questionnaire Design}

The closing questionnaire (Appendix D.2) was part of the last phase of data collection during the session. The questionnaire was completed via Qualtrics on a computer provided by the researcher, covering the following sections: i) discomfort experienced after dancing en pointe in the testing session, ii) previous pointe work related injuries, and iii) overall experience of the testing session. Similar to the introductory questionnaire, the closing questionnaire consisted of close-ended questions with multiple choice and scales. The data collected in this phase allowed the primary researcher to compile and measure participants' overall experience of discomfort when dancing en pointe.

The first section of the questionnaire, "Discomfort", collected data on current discomfort intensity, location, frequency, and coping mechanisms of the participant when dancing en 
pointe. The discomfort assessment questions were consistent throughout the session. The second section of the questionnaire, "Injuries", collected data about the participant's pointe work related injuries. The last section of the questionnaire, "Overall Experience", collected data on the participant's overall experience during the testing session and how long they envision pursuing ballet pointe work classes. Participants were required to provide an answer for each question before moving forward. The questionnaire took, on average 10 minutes to complete.

\subsection{Test Session Procedures}

The test session was designed for one participant at a time, as the precision and accuracy of collecting real-time data collection was key to this research. The session was divided into the following phases: i) pre-test session; ii) test session; and iii) post-test session. The research map below (Figure 29) illustrates the overview structure of each test session, its phases, and key elements. This map was a key tool to visualize and organize all required elements for each test session in the ballet studio laboratory. 


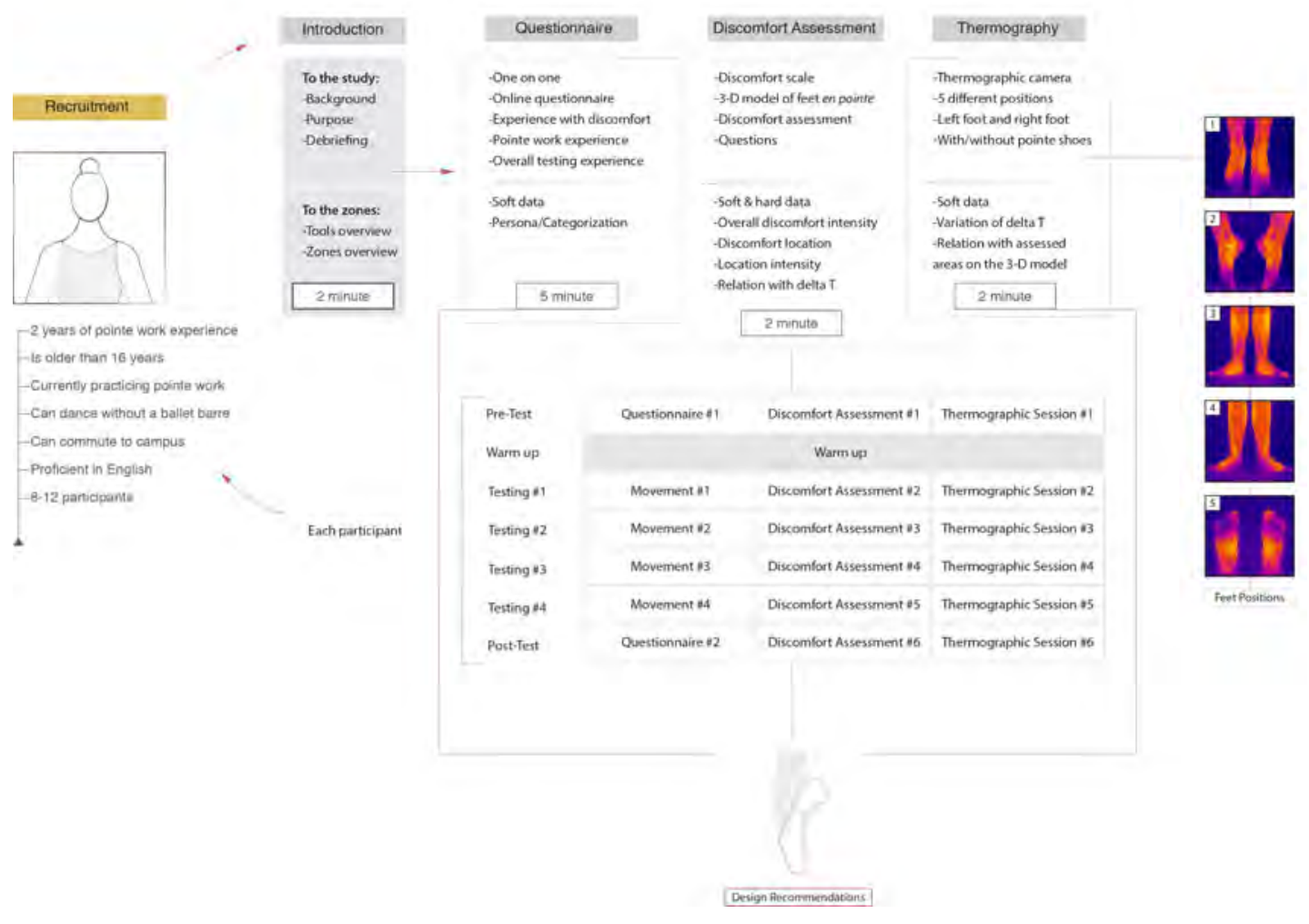

Figure 29. Illustration of the data collection map for each test session.

\subsubsection{Pre-Test Session}

Participants who were interested in participating in the test session, contacted the primary researcher, through on-campus poster advertisements and via e-mail invitations sent by the researcher to ballet dancers in the industry. Ballet participants who met the criteria when contacted the researcher, received the following information:

- E-mail containing the consent form and written content stating the goal and procedures of the research session.

- Invitation to participate in the test session and scheduled a date for the 60 -minute session, which took place at a laboratory ballet studio at Carleton University. 
Due to the age of some of the participants, parents were permitted to accompany them in order to help the participant feel more confident and comfortable during the session, as parents, especially mothers, are known to play a big role in terms of support in the ballet world (Wulff, 2001).

\subsubsection{Preparation Guidelines}

Participants were asked to follow preparation guidelines 24 hours prior to the study, which were sent via e-mail the day prior to the scheduled session (see Appendix F.3). If not followed, certain factors might affect the recordings of skin temperature when collecting thermographic imaging of the ballet dancers' bare feet. Each participant received the following information:

- A list of ballet items to bring to the test session.

- A list of certain activities and measures to avoid for up to 24 hours prior to their scheduled session;

- Participants were told to wear shorts in order to allow proper imagery from the thermographic camera, the camera requires bare skin to record skin temperature.

\subsubsection{Test Session}

On the day of the test session, the primary researcher guided and accompanied each participant to the ballet studio laboratory area. Upon arrival at the laboratory, the participant was introduced to the assistants present during the testing. Each participant went through the following steps prior to starting their test session:

- Each zone's protocol and procedures were demonstrated by the primary researcher, giving the participant a chance to ask questions if unsure. 
- Additional copies of the consent form were given if the participant did not bring their own, as they were sent via e-mail prior to testing.

- $\quad$ Time was afforded to read and complete the consent form (Appendix A.2);

- The study began as soon as the participant gave consent.

\subsubsection{Introductory Questionnaire}

After giving consent and receiving a briefing on the study, the participant completed the introductory questionnaire followed by the first set of thermographic imaging:

- The first questionnaire was completed in zone 1 by the participant as an introductory questionnaire (Appendix D.1) that collected data on the participant's background with pointe work and usual experience with discomfort when en pointe.

- The first set of thermographic imaging was completed in zone 3. Imaging was done on bare feet, capturing four different ballet positions without the participant having had laced their pointe shoes yet, in order to provide a baseline measure.

\subsubsection{Warm-Up}

Following the first set of thermographic imaging, the participant was asked to lace her pointe shoes and warm-up in order to prepare for dancing en pointe:

- A timed five-minute was allocated to complete the warm-up in zone 2.

- Classical music was played in the background to replicate the beginning of a ballet class setting. 
- The participant had freedom to execute her own stretches and exercises during the warm-up in order to reduce risks of cramps and injuries when going en pointe during the test and assessments.

\subsubsection{Real-Time Discomfort Assessment 1}

The first set of real-time discomfort assessment occurred in zone 2 immediately after the participant finished warming-up and was ready to go en pointe:

- First, échappé were quickly explained and demonstrated by the researcher.

- Second, a series of 8 counts of 8 of échappé were performed by the participant, which was timed by the researcher for one minute.

- Third, the participant assessed her discomfort, while holding the relevé position en pointe on both feet and indicated the intensity and area of real-time discomfort on the 3-D apparatus.

- Fourth, thermographic imaging was captured prior to the discomfort assessment, on bare feet and capturing four different ballet positions, without having had laced the pointe shoes.

- Finally, the participant was asked to lace the pointe shoes immediately after being photographed.

\subsubsection{Real-Time Discomfort Assessment 2}

The second set of real-time discomfort assessment occurred in zone 2 immediately after the participant finished their thermographic imaging session:

- First, sissonne simple were quickly explained and demonstrated by the researcher. 
- Second, a series of 8 counts of 8 of sissonne simple were performed by the participant, which was timed by the researcher for one minute.

- Third, the participant assessed her discomfort and indicated the intensity and area of the discomfort on a 3-D apparatus, while holding the relevé coupé position, alternating the weigh berating position one foot at a time and assessing the discomfort accordingly.

- Fourth, the participant assessed her discomfort, while holding the relevé coupé position en pointe, alternating the weight-bearing position one foot at a time, and indicated the intensity and area of the discomfort on a 3-D apparatus.

- Fifth, thermographic imaging was captured prior to the discomfort assessment, using bare feet and capturing four different ballet positions, without having had the participant lace the pointe shoes.

- Finally, the participant was asked to lace the pointe shoes immediately after being photographed.

\subsubsection{Real-Time Discomfort Assessment 3}

The third set of real-time discomfort assessment occurred in zone 2 immediately after the participant finished their thermographic imaging session:

- First, bourrée were quickly explained and demonstrated by the researcher.

- Second, a series of 8 counts of 8 of bourrée, were performed by the participant, timed by the researcher for one minute, with the strongest foot forward, as chosen by the participant. 
- Third, the participant assessed her discomfort, while holding the $5^{\text {th }}$ position en pointe with the chosen strongest foot forward and indicated the intensity and area of the discomfort on a 3-D apparatus.

- Fourth, thermographic imaging was captured prior to the discomfort assessment, using bare feet and capturing four different ballet positions, without having had the participant lace the pointe shoes.

- Finally, the participant was asked to lace her pointe shoes immediately after being photographed.

\subsubsection{Closing Questionnaire}

After completing all assessments, the participant was asked to keep her pointe shoes laced while completing the closing questionnaire, followed by the last set of thermographic imaging:

- A total of 10 minutes was allocated to complete the last set of tests.

- The last questionnaire was given in zone 1 , in regard to experiencing discomfort during and after testing, as well as the overall experience of the testing experience (see Appendix D.2).

- The fourth and last set of thermographic imaging was completed in zone 3, using bare feet and capturing the same four different ballet positions as all other sets.

\subsubsection{Compensation}

A zone was reserved for providing compensation and refreshments in the ballet studio laboratory. At the end of each session, each participant was thanked for partaking in the 
session, and refreshments and compensation were given to each participant. Each participant received the following after completing their test session:

- Refreshments such as water and mineral water.

- A gift card from Brio Dancewear.

- A chance to see their thermographic imaging.

- Gratitude and appreciation were shown by guiding and accompanying each participant when exiting the studio.

\subsection{Data Analysis Methodology}

Throughout the data analysis, reference materials were created to assist each stage of the analysis. An illustrative board was created for each participant containing all data collected during their sessions, enabling an overview of the results for each participant when triangulating the data. In addition, each session was video recorded and transcribed in writing, which was later analyzed and compared to determine findings and inconsistencies within the study.

\subsection{Participant Questionnaire Response Analysis}

Both the pre-test and post-test questionnaires were completed via Qualtrics. Participants' answers were exported into an Excel ${ }^{\mathrm{TM}}$ spreadsheet. Results obtained were then organized by sections of the questionnaires in order to uncover patterns and insights. Qualitative results obtained from both questionnaires were analyzed based on frequency of the multiple-choice answers. Quantitative results obtained from both questionnaires were analyzed based on averages and frequency. Both qualitative and quantitative results lead 
to the creation of a persona for each participant, as illustrated in the participant board (Appendix H.1).

\subsection{Real-Time Discomfort Assessments Analysis}

Foot illustrations, with their allocated assessed areas, were created for each participant using Illustrator ${ }^{\circledR}$, as a visual reference when analyzing the data. Photographs obtained of the assessments on the 3-D apparatus were digitized and re-iterated in Illustrator ${ }^{\circledR}$, to assist when correlating the data (see Figure 30). The researcher created a template of foot outlines for each participant to assist in the synthesis of the data.

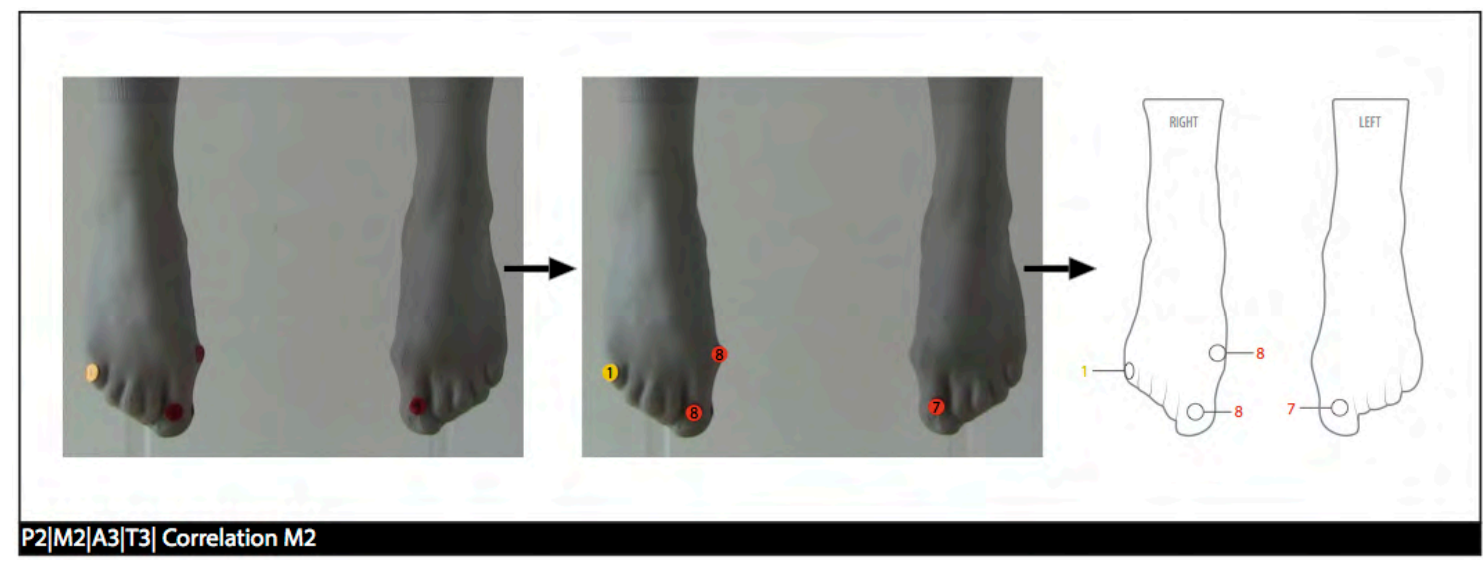

Figure 30. Illustration process for real-time discomfort used as visual reference.

The Quantitative results obtained were organized in an Excel ${ }^{\mathrm{TM}}$ spreadsheet by movement, with allocated areas of the feet, for both the right and left foot. To ease the analysis of the different areas assessed on the feet, results were categorized within the following areas, for both the right and left foot: great toe, $2^{\text {nd }}$ toe, $3^{\text {rd }}$ toe, $4^{\text {th }}$ toe, $5^{\text {th }}$ toe, metatarsal, arch, inner ankle, and outer ankle. If a participant assessed more than once an area of the foot, the average of that area was calculated. The categories allocated for analysis covers the overall area of the foot; for example, if a participant assessed an area 
of the metatarsal of the foot, either in the back or the front, the rating would be inputted in the metatarsal section, as the aim is to look at the overall areas of assessments.

The discomfort ratings were also categorized by the most felt discomfort, least felt discomfort, and the overall discomfort out of 10 for each participant and per movement. The quantitative results collected in this phase were analyzed based on frequency of foot area assessed, average rating, and standard deviation for both the right and left foot. In order to proceed with statistical analysis, the average discomfort ratings of both the right and left foot were calculated and organized in an Excel ${ }^{\mathrm{TM}}$ spreadsheet by areas of assessment (see Appendix H.2).

\subsection{Thermographic Imaging Analysis}

The illustrated feet created in the earlier stages of the analysis were used as a point of reference to assess the specific areas on the thermographic images. The illustrated feet were overlapped on the thermographic images as a point of reference for accuracy when measuring the thermal areas, using Illustrator ${ }^{\circledR}$ (see Figure 31). During the analysis of the thermal images, a board was created for each participant to use as a point of reference in conjunction with the analysis software (Appendix H.3). 


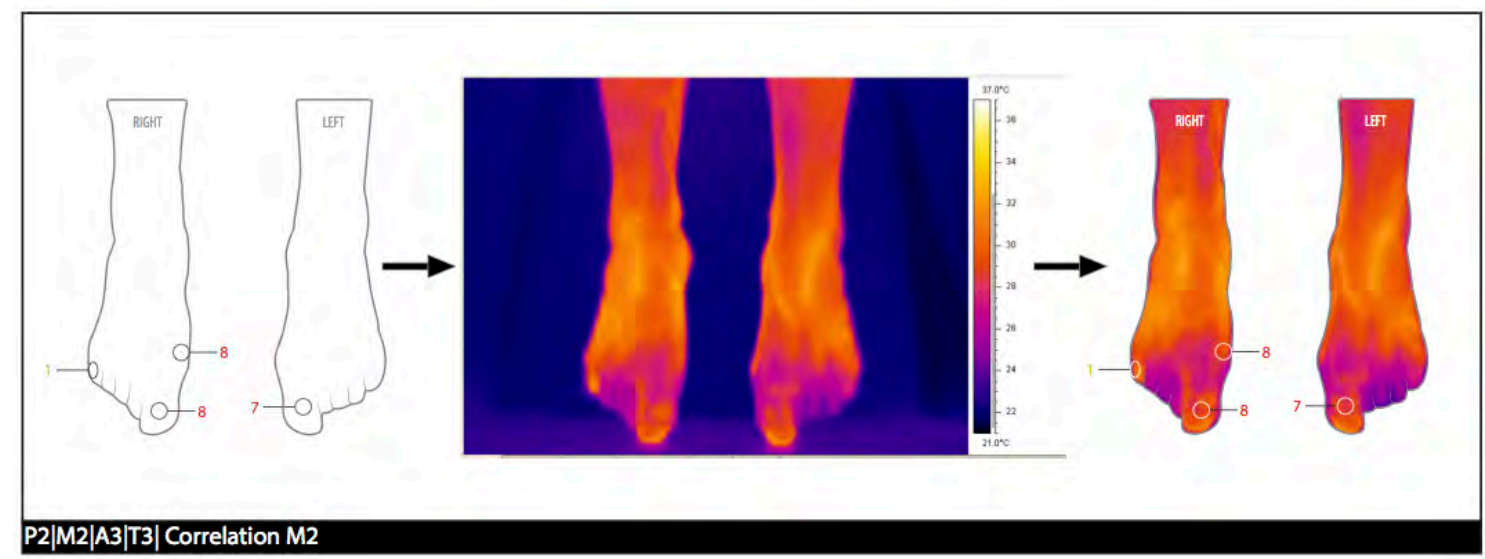

Figure 31. Illustration process for thermal areas used as visual reference.

Since we were interested in temperature variation of the assessed areas on the 3-D feet apparatus, we focused on selecting the areas assessed by the participants to observe temperature change and its relationship with the discomfort rating for movement $(1,2,3)$. First frames were selected from each video sequence and analyzed through FLIR thermal studio Pro. This software allows creation of thermal analysis and reporting by automating tasks for each thermal image. The measurements were then calculated through batch processing for each participant, reducing error when calculating the delta of each image with the base thermal image before dancing en pointe. The batch processing allows for analyzing multiple images at the same time by creating and running automated repetitive tasks to edit and normalize each thermal image.

A report template was created for each participant, which included the base image (T1) and post-movement image (T2), with the measurements of the temperature area for the right and left foot (see Appendix H.4 for report). Three positions were selected to best represent the real-time discomfort feet areas assessed. The temperature measurements were then imputed and organized in an Excel $^{\mathrm{TM}}$ spreadsheet by areas of assessment. The 
delta temperature was then calculated. The formula used in this study is defined as follows: delta $\mathrm{T}(\Delta \mathrm{T}=\mathrm{T} 2-\mathrm{T} 1)$, where temperature was in Celsius, $\mathrm{T} 1$ being base temperature before lacing pointe shoes, and T2 being real-time discomfort area temperature assessed by participants on the 3-D feet apparatus. If a participant assessed more than once the same area of the foot, the average temperature area was calculated. In order to proceed with statistical analysis, the average temperature delta of the right and left foot combined was calculated, as well as the average discomfort rating of both the right and left foot. These calculations were organized in an Excel ${ }^{\mathrm{TM}}$ spreadsheet by areas of assessment (see Appendix H.5).

\subsection{Data Convergence}

The goal of utilizing a triangulation in complex subjects is to form an area of convergence where the collected information overlaps. Our approach was to observe where the findings overlapped and where patterns occurred. The data convergence was performed through design synthesis, visual mapping technique, and using the combination of the quantitative and qualitative findings. As such, we investigated solely the repeated discomfort assessments in relation to our research questions, found in the questionnaires and movement $(1,2,3)$ :

- If discomfort was felt in the left foot, right foot, or both feet.

- Overall discomfort rating on a scale of 0 to 10 .

- Discomfort areas of the feet. 


\subsection{Statistical Analysis}

Statistical analysis of the results obtained from the data convergence was conducted to validate the significance of the results, see Figure 32 for all steps taken during the statistical analysis stage. Statistical tests were performed using GraphPad Prism Version 9.0. This software allows analysis of quantitative and categorical data by choosing suitable analysis tests for your research while generating graphs. Data normality was tested prior to each test ( Razali \& Wah, 2011). Normality was verified by using ShapiroWilk's test, found to be the most powerful test for all types of distribution and sample sizes (Mohd Razali \& Bee Wah, 2011). The test rejects the hypothesis of normality when the $p$-value (significance level) is less than or equal to 0.05 . If the $p$-value is greater than 0.05 , then the null hypothesis is not rejected, and the data is assumed to be normally distributed.

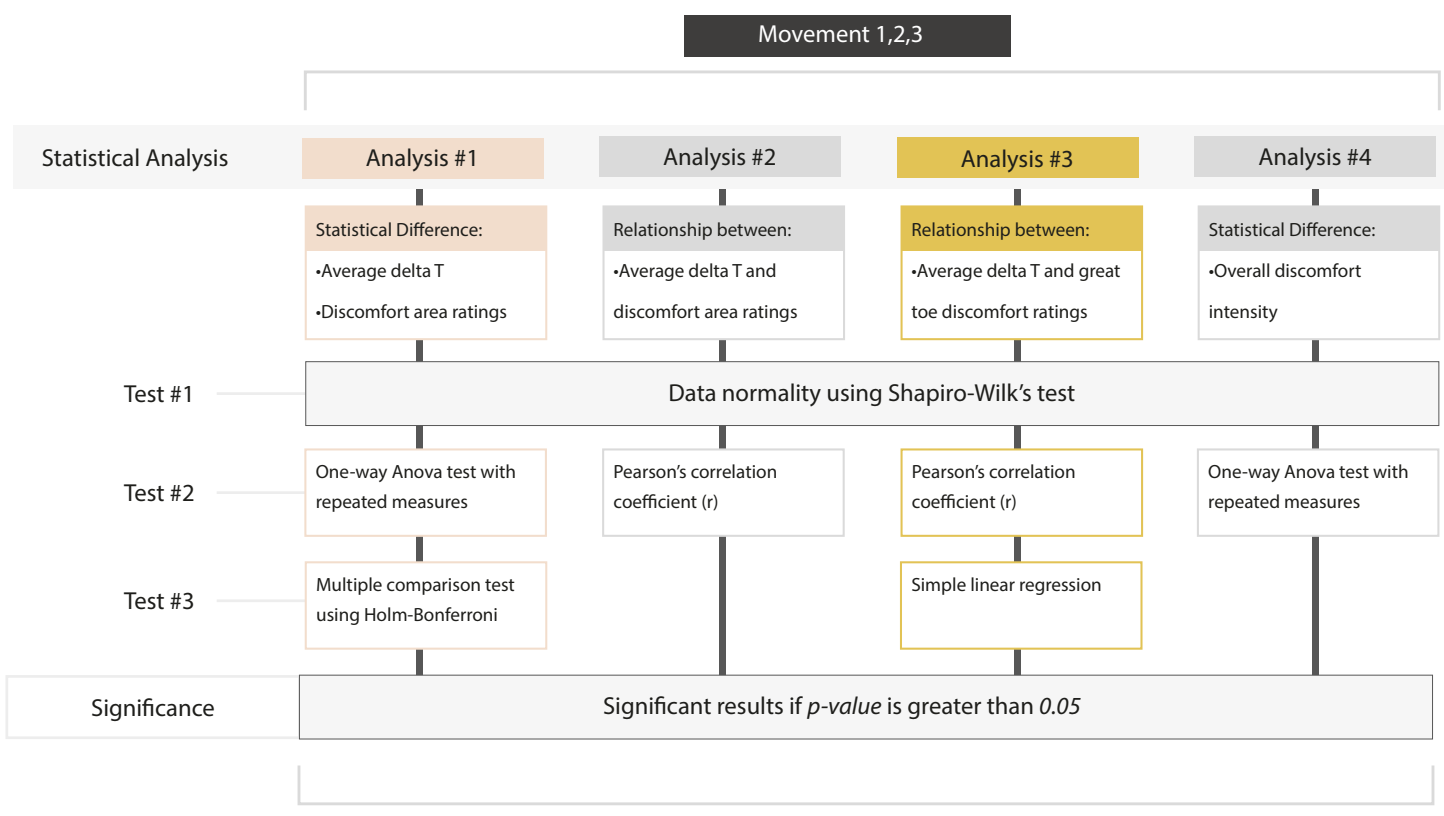

Figure 32. Illustration of the statistical analysis map used during the analysis stage of this study. 


\subsubsection{Average Delta $T$ and Discomfort Area Ratings Differences for Movement $(1,2,3)$}

Our first approach was to see if there was a significant difference in the delta temperatures and real-time discomfort ratings for all pointe movements. First, we assessed data normality using Shapiro-Wilk's test, significant at $p<0.05$. Second, we conducted a one-way ANOVA with repeated measures to compare movement $(1,2,3)$. The statistical test becomes significant when the corresponding $p$-value is greater than 0.05. Repeated measures were used as the same participant went through different conditions (different ballet movements). In addition, a multiple comparison test using the Holm-Bonferroni correction method was performed to compare the average discomfort intensity from one condition to another. The test statistic becomes significant when the $p$ value is greater than 0.05 .

\subsubsection{Relationship Between Average Delta $T$ and Discomfort Area Ratings in Movement $(1,2,3)$}

Our second approach was to evaluate the relationship between the average delta temperatures and discomfort ratings of all areas assessed in all three movements. Statistical correlation was performed to understand the relationship between two continuous variables (Parvin, 2007). In our study, we examined the correlations between average discomfort ratings (out of 10) and delta temperatures (in Celsius). We examined the correlation for each movement $(1,2,3)$ using Pearson's correlation coefficient $(r)$, as the data was normally distributed. The correlation becomes significant when the associated $p$-value is greater than 0.05 . 


\subsubsection{Relationship Between Average Delta Temperatures and Average Discomfort Ratings of the Great Toe in Movement $(1,2,3)$}

The third approach was to evaluate the relationship of the average delta temperatures and average discomfort ratings of the great toe in all three movements. The great toe was found to be most frequently assessed and had the highest average discomfort rating. Given that the data was normally distributed, we examined the correlation for each movement $(1,2,3)$ using Pearson's correlation coefficient $(r)$. Again, a corresponding $p$ value greater than 0.05 indicated significance. Second, a simple linear regression was performed, to observe if delta $\mathrm{T}$ is a predictor of average discomfort ratings of the big toe. A simple linear regression test allows to depict if a predictor variable can predict an outcome variable of interest, based on the estimated linear relation (Parvin, 2007). The test statistic becomes significant when the $p$-value is greater than 0.05 .

\subsubsection{Overall Discomfort Intensity}

The fourth approach was to see if overall discomfort intensity is statistically different at any point in time during our experiment; before, during, or after dancing en pointe. First, we assessed data normality using Shapiro-Wilk's test, significant at $p<0.05$. Second, we conducted one-way ANOVA with repeated measures, to compare movement $(1,2,3)$. The test becomes significant when the p-value is greater than 0.05 . Repeated measures were used as the same participant went through different conditions. 


\section{DATA COLLECTION AND RESULTS}

There were five methods of data collected during each test session per participant. All data were collected in the ballet studio laboratory. All data collected from the sessions were recorded, analyzed, and synthesized to support the research questions. The pre-test questionnaire contained close-ended questions and rating scales. During the real-time discomfort assessments, participants assessed their real-time discomfort while holding the en pointe position, immediately after completing the three pointe movements, échappé, sissonne simple and bourrée. Five thermographic imaging sessions occurred before dancing, after each pointe movement and after completing the test session. Finally, at the end of each test session, the post-test questionnaire allowed participants to assess their post discomfort and final comments on their experience in the ballet studio laboratory. Qualitative data on participants' remarks during the sessions were transcribed for additional validation during data analysis. Statistical analysis was conducted to validate and solidify the findings.

\subsection{Data Collection Duration}

The test sessions took place in a simulated ballet studio environment, created in the School of Industrial Design's gallery at Carleton University in Ottawa, Ontario. All sessions were done with one participant at a time, scheduled for a 1-hour period. Sessions were conducted over a span of one month, with a total of 10 recreational ballet participants. The first participant was withdrawn from the study, as the data was lost during the data collection phase, leaving a sample size of nine participants. The sessions 
were on an average of 45 minutes in length from beginning to end, with slight variance depending on the participants' time response.

\subsection{Zone 1 Pre-Test Questionnaire Results}

The goal of the introductory questionnaire was to assess participants' background, pointe work practices, pointe shoes history, and usual discomfort experienced when dancing en pointe. In result, the data collected in this phase allowed to support and validate findings during the data analysis as well as participant's overall discomfort intensity over time. The questionnaire contained twenty-two (22) questions, displayed one section at a time, via Qualtrics ${ }^{\mathrm{TM}}$ : i) background, ii) practice, iii) pointe shoes, and iv) usual discomfort.

\subsubsection{Participant Background}

During the study, all participants recruited were recreational ballet dancers (nonprofessional ballet dancers). Results indicated that participants started ballet at $5 \pm 2.71$ years old (average). Participants' pointe work experience was, on average, $7.4 \pm 4.37$ years. Pointe work experience varied: six participants $(67 \%)$ at the advanced pointe level, two participants (22\%) at the pre-professional pointe level, one participant at the intermediate pointe level, and none at the beginner or professional level. Of the nine participants, four participants (44\%) reported currently practicing the Royal Academy of Dance (RAD) technique, four participants (44\%) indicated currently practicing the Vaganova (Russian) technique, one participant indicated practicing "other", and, finally, none were reported to practice the Cecchetti (Italian) technique. The two most practiced additional dance genres were Jazz (reported by all nine participants) and Contemporary (reported by seven participants). results see Appendix H.6, section 1 for results. 


\subsubsection{Participant Pointe Work Practices}

Participants were asked about their pointe work practices. Eight out of nine participants (78\%) indicated that they were 'advised by their teacher' to assess their readiness to go en pointe, while one participant reported to have had received 'professional screening by doctors'. All nine participants indicated practicing pointe work 'In class with a teacher'; in addition, four of those participants indicated practicing pointe work by themselves. Results show that participants indicated practicing pointe work $5.5 \pm 5.85$ hours per week (average). In addition, participants practiced pointe work 'alone' on an average of $0.89 \pm$ 1.20 hours. Four participants (44\%) reported that their strongest foot en pointe was the right foot, two participants $(22 \%)$ reported both feet, two participants $(22 \%)$ were uncertain, and one participant reported the left foot. For detailed analysis and results see Appendix H.6, section 2.

\subsubsection{Participant Pointe Shoes}

All nine participants reported that they wore 'used' pointe shoes for the study. The pointe shoes brands used in testing were as follows: three participants $(33 \%)$ reported wearing 'Gaynor Minden' pointe shoes, three participants (33\%) indicated 'Block', and the rest $(33 \%)$ reported 'other' for the brand. Out of the nine participants, five participants $(55 \%)$ indicated that 'the pointe shoe fitter' influenced their pointe shoes brand, three participants (33\%) indicated 'myself', and one participant indicated 'my teacher/the dance school' as an influence. Participants were asked how many pairs of pointe shoes they used in the last year: the average was $4 \pm 3.56$ pairs. Participants were also asked how many pairs of pointe shoes they used to reach the level of comfort when en pointe, the average was $3 \pm 1.37$ pairs. Finally, in this section, all nine participants reported that 
'when my shoes lose structure and are soft' as an indicator to knowing when to buy new

pointe shoes. In addition to those participants, two indicated 'when I feel discomfort', and one participant reported 'when my shoes are dirty'. For detailed analysis and results see Appendix H.6, section 3.

\subsubsection{Participant Usual Discomfort}

Participants were asked about their usual experience with discomfort when dancing en pointe to gain insights on location, intensity, and areas of foot discomfort, and coping styles. When asked if they usually felt discomfort when dancing en pointe, four participants (44\%) reported 'yes', four participants (44\%) indicated 'maybe', and one participant answered 'uncertain'. Out of the nine participants, six indicated that they felt discomfort in 'both feet' when en pointe, whereas the rest of the participants were 'uncertain'. The average of usual discomfort intensity was found to be $2.7 \pm 1$ on a scale of 0 to 10 , with 0 representing no discomfort and 10 representing most discomfort imaginable. Participants were asked to select all areas where they usually experience discomfort when en pointe. All participants (100\%) indicated 'toes' as the area where they felt discomfort. In addition, two of those participants added 'arch', two participants added 'metatarsals', and one reported 'ankle' as an added discomfort area. More than half of the participants (55\%) indicated that they usually felt discomfort 'sometimes', three participants (33\%) reported to have felt discomfort 'often' when en pointe, and one participant reported feeling discomfort 'always'. Finally, participants were asked to select all coping styles when experiencing discomfort when en pointe. Out of all participants, six participants (67\%) indicated that they usually 'ignore discomfort and continue dancing'. For detailed analysis and results see Appendix H.6, section 4. 


\subsection{Zone 2 Real-Time Discomfort Assessments Results}

Discomfort assessments were performed in a real-time setting uncovering the main areas of feet discomfort and their average rating on a scale from $0-10$, with 0 representing no discomfort and 10 representing most discomfort imaginable while being en pointe. The goal was to uncover the prevalent feet discomfort areas assessed on the 3-D feet model apparatus as the movements become more advanced. The three distinct pointe movements performed were: i) échappé, ii) sissonne simple, and iii) bourrée (Appendix E.1). The real-time discomfort assessments contained (4) questions, that participants answered while holding their last en pointe position of each movement.

\subsubsection{Pointe Work Movement 1 Échappé}

The first movement involved assessing both feet at the same time, as the last en pointe position is known as relevé, which involves balancing sur pointe on both feet.

First, participants were asked to verbalize if discomfort was experienced in the left foot, right foot, or both feet, while holding a relevé position sur pointe on both feet. Results show that after performing échappé for one minute, four participants (44\%) felt discomfort in both feet, two participants $(22 \%)$ felt discomfort in their right foot, and three participants (33\%) felt discomfort in their left foot. Second, participants were asked to rate their overall discomfort on a scale of 0 to 10 . The overall discomfort felt was found to be, on average, $4 \pm 1.63$ out of 10. Figure 33 illustrates all areas of the feet assessed by participants for their most (red stickers) and least (yellow stickers) felt discomfort while holding their last en pointe position. The prevalent areas assessed for this movement were found to be: the great toe, the metatarsal area, and the arch area, Figure 33 illustrates all participants' assessed areas on the 3-D apparatus. Lastly, the 
great toe was found to have an average rating of $3.62 \pm 2.44$, the metatarsal $3.37 \pm 1.97$, and the arch $2.75 \pm 0.5$ out of 10 for both feet. See Table 1 for average ratings for assessed areas of both feet and Appendix H.2 for detailed results.

M1 Mouvement 1: Échappé

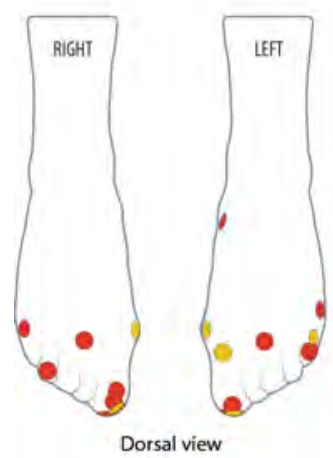

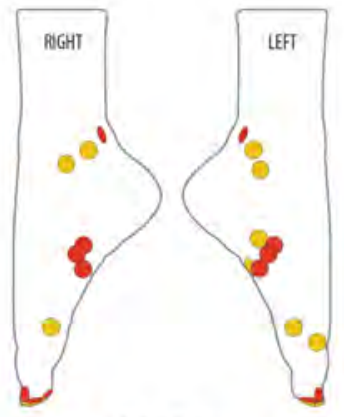

Lateral view

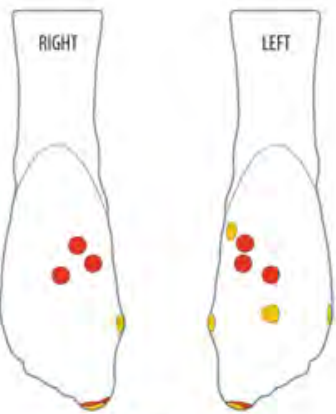

Plantar view

Most felt discomfort Least felt discomfort

Figure 33. Movement 1 real-time discomfort assessment areas results.

\begin{tabular}{|l|l|l|l|}
\hline Real-time discomfort areas & $\%$ participants & \multicolumn{1}{l|}{$\begin{array}{l}\text { Avg discomfort } \\
\text { intensity }\end{array}$} & $\begin{array}{l}\text { STDEV } \\
\text { intensity }\end{array}$ \\
\hline Great Toe & $88 \%$ & 3.62 & 2.44 \\
\hline $5^{\text {th }}$ Toe & $33 \%$ & 4.33 & 2.89 \\
\hline Metatarsal & $44 \%$ & 3.37 & 1.97 \\
\hline Arch & $44 \%$ & 2.75 & 0.5 \\
\hline Ankle (outer) & $11 \%$ & 5 & null \\
\hline Ankle (inner) & $22 \%$ & 1.75 & 1.06 \\
\hline
\end{tabular}

Table 1. Movement 1 real-time discomfort assessment results.

\subsubsection{Pointe Work Movement 2 Sissonne Simple}

The second movement involved assessing one foot at the same time, as the last en pointe position is known as passé position, which involves balancing sur pointe on one foot. Results show that when balancing on the left foot sur pointe, all nine participants felt discomfort in their left foot. Although, when participants assessed their right foot, seven felt discomfort in their right foot and two felt discomfort in both feet. The overall 
discomfort felt was found to be, on average, $5.27 \pm 2.32$ out of 10 . Figure 34 illustrates all areas of the feet assessed by participants for their most (red stickers) and least (yellow stickers) felt discomfort while holding their last en pointe position. The prevalent areas assessed for this movement were found to be, the great toe, the $5^{\text {th }}$ toe, the metatarsal area, and the arch area. Figure 34 illustrates all participants' assessed areas on the 3-D apparatus. Lastly, the great toe was found to have an average rating of $4.86 \pm 2.43$, the $5^{\text {th }}$ toe $1.5 \pm 1$, the metatarsal $4 \pm 2.99$, and the arch $1.75 \pm 0.5$ out of 10 for both feet. See Table 2 for average ratings for assessed areas on both feet and Appendix H.2 for detailed results.

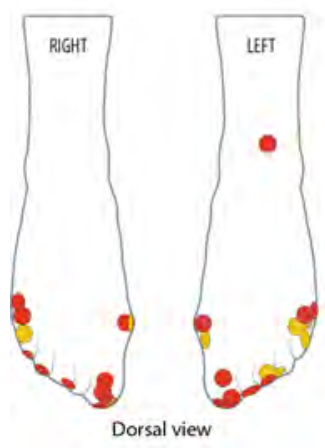

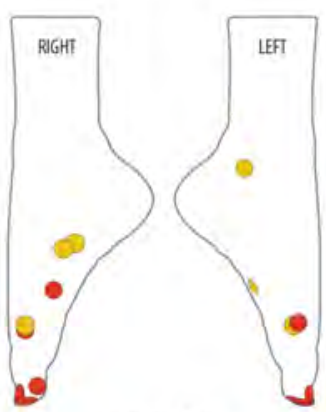

Lateral view

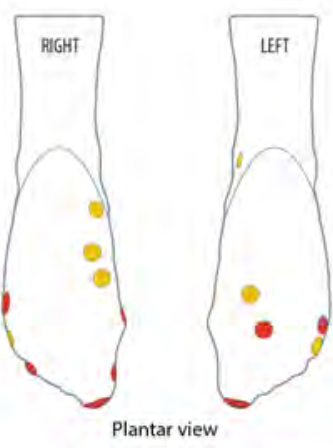

Most felt discomfort Least felt discomfort

Figure 34. Movement 2 real-time discomfort assessment areas results.

\begin{tabular}{|l|l|l|l|}
\hline Real-time discomfort areas & $\%$ participants & \multicolumn{1}{l|}{$\begin{array}{l}\text { Avg discomfort } \\
\text { intensity }\end{array}$} & $\begin{array}{l}\text { STDEV } \\
\text { intensity }\end{array}$ \\
\hline Great Toe & $88 \%$ & 4.86 & 2.43 \\
\hline $2^{\text {nd }}$ Toe & $22 \%$ & 4 & 4.24 \\
\hline $3^{\text {rd }}$ Toe & $33 \%$ & 4 & 3 \\
\hline $4^{\text {th }}$ Toe & $11 \%$ & 7 & null \\
\hline $5^{\text {th }}$ Toe & $44 \%$ & 1.5 & 1 \\
\hline Metatarsal & $55 \%$ & 4 & 2.99 \\
\hline Arch & $44 \%$ & 1.75 & 0.5 \\
\hline Ankle (inner) & $11 \%$ & 2 & 0.96 \\
\hline
\end{tabular}

Table 2. Movement 2 real-time discomfort assessment results. 


\subsubsection{Pointe Work Movement 3 Bourrée}

The third movement involved assessing both feet at the same time, as the last en pointe position is known as sous-sus position, which involves balancing sur pointe on both feet. Results show that after performing bourrée for one minute, seven participants felt discomfort in both feet and two felt discomfort in their right foot. The overall discomfort felt was found to be, on average, $3.78 \pm 1.78$ out of 10 . Figure 35 illustrates all areas of the feet assessed by participants for their most (red stickers) and least (yellow stickers) felt discomfort while holding their last en pointe position. The prevalent areas assessed for this movement were found to be, the great toe, and the metatarsal area. Figure 35 illustrates participants' assessed areas on the 3-D apparatus. The great toe was found to have an average rating of $4 \pm 1.18$ and the metatarsal $3.67 \pm 1.89$. See Table 3 for average ratings for assessed areas on both feet and Appendix H.2 for detailed results.

Mouvement 3: Bourrée
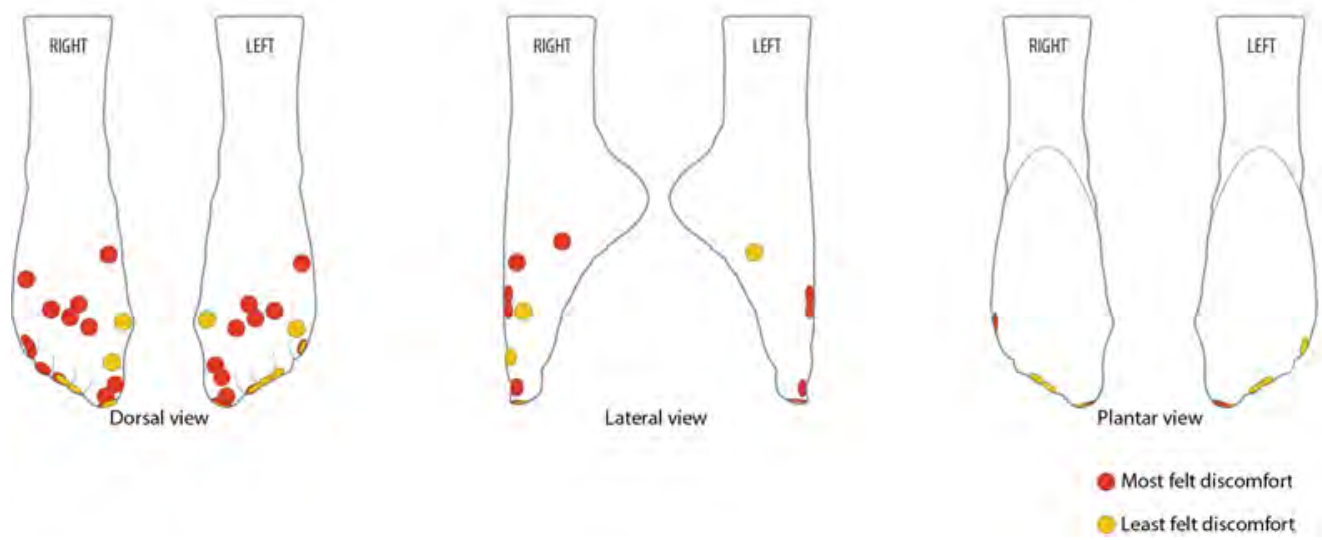

Figure 35. Movement 3 real-time discomfort assessment areas results.

\begin{tabular}{|l|l|l|l|}
\hline Real-time discomfort areas & $\%$ participants & \multicolumn{1}{l|}{$\begin{array}{l}\text { Avg discomfort } \\
\text { intensity }\end{array}$} & $\begin{array}{l}\text { STDEV } \\
\text { intensity }\end{array}$ \\
\hline Great Toe & $66 \%$ & 4 & 1.18 \\
\hline $2^{\text {nd }}$ Toe & $22 \%$ & 1 & 0 \\
\hline
\end{tabular}




\begin{tabular}{|l|l|l|l|}
\hline $3^{\text {rd }}$ Toe & $33 \%$ & 2 & 1.73 \\
\hline $4^{\text {th }}$ Toe & $22 \%$ & 2.5 & 2.12 \\
\hline $5^{\text {th }}$ Toe & $33 \%$ & 1.5 & 1.41 \\
\hline Metatarsal & $44 \%$ & 3.67 & 1.89 \\
\hline Arch & $22 \%$ & 1.75 & 0.35 \\
\hline
\end{tabular}

Table 3. Movement 3 real-time discomfort assessment results.

\subsection{Zone 3 Thermographic Imaging Results}

Thermographic imaging was conducted in a real-time setting in order to uncover temperature difference, in Celsius, of the areas assessed after the three ballet pointe movements. The goal was to measure the delta $\mathrm{T}(\Delta \mathrm{T}=\mathrm{T} 2-\mathrm{T} 1)$ where $\mathrm{T} 1$ is base temperature before lacing pointe shoes and $\mathrm{T} 2$ real-time discomfort area assessed by participants on the 3-D feet apparatus. The average temperature of the base image and post-movement of each area assessed was calculated prior to calculating the average delta $\mathrm{T}(\Delta \mathrm{T})$ for both feet. See Appendix H.4 for the detailed report and Appendix H.5 for results. This was done to observe if the average area temperature of the assessed areas on the 3-D feet apparatus increases as the ballet movements become more advanced. Each participant had five imaging sessions capturing five different feet positions that best locate the discomfort areas assessed.

\subsubsection{Pointe Work Movement 1 Échappé}

Results show that real-time discomfort areas assessed for movement 1 were: the great toe, $5^{\text {th }}$ toe, metatarsal, arch, inner, and outer ankle. In addition, the areas that were the most assessed were the great toe, the metatarsal and the arch. Therefore, solely the average delta $\mathrm{T}(\Delta \mathrm{T})$ of assessed areas by participants was measured for both feet. First, the great toe area was found to have an average $\Delta \mathrm{T}$ of $4.92{ }^{\circ} \mathrm{C} \pm 2.75$, second the arch area with an 
average $\Delta \mathrm{T}$ of $3.57^{\circ} \mathrm{C} \pm 2.75$, and the metatarsal area with an average $\Delta \mathrm{T}$ of $2.04^{\circ} \mathrm{C} \pm$ 1.97. Table 4. presents average delta $\mathrm{T}(\Delta \mathrm{T})$ for all real-time discomfort areas assessed.

\begin{tabular}{|l|l|l|}
\hline Real-time discomfort areas & \multicolumn{1}{|c|}{ Avg delta $\mathrm{T}(\Delta \mathrm{T})$} & \multicolumn{1}{|c|}{ STDEV } \\
\hline Great Toe & $4.92^{\circ} \mathrm{C}$ & 2.75 \\
\hline $5^{\text {th }}$ Toe & $1.48^{\circ} \mathrm{C}$ & 1.59 \\
\hline Metatarsal & $2.04^{\circ} \mathrm{C}$ & 1.97 \\
\hline Arch & $3.57^{\circ} \mathrm{C}$ & 0.65 \\
\hline Ankle (outer) & $3.00^{\circ} \mathrm{C}$ & null \\
\hline Ankle (inner) & $2.35^{\circ} \mathrm{C}$ & 0.31 \\
\hline
\end{tabular}

Table 4. Movement 1 average delta $\mathrm{T}$ for all real-time discomfort areas assessed.

\subsubsection{Pointe Work Movement 2 Sissonne Simple}

Results show that real-time discomfort areas assessed for movement 2 were: the great toe, $2^{\text {nd }}$ toe, $3^{\text {rd }}$ toe, $4^{\text {th }}$ toe, $5^{\text {th }}$ toe, metatarsal, arch, inner, and inner ankle. In addition, the areas that were the most assessed were the great toe, the $5^{\text {th }}$ toe, the metatarsal, and the arch. Therefore, solely the average delta $\mathrm{T}(\Delta \mathrm{T})$ of assessed areas by participants was measured for both feet. The great toe area was found to have an average $\Delta \mathrm{T}$ of $7.68{ }^{\circ} \mathrm{C} \pm$ 2.88 , the $5^{\text {th }}$ toe area with an average $\Delta \mathrm{T}$ of $5.85^{\circ} \mathrm{C} \pm 3.99$, and the metatarsal area with an average $\Delta \mathrm{T}$ of $4.80^{\circ} \mathrm{C} \pm 0.65$ and the arch with an average $\Delta \mathrm{T}$ of $4.80^{\circ} \mathrm{C} \pm 1.42$.

Table 5. presents average delta $\mathrm{T}(\Delta \mathrm{T})$ for all real-time discomfort areas assessed.

\begin{tabular}{|c|c|c|}
\hline Real-time discomfort areas & Avg delta $\mathrm{T}(\Delta \mathrm{T})$ & STDEV \\
\hline Great Toe & $7.68^{\circ} \mathrm{C}$ & 2.88 \\
\hline $2^{\text {nd }}$ Toe & $3.50^{\circ} \mathrm{C}$ & 4.67 \\
\hline $3^{\text {rd }}$ Toe & $4.17^{\circ} \mathrm{C}$ & 3.38 \\
\hline $4^{\text {th }}$ Toe & $2.90^{\circ} \mathrm{C}$ & null \\
\hline $5^{\text {th }}$ Toe & $5.85^{\circ} \mathrm{C}$ & 3.99 \\
\hline Metatarsal & $4.80^{\circ} \mathrm{C}$ & 0.65 \\
\hline Arch & $3.72{ }^{\circ} \mathrm{C}$ & 1.42 \\
\hline Ankle (inner) & $4.60^{\circ} \mathrm{C}$ & null \\
\hline
\end{tabular}

Table 5. Movement 2 average delta $\mathrm{T}$ for all real-time discomfort areas assessed. 


\subsubsection{Pointe Work Movement 3 Bourrée}

Results show that real-time discomfort areas assessed for movement 3 were: the great toe, $2^{\text {nd }}$ toe, $3^{\text {rd }}$ toe, $4^{\text {th }}$ toe, $5^{\text {th }}$ toe, metatarsal, arch, inner, and inner ankle. In addition, the areas that were assessed the most were the great toe and the metatarsal. Therefore, solely the average delta $\mathrm{T}(\Delta \mathrm{T})$ temperature variation of assessed areas by participants was measured for both feet. The great toe area was found to have an average $\Delta \mathrm{T}$ of $10.11^{\circ} \mathrm{C}$ \pm 1.66 and the metatarsal area with an average $\Delta \mathrm{T}$ of $4.51^{\circ} \mathrm{C} \pm 1.91$. For all other areas assessed, refer to Table 6 .

\begin{tabular}{|l|l|l|}
\hline Real-time discomfort areas & Avg delta T $(\Delta \mathrm{T})$ & STDEV \\
\hline Great Toe & $10.11^{\circ} \mathrm{C}$ & 1.66 \\
\hline $2^{\text {nd }}$ Toe & $0.60^{\circ} \mathrm{C}$ & 5.27 \\
\hline $3^{\text {rd }}$ Toe & $4.12^{\circ} \mathrm{C}$ & 4.06 \\
\hline $4^{\text {th }}$ Toe & $2.45^{\circ} \mathrm{C}$ & 3.47 \\
\hline $5^{\text {th }}$ Toe & $8.35^{\circ} \mathrm{C}$ & 3.35 \\
\hline Metatarsal & $4.51^{\circ} \mathrm{C}$ & 1.91 \\
\hline Arch & $4.90^{\circ} \mathrm{C}$ & 2.26 \\
\hline
\end{tabular}

Table 6. Movement 3 average delta T for all real-time discomfort areas assessed.

\subsection{Zone 1 Post-Test Questionnaire Results}

The goal of the closing questionnaire was to assess participants' discomfort experienced after completing all three movements in the ballet studio laboratory. The data collected was used to synthesize each participant's overall discomfort intensity over time. The questionnaire contained eleven (11) questions, displayed one section at a time: i) discomfort experienced after dancing en pointe in the testing session, ii) previous pointe work related injuries, and iii) overall experience of the testing session. 


\subsubsection{Participant Post-test Discomfort}

Participants were asked about their current discomfort after completing their test session, in order to gain insights on location, intensity, areas of discomfort, and coping styles. When the nine participants were asked if they currently felt discomfort in their left foot, right foot, or both, five participants (55\%) reported 'both feet', two participants $(22 \%)$ indicated 'left foot', one participant answered 'right foot', and one participant reported 'no discomfort'. The average of current discomfort intensity rating was $2.11 \pm 1.52$ out of a scale of 10. Participants were asked to select all areas where they were experiencing discomfort. Out of all participants, eight participants (89\%) indicated 'toes' as the area where they felt discomfort, three participants (33\%) reported 'arch', one participant indicated 'ankle, one participant reported 'other', and, finally, one participant indicated 'nowhere'. More than half of the participants $(66 \%)$ indicated that they 'often' felt discomfort during their sessions and three participants (33\%) reported 'sometimes'. Finally, participants were asked to select all coping techniques while experiencing discomfort when en pointe during their sessions. All participants indicated that they ‘ignore it and continue dancing'. For detailed analysis and results see Appendix H.7, section 1 .

\subsubsection{Participant Previous Pointe Injuries}

When participants were asked if they ever had an injury in pointe class that has affected them to go en pointe, six participants $(67 \%)$ answered 'yes' while the remaining three participants reported 'no'. The six participants whom answered 'yes' were prompted with the additional questions, as the ones who answered 'no' moved on to the last section of the questionnaire. Out of the six participants who answered 'yes' to having an injury in 
pointe class, the average rate of injury was $2 \pm 2.31$ injuries per participant. Finally, the participants were asked if they continue dancing en pointe even if they have an injury. Out of the six participants, two participants reported 'definitely yes', 2 participants answered, 'might or might not', one reported 'probably yes', and one 'probably not'. For detailed analysis and results see Appendix H.7, section 2.

\subsubsection{Participant Testing Experience}

At the very end of the post-test questionnaire, participants were asked how many years they foresee continuing pointe work, the average was $2.66 \pm 4.24$ years. In addition, participants were asked to rate their overall experience during the test session, the average was found to be $9.55 \pm 0.83$ out of 10 , with 0 representing 'extremely unsatisfied' and 10 representing 'extremely satisfied'. Half of the participants reported that they would 'definitely' participate again if they had the chance, while the rest indicated 'probably yes'. For detailed analysis and results see Appendix H.7, section 3.

\subsection{Data Convergence Results}

Data triangulation was performed prior to statistical tests to find areas of convergence, where data overlapped, between findings of all methods used. Our approach was to observe where data converged, specifically for the repeated measures throughout all methods. Data convergence shows that participants experienced discomfort in 'both feet'. Overall discomfort intensity was the highest at movement 2, with a rating of 5.27 out of 10. The most frequently assessed real-time discomfort area was found to be the great toe, for all stages of the experiment, although, the $5^{\text {th }}$ toe, the metatarsal, and the arch were consistently assessed for movement $(1,2,3)$. We did not perform statistical analysis on 
the $5^{\text {th }}$ toe, the metatarsal, and the arch as they were not as frequently rated as the great toe. Appendix H.8 illustrates a visual map of data correlation for the analysis. In order to examine the significance and relationship of the findings from data triangulation, statistical tests were conducted.

\subsection{Average Delta $T$ and Discomfort Intensity Differences for Movement $(1,2,3)$}

Statistical differences between movements of average delta $\mathrm{T}$ and average discomfort intensities of the areas assessed was conducted. First, we assessed the normality of the data using Shapiro-Wilk's test, significant at $p<0.05$. Given that all the data was normality distributed, we used a one-way ANOVA with repeated measures to measure whether there are significant differences between all three movements for (a) average discomfort level and (b) average delta T (Figure 36; Appendix H.5 for averages). For average discomfort intensities, we observed no statistical differences between movements, $F=2.04, p=0.18$. This suggests perhaps that participants did not feel great differences between movements. Perhaps the wide variability (standard deviations) in Figure 36 could partially explain why no statistically significant results were found. For average delta $\mathrm{T}$, we observed statistical differences between movements, $F=10.25$, $p=0.008$. Specifically, we observed differences between movement 1 and movement 2 , significant at $p=0.0047$, and movement 1 and 3 , significant at $p=0.026$. The differences between movement 2 and 3 were not statistically significant at $p=0.29$. This suggests that thermographic imaging is able to detect differences between low complexity movement (movement 1) and the rest of the movements that are more weight bearing when en pointe (movements 2 and 3). On the other hand, the thermographic imaging was not able to discern differences between similar weight bearing movements (movements 2 and 3). 
(a) Average Discomfort intensity

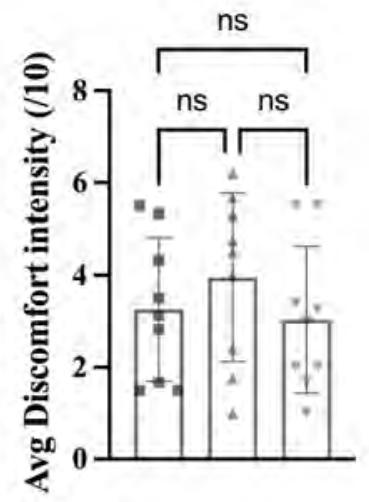

\section{(b) Average Delta T}

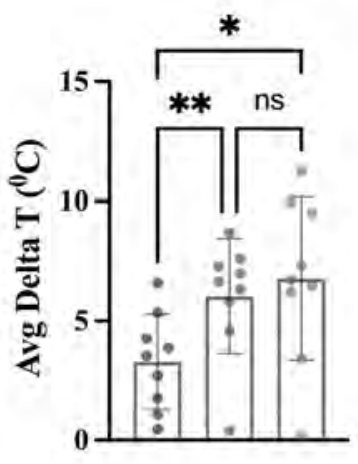

- Movement 1

- Movement 2

- Movement 3

Figure 36. Significant differences of (a) discomfort level and (b) delta T (a).

\subsection{Relationship Between Average Delta T and Discomfort Area Ratings in Movement $(1,2,3)$}

For each of the movements $(1,2,3)$, we examined the correlation between the average delta $\mathrm{T}$ and the average real-time discomfort ratings of all the areas of assessment. Given that all the data was normally distributed, we used Pearson's correlation coefficient to evaluate the presence of the relationship, significant at $p<0.05$. Correlations were not significant in each of the three movements as follows: M1, $r=-0.05,[-0.69-0.63]$ at $95 \%$, $p=0.89 ; \mathrm{M} 2, r=0.44[-0.31-0.86]$ at $95 \%, p=0.23$; and M3, $r=0.55,[-0.18-0.89]$ at $95 \%$, $p=0.13$. This suggests that, perhaps, computing the average of all areas assessed into one value, might have an impact on the lack of correlation. This prompts us to narrow our search to an area in particular that would receive most impact. Given that the great toe was the area localized most frequently by participants in real-time assessments and in the questionnaire in all three movements, we next correlated values corresponding to the great toe only. 


\subsection{Relationship Between Average Delta Temperatures and Discomfort Ratings of the Great Toe in Movement $(1,2,3)$}

For each of the movements $(1,2,3)$, we examined the correlation between the average delta $\mathrm{T}$ and the average real-time discomfort ratings of the big toe only. Given that all the data was normally distributed, we used Pearson's correlation coefficient to evaluate the presence of the relationship, significant at $p<0.05$. Correlations were not significant in M1 and M2 movements, as follows: M1, $r=0.16,[-0.58-0.75]$ at $95 \%, p=0.67$ and M2, $r=0.56[-0.16-0.89]$ at $95 \%, p=0.12$. However, we observed a strong positive correlation in M3 movement as follows: M3, $r=0.91,[0.62-0.98]$ at $95 \%, p=0.0007$. Given the strong correlation, we evaluated the predictive value of the relationship using linear regression and found a significant predicting factor (average delta $\mathrm{T}$ ) of average discomfort ratings as follows: $r^{2}=0.83, F=33.11, p=0.0007$, with equation $\mathrm{Y}=0.38 * \mathrm{X}+0.08$. Our results suggest that the thermographic imaging can predict the level of discomfort of the great toe in higher level of difficulty and complexity movements as seen in movement 3 (Figure 37), suggesting the added value of using this instrument to re-evaluate the potential design of the pointe shoe.

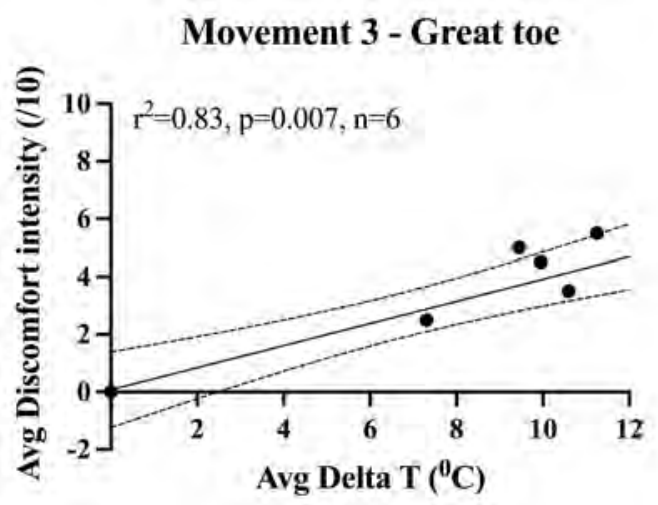

Figure 37. Relationship between the average delta $\mathrm{T}$ of the great toe and average realtime discomfort intensity for movement 3. 


\subsection{Overall Discomfort Intensity}

Finally, we assessed participants overall discomfort ratings before, during and after completing the movements for an overview of their discomfort journey during our experiment. These ratings are meant to observe the overall discomfort journey of the participants when asked in the questionnaire (pre-test and post-test) and while en pointe; movement 1, movement 2, and movement 3. First, all ratings passed Shapiro-Wilk's test of normality at $p<0.05$. Next, a one-way ANOVA with repeated measures was conducted to observe if there is a significant difference between levels of discomfort at all conditions. We observed statistical significance at $F=5.7, p=0.009$. Specifically, there was significant difference between movement 2 and post-test as $p=0.049$, see Figure 38 . This could be that movement 2 involves more exertion to perform and is more weight bearing as you spring from two feet to one foot en pointe. Surprisingly, participants' ratings for overall level of discomfort was not statistically significant between movement 3 and post-test.

\section{Overall Discomfort intensity}

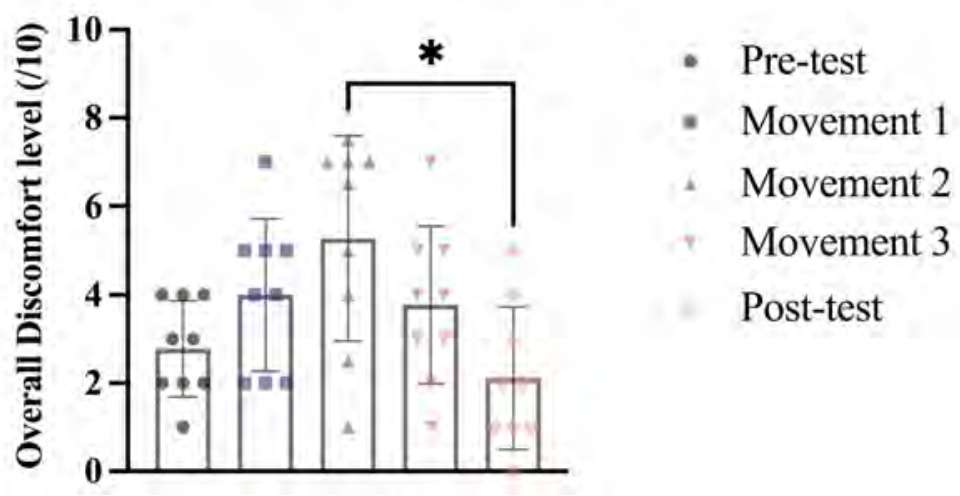

Figure 38. Differences between overall discomfort intensity before, during and after dancing en pointe. 


\section{DISCUSSION}

Dancing en pointe is mandated by ballet tradition, leaving the ballet dancer with no alternative but to wear pointe shoes that were designed in the 1800 's with materials failing to protect the feet from injuries (Anderson et al., 2015; Tuckman et al., 1991). For an in-depth understanding of foot discomfort when en pointe, a mixed-method approach was utilized through, questionnaires, real-time discomfort assessments, and thermographic imaging sessions. The research utilized data triangulation, to identify i) overall discomfort intensity, ii) real-time feet discomfort assessments areas, iii) average discomfort intensity for areas assessed and iv) average temperature variations of areas assessed. This section discusses the findings in relation to the research questions stated in the Introduction as well as the Literature Review.

\subsection{Overall Discomfort Intensity}

Insight 1: Overall Discomfort intensity was statistically different between movement 2 and post-test.

The overall discomfort intensity rating overtime was found to be significantly different between movement 2 and post-test questionnaire. In fact, movement 2 sissonne simple was found to have the highest rating of overall discomfort when asked en pointe, with an average of 5.27 out of 10 . This could be that movement 2 involves more exertion to perform. Also, it is more weightbearing as you spring from two feet to one foot en pointe. In addition, for this movement specifically, real-time discomfort was done while en pointe one foot at a time, implying that the participant's body weight was weighted on one foot twice. This difference between movement 2 and post-test could also be that 
when asked, in post-test questionnaire, the current overall rating was identified when participants were sitting and not when en pointe.

However, Participant 5 had the lowest overall discomfort intensity rating with 1 out of 10 in movement 2. It is very likely that Participant 5 felt the least discomfort as the participant had 16 years of pointe work experience. These results build on existing evidence found by Tajet-Foxell \& Rose, on ballet dancers' high tolerance of pain most likely due to greater exposure to physical training, increased fitness and experience in coping with pain (1995). In fact, all participants indicated in the post-test questionnaire that during testing, 'discomfort was ignored when dancing en pointe'.

\subsection{Real-time Discomfort Assessments}

A series of insights were developed through questionnaires, areas assessed on the 3-D feet apparatus and thermographic imaging. The great toe was found to be the most prevalent area of real-time discomfort when dancing en pointe.

\subsubsection{Feet Discomfort in Questionnaires and Movement $(1,2,3)$}

Insight 2: Discomfort is experienced in both feet when dancing en pointe, when asked in the pre-test questionnaire, movement $(1,2,3)$ and post-test questionnaire.

While holding the last en pointe position of each movement, experiencing discomfort in 'both feet' received the most rating, when identified by participants. In fact, movement 3 bourrée received the highest rating, identified by 7 participants (77\%). Perhaps, this is due to the weight bearing effect that the bourrée implies on the feet, as it entails to interchange one's weight on both feet at a very fast pace. Interestingly, participants 
identified in the pre-test questionnaire that discomfort they usually experienced in "both feet' when in pointe work class.

\subsubsection{Feet Discomfort Areas Assessed in Movement $(1,2,3)$}

Insight 3: Average discomfort intensities for all areas assessed was not found to be statistically different for all three movements.

For all areas of the foot assessed on the 3-D apparatus (Great toe, $2^{\text {nd }}$ toe, $3^{\text {rd }}$ toe, $4^{\text {th }}$ toe, $5^{\text {th }}$ toe, Metatarsal, Arch, outer ankle and inner ankle) the average discomfort intensity did not sense significance for all three movements. This suggests perhaps that discomfort felt in the areas assessed by participants did not differ, as movements became more advanced. In parallel, it is possible that the sample size and wide standard deviations could explain partly why no statistical observations were found.

Insight 4: Average delta temperatures measured through thermographic imaging were found to have statistical difference between movements.

The average temperature variation captured by thermographic imaging was found to be different between movement $(1,2)$ and movement $(1,3)$. There were no statistical differences between movement 2 and 3 . This suggests that thermographic imaging is able to detect differences between fundamental pointe movements (movement 1) and the rest of the movements that are more weightbearing when en pointe (movements 2 and 3). This is in line with DiBenedetto \& al., where the researchers found feet temperature areas increased with weight bearing pressure areas, in military footwear (2002). On the other hand, the thermographic imaging was not able to capture differences between similar weightbearing movements (movements 2 and 3 ). 
Insight 5: Average delta temperatures found in thermographic imaging did not relate to average discomfort ratings of all areas of assessment in all three movements.

The average temperature variation did not correlate with the average discomfort intensity of all areas assessed on the 3-D apparatus for movement $(1,2,3)$. This could be that computing the average of all areas into one value, might have an impact on the correlation not being significant. In relevance with Herry \& Frize (2002), an increase in temperature does not necessarily mean that the individual is feeling pain, or discomfort in the case of our study. In addition, not all areas were assessed as frequently. Therefore, through data triangulation an area in particular that received the most impact, was found to be the great toe in all three movements.

\subsection{The Great Toe Area}

Insight 6: Discomfort is experienced the most at the great toe area, when assessed after each movement.

Through data triangulation, it was found that the great toe area was localized most frequently by participants in real-time assessments in all three movements (see Figure $39)$, movement $1(88 \%)$, movement $2(100 \%)$ and movement $3(66 \%)$. In addition, the

great toe area had the highest average discomfort rating from all areas of the feet assessed with, movement 1 (3.62 out of 10), movement 2 (4.86 out of 10) and movement 3 (4 out of 10). The average temperature variation also was found to be the highest with, movement $1\left(4.92^{\circ} \mathrm{C}\right)$, movement $2\left(7.68^{\circ} \mathrm{C}\right)$ and movement $3\left(10.11^{\circ} \mathrm{C}\right)$. In accordance to Teitz et al., the great toe receives the most pressure when en pointe (1985). As well as Tuckman et al., found pressure was apparent on the great toe, where flattened tissues were visible (1991). Although P5 and P8 and P10, did not identify the great toe in 
movement 3 as they "got used to feeling the discomfort" specifically in that area. This might be due to the extensive training in pointe work and experiencing discomfort.
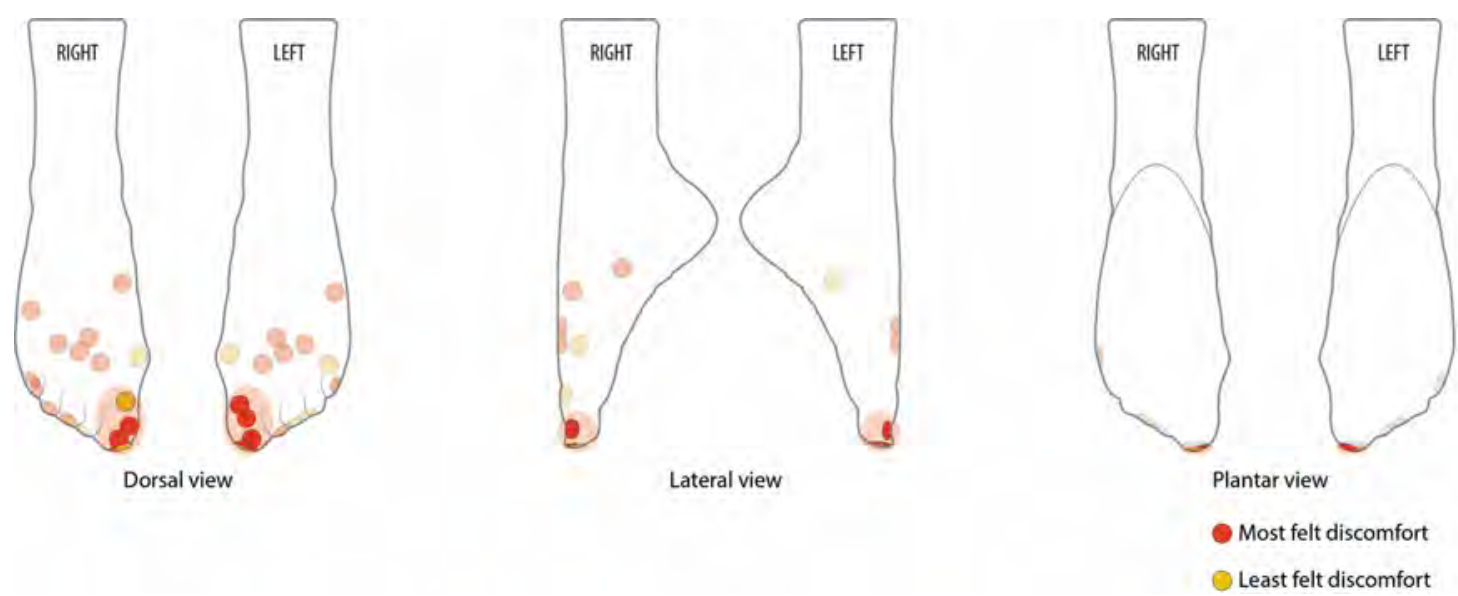

Figure 39. The great toe area localized most frequently by participants in real-time assessments in all three movements.

Insight 7: The great toe's average delta temperatures found in thermographic imaging related and is significant predictor of average discomfort ratings in movement 3.

A strong positive correlation between the great toe's average temperature variation and average discomfort intensity was observed solely in movement 3 at $r=0.91$ and $\mathrm{p}=0.0007$. In addition, average temperature variation of average discomfort intensity was found to be a predicting factor. Indicating that thermographic imaging can predict the level of discomfort of the great toe in higher level of difficulty and weight bearing movements as seen in movement 3. This points to the effectiveness of utilizing a 3-D apparatus in conjunction with thermographic imaging as a means of uncovering discomfort areas when en pointe. As thermographic imaging can detect abnormalities, caused by increases in temperature areas (Jones, 1998) by combining real-time assessments (Herry \& Frize, 2002) which are necessary to capture a person's immediate experience (Stone \& 
Broderick, 2007). In return, the findings can add value for future improvements in pointe shoe design, specifically the toe box area.

\subsection{Pointe Shoe Design Recommendations}

Our findings show that the great toe is the most prominent area of foot discomfort when dancing en pointe, especially in complex and weight bearing movements such as bourrée. It has been frequently identified by participants on the 3-D apparatus and showed high temperature variation through thermographic imaging. Furthermore, an increase in temperature in the great toe area has shown to predict an increase of discomfort intensity. This study brings forth design recommendations for future development of pointe shoes, in the hopes of reducing discomfort intensity, in the toe box area illustrated in Figure 40.

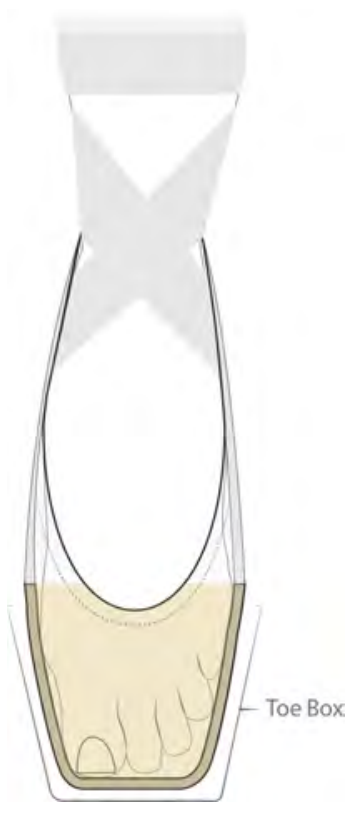

Figure 40. Illustration of the area of recommendation, the pointe shoe's toe box.

The toe box area is known to encase and protect the ballet dancer's toes (Barringer \& Schlesinger, 2012; Minden, 2005). Although it is made of a "papier-mâché-like" failing 
to protect the ballet dancer's foot (Tuckman et al., 1991). In addition, it comes in predetermined shapes, and the dancer has to customize the area, by softening it to allow for comfort(Harris, 2003). Even though most pointe shoes are handmade by a shoemaker, the shape of the toe box and materials selection need to be taken into consideration when designing and constructing the shoe, to reduce discomfort in the great toe area. Tuckman et al. (1985), discusses that carefully designed shock absorbing padding can be considered although Spilken (1990) stresses that this can cause improper alignment when dancing en pointe. Hence, footwear design researchers have indicated that 3-D scanning can be used as a means to customize one's footwear for comfort (Cheng \& Perng, 1999; Di Roma, 2017; Zhang et al., 2010).

A recommendation is to incorporate 3-D scanning technologies within the process of pointe shoe making. This would allow to customize the dancer's pointe shoe, capturing accurate measurements of the foot's biomechanics while aiming to reduce feet discomfort areas, such as the great toe. The dancer's foot shape and size would be captured through 3-D scanning as it is a non-invasive technique and allows to accurately represent the dancer's foot. Second, a customized shoe last created through rapid prototyping techniques such as 3-D printing, as it is known for its inexpensive and rapid prototyping features. The shoe last allows the shoemaker to customize the pointe shoe specifically to the dancer's foot biometrics, targeting the toe box area. It is important to do an investigation on shock absorbing materials, as pointe work applies four times the ballet dancer's body weight on to the toes (Spilken, 1990) and human toes are not made to walk on nor dance on (Aalten, 1997). 


\subsection{Opportunities}

The thesis demonstrated that an interdisciplinary approach, can be applied in the development of pointe shoes of athletic footwear. The use of a multidisciplinary team was key to this research, as it enabled to develop effective data collection tools, protocols and procedures. A simulated ballet studio environment was created for the first time to assess ballet dancers' feet discomfort areas while dancing en pointe, utilizing questionnaires, real-time assessments through a 3-D apparatus of feet en pointe and thermographic imaging. The laboratory accommodated dancers while they dance as well as the researcher while moderating each test session, interchanging testing zones to assess real-time discomfort. The environment allowed the participants to voice and localize their area of discomfort, in a safe and secluded environment. Participants' experience during testing was rated extremely high as they felt that they were heard since discomfort 'is taboo in the ballet world'.

The mixed method approach through real-time assessments used in this study, allowed to measure and capture participants' immediate experience, while accommodating the controlled procedures, as time was sensitive. Furthermore, the assessment tools, such as the questionnaires, the 3-D apparatus and the infrared thermographic camera, allows for the ballet laboratory environment to be re-created in larger groupings as it is, noninvasive, transportable and inexpensive. It stands to reason that ballet dancers should be involved for pointe shoe design evolvement, giving them the opportunity to be heard, as Mandradjeff (2016, p.267) states, "the pointe shoe is part of the ballerina, and the ballerina is part of the pointe shoe." 


\subsection{Barriers}

Thermographic imaging allowed to capture thermal maps for all participants' feet, although with limitations to the study during testing and analysis. First, the data collection software for the infrared thermographic camera generated barriers to the collection of real-time data during testing. A total of ten participants were recruited for this study although, data was lost and could not be retrieved for participant 1 , due to software issues. Therefore, data collection for participant 1 could not be analyzed in this study. This was a barrier as this study required specific requirements for participant recruitment. Furthermore, the equipment used during testing, had to be re-calibrated in between all sessions. This was a barrier as time was a key factor for data collection. Finally, the data analysis software for the thermographic imaging generated barriers when came to analyze the images. The original software used, was unable to retrieve the data analysis that was completed. Therefore, a newer software had to be purchased and data analysis had to be re-done in a timely manner. Although, thermographic imaging is now available as an attachment on smart phones, which would enable the use of this technology for future assessments at a lower cost.

\subsection{Study Limitations}

For future studies, it is recommended to connect with more ballet schools for participants' recruitment. This was proved to be a difficult and time-consuming process as it was challenging to find ballet dancers with levels of pointe work experience, currently practicing pointe work, as well as a minimum of two years of pointe work experience to partake in this study. In return, this challenged the results when came to 
perform data triangulation of the prevalent feet discomfort areas assessed, leaving a small sample limitation of nine participants.

A simulated ballet studio environment was recreated, since ballet dance studios were not available when came to test with participants. There were some limitations to the study as participants were not exposed the elements of the ballet studio, such as proper dance flooring, ballet barres and a sense of familiarity that one develops with the environment. Studio dance flooring is an important element within a dance studio environment as it is meant to absorb impact when dancing. Although, it should be noted that limitations like these occur when testing within a controlled laboratory environment.

The 3-D apparatus enabled ballet participants to localize their discomfort areas, although assessment procedure only allowed to assess points on the 3-D feet. More so, the use of stickers, did not allow the participants to show the area in which discomfort was felt in total, this was limited by showing only a point. Future research should be considered to allow participants to express how discomfort is felt, perhaps a digital application to allow the participant to draw and indicate what is experienced, without limiting it to a point. 


\section{CONCLUSION}

In conclusion, more than $95 \%$ of professional ballet dancers suffer from injuries each year (Barringer \& Schlesinger, 2012, p.262). Scholars emphasize that dancing en pointe is the leading cause to foot discomfort and prolong injuries. While ballet is still viewed as an art form (Hoogsteyns, 2013) rather than an extreme sport, the ballet pointe shoe has yet to be improved. This research aimed to explore for the first-time real-time discomfort assessments of foot areas when dancing en pointe. Through a human-centered approach, real-time discomfort assessments, enabled to uncover prevalent areas of foot discomfort and discomfort intensity overtime, validated through data triangulation and statistical tests.

Discomfort was experienced in both feet while performing, échappé, sissonne simple and bourrée (received the highest rating). Ballet participants experienced discomfort the most when performing complex and weight bearing pointe movements like sissonne simple. In fact, the overall discomfort intensity was found significantly different between sissonne simple and after dancing en pointe.

The great toe area was found to be the most prominent area of foot discomfort when dancing en pointe and showed high temperature variation, convergent with scholars' findings as it receives the most pressure when en pointe. In fact, ballet dancers' discomfort rating assessments on the 3-D apparatus correlated with the heat temperature areas, for complex and weight bearing movements, like bourrée. An increase in temperature in the great toe area has shown to predict an increase of discomfort intensity. 
We propose to incorporate a customized shoe last of the dancer's foot biometrics during the process of pointe shoe fabrication. A combination of 3-D scanning technologies and rapid prototyping methods would be utilized to capture and reproduce the dancer's natural foot shape into a shoe last, aiming to reduce feet discomfort areas, such as the great toe. As the toe box's aim to protect the dancer's toes, it is crucial to further investigate the material properties and future design implementations.

Real-time discomfort assessments were utilized as a new means of data collection, which captured and measured ballet dancers' real-time discomfort experience while accommodating the controlled procedures in the ballet studio laboratory. It allowed participants to voice and localize experienced foot discomfort, in a safe and secluded environment. Participants felt that they were heard since discomfort is meant to be silenced in the ballet discipline. In addition, the use of a 3-D apparatus and infrared thermographic camera allowed the testing environment to be transported and recreated.

This thesis is a step towards raising awareness on future design modernization of the ballet shoe in the hopes to drive multidisciplinary research centered around the ballet dancer's experience. By using a combination of user experience data, the information could contribute to the development of pointe shoes, protecting the foot from injuries. Thus, acknowledging that ballerinas are extreme athletes needing better equipment to perfect and develop their art form. 


\section{FUTURE RESEARCH}

Our study examined if real-time feet discomfort areas when en pointe can be uncovered utilizing a mixed method approach in a simulated ballet studio laboratory. It included participants with a wide range of levels of pointe work and various ballet styles. A larger sample size would further explore the intricacies of real-time discomfort assessments within the ballet industry, specifically with pointe work.

\section{Real-time Assessments in Ballet Studios and Companies:}

We propose that future studies should be performed through real-time assessments of the ballet shoe within the ballerina's natural training environment in ballet schools and companies. Literature research emphasized the influence of ballet culture on the dancer's pain and discomfort interpretation. It would be beneficial to examine the relationship of longer time-exposure when dancing en pointe and real-time discomfort assessments. This would be done by comparing different sequences; before and after pointe class, and before and after a ballet performance. In fact, literature indicated that injuries happen at most in rehearsals, some during class and during a performance on stage (Wulff, 2001).

\section{Ballet Dancers of Diverse Pointe Work Level and Technique:}

A future opportunity would be to study ballet dancers of a diverse age range, level of skill and pointe technique. More specifically if pointe work experience and ballet training style, impacts the assessment of real-time discomfort when localizing and identifying discomfort intensity. Professional ballet dancers, whom practice and perform for long hours daily, might be at a higher risk to develop injuries than recreational dancers who do 
not practice for long hours daily. It is possible that discomfort develops through a poor ballet technique.

\section{Impact of Pointe Shoe Manufacturers:}

Furthermore, pointe shoes' conditions, manufacturers and materials might have an influence on discomfort intensity. The pointe shoe fitter plays a significant role within the ballet dancer's pointe work journey, as they are the key player in appointing the pointe shoes. In addition, a future opportunity for this research would be to explore the relationship of different pointe shoes manufacturers' and discomfort intensity when dancing en pointe. The data collected could lead to further materials and design development of pointe shoes.

\section{Automated Data Collection Software:}

The study could be performed by applying similar controlled measures used in our ballet studio laboratory. The thermographic camera and 3-D apparatus assessment tool used were non-invasive, practical and transportable. Also, the thermographic imaging software could be designed to be fully automated by collecting regions assessed on the and 3-D apparatus. This would increase the quality and the speed for assessed areas needed for correlation. In addition, it would result in accurate detection of regions of correlation and prediction which would accelerate the data collection stage and reduce human error. This could also encourage to analyze the different views of the feet rapidly, depending on the areas assessed. 
Real-time Assessments through Augmented Reality and Virtual Reality:

Real-time discomfort assessments could be explored through, augmented reality and virtual reality, when en pointe. The use of immersive environments has been identified as a means of capturing a user's attention, while giving the illusion of being inside a computer-generated environment, known as: being present in the moment of the interaction. (Hoffman, Garcia-Palacios, Kapa, Beecher, \& Sharar, 2003). This would allow participants to localize their discomfort areas, by solely focusing their attention to their experienced discomfort and nothing else. This could also result in accurate representation of discomfort areas, when en pointe.

\section{Real-time Assessments for Athletic Footwear Design:}

Real-time assessments procedures could be integrated in athletic footwear design development, utilizing a similar interdisciplinary approach. It would be beneficial to examine the athlete's experienced discomfort, when in different real-time environments, through low and high impact training and performance. This could be done by examining the relationship of different athletic footwear and their material properties. The data collected could lead to a customized shoe, prioritizing comfort and enhancing the athlete's technique.

\section{Interdisciplinary Structured Focus Group:}

A future approach would be to conduct an interdisciplinary structured focus group to further explore design recommendations for ballet pointe shoes. A focus group enables to uncover the participants' expectations, needs and desires, during the design process of a product, service and experience (Curedale, 2013). Specifically, a structured focus group, 
centers on specific questions to the problem within a pre-determined time frame, which in return enables the researcher to uncover in depth insights (Curedale, 2013).

The objective would be to explore the role of an interdisciplinary organization in how it could benefit and contribute to the design of improved pointe shoes, by identifying its barriers. In particular, gathering experts from the fields of footwear design, podiatry, and ballet, will help gain a shared understanding about the root causes of the contextual complexities of the point shoe and build analytic frameworks that can be useful for concept generation in the future. This would allow to create specific future pointe shoe recommendations co-created by experts and user-athletes, the ballerinas. 


\section{REFERENCES}

Aalten, A. (1997). Performing the body, creating culture. The European Journal of Women's Studies, 4(2), 197-215. https://doi.org/10.1177/135050689700400205

Aalten, A. (2005). In the Presence of the Body: Theorizing Training, Injuries and Pain in Ballet. Dance Research Journal, 37(2), 55-72. https://doi.org/10.1017/S0149767700008561

Aalten, A. (2007). Listening to the dancer's body. The Sociological Review, 55(1), 109125. https://doi.org/10.1111/j.1467-954X.2007.00696.x

Anderson, A. C., Ng, G., Benwood, J. A., \& Walter Jr., J. H. (2015). F-Scan Evaluation of a New Pointe Shoe Design. Retrieved from https://dancer.com/wpcontent/uploads/2015/02/FScan-Handout_2015_smaller.pdf

Arhippainen, L. (2003). Capturing user experience for product design. The 26th, 1-10. https://doi.org/10.1007/s11036-010-0223-0

Ashkenazy, S., \& DeKeyser Ganz, F. (2019). The Differentiation Between Pain and Discomfort: A Concept Analysis of Discomfort. Pain Management Nursing, 20(6), 556-562. https://doi.org/10.1016/j.pmn.2019.05.003

Barringer, J., \& Schlesinger, S. (2012). The Pointe Book: Shoes, Training \& Technique (Third Edit). Hightstown, Nj: Princeton Book Company.

Cheng, F. T., \& Perng, D. B. (1999). A systematic approach for developing a foot size information system for shoe last design. International Journal of Industrial Ergonomics, 25(2), 171-185. https://doi.org/10.1016/S0169-8141(98)00098-5

Colucci, L. A., \& Klein, D. E. (2008). Development of an Innovative Pointe Shoe. Ergonomics in Design: The Quarterly of Human Factors Applications, 16(3), 6-12. 
https://doi.org/10.1518/106480408X333091

Cunningham, B. W., DiStefano, A. F., Kirjanov, N. A., Levine, S. E., \& Schon, L. C. (1998). A comparative mechanical analysis of the pointe shoe toe box. The American Journal of Sports Medicine, 26(4), 555-561.

https://doi.org/10.1177/03635465980260041501

Curedale, R. A. (2013). Design Research Methods: 150 Ways to Inform Design (First edit). Design Community College Incorporated.

Dancewear Centre. (2021). Pointe Shoes. Retrieved from:

https://www.dancewearcentre.com/collections/pointe-shoes/?sort_by=pricedescending

DFS. (2021). Russian Pointe Radiance Pointe Shoe with $3 / 4$ Shank. Dance Fashion

Superstore. Retrieved from:

https://www.dancefashionssuperstore.com/products/russian-pointe-radiance-pointeshoe

Di Roma, A. (2017). Footwear Design. The paradox of "tailored shoe" in the contemporary digital manufacturing systems. Design Journal, 20(sup1), S2689S2699. https://doi.org/10.1080/14606925.2017.1352780

DiBenedetto, M., Yoshida, M., Sharp, M., \& Jones, B. (2002). Foot evaluation by infrared imaging. Military Medicine, 167(5), 384-392. https://doi.org/10.1093/miled.167.5.384

Encarnacion, M. G., Meyers, M. C., Ryan, N. D., \& Pease, D. G. (1999). Pain Coping Styles of Ballet Performers. Medicine \& Science in Sports \& Exercise, 
31(Supplement), 20-31. https://doi.org/10.1097/00005768-199905001-01015

Encarnacion, M. G., Meyers, M. C., Ryan, N. D., \& Pease, D. G. (2000). Pain Coping Styles of Ballet Performers. Journal of Sport Behavior, 31(1), 20-32.

https://doi.org/10.1097/00005768-199905001-01015

Fisher, J. (2007). Tulle as Tool: Embracing the Conflict of the Ballerina as Powerhouse. Dance Research Journal, 39(1), 3-24. https://doi.org/10.1017/S0149767700000048

Freepik. (2020). Side view of ballerina feet in pointe shoes and tights. Freepik. Retrieved from: https://www.freepik.com/free-photo/side-view-ballerina-feet-pointe-shoestights_6354058.htm

Gromer, C. (2001). Inside Nike's secret sports lab. Popular Mechanics, 178(7), 44-47. Retrieved from http://proxy.library.carleton.ca/login?url=https://search.proquest.com/docview/216 779116?accountid=9894\%0ACopyright

Harris, K. M. (2003). An Examination of the Pointe Shoe as Artifact through Ethnographic and Gender Analysis. Material History Review, 58(Fall), 4-12.

Herry, C. L., \& Frize, M. (2002). Digital processing techniques for the assessment of pain with infrared thermal imaging. Annual International Conference of the IEEE Engineering in Medicine and Biology - Proceedings, 2, 1157-1158. https://doi.org/10.1109/iembs.2002.1106324

Hoffman, H. G., Garcia-Palacios, A., Kapa, V., Beecher, J., \& Sharar, S. R. (2003). Immersive Virtual Reality for Reducing Experimental Ischemic Pain. International Journal of Human-Computer Interaction, 15(3), 469-486. https://doi.org/10.1207/S15327590IJHC1503_10 
Hoogsteyns, M. (2013). Giving more weight to the ballerina: Material agency in the world of pointe shoes. International Journal of Cultural Studies, 16(2), 119-133. https://doi.org/10.1177/1367877912452482

Jones, B. F. (1998). A reappraisal of the use of infrared thermal image analysis in medicine. IEEE Transactions on Medical Imaging, 17(6), 1019-1027. https://doi.org/10.1109/42.746635

Jones, B. F., \& Plassmann, P. (2002). Digital infrared thermal imaging of human skin. IEEE Engineering in Medicine and Biology Magazine, 21(6), 41-48. https://doi.org/10.1109/MEMB.2002.1175137

Karcioglu, O., Topacoglu, H., Dikme, O., \& Dikme, O. (2018). A systematic review of the pain scales in adults: Which to use? American Journal of Emergency Medicine, 36(4), 707-714. https://doi.org/10.1016/j.ajem.2018.01.008

Kelly, D. (2012). Ballerina: Sex, Scandal, and Suffering Behind the Symbol of Perfection. Greystone Books Ltd.

Khan, K., Brown, J., Way, S., Vass, N., Crichton, K., Alexander, R., ... Wark, J. (1995). Overuse Injuries in Classical Ballet. Sports Medicine, 19(5), 341-357. https://doi.org/10.2165/00007256-199519050-00004

Kirstein, L., \& Stuart, M. (2004). The Classical Ballet: Basic Technique \& Terminology. New York, N. Y: Alfred A. Knopf.

Kumar, V. (2013). 101 Design Methods: A structured Approach for Driving Innovation in Your Organization. New Jersey: John Wiley \& Sons, Inc.

Kus, A., Unver, E., \& Taylor, A. (2009). A comparative study of 3D scanning in engineering, product and transport design and fashion design education. Computer 
Applications in Engineering Education, 17(3), 263-271.

https://doi.org/10.1002/cae.20213

Llana, S., Brizuela, G., Durá, J. V., \& García, A. C. (2002). A study of the discomfort associated with tennis shoes. Journal of Sports Sciences, 20(9), 671-679. https://doi.org/10.1080/026404102320219374

Mandradjieff, M. (2016). Ballerina-pointe shoe becoming, fluid multiplicities, and The Red Shoes. Text and Performance Quarterly, 36(4), 265-278. https://doi.org/10.1080/10462937.2016.1227873

Martin, B., \& Hanington, B. (2012). Universal Methods of Design: 100 Ways to Research Complex Problems, Develop Innovative Ideas, and Design Effective Solutions (First edit). Rockport Publishers.

Martins, P. (1997). The New York City Ballet Workout: 50 stretches and Exercises Anyone Can Do for a Strong Graceful, and Sculpted Body. New York, N. Y: HarperCollins.

McEwen, K., \& Young, K. (2011). Ballet and pain: Reflections on a risk-dance culture. Qualitative Research in Sport, Exercise and Health, 3(2), 152-173. https://doi.org/10.1080/2159676X.2011.572181

Minden, E. G. (2005). The Ballet Companion: A Dancer's Guide to the Technique, Traditions, and Joys of Ballet. New York, N. Y: Simon and Schuster.

Minden, G. (2020). Peek inside pointe shoes. Gaynor Minden. Retrieved from: https://dancer.com/ballet-info/about-pointe-shoes/peek-inside/

Mohd Razali, N., \& Bee Wah, Y. (2011). Power comparisons of Shapiro-Wilk, Kolmogorov-Smirnov, Lilliefors and Anderson-Darling tests. Journal of Statistical 
Modeling and Analytics, 2(1), 21-33.

O’Brien, C. (2014). The Fashion System and the Ephemeral: Ballet and Costume. In Shapeshifting Conference (pp. 1-16).

O'connor, R. (2020). SAB alumna Jenifer Ringer, former NYCB principal, Dean of Dance at Colburn School in Los Angeles. The School of American Ballet. Retrieved from: https://sab.org/scenes/be-our-guest-meet-sabs-recent-guest-teachers/ Parvin, C. A. (2007). Statistical topics in the laboratory sciences. Methods in molecular biology (Clifton, N.J.) (Vol. 404). https://doi.org/10.1007/978-1-59745-530-5_18

Pearson, S. J., \& Whitaker, A. F. (2012). Footwear in classical ballet: a study of pressure distribution and related foot injury in the adolescent dancer. Journal of Dance Medicine \& Science, 16(2), 51-56.

Picon, A. P., Lobo da Costa, P. H., De Sousa, F., De C.N.Sacco, I., \& Amadio, A. C. (1985). Biomedichanical Approach to Ballet Movements: A Preliminary Study, 4-7. Raja, S. N., Carr, D. B., Cohen, M., Finnerup, N. B., Flor, H., Gibson, S., ... Vader, K. (2020). The revised International Association for the Study of Pain definition of pain. Pain, 161, 1976-1982.

Ring, E. F. J., \& Ammer, K. (2015). The technique of infrared imaging in medicine. Infrared Imaging: A Casebook in Clinical Medicine, (May). https://doi.org/10.1088/978-0-7503-1143-4ch1

Ring, F. J. (1995). Criteria for thermal imaging in medicine. Annual International Conference of the IEEE Engineering in Medicine and Biology - Proceedings, 17(2), 1697-1698. https://doi.org/10.1109/iembs.1995.579897

Royo, S., \& Panyella, D. (2014). 3-D Scanning System for In-Vivo Imaging of Human 
Body. Fringe 2013, (January). https://doi.org/10.1007/978-3-642-36359-7

Russell, J. A., Shave, R. M., Kruse, D. W., Koutedakis, Y., \& Wyon, M. A. (2011). Ankle and foot contributions to extreme plantar- and dorsiflexion in female ballet dancers. Foot and Ankle International, 32(2), 183-188. https://doi.org/10.3113/FAI.2011.0183

Russell, J. A., \& Yoshioka, H. (2015). Assessment of female ballet dancers' ankles in the en pointe position using high field strength magnetic resonance imaging. Acta Radiologica, 57(8), 978-984. https://doi.org/10.1177/0284185115616295

Shah, S. (2009). Determining a young dancer's readiness for dancing on pointe. Current Sports Medicine Reports, 8(6), 295-299. https://doi.org/10.1249/JSR.0b013e3181c1ddf1

Spilken, T. L. (1990). The Dancer's Foot Book: A Complete Guide to Footcare \& Health for People who Dance. Princeton Book Company.

Stone, A. A., \& Broderick, J. E. (2007). Real-time data collection for pain: Appraisal and current status. Pain Medicine, 8(SUPPL.3). https://doi.org/10.1111/j.15264637.2007.00372.x

Tajet-Foxell, B., \& Rose, F. D. (1995). Pain and pain tolerance in professional ballet dancers. British Journal of Sports Medicine, 29(1), 31-34. https://doi.org/10.1136/bjsm.29.1.31

Teitz, C. C., Harrington, R. M., \& Wiley, H. (1985). Pressures on the Foot in Pointe Shoes. Foot \& Ankle, 5(5), 216-221. https://doi.org/10.1177/107110078500500502

Tenenbaum, G., Fogarty, G., Stewart, E., Calcagnini, N., Kirker, B., Thorne, G., \& Christensen, S. (1999). Perceived discomfort in running: Scale development and 
theoretical considerations. Journal of Sports Sciences, 17(3), 183-196.

https://doi.org/10.1080/026404199366082

Torba, R. G., \& Rice, D. A. (1993). Pressure analysis of the ballet foot while en pointe. In Proceedings of the 12th Southern Biomedical Engineering Conference, SBEC 1993 (pp. 48-50). https://doi.org/10.1109/SBEC.1993.247350

Travis, D., \& Hodgson, P. (2019). Think like a UX researcher : how to observe users, influence design, and shape business strategy. CRC Press.

Tuckman, A. S., Werner, F. W., James, C., \& Bayley, J. C. (1991). Analysis of the Forefoot on Pointe in the Ballet Dancer. Foot \& Ankle, 12(3), 144-148. https://doi.org/10.1177/107110079101200303

Turner, B. S., \& Wainwright, S. P. (2003). Corps de Ballet: The case of the injured ballet dancer. Sociology of Health and Illness, 25(4), 269-288. https://doi.org/10.1111/1467-9566.00347

Vaganova, A. (1969). Basic Principles of Classical Ballet: Russian Ballet Technique. New York, N. Y: Dover Publications, Inc.

Woo, A., Lechner, B., Fu, T., Wong, C. S., Chiu, N., Lam, H., ... Chow, E. (2015). Cut points for mild, moderate, and severe pain among cancer and non-cancer patients: a literature review. Annals of Palliative Medicine, 4(4), 176-183. https://doi.org/10.3978/j.issn.2224-5820.2015.09.04

Wulff, H. (2001). Ballet Across Borders: Career and culture in the world of dancers. New York, N. Y: Berg Publishers.

Yan, A. F., Hiller, C., Smith, R., \& Vanwanseele, B. (2011). Effect of Footwear on Dancers: A Systematic Review. Journal of Dance Medicine \& Science, 15(2), 86- 
92.

Zhang, Y.-F., Rout, N., Zhang, Y. F., Khandual, A., \& Luximon, A. (2010). 3D foot scan to custom shoe last 3D Foot Scan to Custom Shoe Last 3D Foot Scan to Custom Shoe Last. Special Issue of IJCCT, 1(January), 3-5. Retrieved from https://www.researchgate.net/publication/228879419 
APPENDICES

Appendix A: Ethics 


\title{
A.1 Ethics Clearance
}

\author{
Carleton \\ Canada's Capital University \\ Office of Research Ethics \\ 4500 ARISE Building I 1125 Colonel By Drive \\ 4500 AR SE Billing 1125 \\ Ottawa, OntarioK1S5B6 \\ ethics@carleton.ca
}

\section{CERTIFICATION OF INSTITUTIONAL ETHICS CLEARANCE}

The Carleton University Research Ethics Board-B (CUREB-B) at Carleton University has renewed ethics clearance for the research project detailed below. CUREB-B is constituted and operates in compliance with the Tri-Council Policy Statement: Ethical Conduct for Research Involving Humans (TCPS2).

Title: Examining Pointe Shoe Discomfort

Protocol \#: 111156

Principal Investigator: Ms. Christel Ayoub

Department and Institution: Faculty of Engineering and DesignlIndustrial Design (School of), Carleton University

Project Team (and Roles): Ms. Christel Ayoub (Primary Investigator)

Stephen Field (Research Supervisor)

Adrian Chan (Research Supervisor)

Funding Source (If applicable):

Effective: July 30, 2020 Expires: July 30, 2021.

Please ensure the study clearance number is prominently placed in all recruitment and consent materials: CUREB-B Clearance \# 111156.

\section{Restrictions:}

This certification is subject to the following conditions:

1. Clearance is granted only for the research and purposes described in the application.

2. Any modification to the approved research must be submitted to CUREB-B via a Change to Protocol Form. All changes must be cleared prior to the continuance of the research.

3. An Annual Status Report for the renewal or closure of ethics clearance must be submitted and cleared by the renewal date listed above. Failure to submit the Annual Status Report will result in the closure of the file. If funding is associated, funds will be frozen. 


\section{A.1 Ethics Clearance}

4. During the course of the study, if you encounter an adverse event, material incidental finding, protocol deviation or other unanticipated problem, you must complete and submit a Report of Adverse Events and Unanticipated Problems Form.

5. It is the responsibility of the student to notify their supervisor of any adverse events, changes to their application, or requests to renew/close the protocol.

6. Failure to conduct the research in accordance with the principles of the Tri-Council Policy Statement: Ethical Conduct for Research Involving Humans 2nd edition and the Carleton University Policies and Procedures for the Ethical Conduct of Research may result in the suspension or termination of the research project.

Special requirements for COVID-19:

If this study involves in-person research interactions with human participants, whether on- or offcampus, the following rules apply:

1. The study requires prior approval of the relevant Dean's Office. See Principles and Procedures for On-campus Research at Carleton University and note that this document applies both to on- and off-campus research that involves human participants. Please contact your Dean's Office for information about obtaining this approval.

2. You must submit a copy of that approval to the Office of Research Ethics prior to starting any in-person research activities.

3. If the Dean's approval requires any significant change(s) to any element of the study, you must notify the Office of Research Ethics of such change.

Upon reasonable request, it is the policy of CUREB, for cleared protocols, to release the name of the $\mathrm{PI}$, the title of the project, and the date of clearance and any renewal(s).

Please email the Research Compliance Coordinators at ethics@carleton.ca if you have any questions.

\section{CLEARED BY:}

Date: July 30, 2020

Bernadette Campbell, PhD, Chair, CUREB-B

Natasha Artemeva, PhD, Co-Chair, CUREB-B

This email contains links to content or websites. Always be cautious when clicking on external links or attachments. If in doubt, please forward suspicious emails to phishing@carleton.ca. 


\section{A.2 Informed Consent Form}

\section{Carleton \\ U N I VER SITY \\ Canada's Capital University}

\section{Informed Consent Form}

Name and Contact Information of Researchers:

Name: Christel Ayoub

Tel.:

Email:Christelayoub@cmail.carleton.ca

Supervisor and Contact Information:

Name: Stephen Field

Department: School of Industrial Design, Carleton University

Tel.: 613-520-2600 Ext: 8371

Email: Stephen.field@carleton.ca

\section{Project Title}

Examining Pointe Shoe Discomfort

Project Sponsor and Funder (if any)

Not applicable

\section{Carleton University Project Clearance}

Clearance \#: $111156 \quad$ Date of Clearance: July 31, 2021

\section{Invitation}

You are invited to take part in a research project, since you are a ballet dancer that currently dances en pointe. The information in this form is intended to help you understand what we are asking of you so that you can decide whether you agree to participate in this study. Your participation in this study is voluntary, and a decision not to participate will not be used against you in any way. As you read this form, and decide whether to participate, please ask all the questions you might have, take whatever time you need, and consult with others as you wish.

\section{What is the purpose of the study?}

This study is a study, involving ballet dancers to identify their feet discomfort areas when dancing en pointe, through different assessments. The purpose of this study is to identify the pain points of ballet pointe shoes, through discomfort assessments using real-time user experience evaluation of what ballet dancers feel when dancing en pointe. In this study, pain points are referred to as specific problems that the dancers would experience with their pointe shoes. Additionally, in this study, discomfort is referred to as the intensity and the physical location of these pain points that the dancers are experiencing when going en pointe. The researcher for this study is Christel Ayoub from the School of Industrial Design at Carleton University. She will be accompanied by two assistants, from the same program. She is working 


\section{A.2 Informed Consent Form}

\section{Sarleton \\ Canada's Capital University}

\section{Possible Benefits}

Participating in this study, will benefit you to contribute to future design recommendations for improved ballet pointe shoes, since very few researchers have tried to investigate it. This contribution will also benefit the ballet community and future researchers, to innovate ballet pointe shoes and promoting health and wellness to ballet dancers.

\section{Compensation/Incentives}

As a token of appreciation, you will receive a $10 \$$ gift card at Brio Bodywear, refreshments and snack will be offered at the end of the testing.

\section{No waiver of your rights}

By signing this form, you are not waiving any rights or releasing the researchers from any liability.

\section{Withdrawing from the study}

If you withdraw your consent during the course of the study, all information collected from you before your withdrawal will be discarded, unless you request that it be removed from the study data. You can withdraw by contacting the researcher or the research supervisor by phone or email.

After the study, you may request that your data be removed from the study and deleted by notice given to the Principal Investigator (named above) within two weeks after your completion.

\section{Confidentiality}

We will remove all identifying information from the study data as soon as possible, which will be after the testing is completed. Your participation is completely voluntary, confidential and will not result in any negative consequences, including future professional relationships. You are free to skip any questions and activities during the study.

We will treat your personal information as confidential, although absolute privacy cannot be guaranteed. No information that discloses your identity will be released or published without your specific consent. Research records may be accessed by the Carleton University Research Ethics Board in order to ensure continuing ethics compliance

The results of this study may be published or presented at an academic conference or meeting, but the data will be presented so that it will not be possible to identify any participants unless you give your express consent.

You will be assigned a code, so that your identity will not be directly associated with the data you have provided. All data, including coded information, will be kept in an encrypted file on a secure computer.

We will encrypt any research data that we store or transfer.

\section{Data Retention}

All research data, including, photographs and any notes will be anonymized and encrypted. Any hard copies of data (including any handwritten notes or USB keys) will be kept in locked cabinet at Carleton University. Research data will only be accessible by the researcher and the research supervisor. 


\title{
A.2 Informed Consent Form
}

\author{
Carleton \\ U N I VER S I T Y \\ Canada's Capital University
}

Once the testing will be completed, the summary of the data will be used for a secondary testing for the project. The summary of the data will be reviewed by experts in a design workshop. All research data will be anonymized and coded. Although, all research data will only be accessible by the researcher and the research supervisor. Once the project is completed, all de-identified research data will be kept for five years. At the end of five years, all research data will be securely destroyed. (Electronic data will be erased, and hard copies will be shredded.)

If you would like a copy of the finished research project, you are invited to contact the researcher to request an electronic copy which will be provided to you.

New information during the study

In the event that any changes could affect your decision to continue participating in this study, you will be promptly informed.

\section{Ethics review}

This project was reviewed and cleared by the Carleton University Research Ethics Board B, which provided clearance (CUREB-B Clearance \# 111156) to carry out the research (Clearance expires July 31, 2021). If you have any ethical concerns with the study, please contact The Research Ethics Board at 613520-2600 ext. 4085 or via email at ethics@.carleton.ca.

\section{Statement of consent - print and sign name}

I voluntarily agree to participate in this study.

I agree to be photographed.

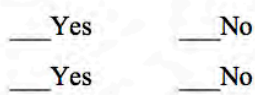

I want a report (or summary) of the research findings once the study is complete.

$$
\text { Yes }
$$

The researcher may contact me (the participant at)

Email: 


\section{A.2 Informed Consent Form}

\section{Carleton \\ Canada's Capital University}

Research team member who interacted with the subject

I have explained the study to the participant and answered any and all of their questions. The participant appeared to understand and agree. I provided a copy of the consent form to the participant for their reference.

Signature of researcher

Date 


\section{A.3 Debriefing Statement}

\section{DEBRIEFING STATEMENT}

Name and Contact Information of Researchers:

Name: Christel Ayoub

Tel.:

Email:Christelayoub@cmail.carleton.ca

\section{Supervisor and Contact Information:}

Name: Stephen Field

Department: School of Industrial Design, Carleton University

Tel.: 613-520-2600 Ext: 8371

Email: Stephen.field@carleton.ca

\section{Project Title}

Examining Pointe Shoe Discomfort

Project Sponsor and Funder (if any)

Not applicable

Carleton University Project Clearance

Clearance \#: $111156 \quad$ Date of Clearance: July 31, 2021

What are we trying to learn in this research?

Real-time is defined as, the actual time during which a process or event occurs. In this study, the event refers as the moment when going en pointe. We have found that real-time discomfort assessment has been applied in medicine as a measurement to assess the user's discomfort in real-time. Although, there appears to be a lack of academic research on real-time user experience discomfort dancing in pointe shoes. Given this opportunity, there could be an obstacle to identify whether or not real-time discomfort assessment is a viable tool to innovate ballet pointe shoes.

In order to gain a clearer understanding with using real-time as a tool, this study seeks to identify your experience with discomfort in real-time, using different tools to help assess your personal discomfort while dancing en pointe. Which later on, will be analyzed through an interdisciplinary approach by professional experts in order to create a set of design guidelines for improved pointe shoes. This could immensely help the ballet community, and aspiring designers to innovate the world of ballet.

Information will be collected through, a questionnaire, a set of performed pointe movements, discomfort assessment using a colored scale analog and thermographic imaging. The study will take place in a dance studio at Carleton University, where all the different testing methods will be organized and stationed in designated areas and moderated by the researcher, who has experience as a ballet dancer/teacher. 


\title{
A.3 Debriefing Statement
}

\author{
Garleton \\ Canada's Capital University
}

Why is this important to scientists or the general public?

From a review of related literature, it appears that real-time user experience discomfort assessments with pointe shoes has not been analyzed, discussed and documented from an academic perspective. This research study will benefit to improve ballet pointe shoes and improve the dancer's experience while dancing en pointe. This contribution will also benefit the ballet community and future researchers, to innovate ballet pointe shoes. This study aims to investigate, if real-time user experience data can benefit the design of improved pointe shoes, while exploring the benefits and barriers of real-time user experience data. Furthermore, exploring the role of an interdisciplinary organization in assessing real-time data, how it could benefit and contribute the design of improved pointe shoes, as well as validating if realtime data is a viable tool to facilitate an interdisciplinary workshop.

\section{What are our hypotheses and predictions?}

We predict that discomfort perceived by ballet dancers will predict how they assess their own discomfort during the study, as pain is regarded as necessary in a ballet dancer's career. We also predict that design research methods will help identify, describe and localize their discomfort. Hence, contributing to the health and wellness of ballet dancers, prolonging and improving their performance and dance career.

\section{Where can I learn more?}

\section{Academic Resources}

- https://www.researchgate.net/profile/Kurt_Ammer2/publication/221866446_Infrared thermal im aging in medicine/links/0deec5170384308c51000000/Infrared-thermal-imaging-in-medicine.pdf

- https://academic.oup.com/painmedicine/article-pdf/8/suppl 3/S85/5238715/8-suppl 3-S85.pdf

- https://www.interaction-design.org/literature/article/key-question-in-user-experience-designusability-vs-desirability

- https://www.sciencedirect.com/science/article/pii/0304395995001719

- http://dare.ubvu.vu.nl/bitstream/handle/1871/18441/Scherder Gerontology 46\%281\%29 $2000 \mathrm{u}$ .pdf? sequence $=2$

- https://www.researchgate.net/publication/316532311_Research design the methodology for int erdisciplinary research framework

Is there anything I can do if I found this experiment to be emotionally upsetting? Yes. If you feel any distress or anxiety after participating in this study, please feel free to contact the Carleton University Health and Counseling Services at: 613-520-6674, or the Distress Centre of Ottawa and Region at 613-238-3311 (http://www.dcottawa.on.ca).

\section{What if I have questions later?}

If you have any remaining concerns, questions, or comments about the experiment, please feel free to contact Christel Ayoub, at: Christelayoub@carleton.ca, Professor Stephen Field (research supervisor), at: Stephen.field@carleton.ca (613-520-2600, ext. 8371). 


\title{
A.3 Debriefing Statement
}

\author{
Carleton \\ U N I VER S I T Y \\ Canada's Capital University
}

CUREB-B:

This project was reviewed and cleared by the Carleton University Research Ethics Board B, which provided clearance (CUREB-B Clearance \# 111156) to carry out the research (Clearance expires July 31 2020). If you have any ethical concerns with the study, please contact The Research Ethics Board at 613520-2600 ext. 4085 or via email at ethics@.carleton.ca.

Thank you for participating in this research! 
Appendix B: Recruitment 


\section{B.1 Recruitment Email}

E-mail Invitation

\section{Carleton}

Subject: Invitation to participate in a research project on examining pointe shoe discomfort.

\section{Would you like to participate in a study on examining pointe shoe discomfort?}

If you are interested, please read below to sign up for a session of pointe work, and discomfort assessments with different technologies.

We are looking for ballet dancers that are currently taking ballet pointe classes and have at least 2 years of experience in pointe work. The participants must be comfortable with the language of English and at least 16 years of age.

\section{Benefits:}

- Contributing to the design of improved pointe shoes

- Promoting health and wellness to the ballet community

- Exploring discomfort assessments through different tools

Sign up to participate at christelayoub@cmail.carleton.ca

My name is Christel Ayoub and I am a Master's student in the Industrial Design department at Carleton University. I am working on a research project under the supervision of Professor Stephen Field and Professor Adrian Chan.

\section{The Study}

You are invited to participate in a study entitled "Examining pointe shoe discomfort". The purpose of this study is to identify the pain points of ballet pointe shoes, through discomfort assessments using real-time user experience evaluation of what you experience when dancing in pointe shoes. In this study, pain points are referred to as specific problems that the dancers would experience with their pointe shoes. Additionally, in this study, discomfort is referred to as the intensity and the physical location of these pain points that the dancers are experiencing when going en pointe. 


\section{Would you like to participate in a study on examining pointe shoe discomfort?}

To participate in this study, you must be:

- Experienced dancing en pointe for at least 2 years

- At least 16 years old

- Comfortable in the English language

- Currently taking ballet pointe classes

- Available to participate on the University's campus

- Comfortable dancing and balancing en pointe without the use of the ballet barre

This study will focus on examining pointe shoe discomfort using a variation of assessments in Carleton's Dance Studio. You will be asked to fill out a short questionnaire, practice a few pointe work movements, identify your discomfort and participate in a session of thermographic imaging.

The study will take place at Carleton University's campus for over 1 hour.

Participants will be compensated with a \$10 Brio Bodywear gift card.

The ethics protocol for this research has been reviewed and approved by the Carleton University Research Ethics Board [B], which provided clearance (CUREB-B Clearance \# 111156 ) to carry out the research (Clearance expires July 312021 ). If you have any ethical concerns with the study, please contact The Research Ethics Board at 613-520-2600 ext. 4085 or via email at ethics@carleton.ca.

Please contact the researcher: Christel Ayoub

For more details and to sign up: christelayoub@cmail.carleton.ca 
Appendix C: The Ballet Studio Laboratory 


\section{C.1 Test Session Map}

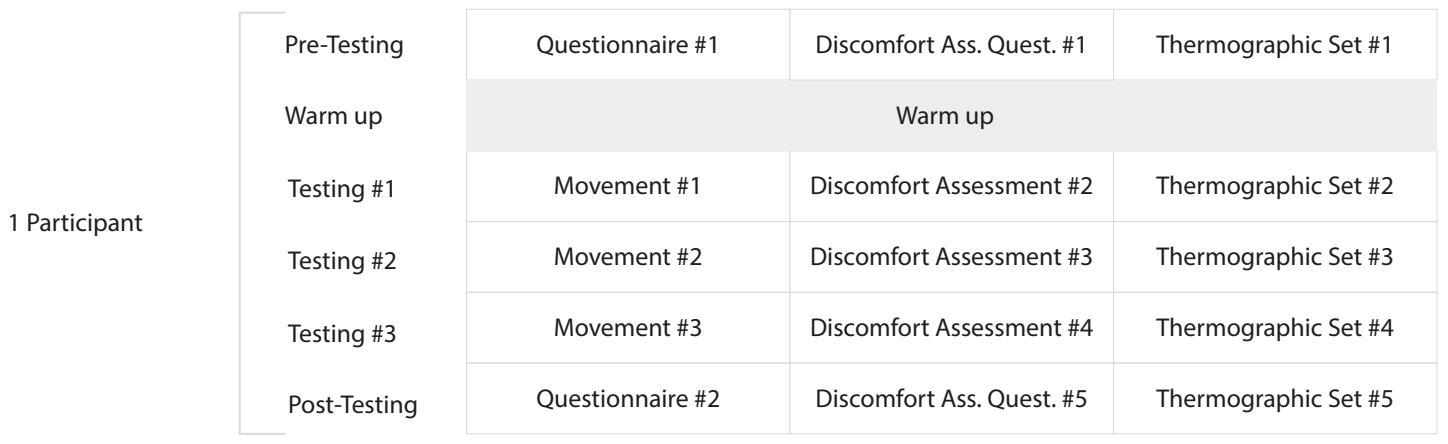


C.2 Test Session Action Board

\section{BALLET STUDIO LABORATORY}

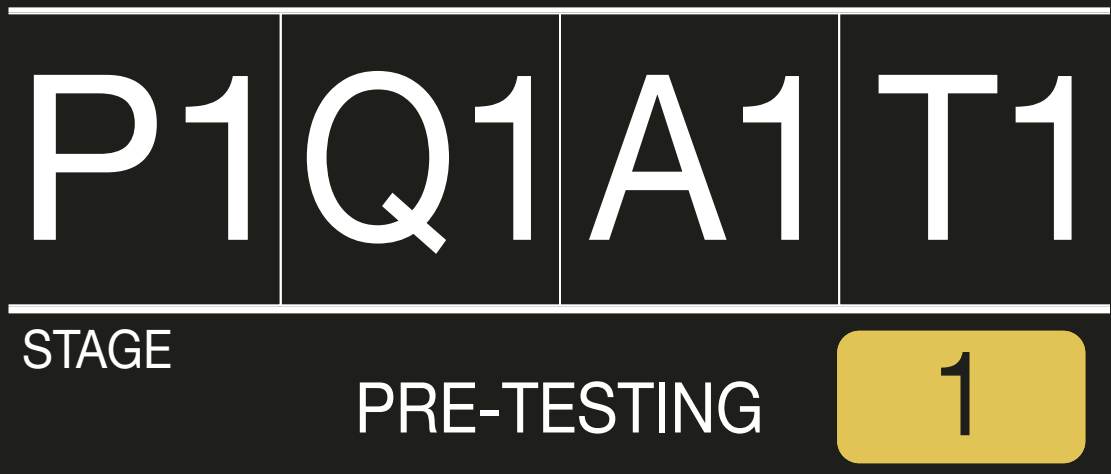

HOUR

BARRE

DATE

$T^{\circ}$

\section{BALLET STUDIO LABORATORY}

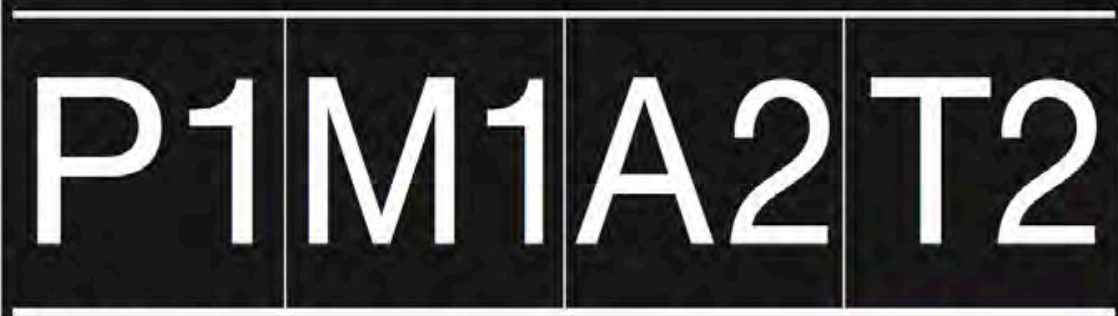

STAGE

TESTING \#1

BARRE

DATE

$T^{\circ}$ 
C.2 Test Session Action Board

\section{BALLET STUDIO LABORATORY}

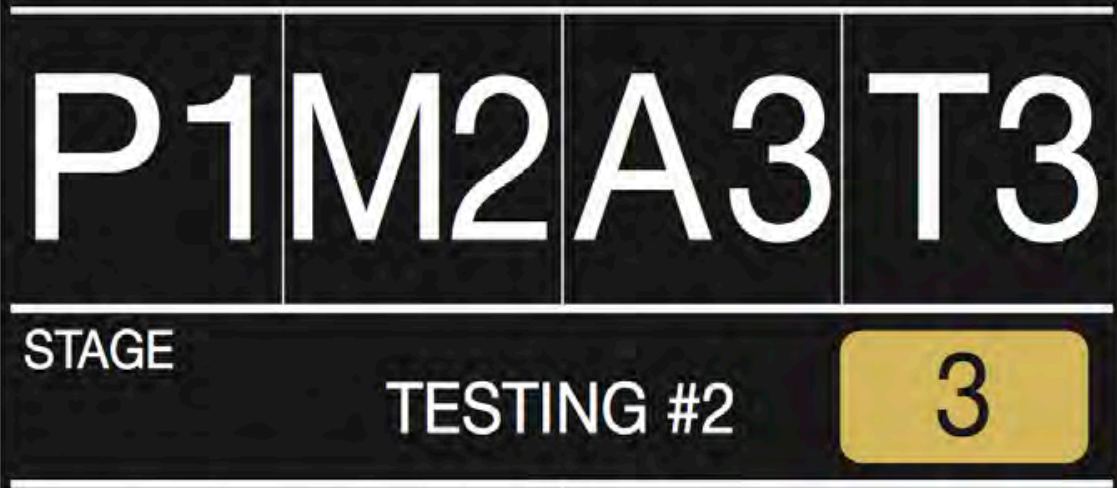

HOUR

BARRE

DATE

$T^{\circ}$

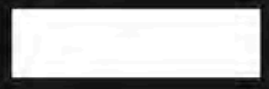

BALLET STUDIO LABORATORY

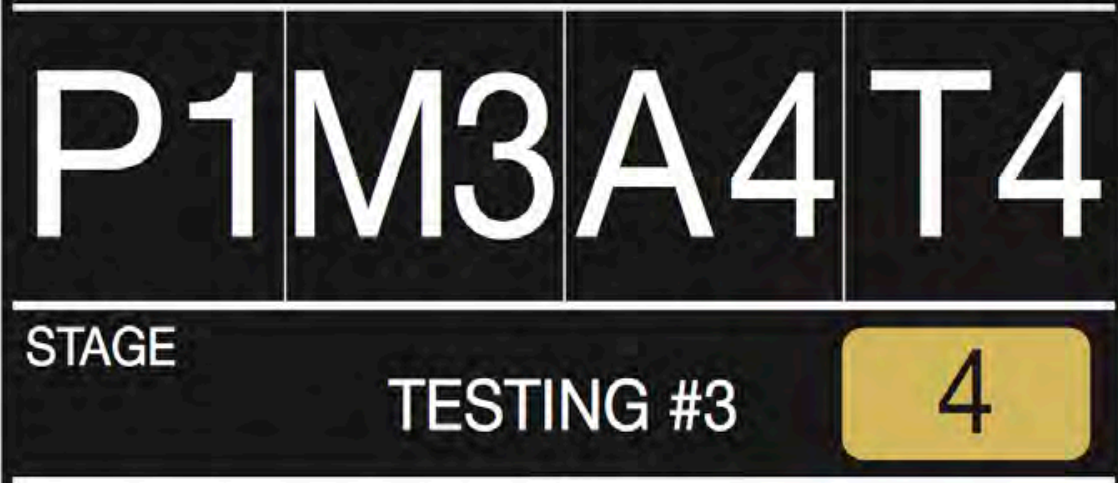

HOUR

BARRE

DATE

$\mathrm{T}^{\circ}$ 
C.2 Test Session Action Board

\section{BALLET STUDIO LABORATORY}
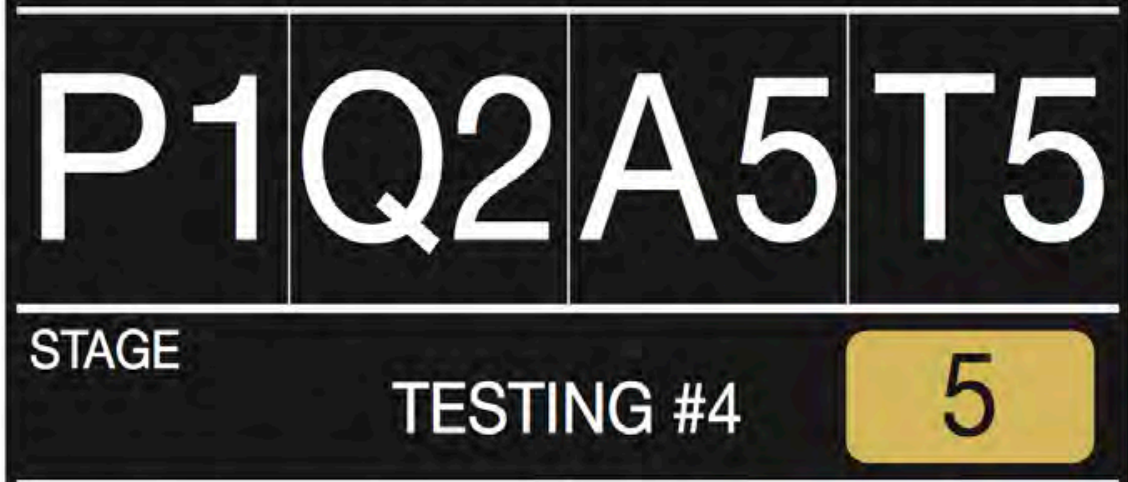

\section{HOUR $\square$ BARRE}

DATE

$T^{\circ}$ 
Appendix D: Zone 1 Questionnaires 
D.1 Pre-test Questionnaire

Pre-test Questionnaire

Start of Block: Background

Your background...

1. When did you start practicing ballet?

$$
\begin{array}{lllllllllll}
0 & 2 & 4 & 6 & 8 & 10 & 12 & 14 & 16 & 18 & 20
\end{array}
$$

Age

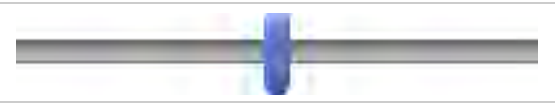

2. How long have you been dancing en pointe?

$\begin{array}{lllllllllll}0 & 2 & 4 & 6 & 8 & 10 & 12 & 14 & 16 & 18 & 20\end{array}$

Years

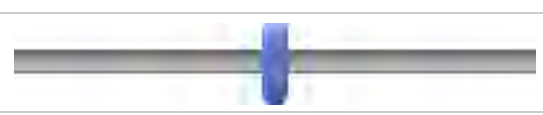

3. What level of pointe class are you currently in?
Beginner
Intermediate
Advanced
Pre-professional
Professional 
4. What ballet style are you currently practicing?

Vaganova (Russian)

Cecchetti (Italian)

RAD (Royal Academy of Dance)

Other

5. What other dance genres do you currently practice?

Please select all that apply.

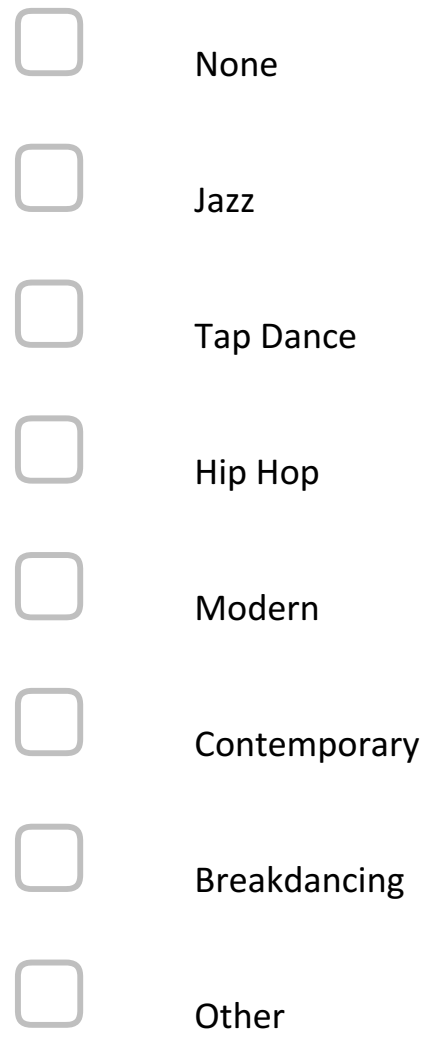

Page Break 
Your practice...

1. How did you know you were ready to go en pointe?

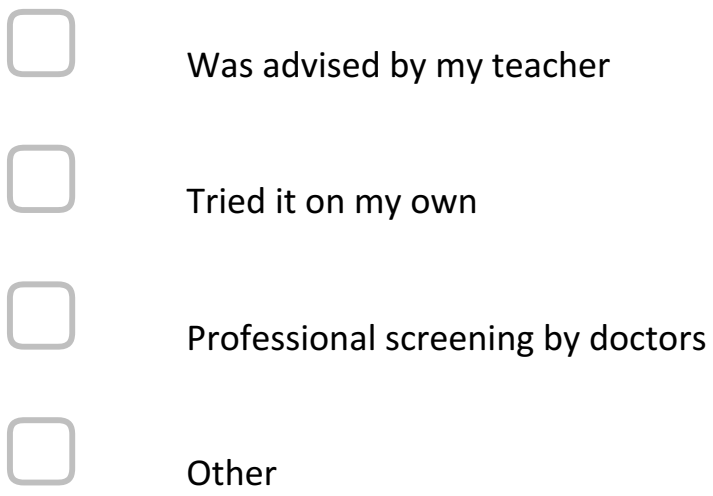

2. How do you practice pointe work?

In class with a teacher

By myself

All of the above

3. How many hours do you practice pointe work, a week, in class?

$\begin{array}{lllllllllll}0 & 2 & 4 & 6 & 8 & 10 & 12 & 14 & 16 & 18 & 20\end{array}$

Hours

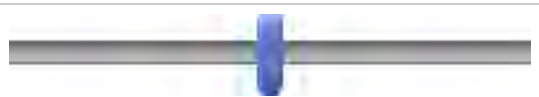

4. How many hours do you practice pointe work a week, by yourself?

$\begin{array}{lllllllllll}0 & 2 & 4 & 6 & 8 & 10 & 12 & 14 & 16 & 18 & 20\end{array}$ 
5. What is your strongest foot when dancing en pointe?

Right foot

Left foot

Both

Uncertain

None

\section{Page Break}

Your pointe shoes...

1. What brand of pointe shoes are you using for the testing?

Gaynor Minden
Bloch
Freed
Sapezio
Grishkho
Other


2. What is the condition of your pointe shoes?

Brand new

New

Used

Uncertain

3. Who decides the brand of your pointe shoes?

Please select all that apply.

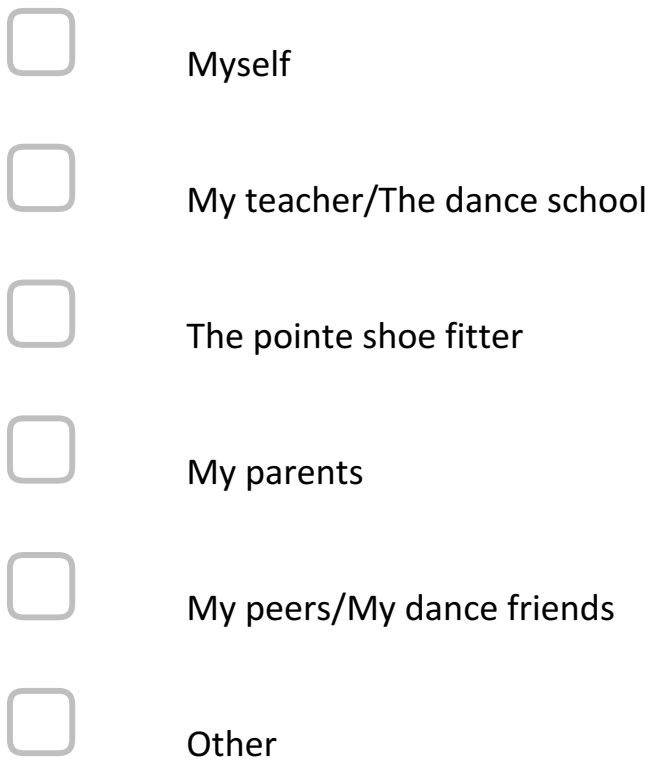

4. How many pointe shoes have you used over the last year?

$\begin{array}{lllllllllll}0 & 3 & 6 & 9 & 12 & 15 & 18 & 21 & 24 & 27 & 30\end{array}$

Years


5. How many pointe shoes did you use before being comfortable to dance en pointe (approximately)?

Pointe Shoes

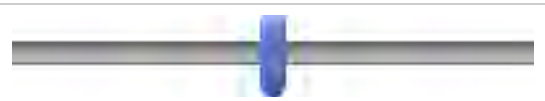

6. How do you know when you need to buy new pointe shoes?

Please select all that apply.

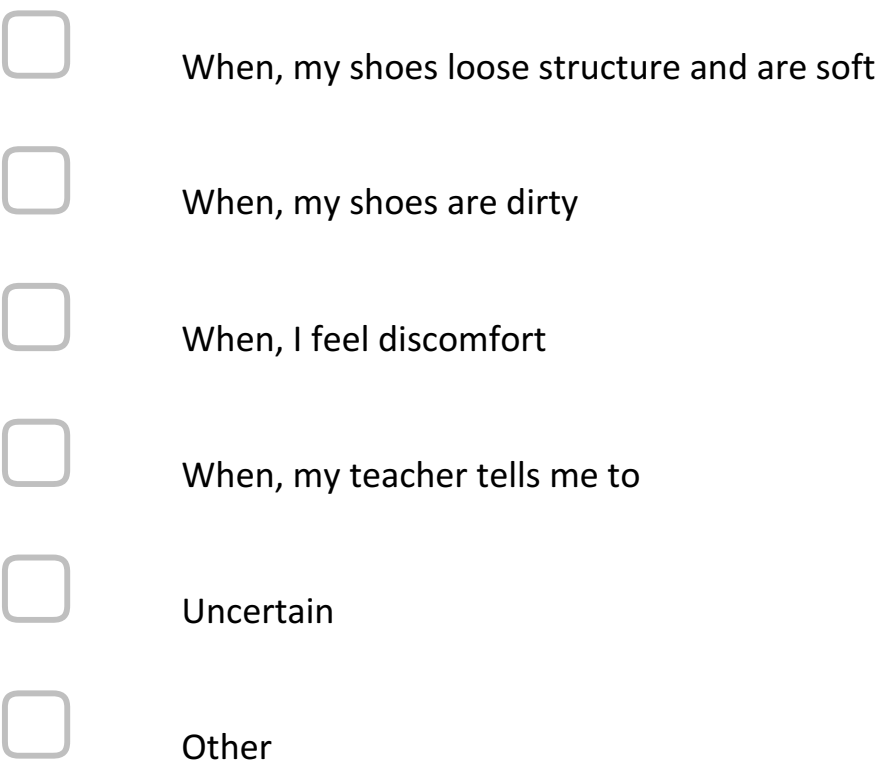

Page Break 
Your discomfort...

1. Do you usually feel any discomfort when dancing en pointe?

Yes

Maybe

Uncertain

No

2. Do you usually feel discomfort in your left foot, right foot or both feet?

Left foot

Right foot

Both feet

Uncertain

No discomfort

3. How would you rate your discomfort when dancing en pointe? No Discomfort

Most discomfort imaginable

$\begin{array}{llllll}0 & 2 & 4 & 6 & 8 & 10\end{array}$

Discomfort 
4. Where do you usually feel the discomfort when dancing en pointe? Please select all that apply.

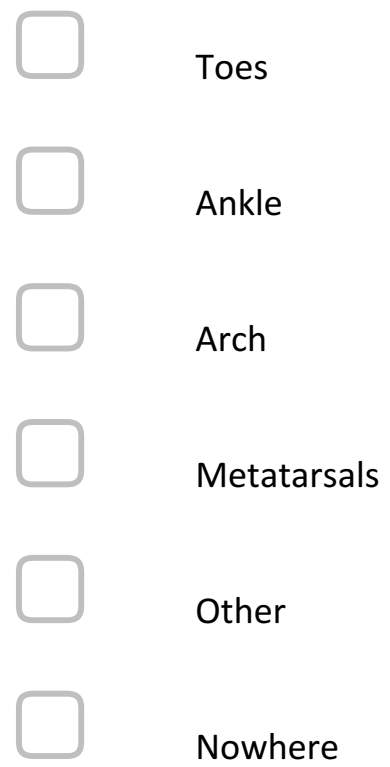

5. How often do you usually feel discomfort when dancing en pointe?

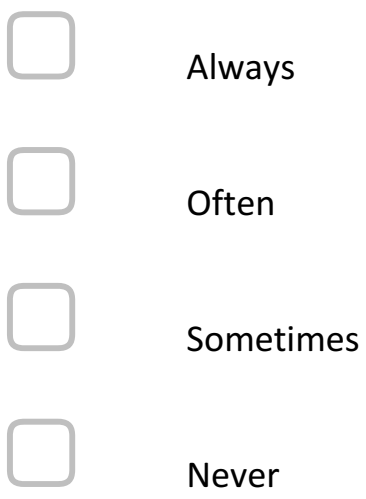


6. How do you usually cope with your discomfort when dancing en pointe? Please select all that apply.

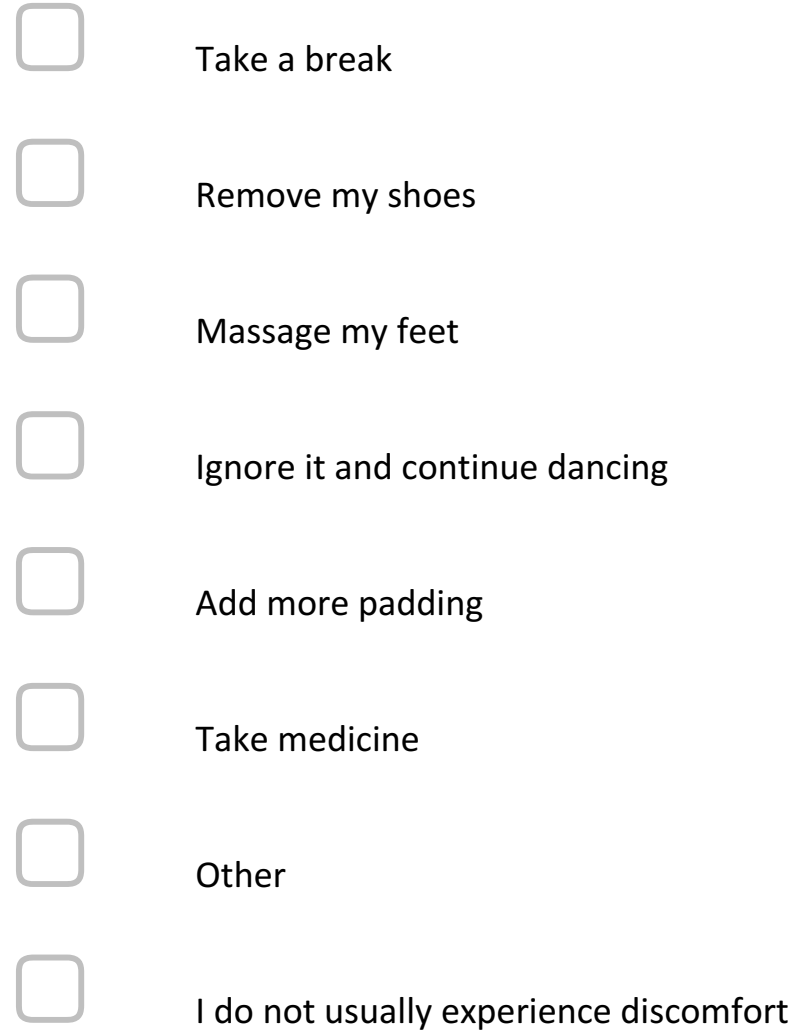

Thank You for completing the first part of the questionnaire!

Please let the researcher know that you are ready for testing. 
D.2 Post-test Questionnaire

Post-test questionnaire

Page Break

1. Do you currently feel discomfort in your left foot, right foot or both feet?

Left foot

Right foot

Both feet

Uncertain

No discomfort

2. How can you rate your current discomfort?

No discomfort

Most discomfort imaginable

$\begin{array}{lllllll}0 & 2 & 3 & 5 & 7 & 8 & 10\end{array}$

Discomfort 
3. Where are you experiencing the discomfort?

Please select all that apply.

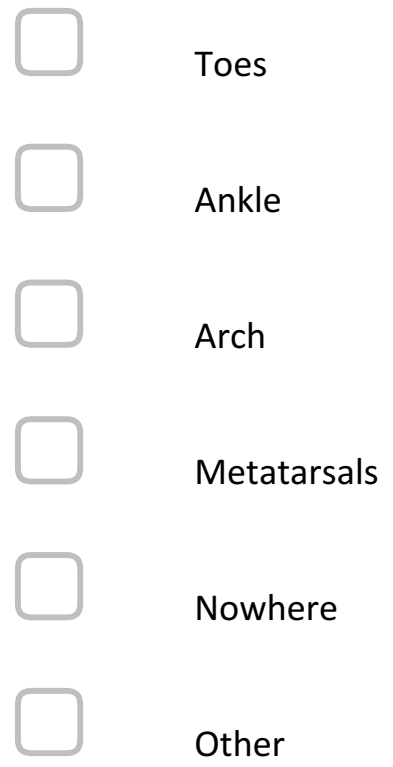

4. How often did you feel discomfort when dancing en pointe, during the testing?

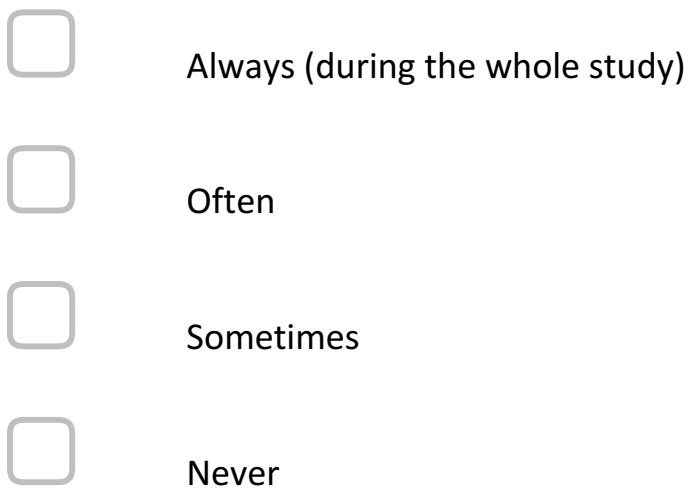


5. How did you cope with your discomfort when dancing en pointe during the testing? Please select all that apply.

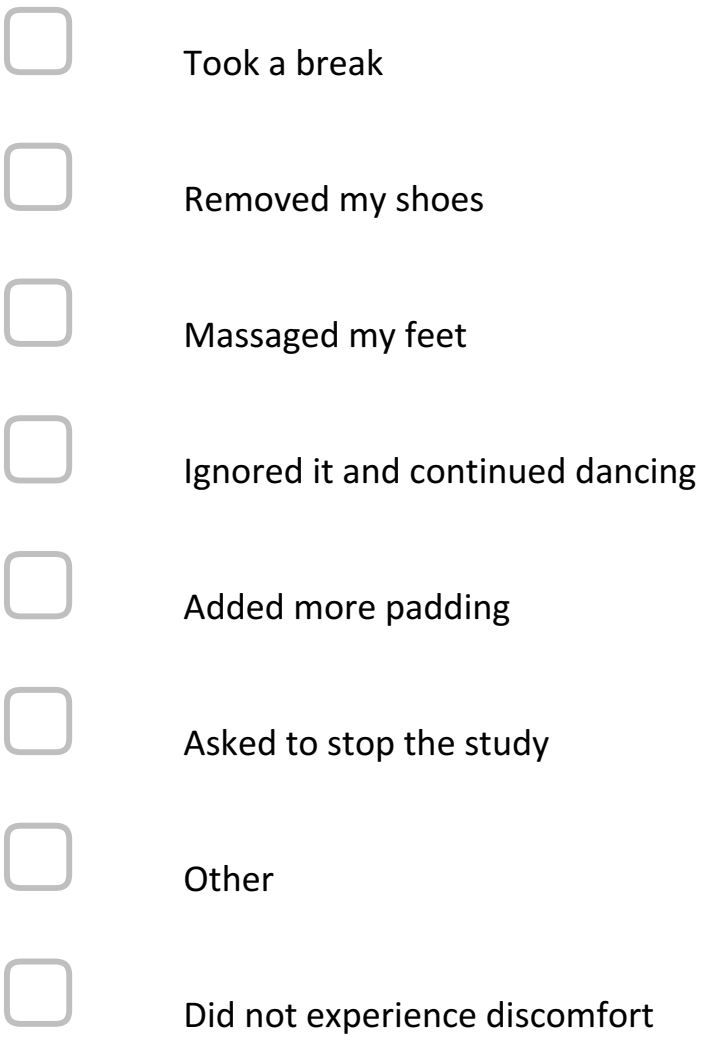

6. Have you had an injury in pointe class that has affected you to go en pointe?

Yes

No

\section{Page Break}

* If answered Yes, please continue the questionnaire by clicking the blue arrow.

**If answered No, please skip to question \#1 in the section titled "Your thoughts", by clicking the blue arrow.

Thank You! 
7. How many times have you had an injury in pointe class?

$\begin{array}{lllllllllll}0 & 1 & 2 & 3 & 4 & 5 & 6 & 7 & 8 & 9 & 10\end{array}$

Times

8. Do you continue dancing en pointe, even if you have an injury?

Definitely yes

Probably yes

Might or might not

Probably not

Definitely not

Your thoughts...

1. How many years do you see yourself continuing pointe work?

$$
\begin{array}{lllllllllll}
0 & 1 & 2 & 3 & 4 & 5 & 6 & 7 & 8 & 9 & 10
\end{array}
$$

Years


2. How would you rate your overall experience with this study?

$\begin{array}{cc}\text { Extremely Neutral } & \text { Extremely } \\ \text { unsatisfied } & \text { satisfied }\end{array}$

$\begin{array}{lllllll}1 & 3 & 4 & 6 & 7 & 9 & 10\end{array}$

Satisfaction

3. If you were to be given an opportunity to participate again, would you?

Definetely yes

Probably yes

Might or might not

Probably not

Definetely not

Any other comments, you would like to leave for the researcher?

\section{Page Break}

Thank You for completing the questionnaire!

Please let the researcher know that you are ready done. 
Appendix E: Zone 2 Real-time Discomfort Assessments 


\section{E.1 Fundamental Pointe Work Movements}

\section{Échappé}

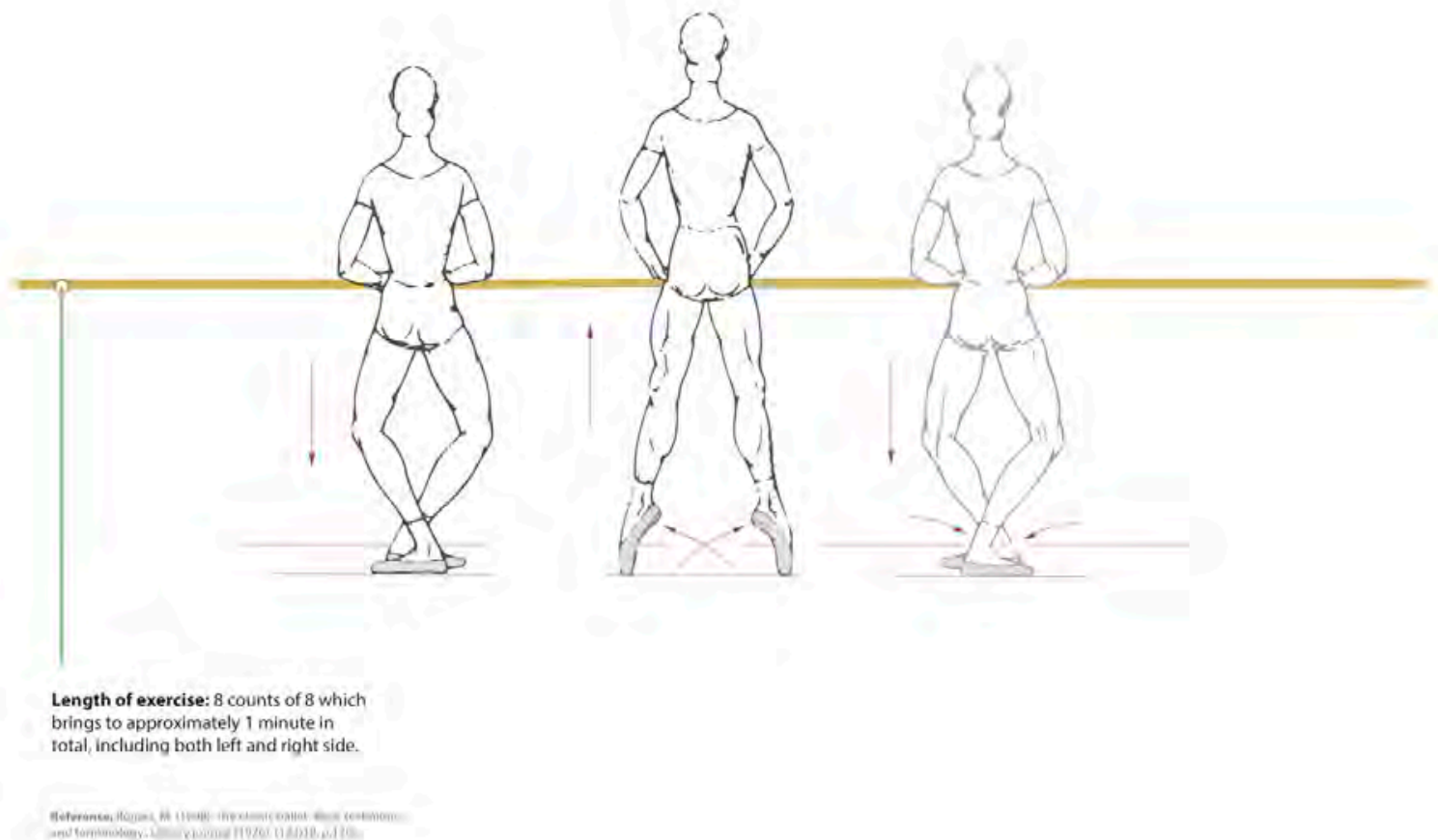




\section{E.1 Fundamental Pointe Work Movements}

Sissonne Simple

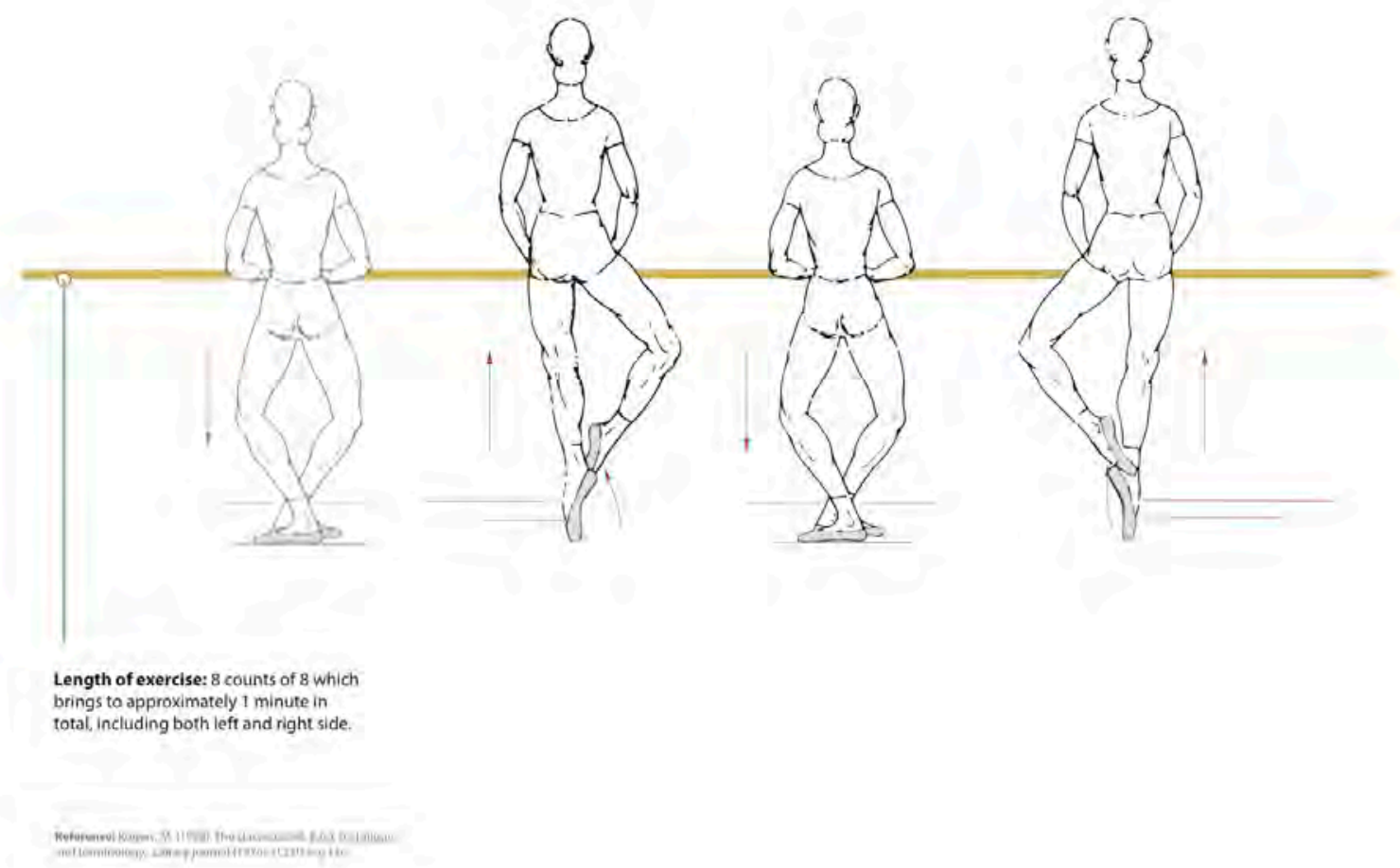


E.1 Fundamental Pointe Work Movements

Bourrée

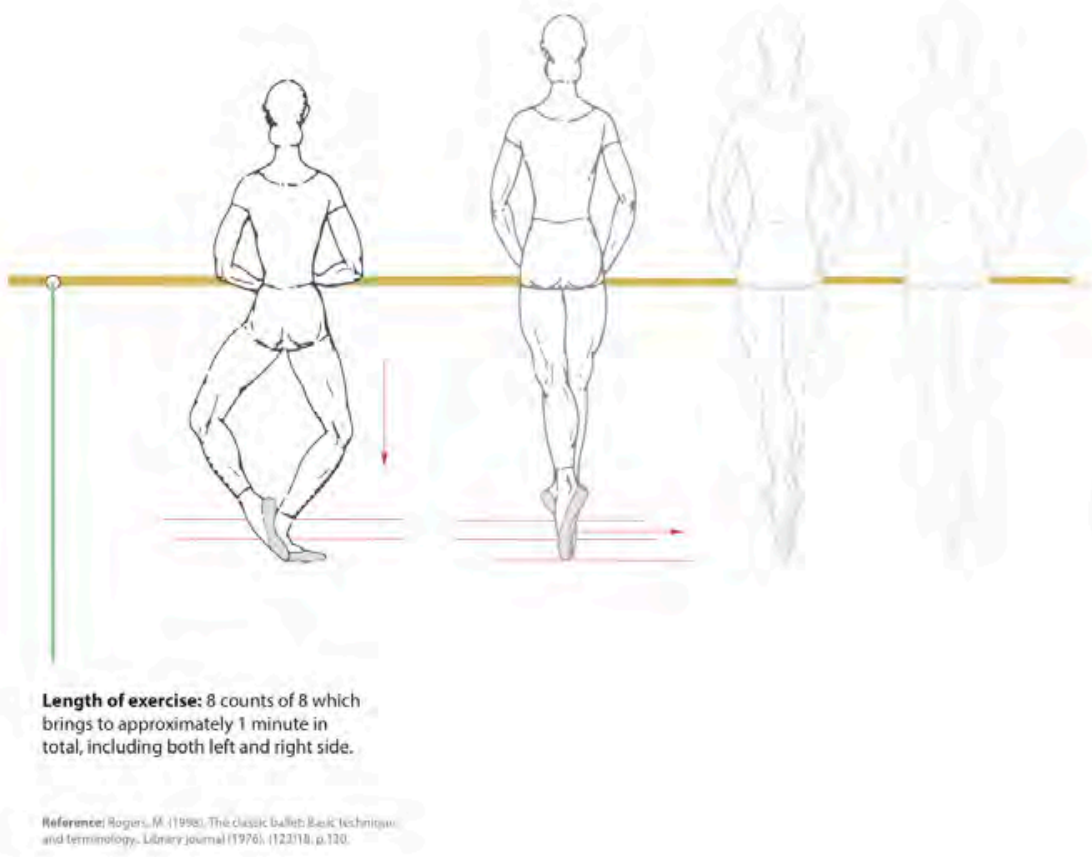


E.2 Real-time Discomfort Assessment Questions

\section{Discomfort Assessment}

*After completing the movement please hold the last pointe position en pointe, as long as you can during this assessment, while holding on to the ballet barre. **In this study we are looking at discomfort as a feeling of being uncomfortable while being en pointe.

1. Do you feel discomfort in your left foot, right foot or both feet?

2. On a scale from $0-10,0$ being no discomfort and 10 most discomfort imaginable, please pointe out your overall discomfort.

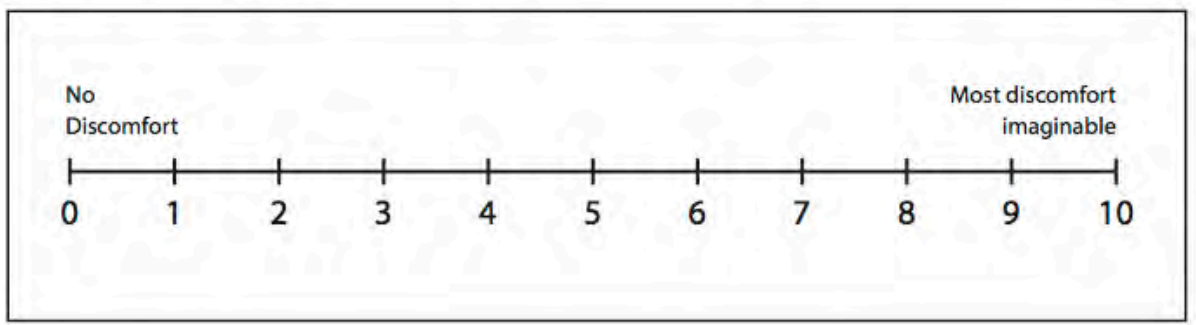

3. Using the 3-D model, as a visual tool and a representation of your feet, please identify: where you feel the most discomfort (5-10) using the red stickers. On a scale from 0-10, 0 being no discomfort and 10 most discomfort imaginable, how would you rate each point?

4. Using the 3-D model, as a visual tool and a representation of your feet, please identify: your least discomfort (0-5) On a scale from 0-10, 0 being no discomfort and 10 most discomfort imaginable, how would you rate each point? 
E.3 Guidance Steps for Data Collection

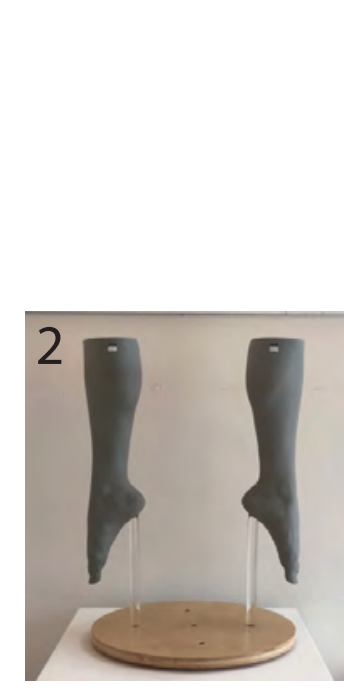

FRONT FIRST POSITION

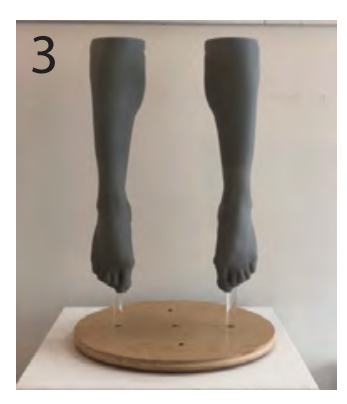

FRONT FEET

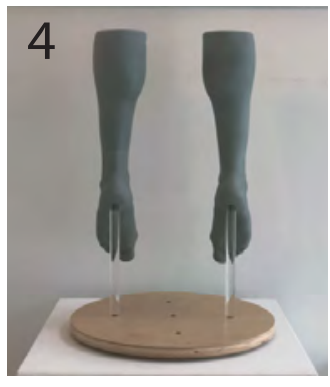

BACK OF FEET

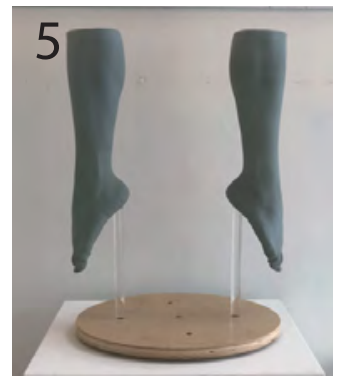

BACK FIRST POSITION
6

REMOVE STICKERS 
E.4 3-D Feet Positions for Real-time Discomfort Assessment Movement $(1,2,3)$
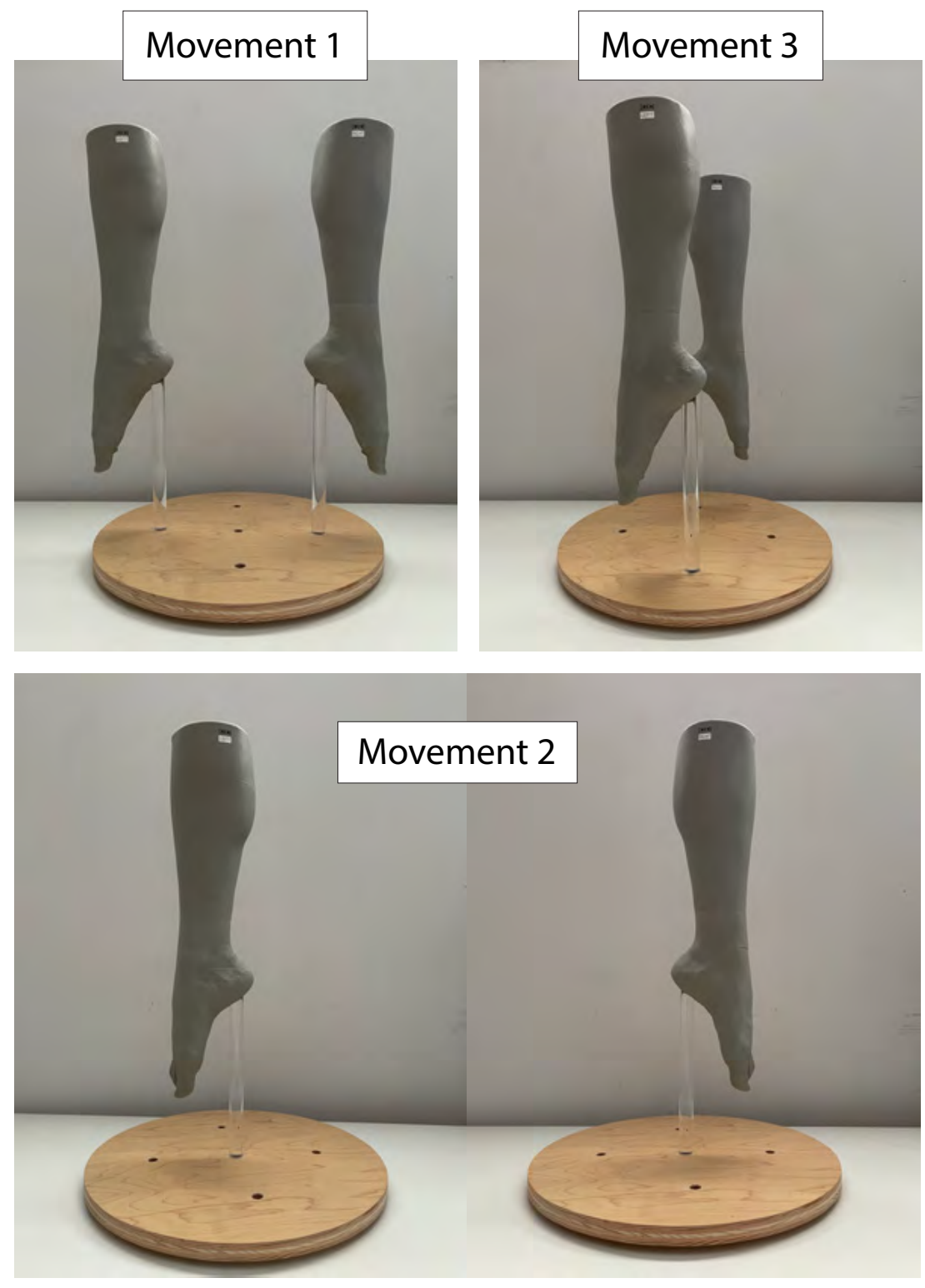
Appendix F: Zone 3 Thermographic Imaging 


\section{F.1 Thermographic Imaging Setup Protocols}
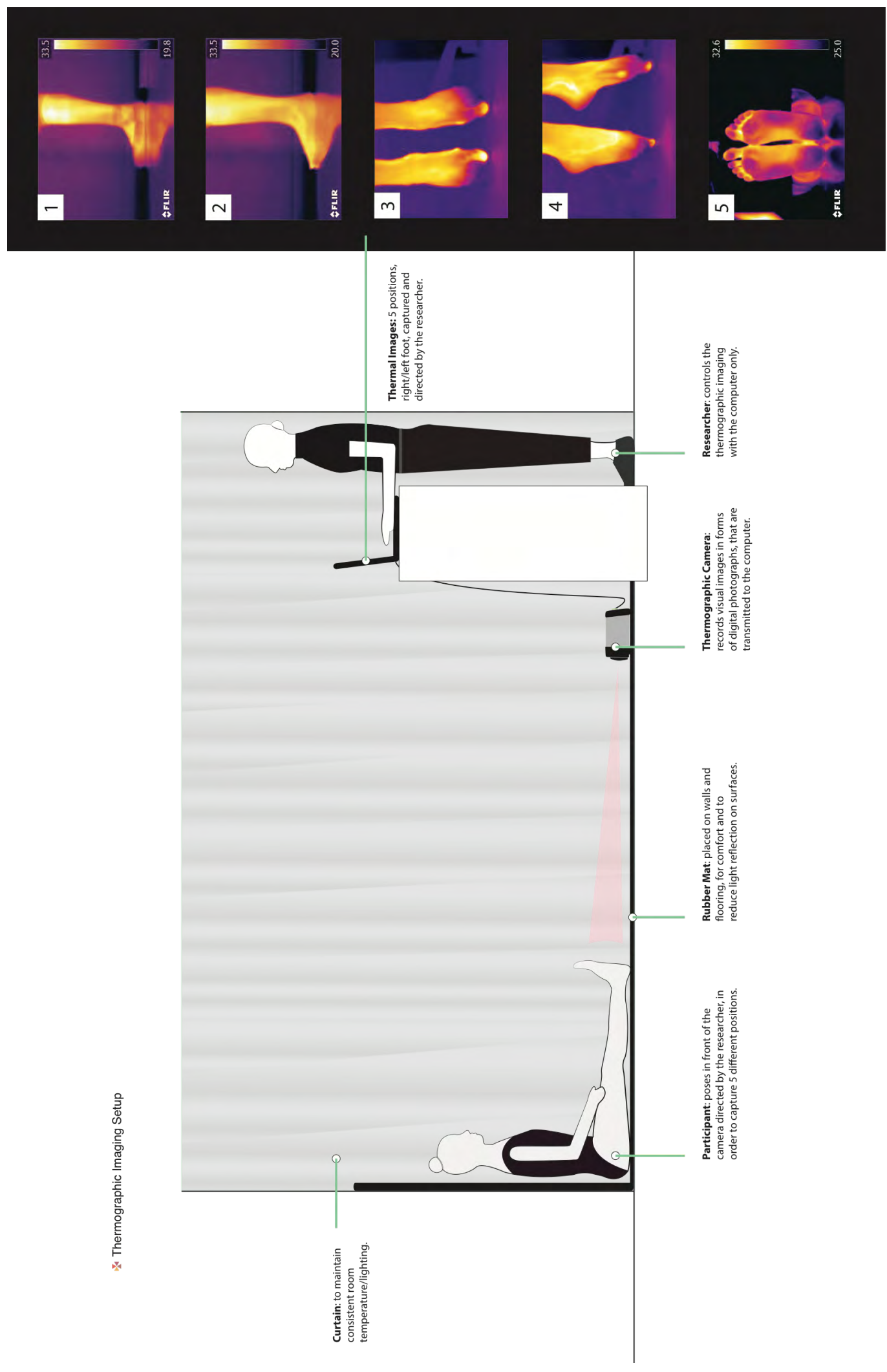
F.2 Feet Positions for Thermographic Imaging Sessions
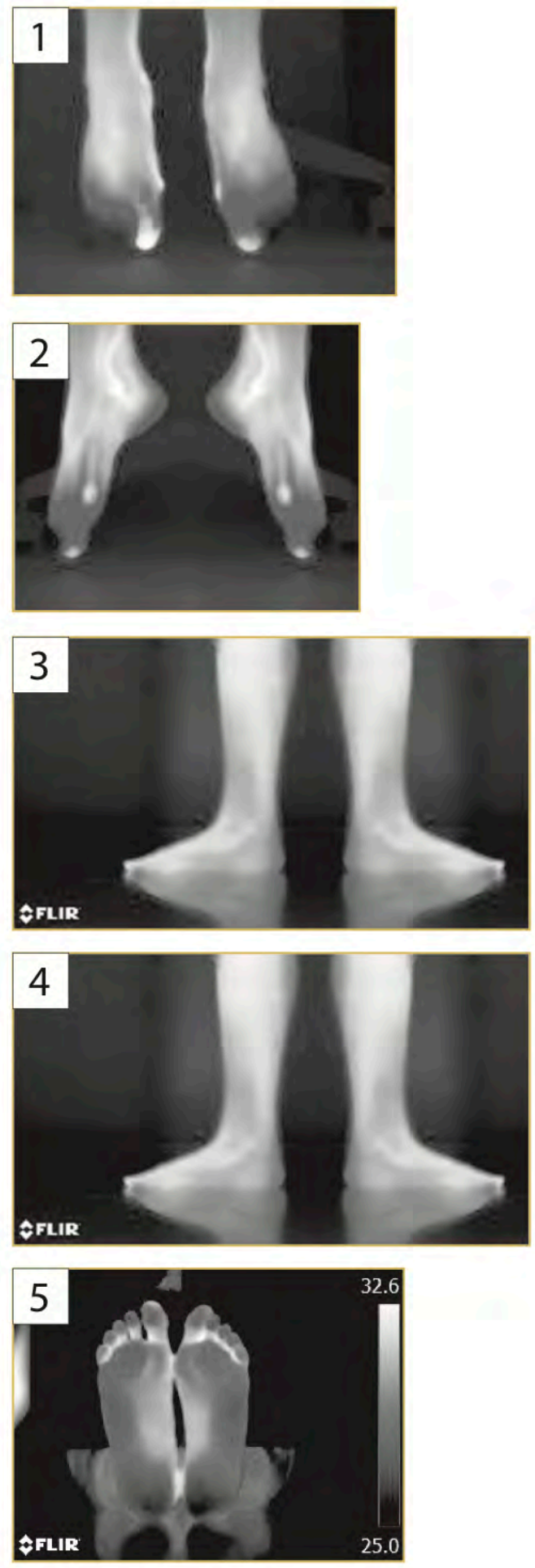


\section{F.3 Thermographic Imaging Preparation Checklist for Participants}

\section{Testing Preparation Checklist}

(1) To be determined by the researcher

(9) 450 Azrielli pavilion (The Gallery), Carleton University

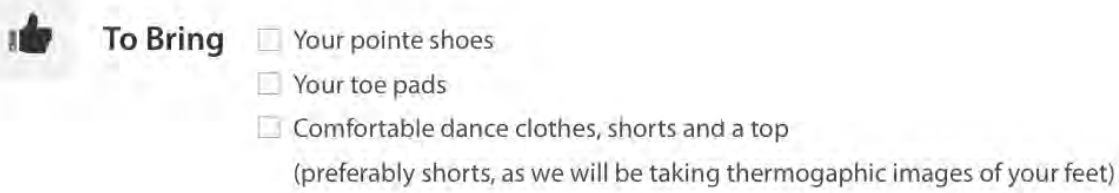

Q To Avoid One week prior to testing, avoid prolonged sun exposure should

24 Hours prior to testing, avoid consuming alcoholic beverages

24 Hours prior to testing, avoid any form of physiotherapy or electrical stimulation techniques (i.e. acupuncture, electromyography, hot/cold patches etc.)

4 Hours prior to testing, avoid high intensity physical exercises and training

2 Hours prior to testing, avoid smoking

1 Hour prior to testing, avoid hot beverages

On the day of testing, avoid wearing anklets or toe rings

On the day of testing, avoid using lotions and talcum powder on the skin

A. Solely guidelines to be followed prior and during testing, as some of these might impact the temperature of the skin, when capturing images of the feet during the thermographic imaging. 
Appendix H: Data Collection and Results 
H.1 Participants Persona Board
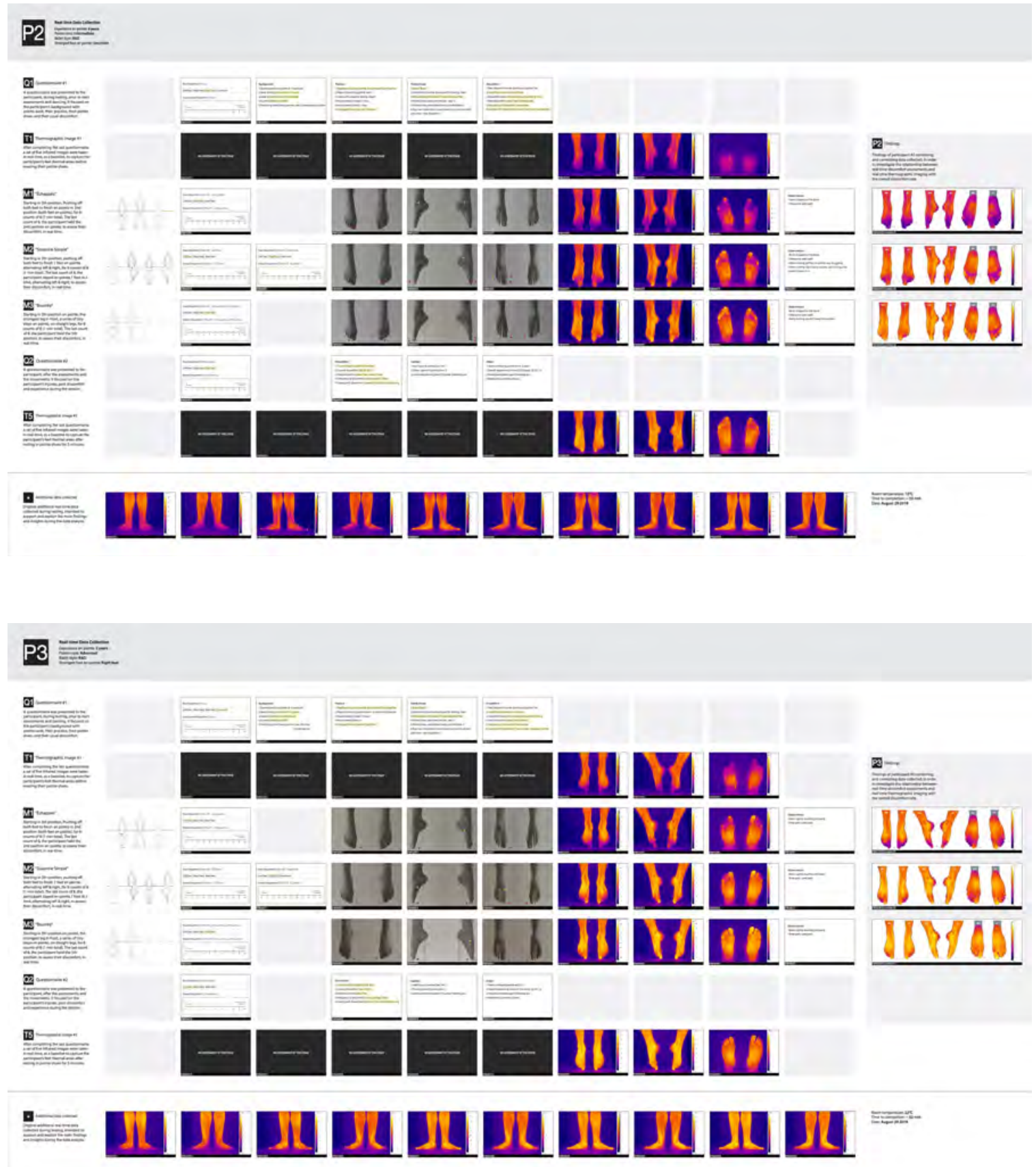
H.1 Participants Persona Board
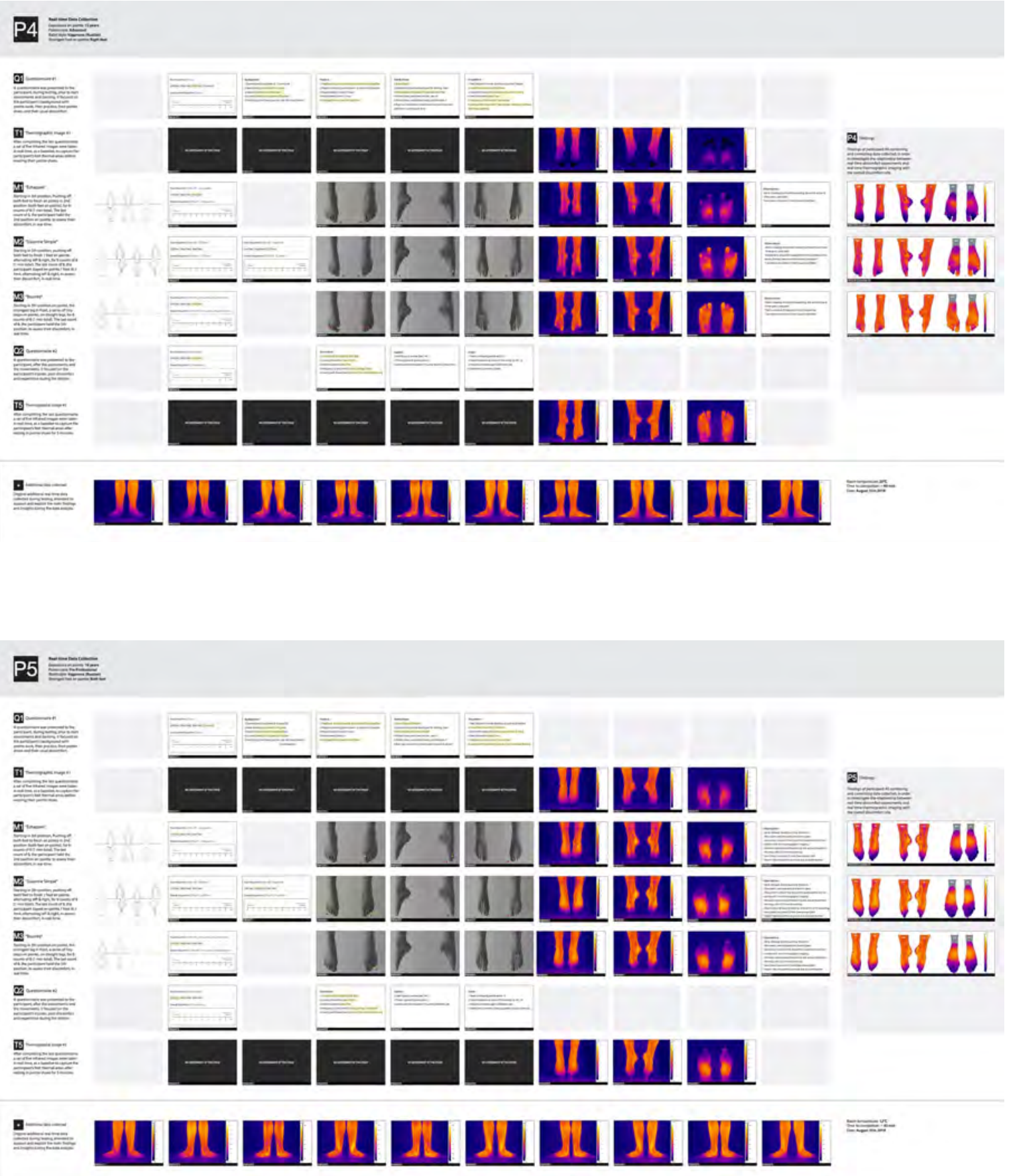
H.1 Participants Persona Board
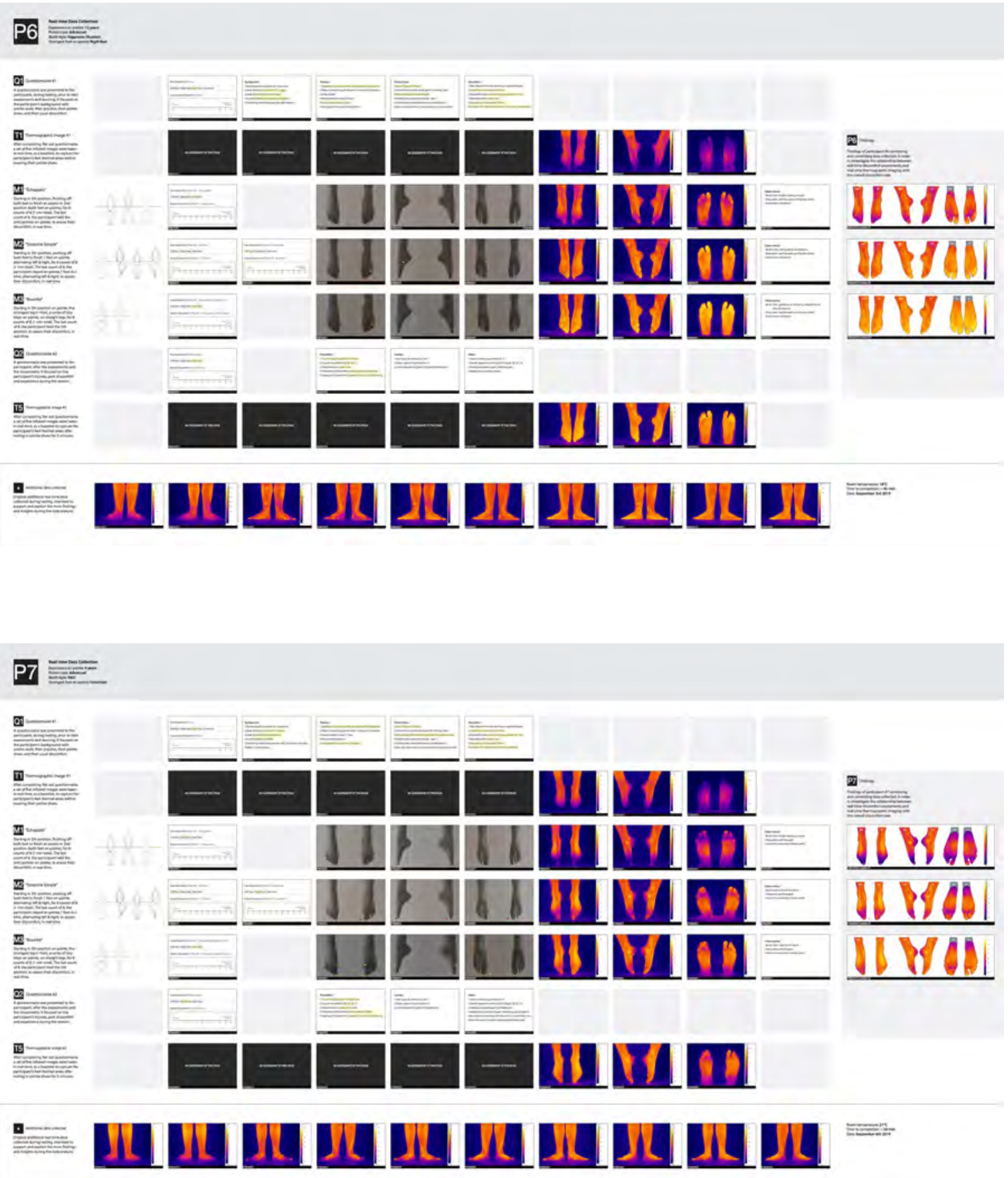
H.1 Participants Persona Board
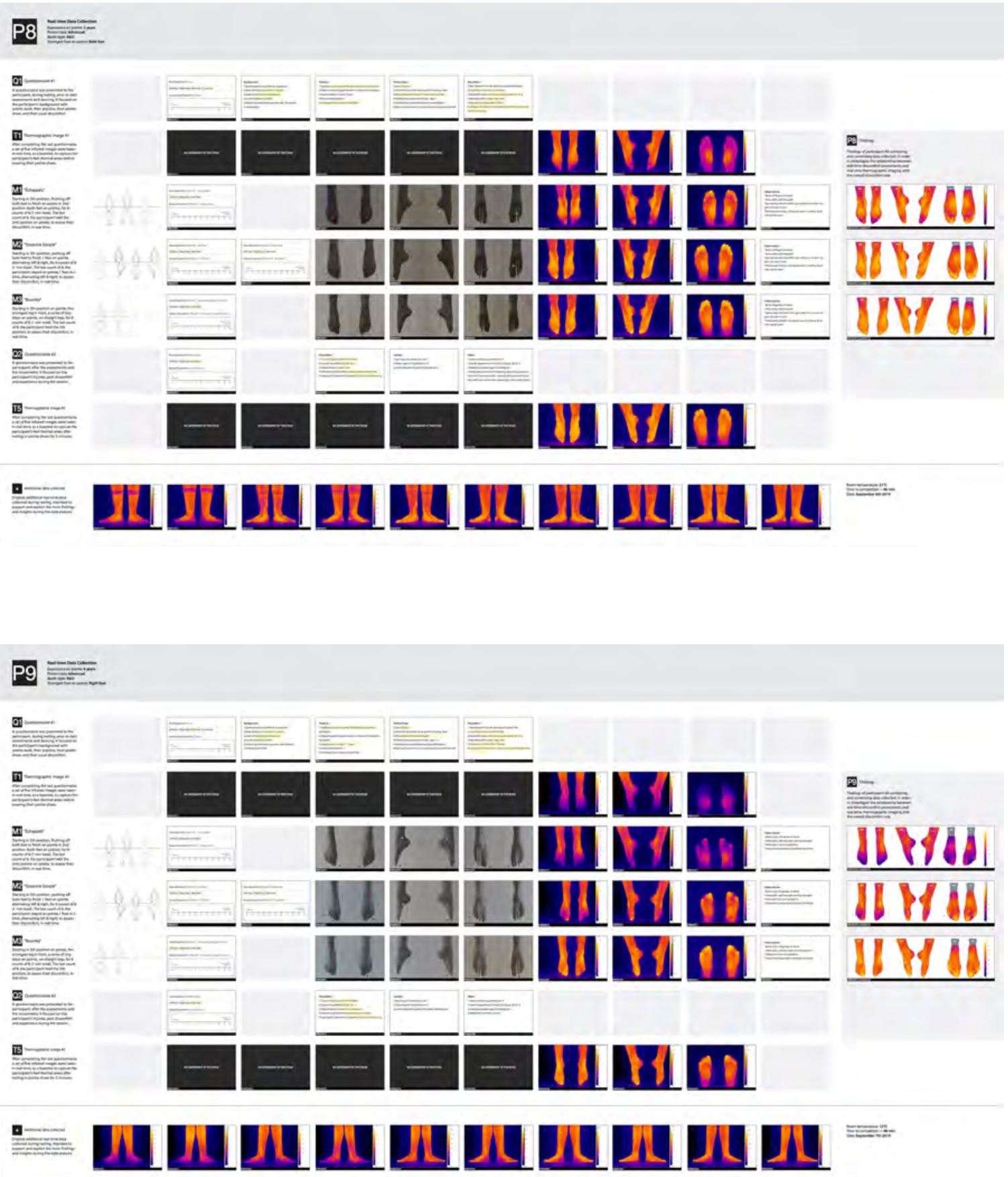
H.1 Participants Persona Board

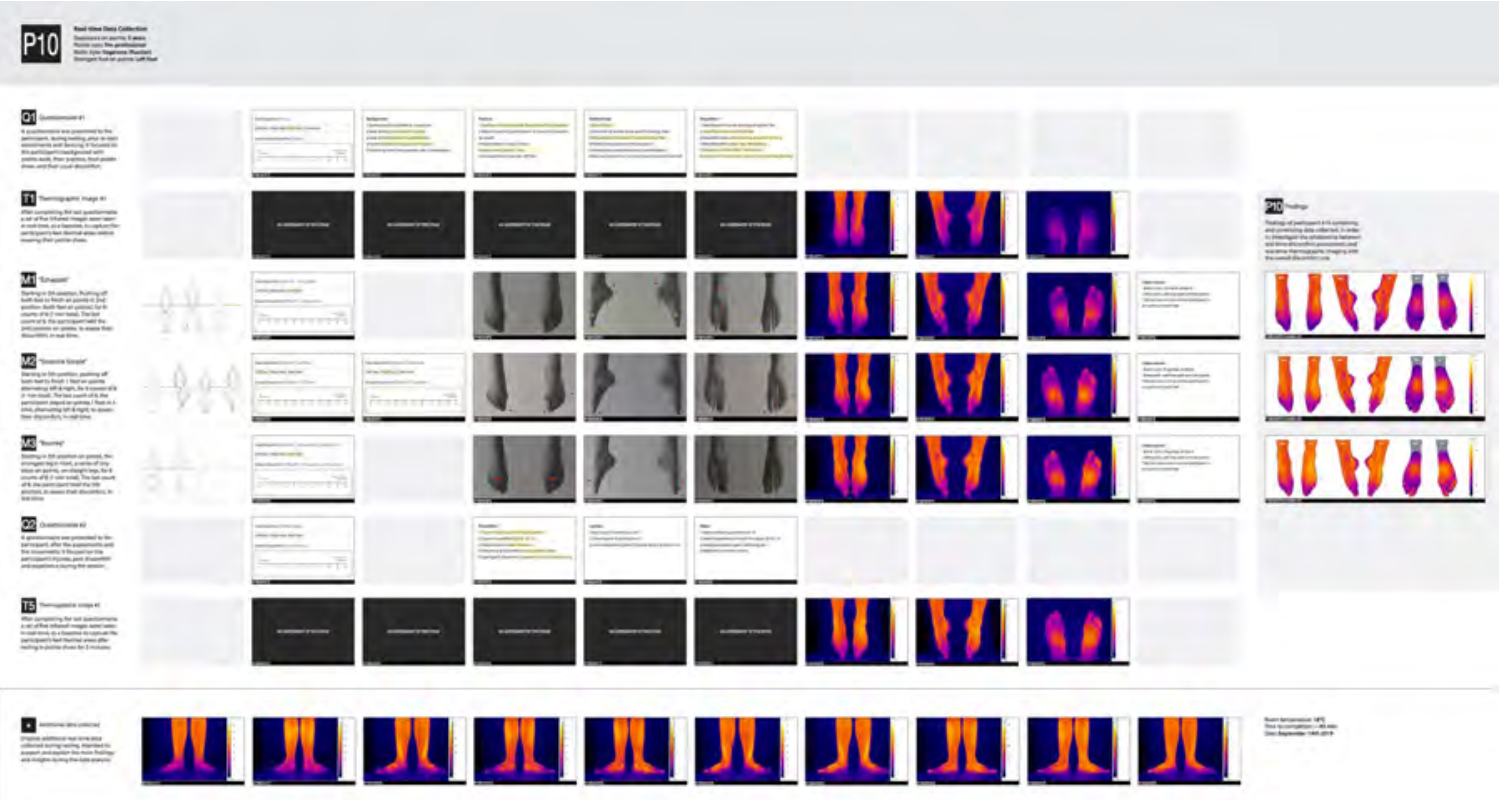




\section{H.2 Average Discomfort Intensity of Both Feet for Movement $(1,2,3)$}

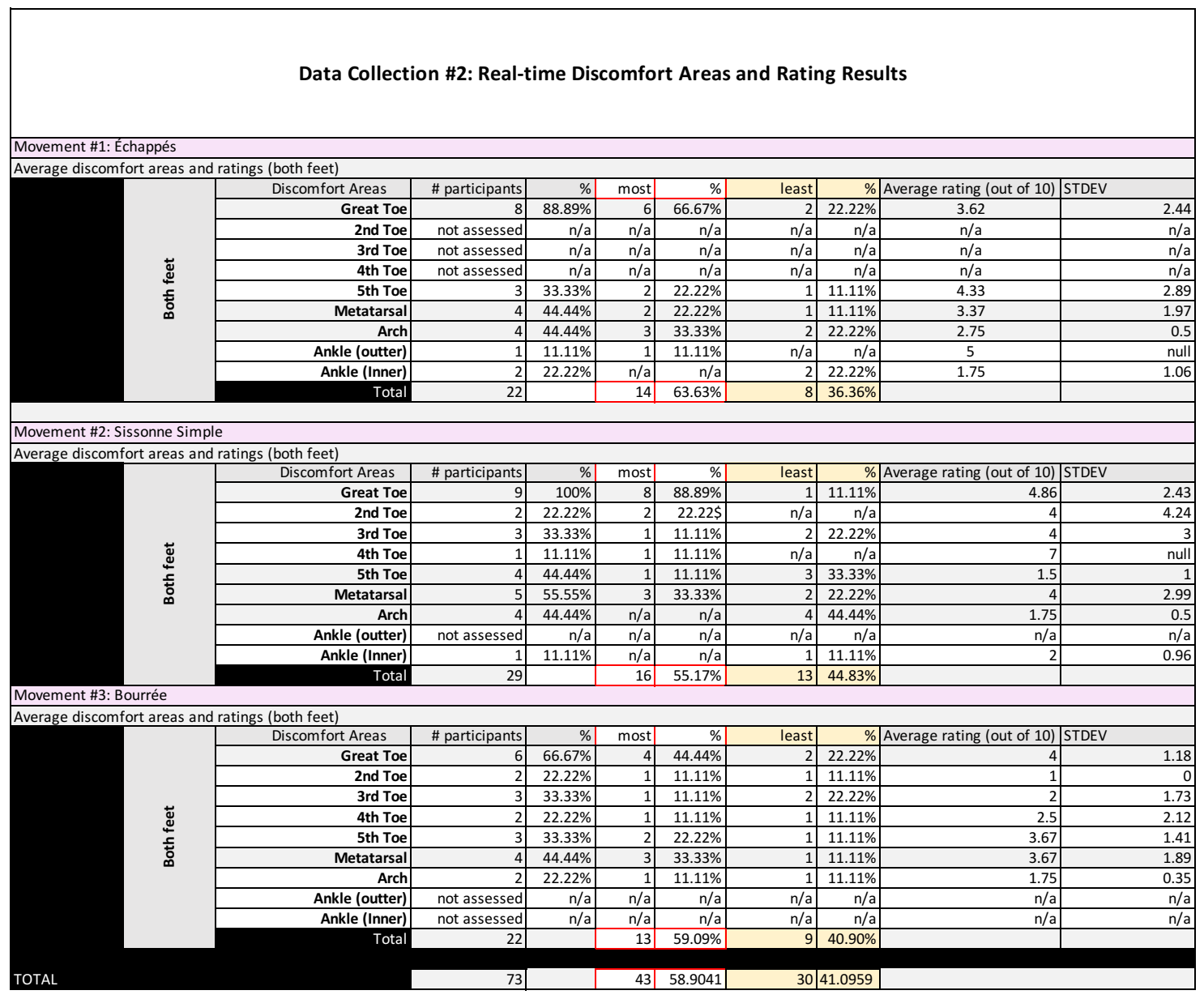


H.3 Reference Material used for Thermographic Imaging Analysis

P2
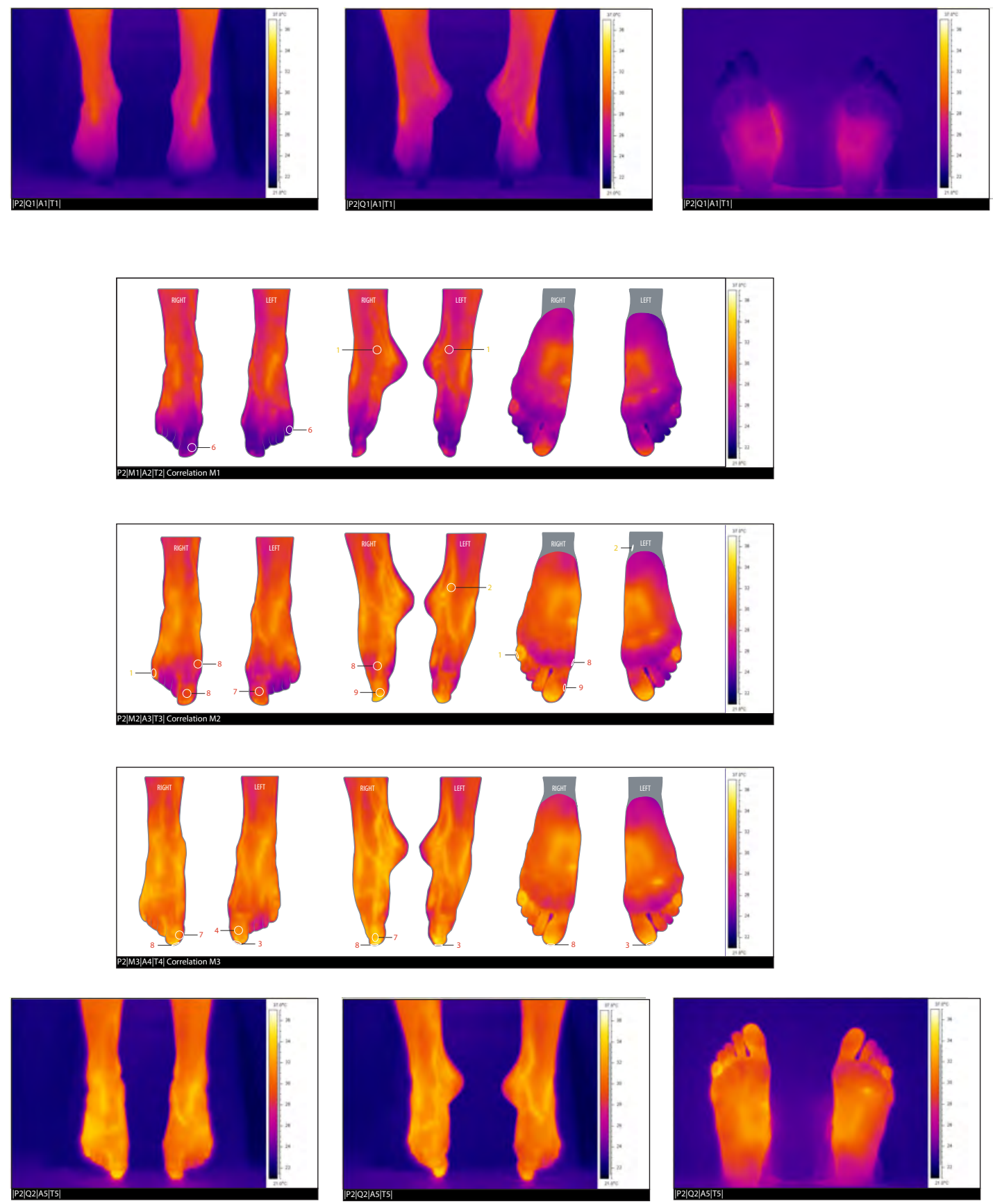
H.3 Reference Material used for Thermographic Imaging Analysis
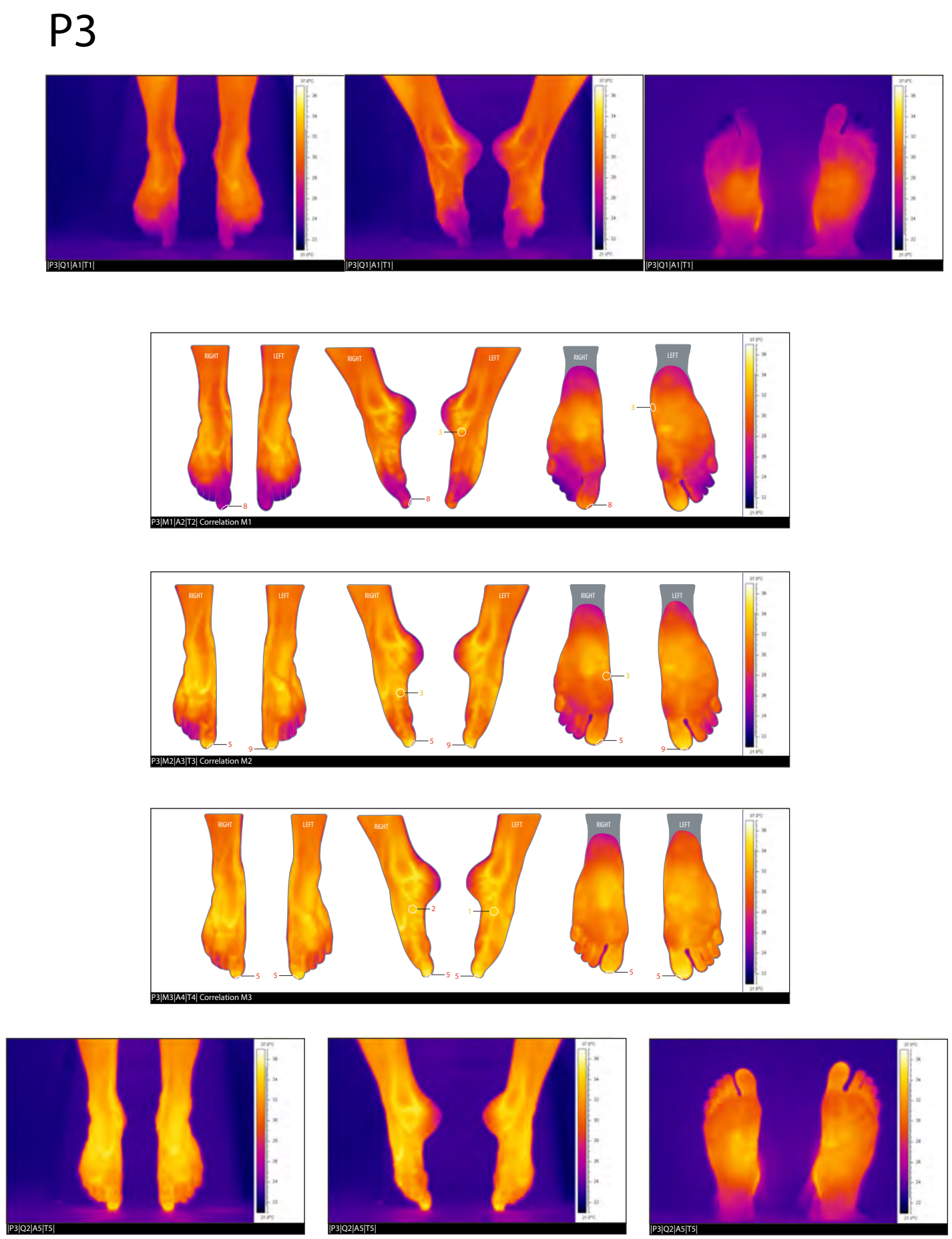
H.3 Reference Material used for Thermographic Imaging Analysis
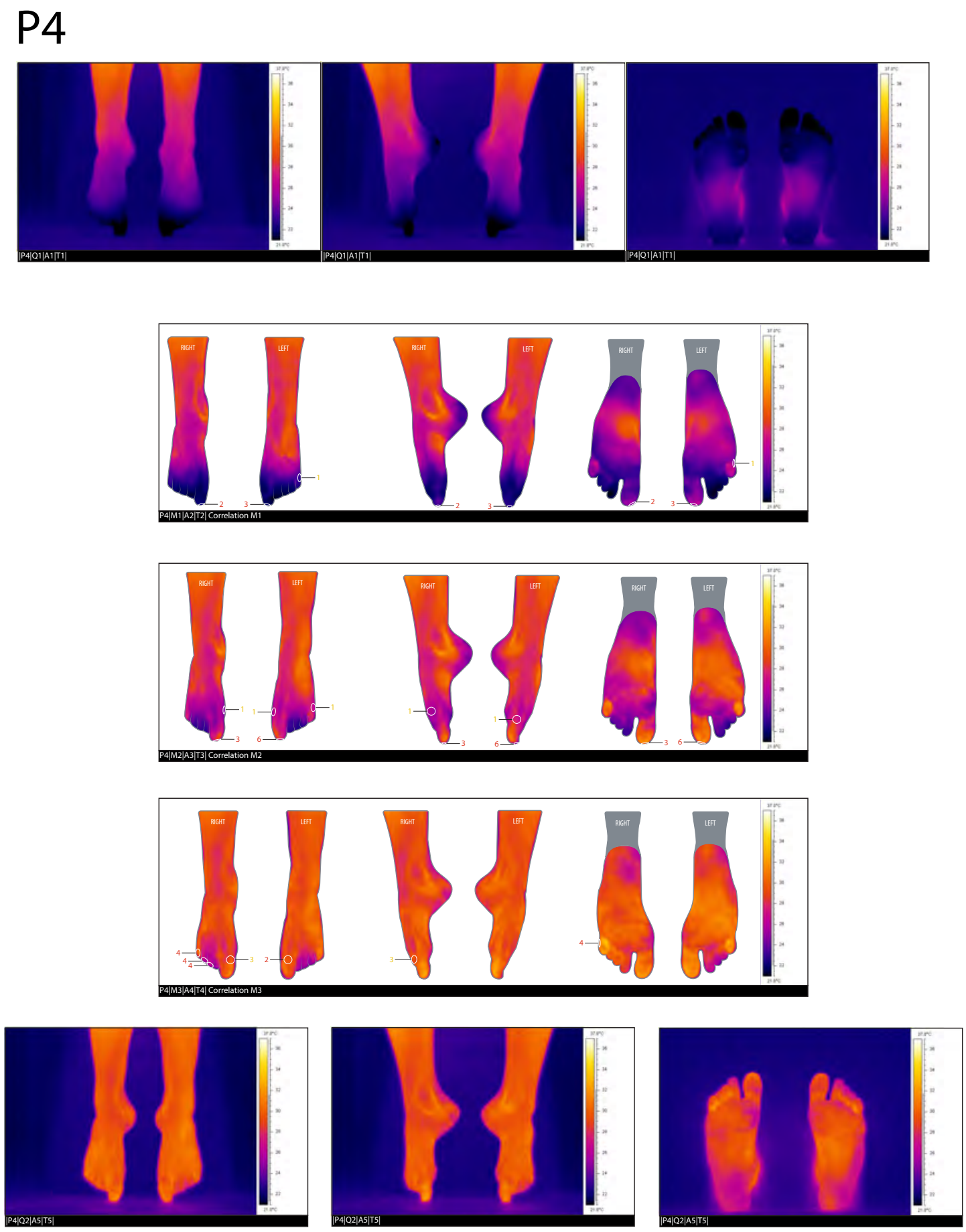
H.3 Reference Material used for Thermographic Imaging Analysis
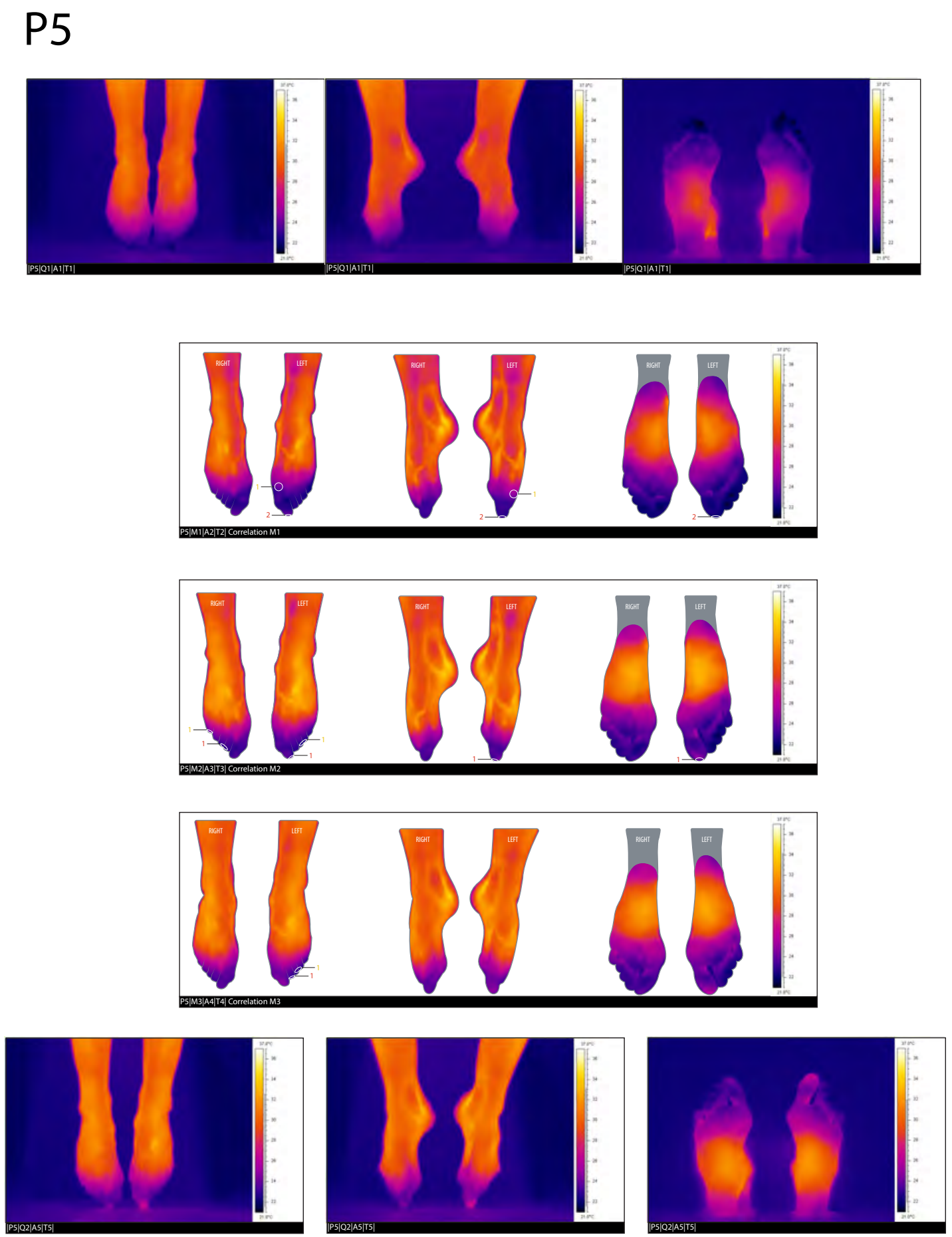
H.3 Reference Material used for Thermographic Imaging Analysis
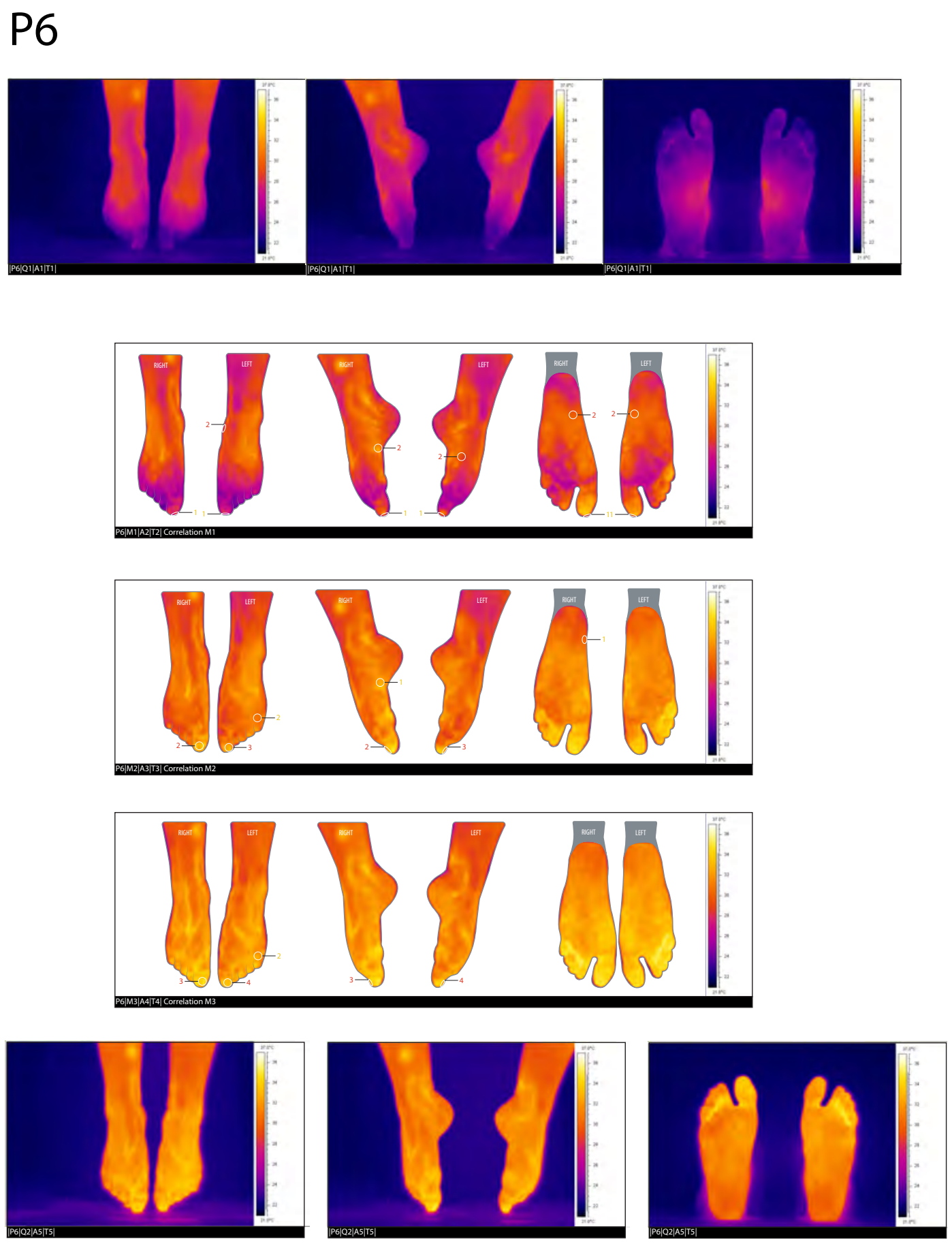
H.3 Reference Material used for Thermographic Imaging Analysis
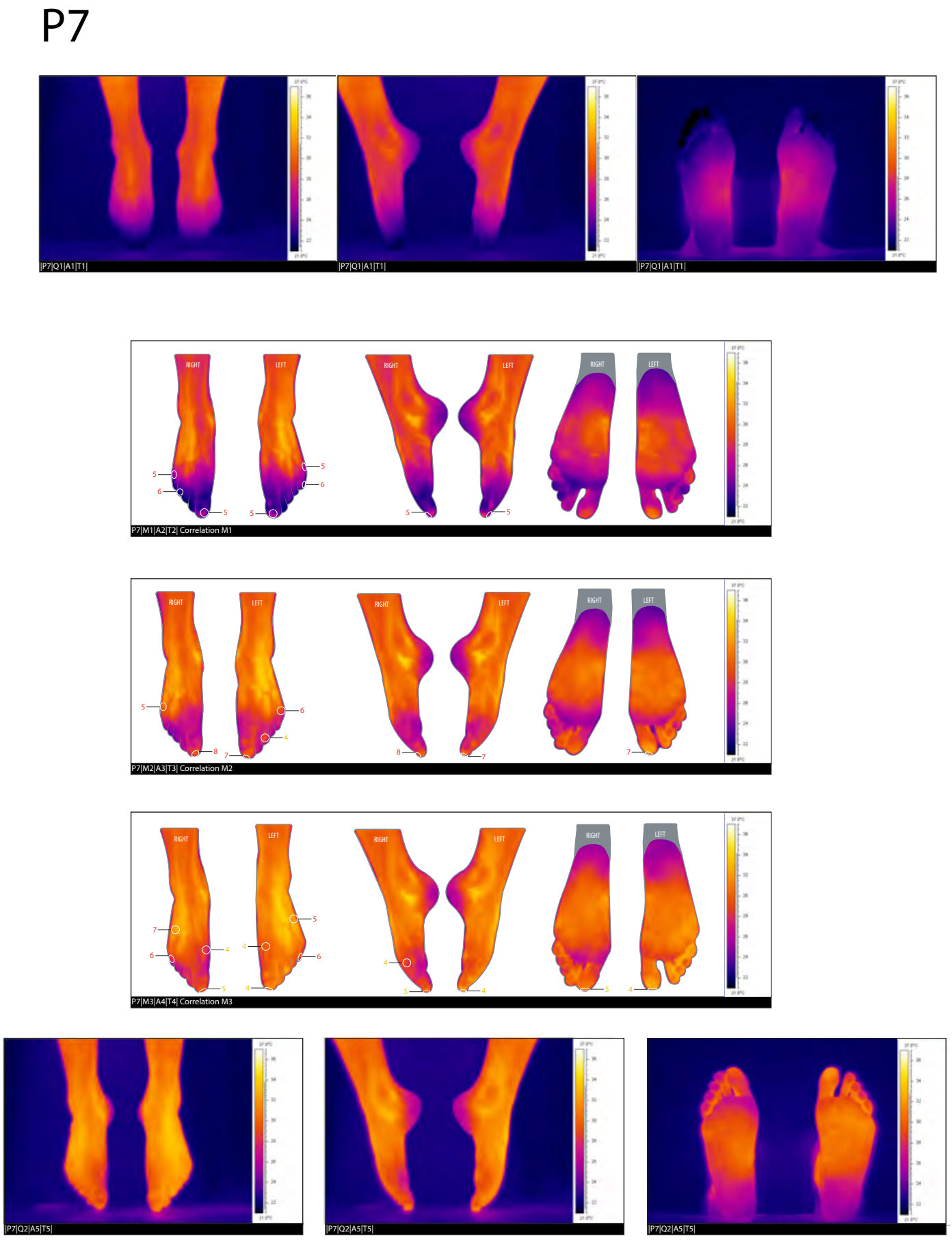
H.3 Reference Material used for Thermographic Imaging Analysis
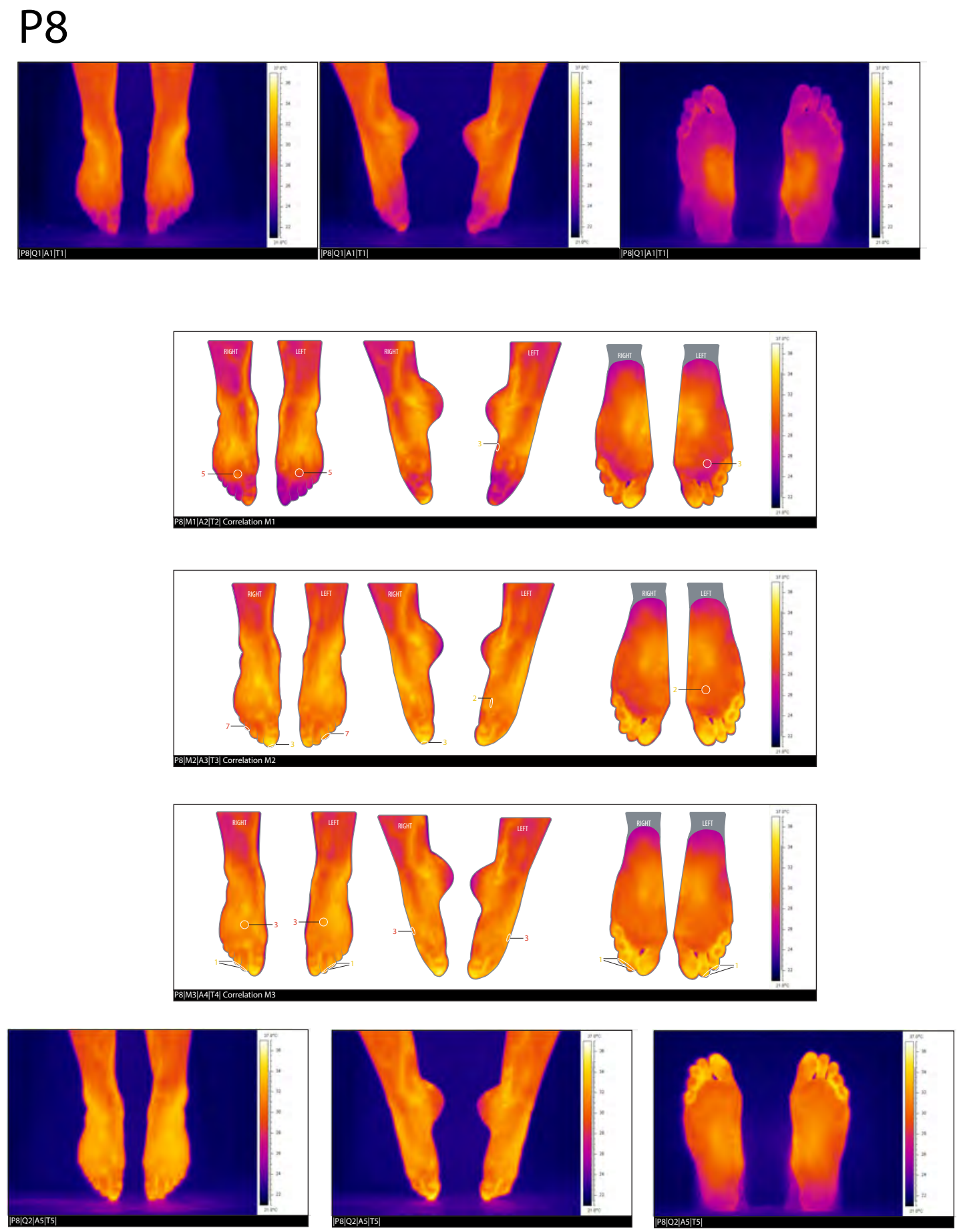
H.3 Reference Material used for Thermographic Imaging Analysis
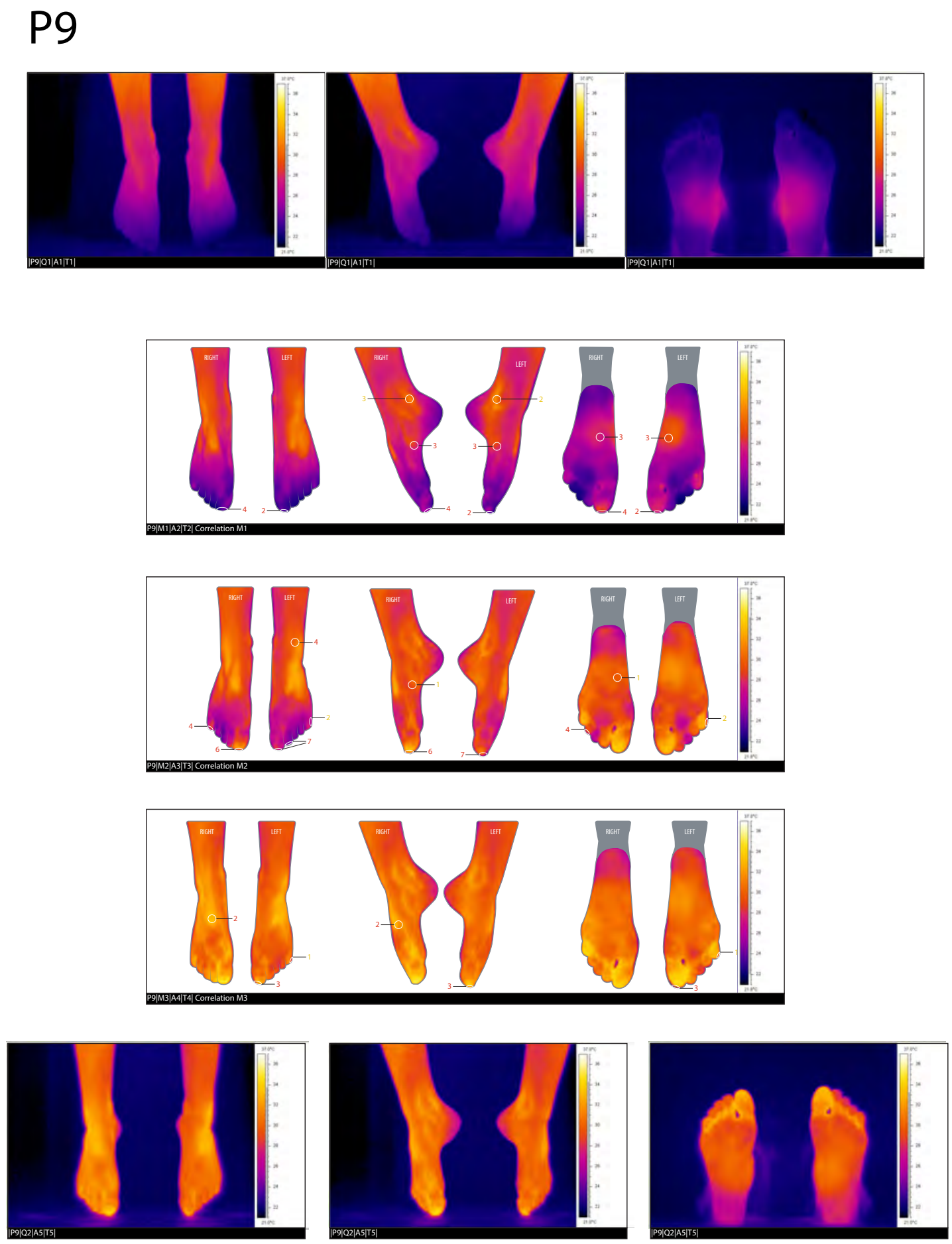
H.3 Reference Material used for Thermographic Imaging Analysis
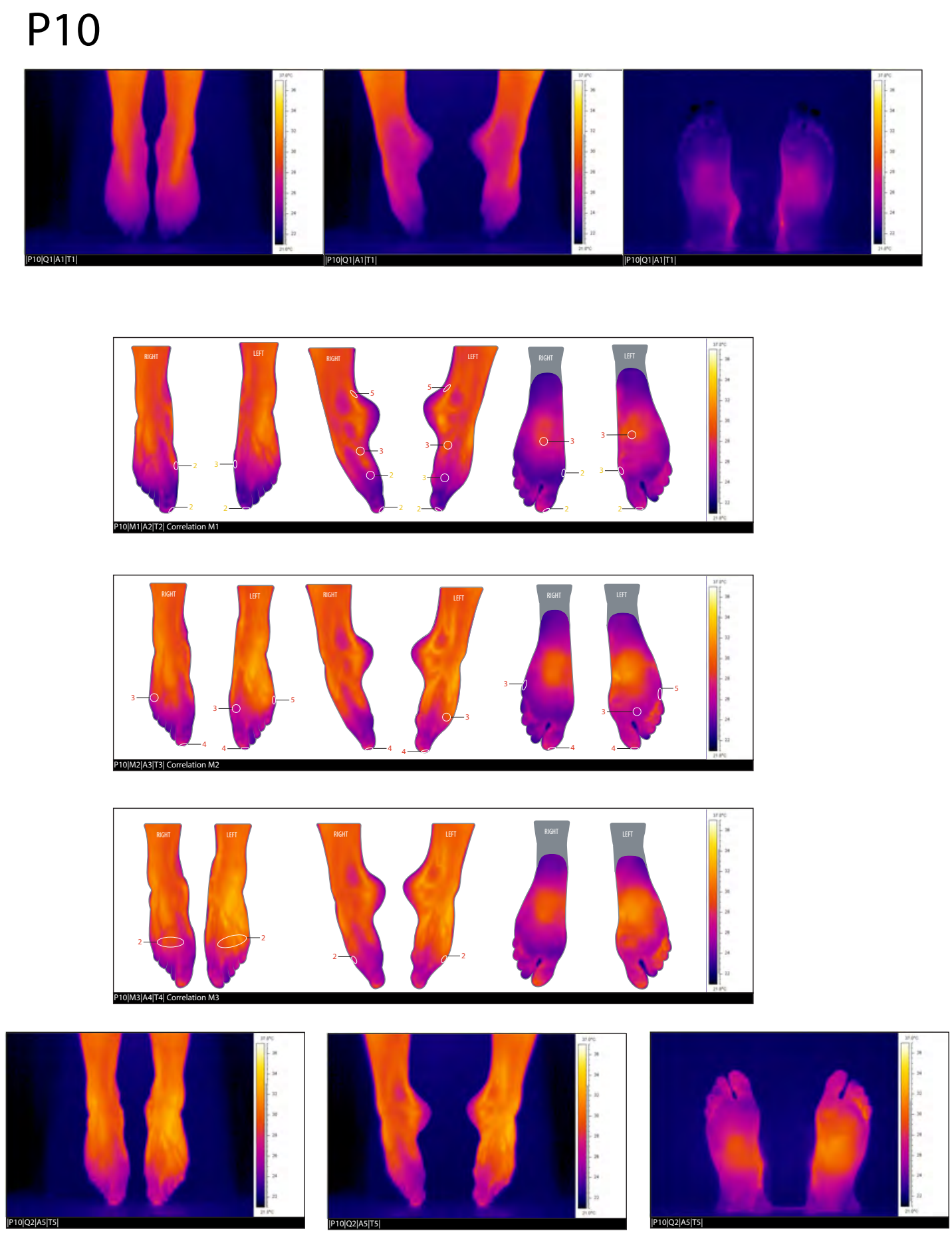
H.4 Thermographic Imaging Analysis Report

P2

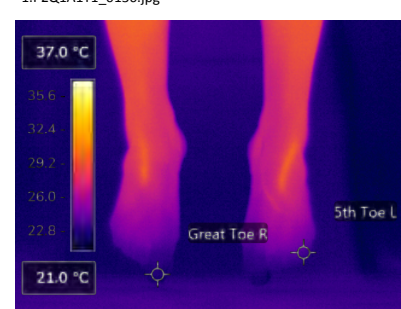

Measurements

\begin{tabular}{l|l}
\hline Great Toe R & $22.7^{\circ} \mathrm{C}$ \\
\hline
\end{tabular}

5th Toe L

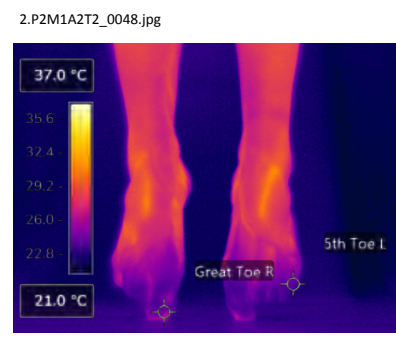

Measurements

\begin{tabular}{l|l}
\hline Great Toe R & $24.8^{\circ} \mathrm{C}$ \\
\hline 5
\end{tabular}

5th Toe L
1.P2Q1A1T1_0205.jpg

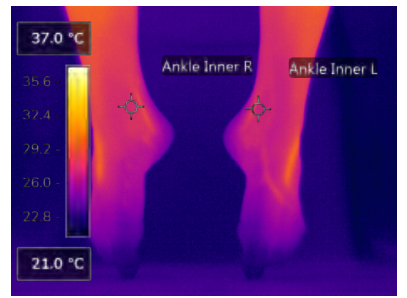

Measurements

\begin{tabular}{l|l} 
Ankle Inner R & $27.8^{\circ} \mathrm{C}$
\end{tabular}

$\begin{array}{ll}\text { Ankle Inner } \mathrm{L} & 27.3^{\circ} \mathrm{C}\end{array}$

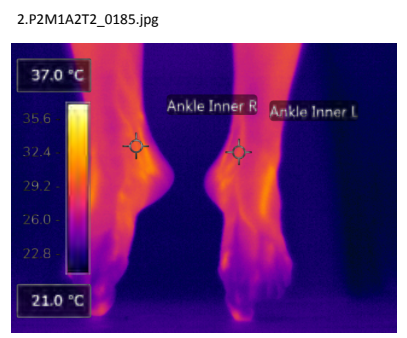

Measurements

\begin{tabular}{l|l}
\hline Ankle Inner R & $29.9^{\circ} \mathrm{C}$ \\
Ankle Inner L & $29.0^{\circ} \mathrm{C}$
\end{tabular}

P2

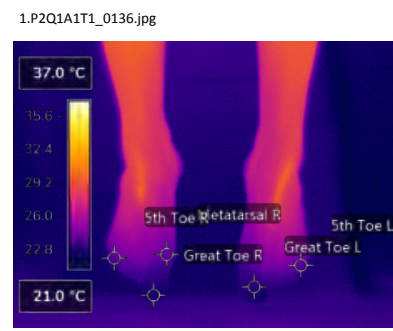

Measurements

\begin{tabular}{l|l}
\hline Great Toe R & $22.4^{\circ} \mathrm{C}$ \\
Metotase & $240^{\circ} \mathrm{C}$
\end{tabular}

$\begin{array}{ll}\text { Metatarsal R } & 24.0^{\circ} \mathrm{C} \\ & 238^{\circ} \mathrm{C}\end{array}$

\begin{tabular}{l|l} 
Sth Toe R & $23.8^{\circ} \mathrm{C}$ \\
Great Toe L & $22.8^{\circ} \mathrm{C}$ \\
\hline & $23.7^{\circ} \mathrm{C}$
\end{tabular}

3.P2M2A3T3_0086.jpg

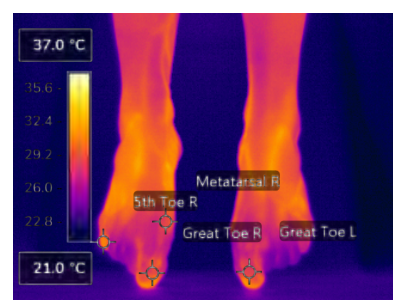

Measurements

\begin{tabular}{l|l}
\hline Great Toe R & $29.1^{\circ} \mathrm{C}$ \\
\hline
\end{tabular}

Metatarsal R

P2Q1A1T1_0205.jpg

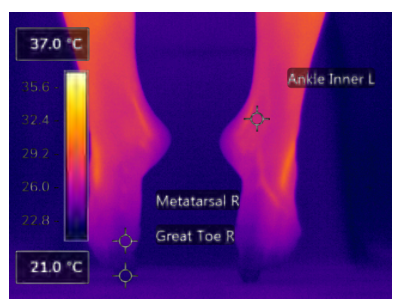

Measurements

\begin{tabular}{l|l|l}
\hline Great Toe R & $22.5^{\circ} \mathrm{C}$ \\
\hline
\end{tabular}

\begin{tabular}{ll}
\hline Great Toe R & $22.5^{\circ} \mathrm{C}$ \\
Metatarsal R & $23.7^{\circ} \mathrm{C}$ \\
\hline A &
\end{tabular}

$273^{\circ} \mathrm{C}$

3.P2M2A3T3_0233.jpg

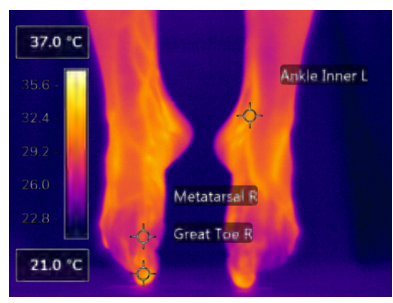

Measurements

\begin{tabular}{l|l|l}
\hline Great Toe R & $31.4^{\circ} \mathrm{C}$ \\
\hline
\end{tabular}

\begin{tabular}{lll} 
Metatarsal R & $29.5^{\circ} \mathrm{C}$ \\
\hline Ante &
\end{tabular}

\begin{tabular}{l|l} 
Ankle Inner $\mathrm{L}$ & $31.9^{\circ} \mathrm{C}$
\end{tabular}

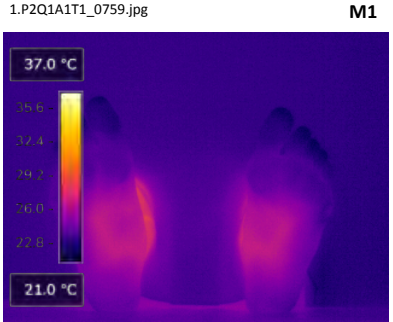

2.P2M1A2T2_0821.jpg

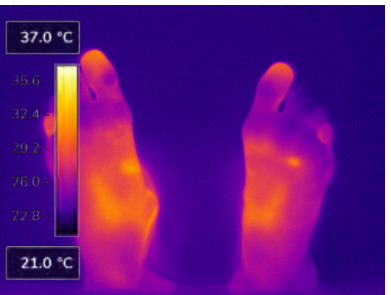

$21.0^{\circ} \mathrm{C}$

M2

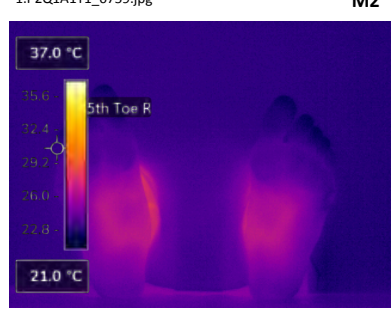

Measurements

5th Toe R

3.P2M2A3T3_0795.jpg

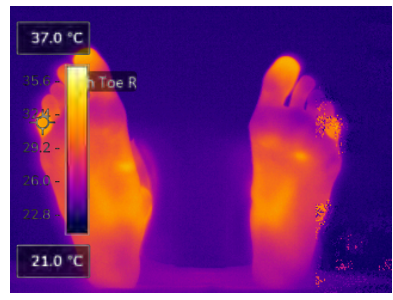

Measurements

\begin{tabular}{l|l}
\hline Sth Toe R & $32.0^{\circ} \mathrm{C}$
\end{tabular} 
P2

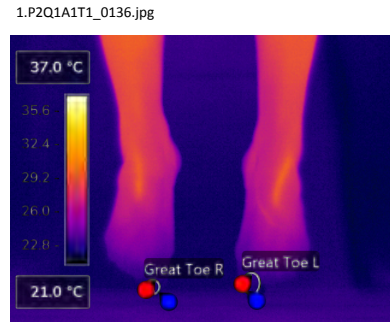

Measurements

Great Toe R

Avg

Avg

Avg

4.P2M3A4T4_0046.jpg

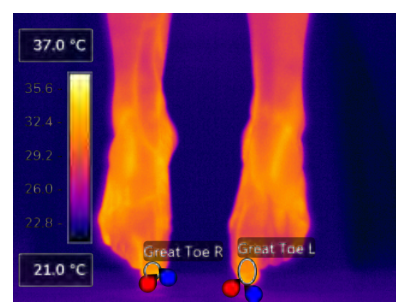

Measurements

Great Toe L

Avg

Avg

$31.6^{\circ} \mathrm{C}$

$32.2^{\circ} \mathrm{C}$

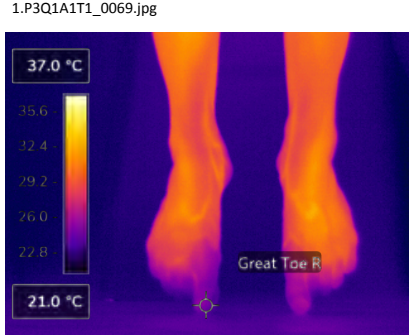

Measurements Great Toe $\mathbf{R}$

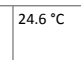

2.P3M1A2T2_0085.jpg

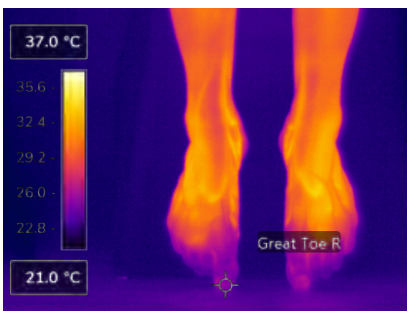

Measurements Great Toe R

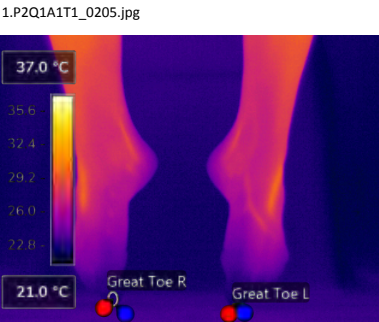

Measurements

Great Toe R

Avg

Great Toe L

Avg

4.P2M3A4T4_0136.jpg

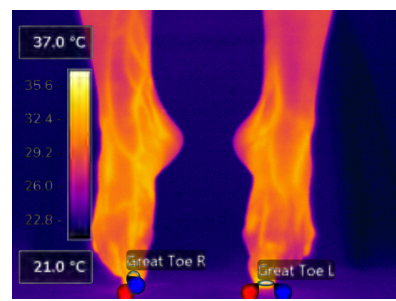

Measurements

Great Toe R

Avg

Great Toe

Avg

1.P3Q1A1T1_0264.jpg

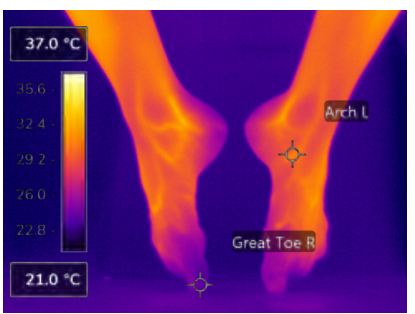

Measurements

\begin{tabular}{l|l}
\hline Great Toe R & $24.1{ }^{\circ} \mathrm{C}$ \\
\hline & $310^{\circ} \mathrm{C}$
\end{tabular}

Arch L

2.P3M1A2T2_0434.jpg

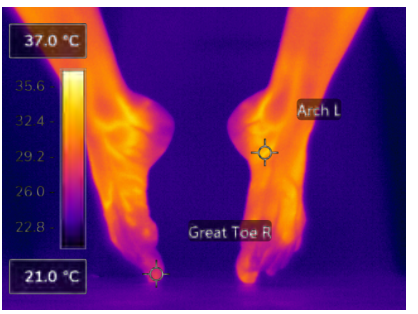

Measurements

\begin{tabular}{l|l}
\hline Great Toe R & $28.3^{\circ} \mathrm{C}$
\end{tabular}

Arch

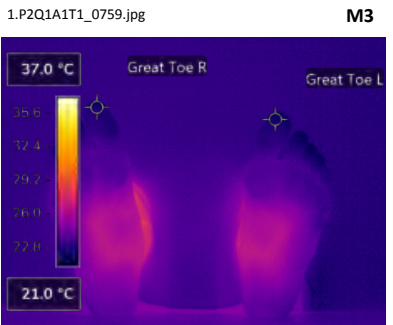

Measurements

\begin{tabular}{l|l}
\hline Great Toe R & $22.3^{\circ} \mathrm{C}$ \\
\hline
\end{tabular}

$\begin{array}{ll}\text { Great Toe L } & 22.3^{\circ} \mathrm{C}\end{array}$

4.P2M3A4T4_0676.jpg

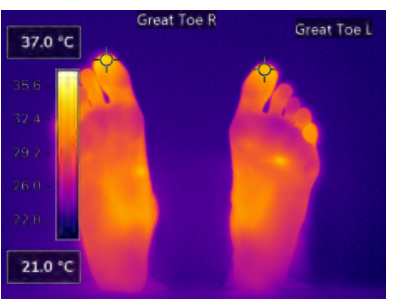

Measurements

\begin{tabular}{l|l} 
Great Toe $\mathbf{R}$ & $33.7^{\circ} \mathrm{C}$ \\
&
\end{tabular}

$\begin{array}{ll}\text { Great Toe L } & 33.1^{\circ} \mathrm{C}\end{array}$

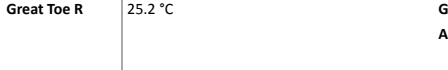

ard

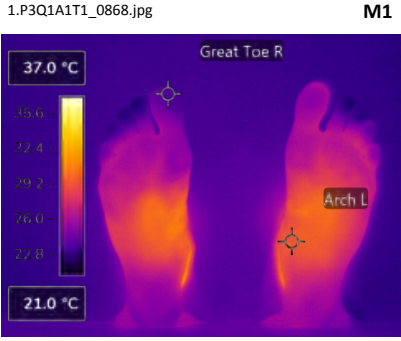

Measurements

\begin{tabular}{l|l}
\hline Great Toe R & $23.6^{\circ} \mathrm{C}$
\end{tabular}

Arch L

2.P3M1A2T2_0816.jpg

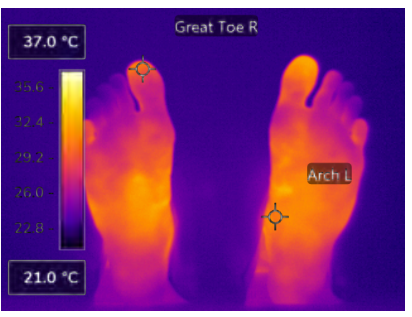

Measurements

\begin{tabular}{ll}
\hline Great Toe R & $29.9^{\circ} \mathrm{C}$ \\
\hline
\end{tabular}

Arch L

M1 
P3

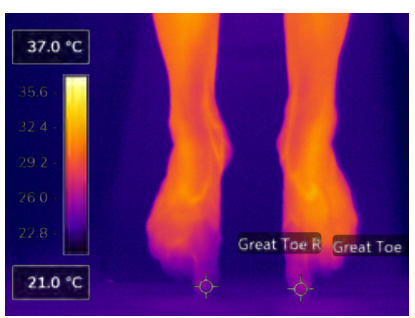

Measurements

\begin{tabular}{l|l}
\hline Great Toe R & $24.6^{\circ} \mathrm{C}$ \\
C &
\end{tabular}

Great Toe

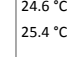

3.P3M2A3T3_0151.jpg

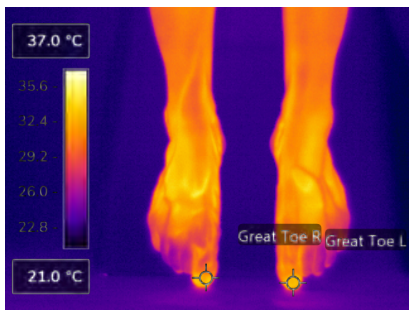

Measurements

Great Toe R

Great Toe L

$32.6^{\circ} \mathrm{C}$

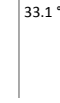

1.P3Q1A1T1_0264.jpg

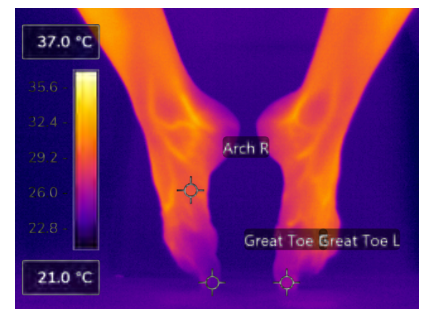

Measurements

\begin{tabular}{l|l}
\hline Great Toe R & $24.1^{\circ} \mathrm{C}$ \\
Arch R & $29.1^{\circ} \mathrm{C}$ \\
\hline
\end{tabular}

$\begin{array}{ll}\text { Great Toe L } & 25.7^{\circ} \mathrm{C}\end{array}$

3.РзМ2АЗТ3_0311.jpg

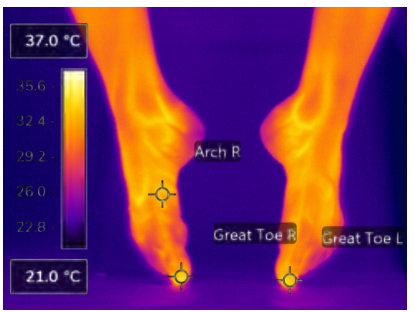

Measurements

\begin{tabular}{l|l}
\hline Great Toe R & $34.3^{\circ} \mathrm{C}$ \\
\hline & $32.4^{\circ} \mathrm{C}$
\end{tabular}

$\begin{array}{ll}\text { Arch R } & 32.4^{\circ} \mathrm{C}\end{array}$

$\begin{array}{ll}\text { Great Toe L } & 33.6^{\circ} \mathrm{C}\end{array}$

1.P3Q1A1T1_0264.jpg

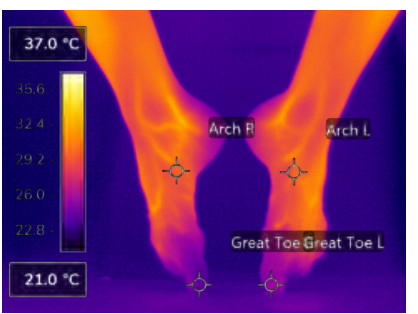

Measurements

\begin{tabular}{l|l} 
Great Toe R & $24.1^{\circ} \mathrm{C}$ \\
\hline & $298^{\circ} \mathrm{C}$
\end{tabular}

\begin{tabular}{l|l} 
Arch R & $29.8^{\circ} \mathrm{C}$ \\
Arch L & $30.0^{\circ} \mathrm{C}$
\end{tabular}

4.P3M3A4T4_0320.jpg

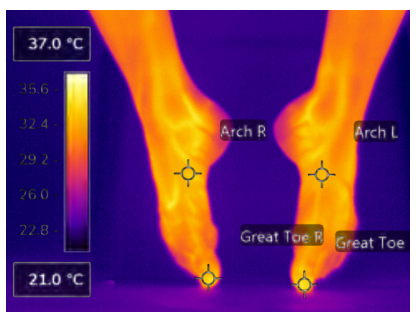

Measurements

\begin{tabular}{l|l} 
Great Toe R & $34.1^{\circ} \mathrm{C}$
\end{tabular}

\begin{tabular}{l|l} 
Arch R & $33.5^{\circ} \mathrm{C}$
\end{tabular}

\begin{tabular}{ll} 
Great Toe L & $34.4^{\circ} \mathrm{C}$ \\
\hline
\end{tabular}

\begin{tabular}{l|l} 
Arch L & $32.9^{\circ} \mathrm{C}$
\end{tabular}
1.P3Q1A1T1_0868.jpg

M2

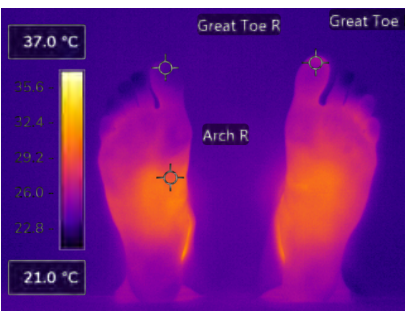

Measurements

\begin{tabular}{l|l}
\hline Great Toe R & $23.6^{\circ} \mathrm{C}$
\end{tabular}

\begin{tabular}{l|l}
\hline Arch R & $29.2^{\circ} \mathrm{C}$ \\
\hline
\end{tabular}

$\begin{array}{ll}\text { Great Toe L } & 25.6^{\circ} \mathrm{C}\end{array}$

3.Р3М2A3T3_0825.jpg

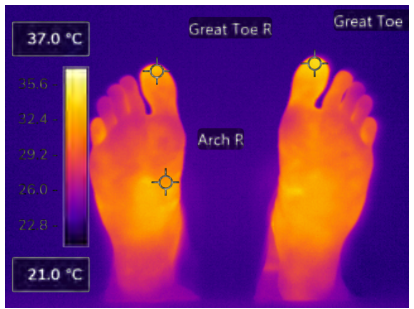

Measurements

\begin{tabular}{l|l}
\hline Great Toe R & $32.9^{\circ} \mathrm{C}$
\end{tabular}

$\begin{array}{lll}\text { Arch R } & 31.5^{\circ} \mathrm{C} \\ & & \end{array}$

$\begin{array}{ll}\text { Great Toe L } & 34.3^{\circ} \mathrm{C}\end{array}$

1.P3Q1A1T1_0868.jpg

M3

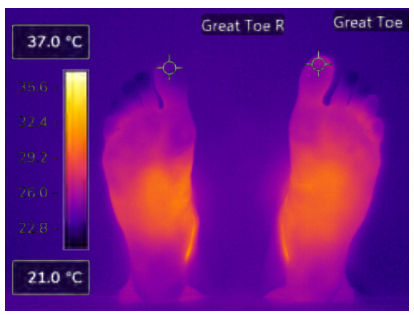

Measurements

\begin{tabular}{l|l}
\hline Great Toe R & $23.6^{\circ} \mathrm{C}$ \\
Great Toe L & $25.4^{\circ} \mathrm{C}$
\end{tabular}

4.P3M3A4T4_1116.jpg

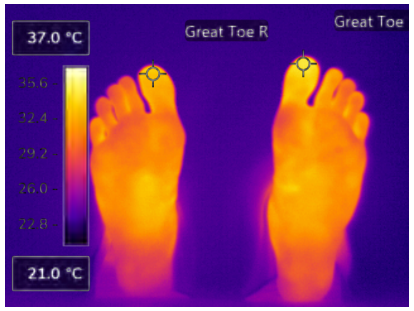

Measurements

\begin{tabular}{l|l}
\hline Great Toe R & $33.4^{\circ} \mathrm{C}$ \\
\hline Ge
\end{tabular}

\begin{tabular}{l|l}
\hline Great Toe L & $35.1^{\circ} \mathrm{C}$
\end{tabular} \begin{tabular}{l|l}
\hline Great Toe R & $32.2^{\circ} \mathrm{C}$ \\
\hline
\end{tabular}

Great Toe L 


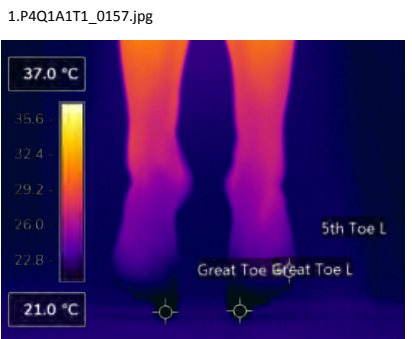

Measurements

\begin{tabular}{l|l}
\hline Great Toe R & $20.9^{\circ} \mathrm{C}$ \\
& $22.4^{\circ} \mathrm{C}$
\end{tabular}

\begin{tabular}{l|l} 
5th Toe L & $22.4^{\circ} \mathrm{C}$
\end{tabular}

Great Toe L

1.P4Q1A1T1_0273.jpg

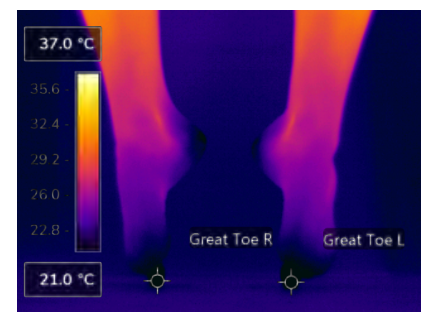

Measurements

\begin{tabular}{l|l}
\hline Great Toe R & $20.7^{\circ} \mathrm{C}$
\end{tabular}

$\begin{array}{ll}\text { Great Toe L } & 20.7^{\circ} \mathrm{C}\end{array}$

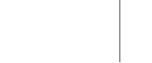

2.P4M1A2T2_0466.jpg

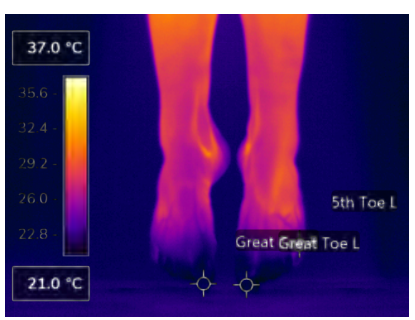

Measurements

\begin{tabular}{l|l}
\hline Great Toe R & $21.9^{\circ} \mathrm{C}$ \\
\hline 5 & $23 .{ }^{\circ} \mathrm{C}$
\end{tabular}

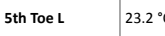

\begin{tabular}{l|l} 
Great Toe L & $21.7^{\circ} \mathrm{C}$
\end{tabular}

P4

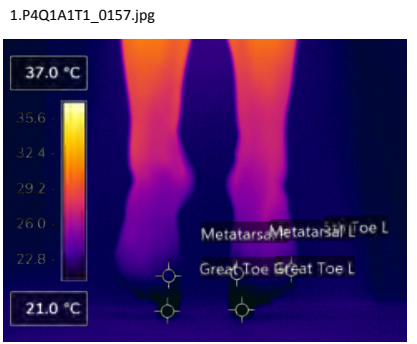

Measurements

\begin{tabular}{l|l}
\hline Great Toe R & $20.9^{\circ} \mathrm{C}$ \\
Metatarsal R & $22.0^{\circ} \mathrm{C}$ \\
\hline & $20.7{ }^{\circ} \mathrm{C}$
\end{tabular}

\begin{tabular}{l|l} 
Great Toe L & $20.7^{\circ} \mathrm{C}$ \\
&
\end{tabular}

\begin{tabular}{l|l} 
5th Toe L & $22.4^{\circ} \mathrm{C}$ \\
Metatarsal L & $22.0^{\circ} \mathrm{C}$
\end{tabular}

3.P4M2A3T3_0196.jpg

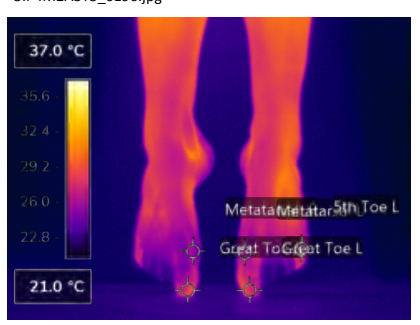

Measurements

\begin{tabular}{l|l}
\hline Metatarsal R & $25.7^{\circ} \mathrm{C}$ \\
\hline
\end{tabular}

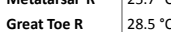

$\begin{array}{ll}\text { Metatarsal L } & 26.3^{\circ} \mathrm{C} \\ & \end{array}$

$\begin{array}{ll}\text { Great Toe L } & 27.6^{\circ} \mathrm{C} \\ & 27.3^{\circ} \mathrm{C}\end{array}$

\begin{tabular}{l|l} 
5th Toe L & $27.3^{\circ} \mathrm{C}$
\end{tabular}

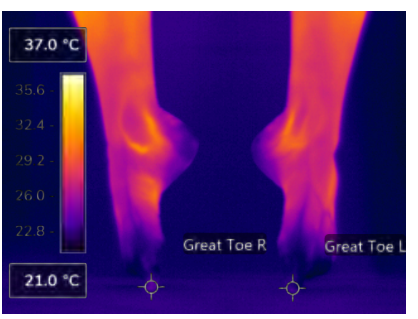

Measurements

\begin{tabular}{l|l}
\hline Great Toe R & $24.0^{\circ} \mathrm{C}$ \\
\hline
\end{tabular}

$\begin{array}{ll}\text { Great Toe L } & 22.9^{\circ} \mathrm{C}\end{array}$

1.P4Q1A1T1_0273.jpg

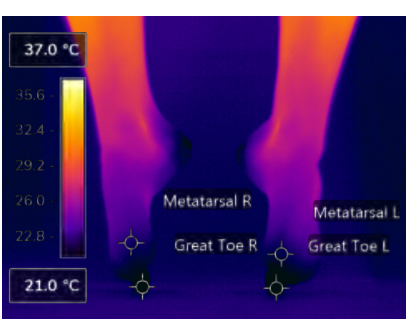

Measurements

\begin{tabular}{l|l}
\hline Great Toe R & $20.7^{\circ} \mathrm{C}$
\end{tabular}

\begin{tabular}{l|l}
\hline Metatarsal R & $22.2^{\circ} \mathrm{C}$ \\
& $21.9^{\circ} \mathrm{C}$
\end{tabular}

$\begin{array}{ll}\text { Metatarsal L } & 21.9^{\circ} \mathrm{C}\end{array}$

\begin{tabular}{l|l} 
Great Toe L & $20.7^{\circ} \mathrm{C}$
\end{tabular}

3.P4M2A3T3_0416.jpg

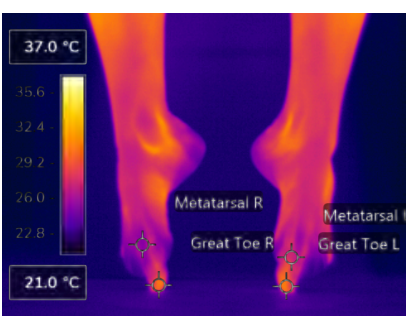

Measurements

\begin{tabular}{l|l} 
Metatarsal R & $25.1^{\circ} \mathrm{C}$
\end{tabular}

\begin{tabular}{l|l} 
Great Toe R & $30.5^{\circ} \mathrm{C}$ \\
Great Toe L & $30.2^{\circ} \mathrm{C}$
\end{tabular}

\begin{tabular}{l|l} 
Metatarsal L & $27.6{ }^{\circ} \mathrm{C}$
\end{tabular}
1.P4Q1A1T1_0646.jpg

M1

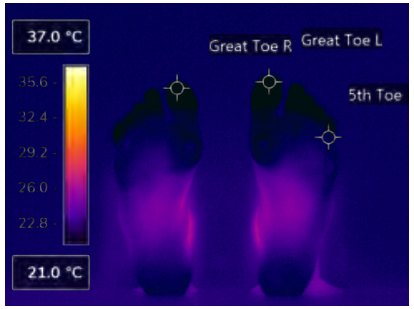

Measurements

\begin{tabular}{l|l}
\hline Great Toe R & $20.8^{\circ} \mathrm{C}$ \\
\hline
\end{tabular}

\begin{tabular}{l|l} 
Great Toe R & $20.8^{\circ} \mathrm{C}$ \\
5th Toe L & $21.9^{\circ} \mathrm{C}$
\end{tabular}

\begin{tabular}{l|l} 
Great Toe L & $20.3^{\circ} \mathrm{C}$
\end{tabular}

2.P4M1A2T2 0902.jpg

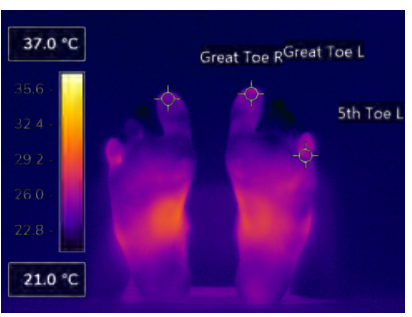

Measurements

\begin{tabular}{l|l}
\hline Great Toe R & $24.4^{\circ} \mathrm{C}$ \\
\hline
\end{tabular}

\begin{tabular}{l|l} 
5th Toe L & $25.2^{\circ} \mathrm{C}$ \\
Great Toe L & $24.9^{\circ} \mathrm{C}$
\end{tabular}

1.P4Q1A1T1_0646.jpg

M2

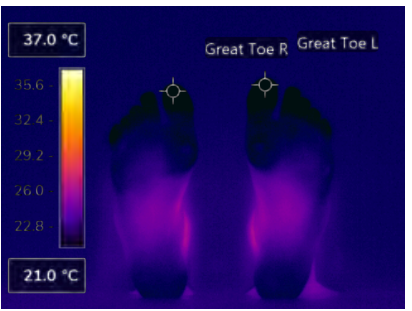

Measurements

\begin{tabular}{l|l}
\hline Great Toe R & $20.8^{\circ} \mathrm{C}$ \\
\hline
\end{tabular}

$\begin{array}{lll}\text { Great Toe L } & 20.3^{\circ} \mathrm{C}\end{array}$

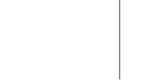

3.Р4M2A3T3 0997.jp

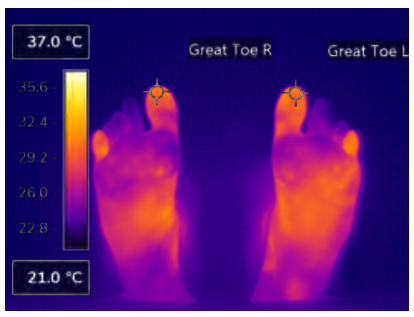

Measurements

\begin{tabular}{l|l}
\hline Great Toe R & $30.7^{\circ} \mathrm{C}$
\end{tabular}

\begin{tabular}{ll} 
Great Toe L $\quad 30.5^{\circ} \mathrm{C}$ & \\
\hline
\end{tabular} 


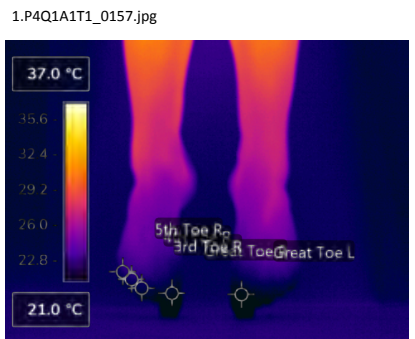

Measurements

\begin{tabular}{l|l}
\hline Great Toe R & $21.3^{\circ} \mathrm{C}$ \\
\hline th & $22 .{ }^{\circ} \mathrm{C}$
\end{tabular}

\begin{tabular}{lll} 
4th Toe $\mathrm{R}$ & $22.3^{\circ} \mathrm{C}$ \\
\hline
\end{tabular}

\begin{tabular}{l|l} 
5th Toe R & $22.3^{\circ} \mathrm{C}$ \\
&
\end{tabular}

\begin{tabular}{ll} 
3rd Toe R & $21.9^{\circ} \mathrm{C}$ \\
\hline &
\end{tabular}

$\begin{array}{ll}\text { Great Toe } \mathrm{L} & 21.0^{\circ} \mathrm{C}\end{array}$

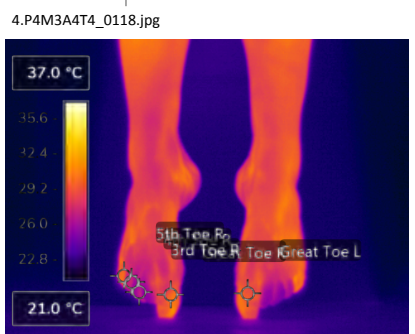

Measurements

\begin{tabular}{l|l}
\hline Great Toe R & $30.0^{\circ} \mathrm{C}$
\end{tabular}

$\begin{array}{ll}\text { 4th Toe R } & 27.2^{\circ} \mathrm{C}\end{array}$

$29.8^{\circ} \mathrm{C}$

\begin{tabular}{l|l} 
Great Toe L & $29.4^{\circ} \mathrm{C}$ \\
3rd Toe R & $27.0^{\circ} \mathrm{C}$
\end{tabular}

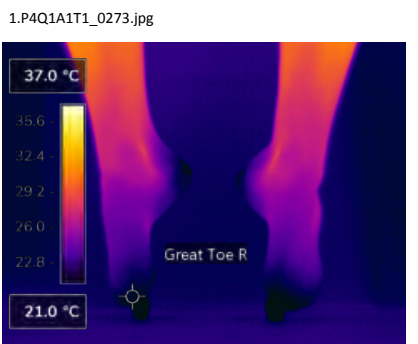

1.P4Q1A1T1_0646.jpg

M3

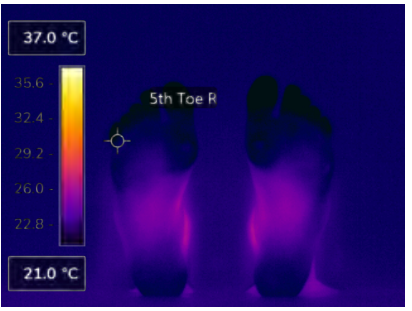

Measurements

\begin{tabular}{l|l}
\hline Great Toe R & $21.2^{\circ} \mathrm{C}$
\end{tabular}

Measurements

\begin{tabular}{l|l}
\hline 5th Toe R & $21.6^{\circ} \mathrm{C}$
\end{tabular}

4.P4M3A4T4_0283.jpg

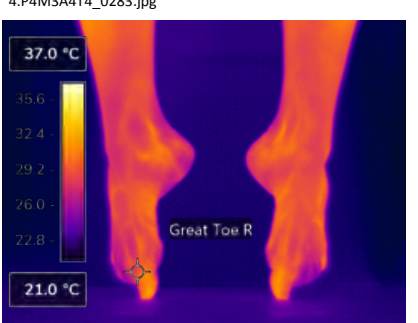

Measurements

\begin{tabular}{l|l}
\hline Great Toe R & $29.2^{\circ} \mathrm{C}$
\end{tabular}

$21.6^{\circ} \mathrm{C}$

4.P4M3A4T4_0736.jpg

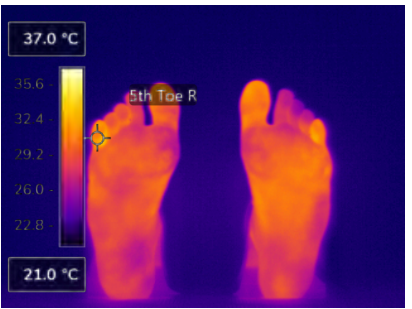

Measurements

\begin{tabular}{l|l}
\hline 5th Toe R & $31.6^{\circ} \mathrm{C}$
\end{tabular}

1.P5Q1A1T1_0619.jpg

M1
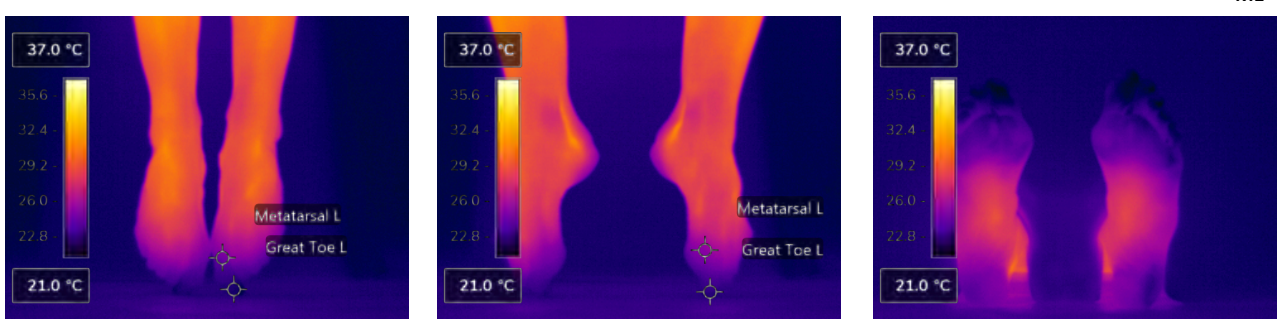

Measurements

\begin{tabular}{l|l} 
Metatarsal L & $24.5^{\circ} \mathrm{C}$ \\
& $225^{\circ} \mathrm{C}$
\end{tabular}

Measurements

\begin{tabular}{l|l}
\hline Great Toe L & $22.8^{\circ} \mathrm{C}$ \\
\hline
\end{tabular}

\begin{tabular}{l|l} 
Metatarsal L & $25.2^{\circ} \mathrm{C}$
\end{tabular}
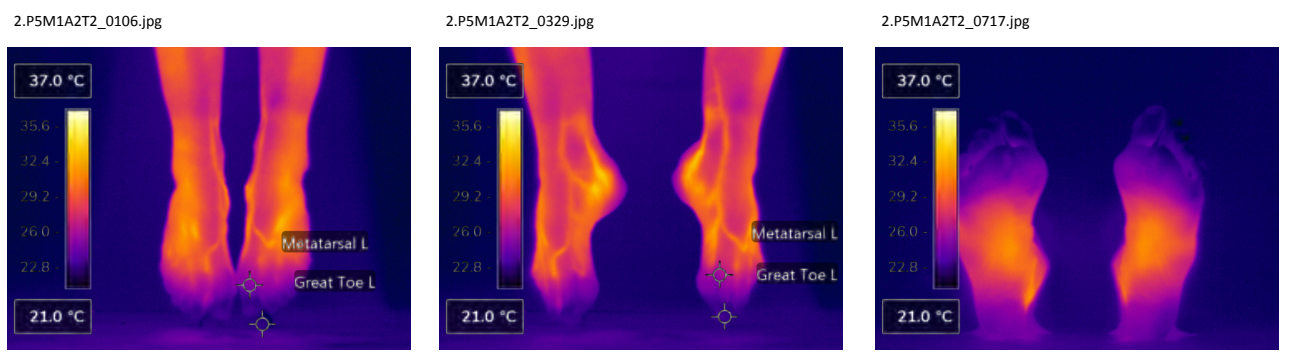

Measurements

\begin{tabular}{l|l} 
Great Toe $\mathrm{L}$ & $22.9^{\circ} \mathrm{C}$ \\
&
\end{tabular}

Measurements

\begin{tabular}{l|l}
\hline Great Toe L & $23.2^{\circ} \mathrm{C}$ \\
\hline
\end{tabular}

Metatarsal L $25.0^{\circ} \mathrm{C}$

$\begin{array}{ll}\text { Metatarsal L } & 26.0^{\circ} \mathrm{C}\end{array}$ 

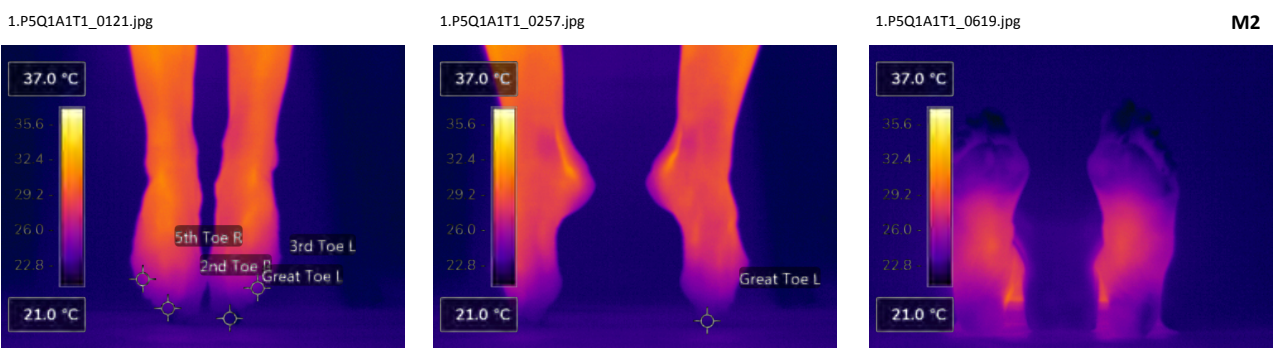

Measurements

Measurements

\begin{tabular}{l|l}
\hline 2nd Toe R & $23.4^{\circ} \mathrm{C}$ \\
\hline Sth & $249^{\circ} \mathrm{C}$
\end{tabular}

\begin{tabular}{ll} 
5th Toe R & $24.9^{\circ} \mathrm{C}$ \\
\hline
\end{tabular}

$\begin{array}{ll}\text { Great Toe L } & 22.5^{\circ} \mathrm{C}\end{array}$

3rd Toe L

\begin{tabular}{l|l}
\hline Great Toe L & $22.8^{\circ} \mathrm{C}$
\end{tabular}

3.Р5М2A3T3_0085.jpg

3.P5M2A3T3_0185.jpg

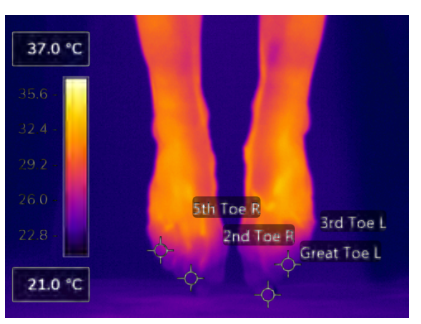

Measurements

\begin{tabular}{l|l}
\hline 2nd Toe $R$ & $23.2^{\circ} \mathrm{C}$ \\
\hline & $25.4^{\circ} \mathrm{C}$
\end{tabular}

\begin{tabular}{l|l} 
5th Toe $\mathrm{R}$ & $25.4^{\circ} \mathrm{C}$ \\
\hline
\end{tabular}

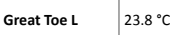

\begin{tabular}{l|l} 
3rd Toe L & $23.6^{\circ} \mathrm{C}$
\end{tabular}

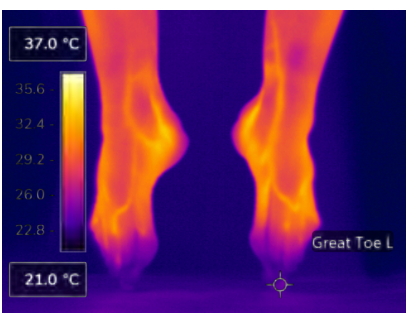

\begin{tabular}{l} 
Measurements \\
\hline Great Toe L $24.1^{\circ} \mathrm{C}$
\end{tabular}
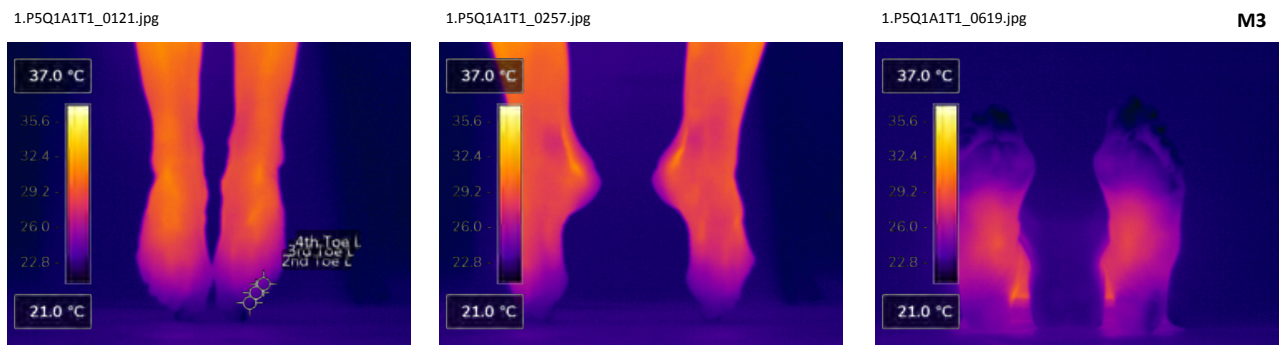

Measurements

\begin{tabular}{l|l}
\hline 4th Toe $\mathrm{L}$ & $24.2^{\circ} \mathrm{C}$
\end{tabular}

\begin{tabular}{l|l} 
2nd Toe L & $23.0^{\circ} \mathrm{C}$ \\
3rd Toe L & $23.9^{\circ} \mathrm{C}$
\end{tabular}

4.P5M3A4T4_0095.jpg
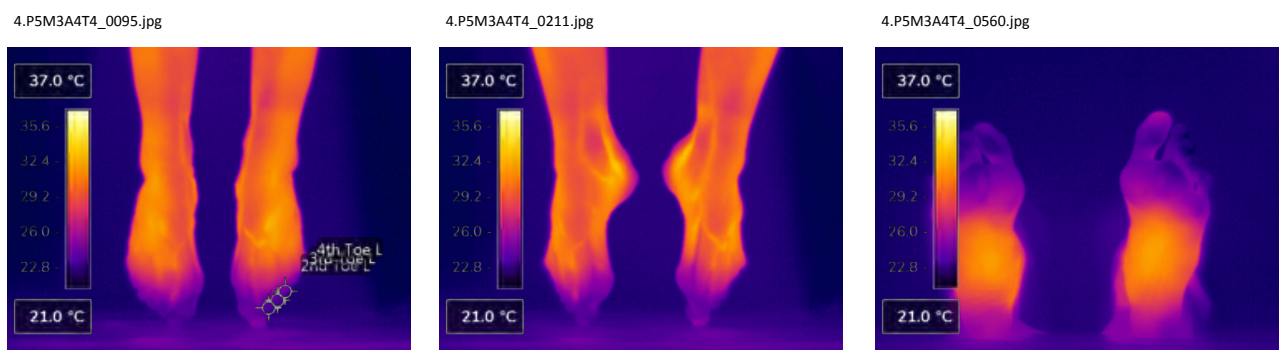

Measurements

\begin{tabular}{l|l}
\hline 4th Toe $\mathrm{L}$ & $24.2^{\circ} \mathrm{C}$ \\
\hline
\end{tabular}

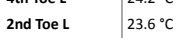

$23.8^{\circ} \mathrm{C}$ 


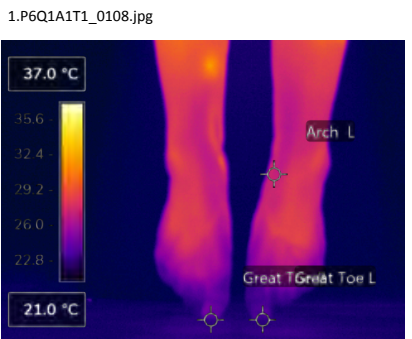

Measurements

\begin{tabular}{l|l}
\hline Great Toe R & $23.1^{\circ} \mathrm{C}$ \\
C &
\end{tabular}

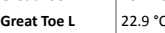

Arch L

1.P6Q1A1T1_0205.jpg

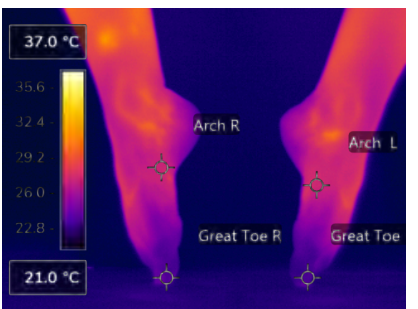

Measurements

\begin{tabular}{l|l}
\hline Great Toe R & $23.6^{\circ} \mathrm{C}$
\end{tabular}

\begin{tabular}{l|l}
\hline Great Toe R & $23.6^{\circ} \mathrm{C}$ \\
Arch R & $27.5^{\circ} \mathrm{C}$ \\
\hline
\end{tabular}

\begin{tabular}{ll} 
Great Toe $\mathrm{L}$ & $23.6^{\circ} \mathrm{C}$ \\
\hline & $27.6^{\circ} \mathrm{C}$
\end{tabular}

\begin{tabular}{l|l} 
Arch L & $27.6^{\circ} \mathrm{C}$
\end{tabular}

1.P6Q1A1T1_0639.jpg

M1

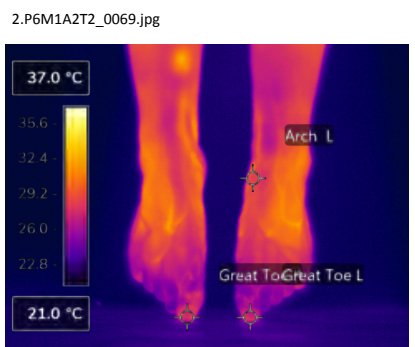

2.P6M1A2T2_0197.jpg

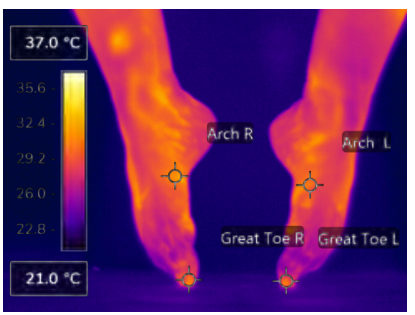

Measurements

\begin{tabular}{l|l}
\hline Great Toe R & $30.6^{\circ} \mathrm{C}$ \\
Arch R & $31.7^{\circ} \mathrm{C}$ \\
\hline
\end{tabular}

\begin{tabular}{l|l} 
Great Toe L & $30.4^{\circ} \mathrm{C}$
\end{tabular}

Arch L

$30.5^{\circ} \mathrm{C}$

1.P6Q1A1T1_0205.jpg

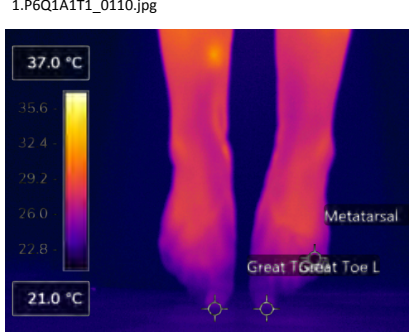

Measurements

\begin{tabular}{l|l}
\hline Great Toe R & $23.1^{\circ} \mathrm{C}$ \\
\hline
\end{tabular}

Great Toe L

$\begin{array}{ll}\text { Metatarsal L } & 25.1^{\circ} \mathrm{C}\end{array}$

3.P6M2A3T3_0144.jpg

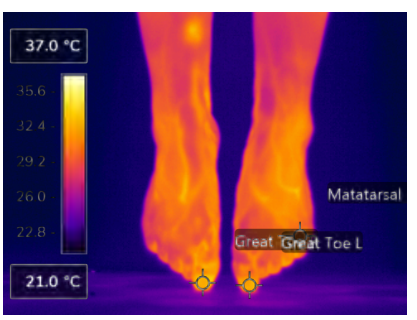

Measurements

\begin{tabular}{l|l}
\hline Great Toe R & $32.5^{\circ} \mathrm{C}$ \\
\hline
\end{tabular}

$\begin{array}{ll}\text { Matatarsal L } & 30.3^{\circ} \mathrm{C}\end{array}$

$\begin{array}{ll}\text { Great Toe L } & 32.4^{\circ} \mathrm{C}\end{array}$

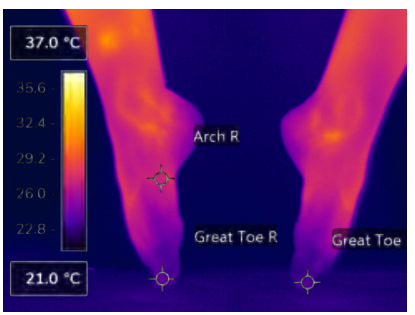

Measurements

\begin{tabular}{l|l}
\hline Great Toe R & $24.1^{\circ} \mathrm{C}$ \\
\hline & $2.5^{\circ} \mathrm{C}$
\end{tabular}

\begin{tabular}{l|l} 
Arch R & $27.5^{\circ} \mathrm{C}$ \\
Great Toe L & $23.4^{\circ} \mathrm{C}$
\end{tabular}

3.P6M2A3T3_0336.jpg

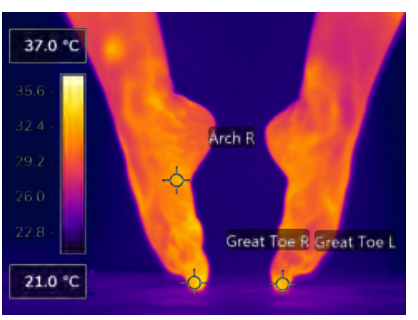

3.P6M2A3T3_0670.jpg

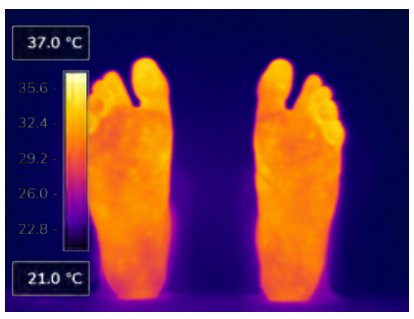

Measurements

\begin{tabular}{l|l}
\hline Great Toe $\mathbf{R}$ & $33.0^{\circ} \mathrm{C}$ \\
\hline
\end{tabular}

\begin{tabular}{l|l} 
Arch R & $32.7^{\circ} \mathrm{C}$ \\
\end{tabular}

$\begin{array}{ll}\text { Great Toe L } & 33.0^{\circ} \mathrm{C}\end{array}$
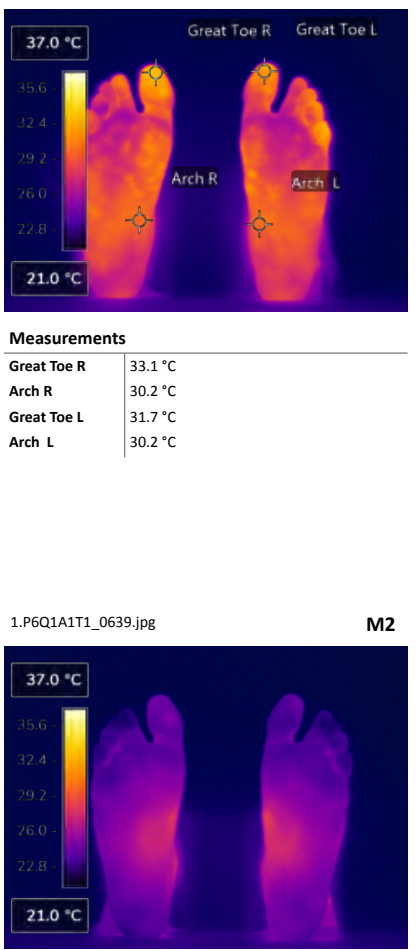

Measurements

\begin{tabular}{l|l}
\hline Great Toe R & $33.1^{\circ} \mathrm{C}$ \\
\hline
\end{tabular}

\begin{tabular}{l|l}
\hline Arch R & $30.2^{\circ} \mathrm{C}$ \\
\hline Ge
\end{tabular}

Great Toe L $\quad 31.7^{\circ} \mathrm{C}$
A

$\begin{array}{ll}\text { Arch L } & 30.2^{\circ} \mathrm{C}\end{array}$

$21.0 \mathrm{C}$ 


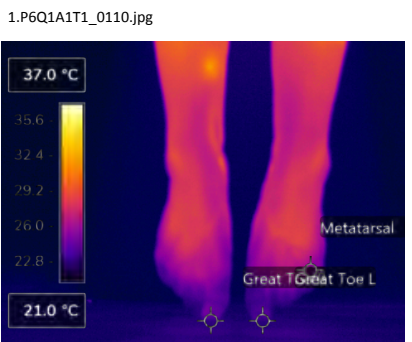

1.P6Q1A1T1_0205.jpg

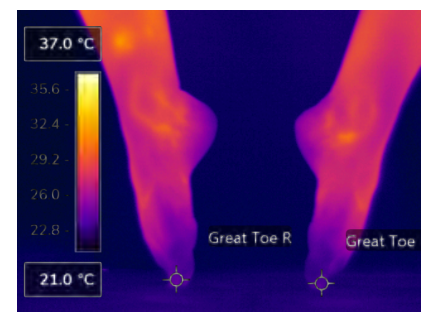

Measurements

Measurements

\begin{tabular}{l|l}
\hline Great Toe R & $23.11^{\circ} \mathrm{C}$ \\
& Geat Toe
\end{tabular}

Great Toe L $\quad 22.9^{\circ} \mathrm{C}$
Ge

\begin{tabular}{l|l} 
Metatarsal L & $25.1^{\circ} \mathrm{C}$
\end{tabular}

4.P6M3A4T4_0167.jpg

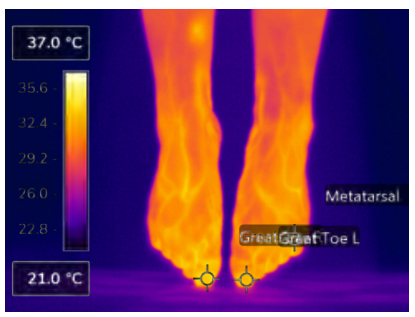

Measurements

\begin{tabular}{l|l}
\hline Great Toe R & $33.6^{\circ} \mathrm{C}$ \\
\hline
\end{tabular}

\begin{tabular}{ll} 
Great Toe L $\quad 32.9^{\circ} \mathrm{C}$ \\
\hline
\end{tabular}

Metatarsal

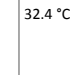

\begin{tabular}{l|l}
\hline Great Toe R & $24.1^{\circ} \mathrm{C}$ \\
\hline
\end{tabular}

\begin{tabular}{ll} 
Great Toe $\mathrm{L} \quad 23.4^{\circ} \mathrm{C}$ \\
\hline
\end{tabular}

4.P6M3A4T4_0336.jpg

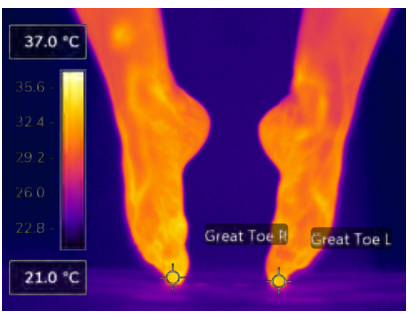

Measurements

\begin{tabular}{l|l} 
Great Toe R & $33.7^{\circ} \mathrm{C}$ \\
\hline
\end{tabular}

\begin{tabular}{ll} 
Great Toe L $\quad 33.5^{\circ} \mathrm{C}$ \\
\hline
\end{tabular}
P7

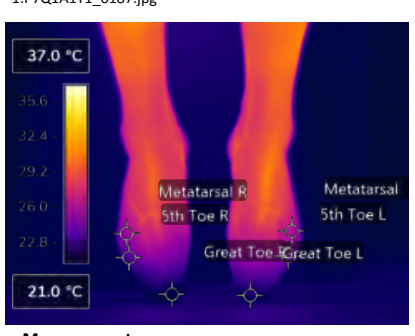

Measurements

\begin{tabular}{l|ll|l|l|l|l|l|l|l|}
\hline Great Toe R & $21.8^{\circ} \mathrm{C}$ & Great Toe $\mathrm{L}$ & $22.4^{\circ} \mathrm{C}$ \\
\hline
\end{tabular}

\begin{tabular}{llll}
\hline 5th Toe R & $23.5^{\circ} \mathrm{C}$ & 5 th Toe $\mathrm{L}$ & $24.3^{\circ} \mathrm{C}$
\end{tabular}

\begin{tabular}{l|ll|l} 
Metatarsal R & $25.7^{\circ} \mathrm{C}$ & Metatarsal L & $26.1^{\circ} \mathrm{C}$
\end{tabular}

2.P7M1A2T2_0193.jpg

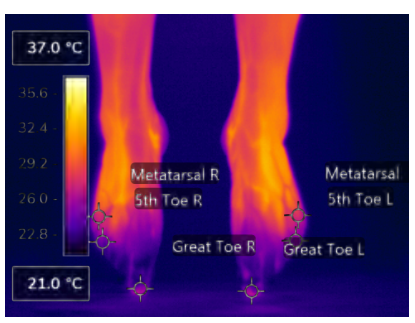

Measurements

\begin{tabular}{l|ll|l}
\hline Great Toe R & $25.2^{\circ} \mathrm{C}$ & Great Toe L & $25.3^{\circ} \mathrm{C}$
\end{tabular}

The $R$

Metatarsal
1.P6Q1A1T1_0639.jpg

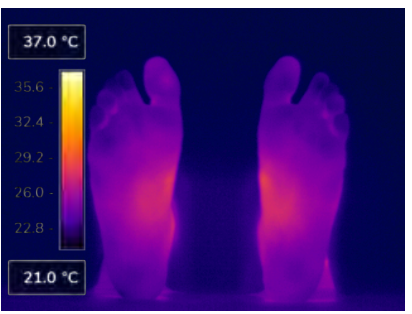

P6M3A4T4_0613.jp

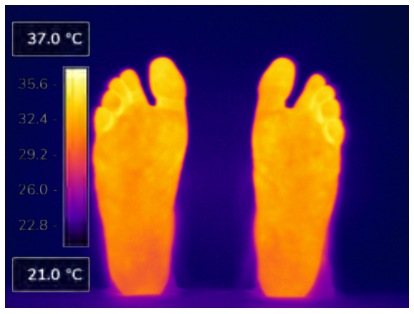

1.P7Q1A1T1_0271.jpg

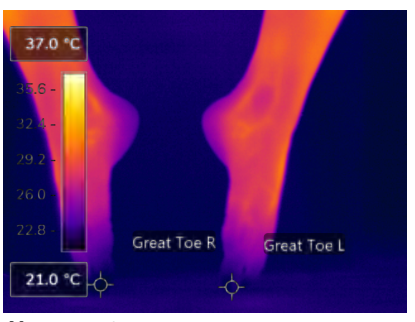

Measurements

\begin{tabular}{l|l}
\hline Great Toe R & $21.5^{\circ} \mathrm{C}$ \\
\hline Get & $22 .{ }^{\circ} \mathrm{C}$
\end{tabular}

$\begin{array}{lll}\text { Great Toe L } & 22.2^{\circ} \mathrm{C}\end{array}$

2.P7M1A2T2_0305.jpg

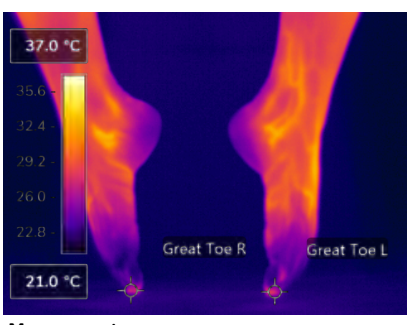

Measurements

\begin{tabular}{l|l}
\hline Great Toe R & $27.1^{\circ} \mathrm{C}$ \\
\hline Geat & $272^{\circ} \mathrm{C}$
\end{tabular}

$\begin{array}{ll}\text { Great Toe L } & 27.2^{\circ} \mathrm{C}\end{array}$
1.P7Q1A1T1_0807.jpg

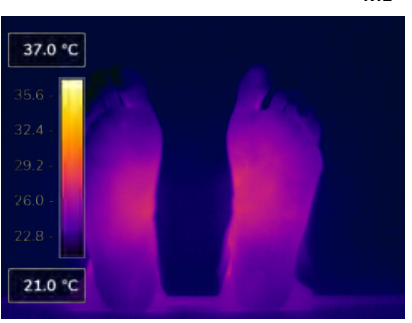

2.P7M1A2T2_0742.jpg

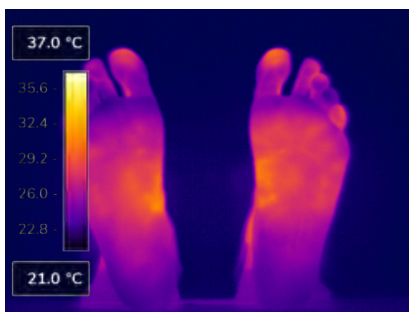




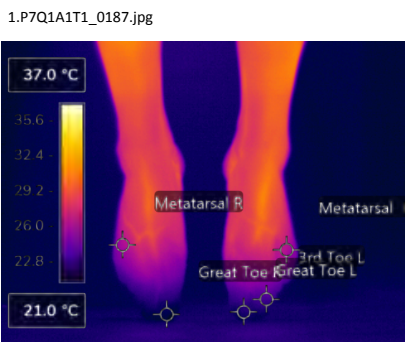

Measurements

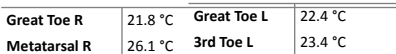

\begin{tabular}{l|ll|l}
\hline Great Toe R & $21.8^{\circ} \mathrm{C}$ & Great Toe $\mathrm{L}$ & $22.4^{\circ} \mathrm{C}$ \\
Metatarsal R & $26.1^{\circ} \mathrm{C}$ & 3rd Toe $\mathrm{L}$ \\
& & $23.4^{\circ} \mathrm{C}$ \\
& & Metatarsal L $\mathrm{L}$ & $26.4^{\circ} \mathrm{C}$
\end{tabular}

3.P7M2A3T3_0344.jpg

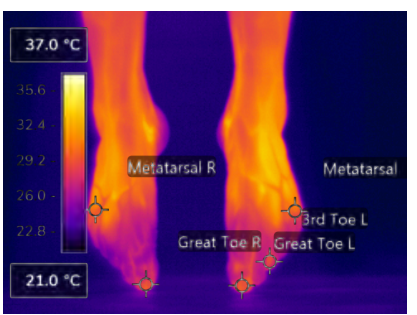

Measurements

\begin{tabular}{l|l|l|l|}
\hline Great Toe R & $29.4^{\circ} \mathrm{C}$ & Great Toe L & $29.3^{\circ} \mathrm{C}$ \\
\hline
\end{tabular}

Metatarsal

\begin{tabular}{|ll|l}
$30.1{ }^{\circ} \mathrm{C}$ & 3rd Toe L & $29.0^{\circ} \mathrm{C}$ \\
& Metatarsal L & $30.2^{\circ} \mathrm{C}$
\end{tabular}

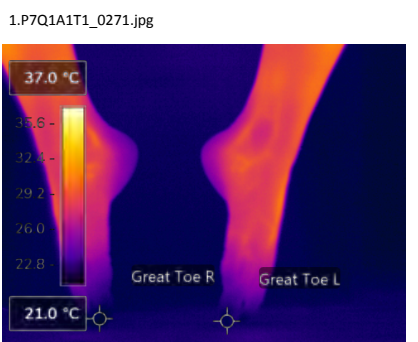

Measurements

\begin{tabular}{l|l}
\hline Great Toe R & $21.5^{\circ} \mathrm{C}$ \\
\hline
\end{tabular}

\begin{tabular}{l|l} 
Great Toe L & $21.7^{\circ} \mathrm{C}$
\end{tabular}

3.P7M2A3T3_0463.jpg

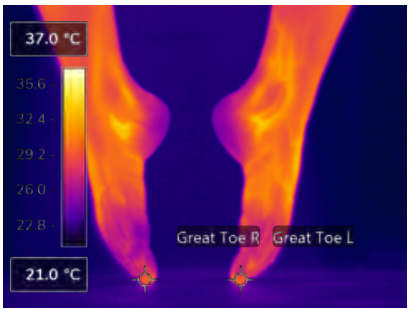

Measurements

\begin{tabular}{l|l} 
Great Toe R & $30.0^{\circ} \mathrm{C}$ \\
& $30.0^{\circ} \mathrm{C}$
\end{tabular}

\begin{tabular}{ll} 
Great Toe L $\quad 30.0^{\circ} \mathrm{C}$ \\
\hline
\end{tabular}

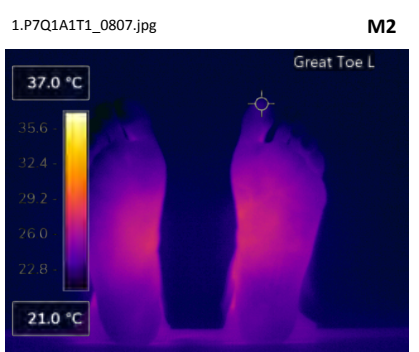

Measurements \begin{tabular}{l|l}
\hline Great Toe L & $22.6^{\circ} \mathrm{C}$
\end{tabular}

3.P7M2A3T3_0984.jpg

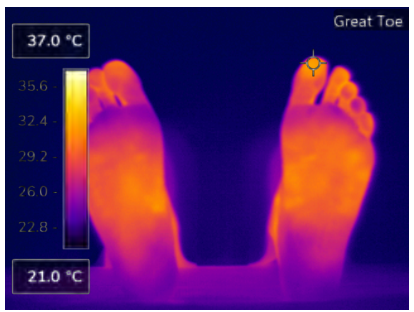

Measurements

\begin{tabular}{l|l}
\hline Great Toe L & $32.0^{\circ} \mathrm{C}$
\end{tabular}

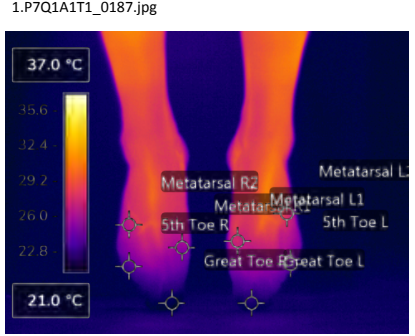

Measurements

\begin{tabular}{l|ll|l}
\hline Great Toe R & $21.8^{\circ} \mathrm{C}$ & Great Toe $\mathrm{L}$ & $22.4^{\circ} \mathrm{C}$ \\
& $23.5^{\circ} \mathrm{C}$ & 5 th Toe & $24 .{ }^{\circ} \mathrm{C}$
\end{tabular}

\begin{tabular}{l|lll} 
5th Toe R & $23.5^{\circ} \mathrm{C}$ & 5 th Toe $\mathrm{L}$ & $24.3^{\circ} \mathrm{C}$
\end{tabular}

\begin{tabular}{l|lll} 
Metatarsal R1 & $25.5^{\circ} \mathrm{C}$ & Metatarsal L1 & $27.8^{\circ} \mathrm{C}$
\end{tabular} $\begin{array}{llll}\text { Metatarsal R2 } & 27.0^{\circ} \mathrm{C} & \text { Metatarsal L2 } & 28.1^{\circ} \mathrm{C}\end{array}$

4.P7M3A4T4_0167.jpg

1.P7Q1A1T1_0271.jpg

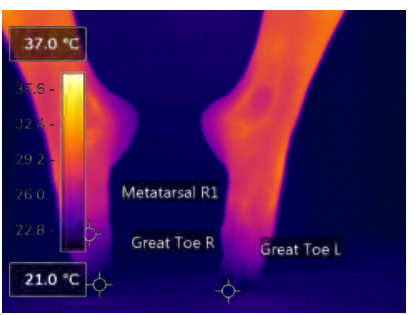

Measurements

\begin{tabular}{l|l}
\hline Metatarsal R1 & $24.6^{\circ} \mathrm{C}$ \\
\hline
\end{tabular}

\begin{tabular}{l|l|l}
\hline Great Toe R & $21.5^{\circ} \mathrm{C}$ \\
\hline Get & $22.0^{\circ} \mathrm{C}$
\end{tabular}

$\begin{array}{ll}\text { Great Toe L } & 22.0^{\circ} \mathrm{C}\end{array}$

4.P7M3A4T4_0319.jpg

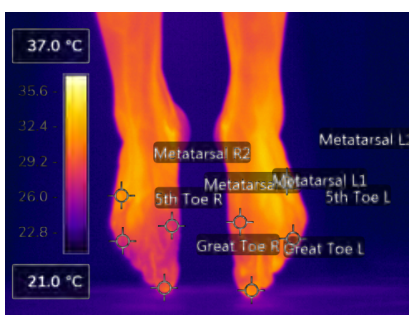

Measurements

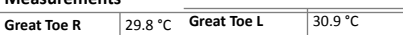

5th Toe R

(29. $24^{\circ} \mathrm{C}$

$\begin{array}{llll}\text { Metatarsal R2 } & 31.7^{\circ} \mathrm{C} & \text { Metatarsal L2 } & 31.5^{\circ} \mathrm{C}\end{array}$

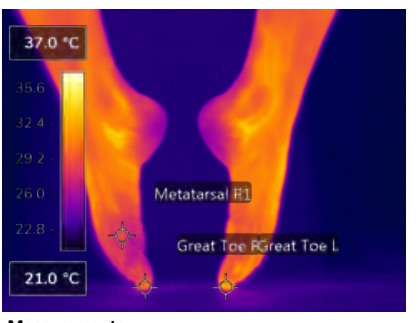

Measurements

\begin{tabular}{l|l}
\hline Great Toe R & $30.2^{\circ} \mathrm{C}$ \\
\hline
\end{tabular}

$\begin{array}{lll}\text { Metatarsal R1 } 29.1{ }^{\circ} \mathrm{C} & \\ & \end{array}$

$\begin{array}{ll}\text { Great Toe L } & 32.2^{\circ} \mathrm{C}\end{array}$
1.P7Q1A1T1_0807.jpg

M3

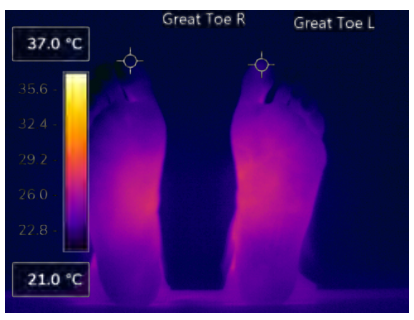

Measurements

\begin{tabular}{l|l}
\hline Great Toe R & $21.5^{\circ} \mathrm{C}$
\end{tabular}

$\begin{array}{ll}\text { Great Toe L } & 22.6^{\circ} \mathrm{C}\end{array}$

4.P7M3A4T4_0784.jpg

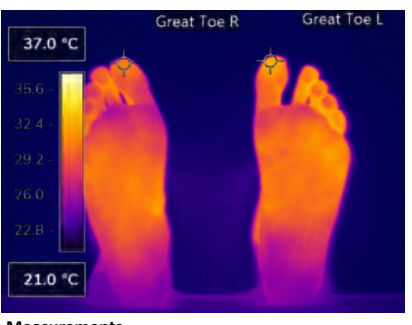

Measurements

\begin{tabular}{l|l} 
Great Toe R & $30.9^{\circ} \mathrm{C}$ \\
\hline
\end{tabular}

$\begin{array}{ll}\text { Great Toe L } 32.5^{\circ} \mathrm{C} & \end{array}$ 


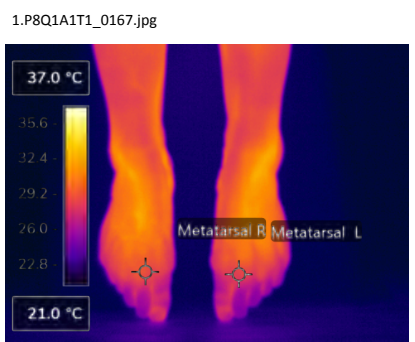

Measurements

\begin{tabular}{l|l} 
Metatarsal R & $29.3^{\circ} \mathrm{C}$
\end{tabular}

\begin{tabular}{l|l} 
Metatarsal L & $28.7^{\circ} \mathrm{C}$
\end{tabular}

2.P8M1A2T2_0075.jpg

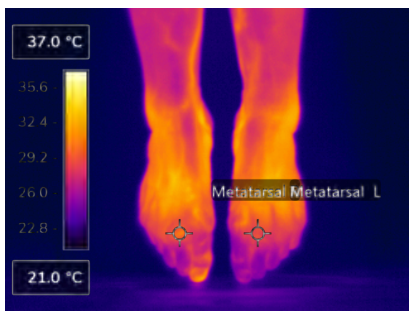

Measurements

\begin{tabular}{l|l} 
Metatarsal R & $30.7^{\circ} \mathrm{C}$
\end{tabular}

$\begin{array}{ll}\text { Metatarsal L } & 29.0^{\circ} \mathrm{C}\end{array}$

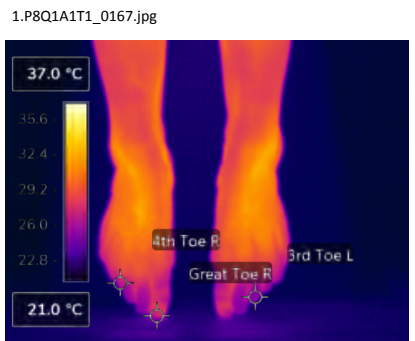

Measurements

\begin{tabular}{l|l}
\hline Great Toe R & $27.2^{\circ} \mathrm{C}$ \\
4th Toe R & $26.7^{\circ} \mathrm{C}$ \\
\hline & $25.1^{\circ} \mathrm{C}$
\end{tabular}

\begin{tabular}{l|l} 
4th Toe R & $26.7^{\circ} \mathrm{C}$ \\
3rd Toe L & $25.1^{\circ} \mathrm{C}$
\end{tabular}

3.Р8M2A3T3_0160.jpg

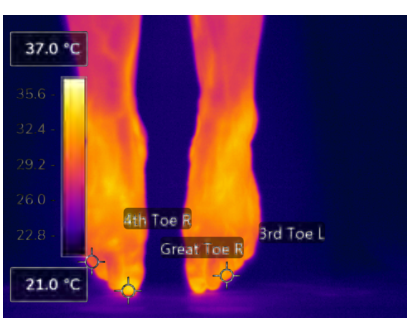

Measurements

\begin{tabular}{l|l}
\hline Great Toe R & $34.0^{\circ} \mathrm{C}$ \\
4th & $29.6^{\circ} \mathrm{C}$
\end{tabular}

4th Toe $R$

3rd Toe L

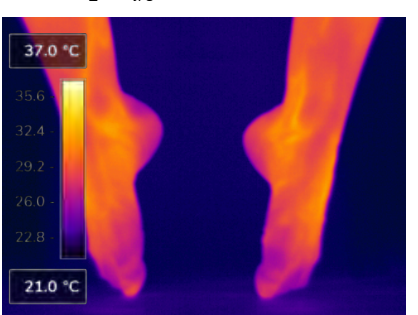

$21.0^{\circ} \mathrm{C}$

2.P8M1A2T2_0321.jpg

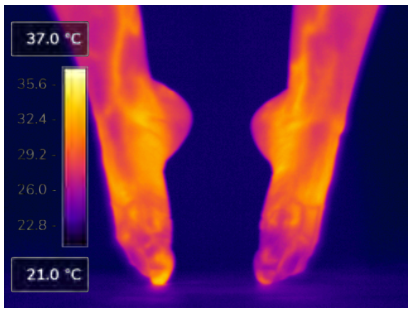

P8Q1A1T1_0354.jpg

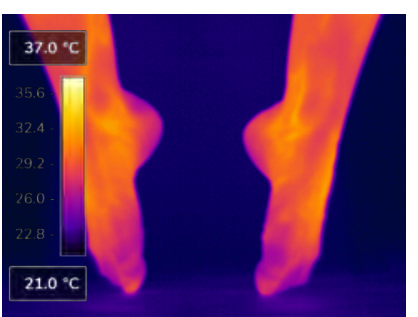

3.P8M2A3T3_0325.jpg

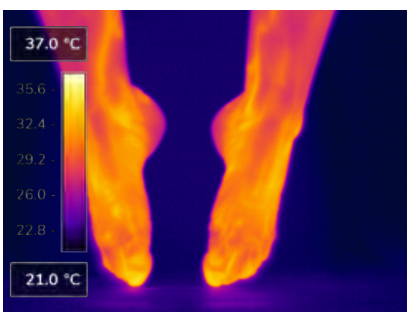

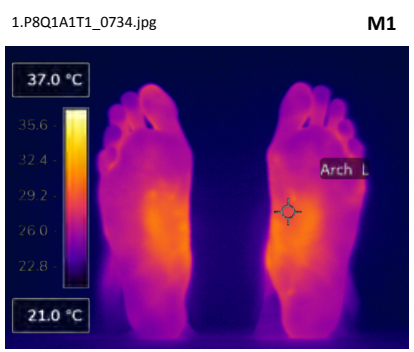

Measurements

\begin{tabular}{l|l} 
Arch L & $28.8^{\circ} \mathrm{C}$
\end{tabular}

2.P8M1A2T2_0771.jpg

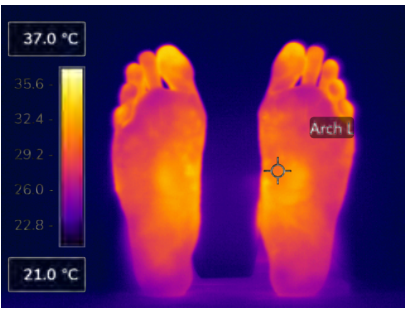

Measurements

\begin{tabular}{l|l} 
Arch L & $30.3^{\circ} \mathrm{C}$
\end{tabular}

1.P8Q1A1T1_0734.jpg

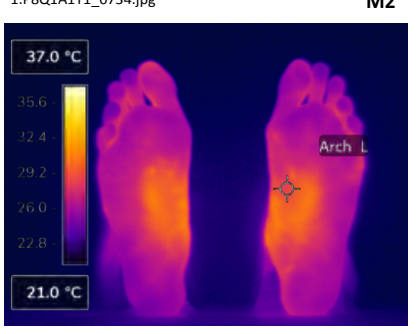

Measurements

Arch

3.Р8M2А3T3_0704.jpg

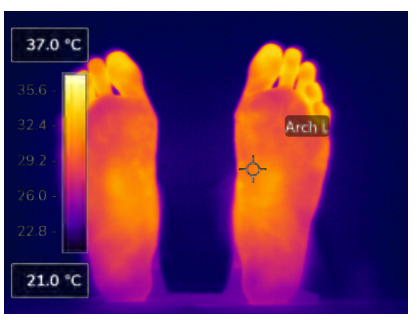

Measurements

Arch L 


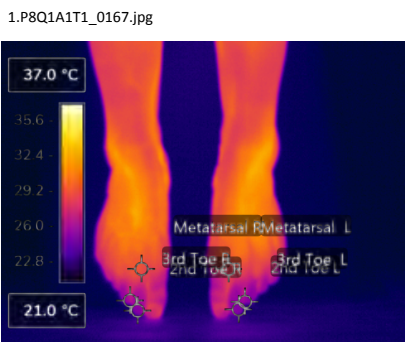

Measurements
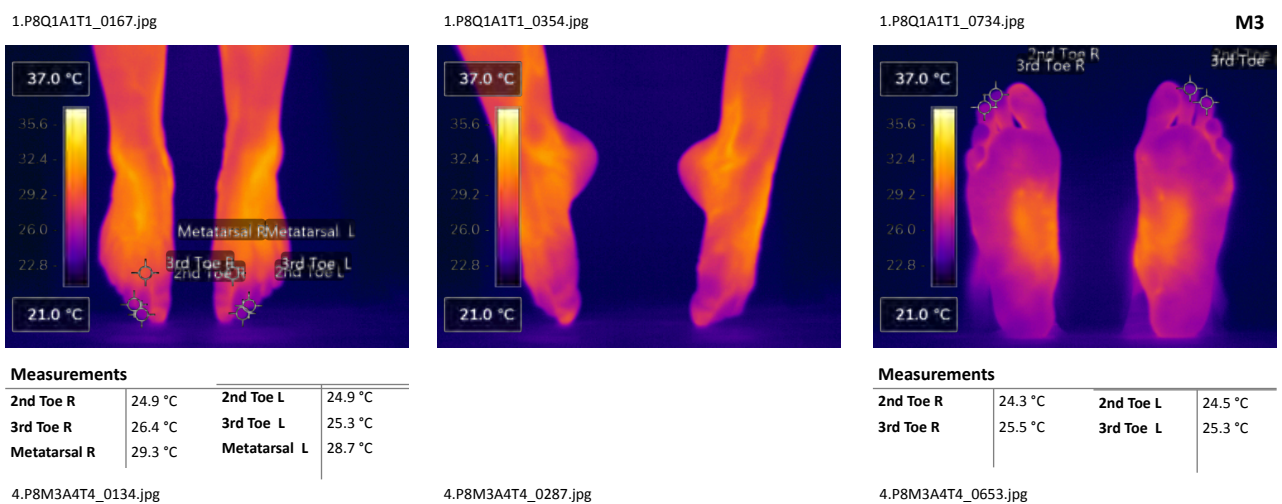

Measurements

\begin{tabular}{l|lll|l}
\hline 2nd Toe $\mathrm{R}$ & $24.3^{\circ} \mathrm{C}$ & 2nd Toe $\mathrm{L}$ & $24.5^{\circ} \mathrm{C}$ \\
\hline
\end{tabular} \begin{tabular}{l|ll|l} 
3rd Toe R & $25.5^{\circ} \mathrm{C}$ & 3rd Toe L & $25.3^{\circ} \mathrm{C}$
\end{tabular}

4.P8M3A4T4_0134.jpg

4.P8M3A4T4_0287.jpg
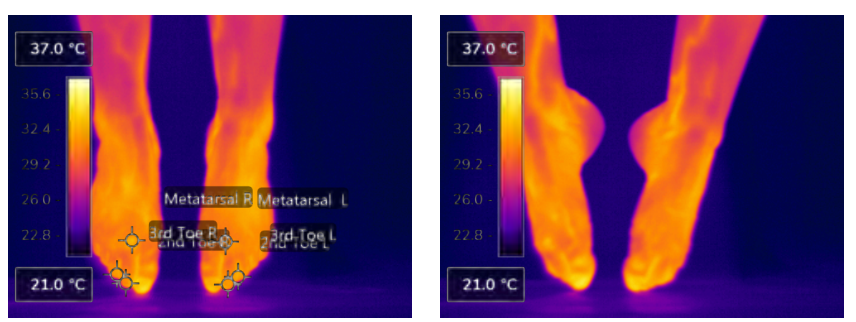

4.P8M3A4T4_0653.jpg

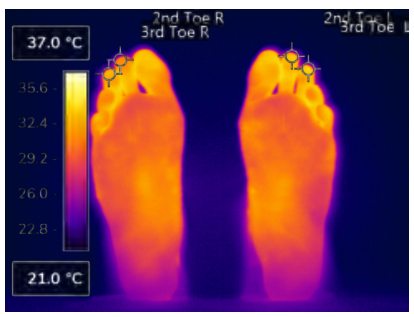

Measurements

\begin{tabular}{l|ll|l}
\hline 2nd Toe $\mathrm{R}$ & $31.2^{\circ} \mathrm{C}$ & 2nd Toe $\mathrm{L}$ & $31.9^{\circ} \mathrm{C}$ \\
\hline
\end{tabular}

\begin{tabular}{l|lll} 
3rd Toe R & $31.9^{\circ} \mathrm{C}$ & 3 rd Toe L & $32.2^{\circ} \mathrm{C}$
\end{tabular}

$\begin{array}{lll}\text { Metatarsal R } & 33.1^{\circ} \mathrm{C} \quad \text { Metatarsal L } & 31.2^{\circ} \mathrm{C}\end{array}$

P9

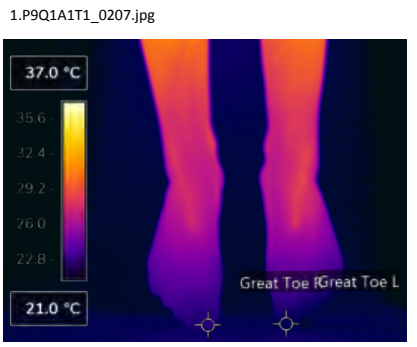

Measurements

\begin{tabular}{l|l}
\hline Great Toe R & $22.8^{\circ} \mathrm{C}$ \\
Gea & \\
\hline
\end{tabular}

\begin{tabular}{l|l} 
Great Toe L & $21.9^{\circ} \mathrm{C}$
\end{tabular}
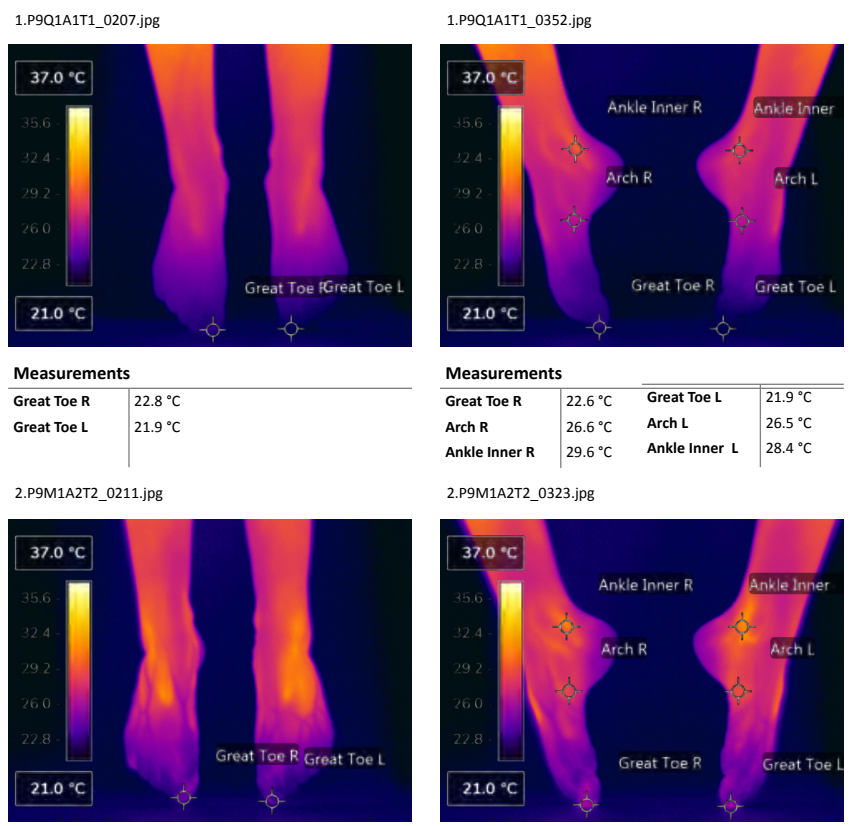

Measurements

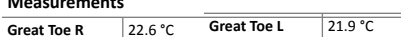

\begin{tabular}{l|ll|l|}
\hline Great Toe R & $22.6^{\circ} \mathrm{C}$ & Great Toe L & $21.9^{\circ} \mathrm{C}$ \\
Arch R & $26.6^{\circ} \mathrm{C}$ & Arch L & $26.5^{\circ} \mathrm{C}$ \\
\hline
\end{tabular}

\begin{tabular}{l|ll|l} 
Arch R & $26.6^{\circ} \mathrm{C}$ & Arch L & $26.5^{\circ} \mathrm{C}$ \\
Ankle Inner R & $29.6^{\circ} \mathrm{C}$ & Ankle Inner L & $28.4^{\circ} \mathrm{C}$
\end{tabular}

2.P9M1A2T2_0323.jpg

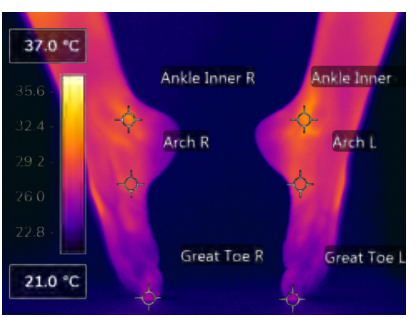

Measurements

\begin{tabular}{l|l} 
Great Toe R & $24.0^{\circ} \mathrm{C}$ \\
Ge
\end{tabular}

Measurements

\begin{tabular}{l|ll|l}
\hline Great Toe R & $25.9^{\circ} \mathrm{C}$ & Great Toe $\mathrm{L}$ & $25.9^{\circ} \mathrm{C}$
\end{tabular}

\begin{tabular}{l|l|l|l|}
\hline Ankle Inner R & $30.7^{\circ} \mathrm{C}$ & Ankle Inner $\mathrm{L}$ & $31.1^{\circ} \mathrm{C}$
\end{tabular}

\begin{tabular}{l|ll|l} 
Arch R & $28.7^{\circ} \mathrm{C}$ & Arch L & $29.1^{\circ} \mathrm{C}$
\end{tabular}

1.P9Q1A1T1_0792.jpg

M1

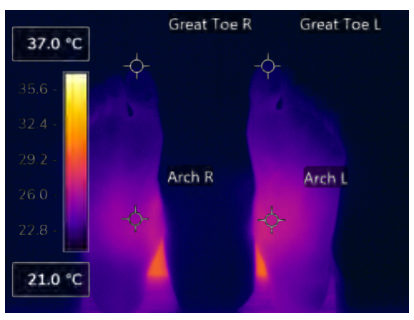

Measurements

\begin{tabular}{l|l|l|l|}
\hline Great Toe R & $21.5^{\circ} \mathrm{C}$ & Great Toe L & $22.1^{\circ} \mathrm{C}$ \\
\hline
\end{tabular} \begin{tabular}{|l|l|l|l|}
\hline Great Toe R & $21.5^{\circ} \mathrm{C}$ & Great Toe $\mathrm{L}$ & $22.1{ }^{\circ} \mathrm{C}$ \\
Arch R & $25.5^{\circ} \mathrm{C}$ & Arch L & $26.8^{\circ} \mathrm{C}$
\end{tabular}

2.P9M1A2T2_0631.jpg

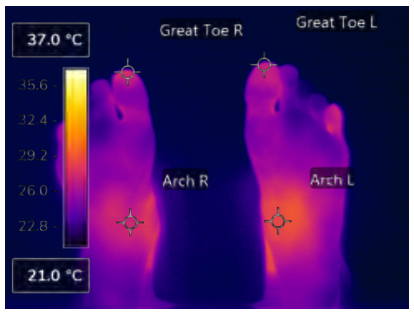

Measurements

\begin{tabular}{l|l} 
Great Toe R & $27.9^{\circ} \mathrm{C}$ \\
\hline
\end{tabular}

\begin{tabular}{l|l} 
Arch R & $27.7^{\circ} \mathrm{C}$ \\
\hline
\end{tabular}

Great Toe L $\quad 27.1^{\circ} \mathrm{C}$

\begin{tabular}{l|l} 
Arch L & $28.9^{\circ} \mathrm{C}$
\end{tabular} 


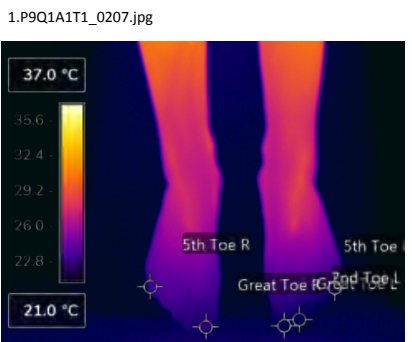

Measurements

\begin{tabular}{l|ll|l}
\hline Great Toe R & $22.8^{\circ} \mathrm{C}$ & Great Toe $\mathrm{L}$ & $21.9^{\circ} \mathrm{C}$ \\
5th Toe R & $23.3^{\circ} \mathrm{C}$ & 2nd Toe L & $22.0^{\circ} \mathrm{C}$ \\
& & 5th Toe L & $22.4^{\circ} \mathrm{C}$
\end{tabular}

3.P9M2А3T3_0058.jpg
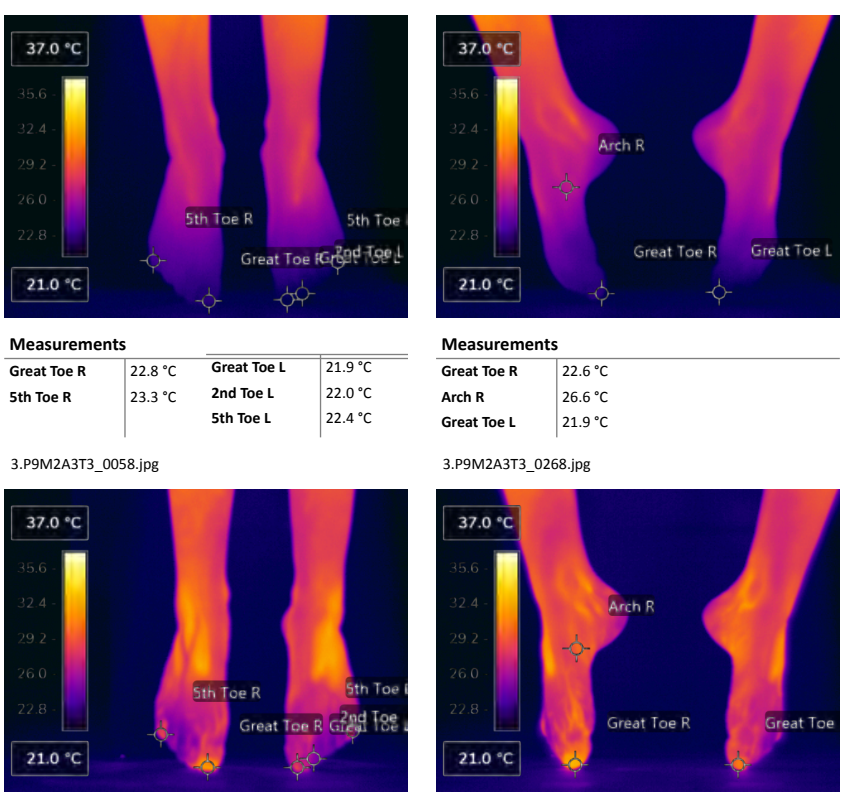

Measurements

\begin{tabular}{l|l}
\hline Great Toe R & $22.6^{\circ} \mathrm{C}$ \\
\hline Arth R & $26.6{ }^{\circ} \mathrm{C}$
\end{tabular}

\begin{tabular}{l|l} 
Arch R & $26.6^{\circ} \mathrm{C}$ \\
& $21.9^{\circ} \mathrm{C}$
\end{tabular}

\begin{tabular}{l|l} 
Great Toe L & $21.9^{\circ} \mathrm{C}$
\end{tabular}

3.P9M2А3Т3_0268.jpg

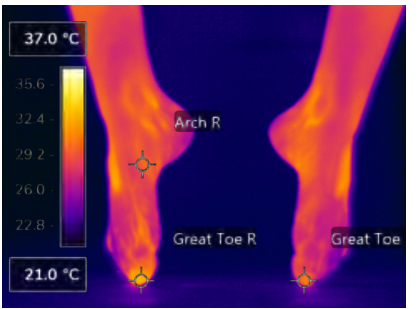

Measurements

\begin{tabular}{l|ll|l} 
Great Toe R & $31.9^{\circ} \mathrm{C}$ & Great Toe $\mathrm{L}$ & $28.5^{\circ} \mathrm{C}$ \\
& $28.5^{\circ} \mathrm{C}$ & 2nd & \\
\hline
\end{tabular}

5th Toe $\mathrm{R}$

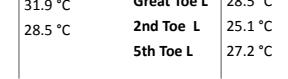

Measurements

\begin{tabular}{l|l}
\hline Great Toe R & $32.7^{\circ} \mathrm{C}$ \\
\hline & 30.0
\end{tabular}

\begin{tabular}{l|l} 
Arch R & $30.0^{\circ} \mathrm{C}$ \\
\hline
\end{tabular}

$\begin{array}{ll}\text { Great Toe L } & 30.8^{\circ} \mathrm{C}\end{array}$

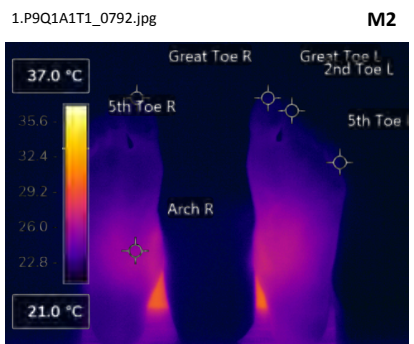

Measurements

\begin{tabular}{l|llll}
\hline Great Toe R & $21.5^{\circ} \mathrm{C}$ & Great Toe L & $22.1{ }^{\circ} \mathrm{C}$ \\
\hline
\end{tabular} \begin{tabular}{l|lll}
\hline 5th Toe R & $22.2^{\circ} \mathrm{C}$ & 5 th Toe L & $21.6^{\circ} \mathrm{C}$
\end{tabular} \begin{tabular}{l|ll|l} 
5th Toe R & $22.2^{\circ} \mathrm{C}$ & 5th Toe L & $21.6^{\circ} \mathrm{C}$ \\
Arch R & $25.5^{\circ} \mathrm{C}$ & 2nd Toe L & $21.6^{\circ} \mathrm{C}$
\end{tabular}

3.P9M2A3T3_0625.jpg

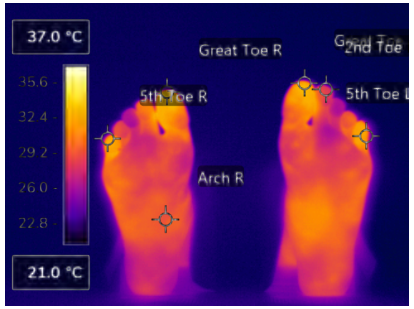

Measurements

\begin{tabular}{l|ll|l}
\hline Great Toe $\mathrm{R}$ & $32.9^{\circ} \mathrm{C}$ & Great Toe $\mathrm{L}$ & $32.4^{\circ} \mathrm{C}$ \\
\hline
\end{tabular}

\begin{tabular}{l|lll} 
Arch $R$ & $29.4^{\circ} \mathrm{C}$ & 2nd Toe $L$ & $28.4^{\circ} \mathrm{C}$
\end{tabular}

\begin{tabular}{l|ll|l} 
5th Toe R & $31.8^{\circ} \mathrm{C}$ & 5 th Toe $\mathrm{L}$ & $31.3^{\circ} \mathrm{C}$
\end{tabular}
P9

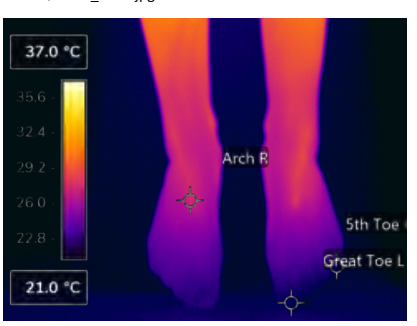

Measurements

$$
\text { Arch R }
$$

5th Toe L

Great Toe L

4.P9M3A4T4_0132.jpg

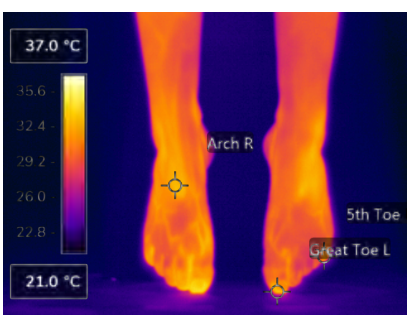

Measurements

\begin{tabular}{l|l} 
Arch R & $33.1^{\circ} \mathrm{C}$ \\
& $31.5^{\circ} \mathrm{C}$
\end{tabular}

5th Toe L $\quad 31.5^{\circ} \mathrm{C}$

Great Toe L
1.P9Q1A1T1_0352.jpg

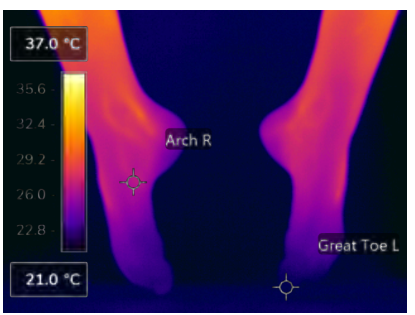

Measurements

Arch $R$

\begin{tabular}{l|l} 
Great Toe L & $21.9^{\circ} \mathrm{C}$
\end{tabular}

4.P9M3A4T4_0217.jpg

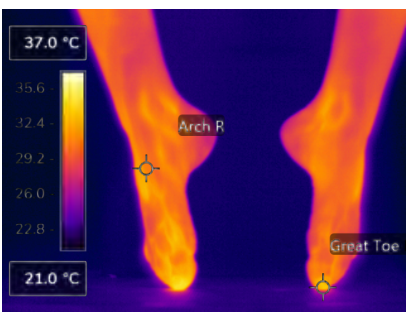

Measurements

Arch R $30.9^{\circ} \mathrm{C}$
$33.6^{\circ} \mathrm{C}$

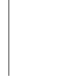

1.P9Q1A1T1_0792.jpg

M3

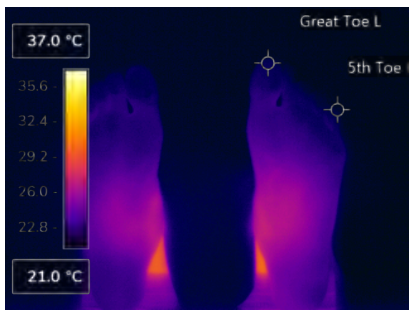

Measurements

\begin{tabular}{l|l}
\hline Great Toe L & $22.1^{\circ} \mathrm{C}$
\end{tabular}

\begin{tabular}{l|l} 
5th Toe L & $21.4^{\circ} \mathrm{C}$ \\
\end{tabular}

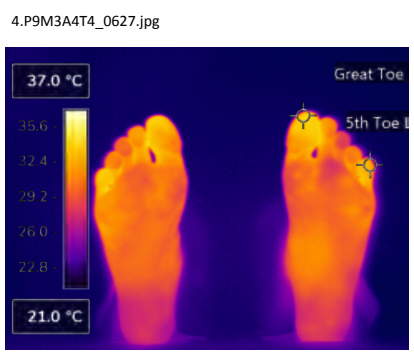

Measurements

\begin{tabular}{l|l}
\hline Great Toe L & $33.9^{\circ} \mathrm{C}$ \\
\hline & $32.6^{\circ} \mathrm{C}$
\end{tabular}

$\begin{array}{ll}\text { 5th Toe } \mathrm{L} & 32.6^{\circ} \mathrm{C}\end{array}$ 


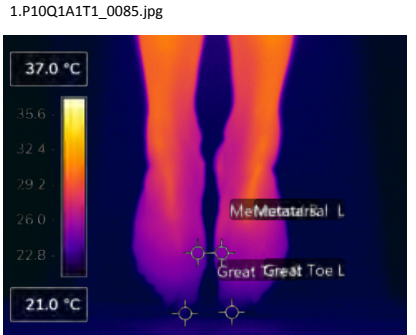

Measurements

\begin{tabular}{l|l}
\hline Great Toe R & $22.0^{\circ} \mathrm{C}$ \\
\hline
\end{tabular}

Metatarsal R $24.6^{\circ} \mathrm{C}$

\begin{tabular}{lll} 
& Great Toe L & $22.2^{\circ} \mathrm{C}$ \\
\hline & &
\end{tabular}

$\begin{array}{ll}\text { Metatarsal L } & 25.0^{\circ} \mathrm{C}\end{array}$

2.P10M1A2T2_0096.jpg

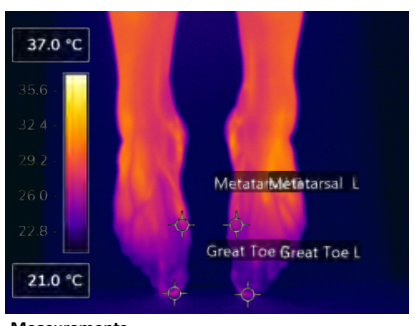

Measurements

\begin{tabular}{l|l}
\hline Great Toe R & $26.9^{\circ} \mathrm{C}$ \\
& $26.4^{\circ} \mathrm{C}$
\end{tabular}

\begin{tabular}{ll} 
Metatarsal R $\quad 26.4^{\circ} \mathrm{C}$ \\
\hline
\end{tabular}

\begin{tabular}{l|l} 
Great Toe L & $25.7^{\circ} \mathrm{C}$ \\
\hline
\end{tabular}

$\begin{array}{ll}\text { Metatarsal L } & 26.2^{\circ} \mathrm{C}\end{array}$

P10

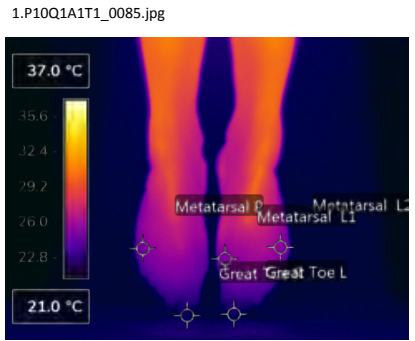

Measurements

\begin{tabular}{l|l} 
Great Toe R & $22.0^{\circ} \mathrm{C}$ \\
Met
\end{tabular}

\begin{tabular}{ll} 
Metatarsal R $24.8^{\circ} \mathrm{C}$ \\
\hline
\end{tabular}

\begin{tabular}{l|l} 
Great Toe L & $22.2^{\circ} \mathrm{C}$ \\
\hline
\end{tabular}

Metatarsal L1 $25.0^{\circ} \mathrm{C}$

Metatarsal L2 $25.2^{\circ} \mathrm{C}$

3.P10M2A3T3_0070.jpg

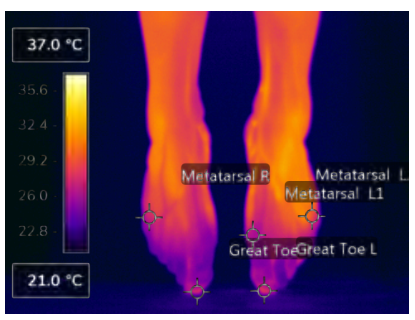

Measurements

\begin{tabular}{l|lll|}
\hline Great Toe R & $27.4^{\circ} \mathrm{C}$ & Great Toe L & $28.0^{\circ} \mathrm{C}$
\end{tabular}

\begin{tabular}{l|lll} 
Metatarsal R & $27.5^{\circ} \mathrm{C}$ & Metatarsal L1 & $28.4^{\circ} \mathrm{C}$
\end{tabular}
1.P10Q1A1T1_0222.jpg

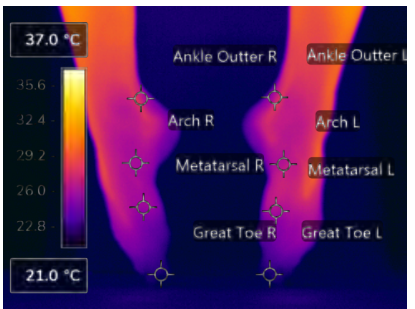

Measurements

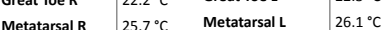
\begin{tabular}{l|lll} 
Metatarsal R & $25.7{ }^{\circ} \mathrm{C}$ & Metarch & $26.1^{\circ} \mathrm{C}$ \\
Arch R & $260^{\circ} \mathrm{C}$ & Arch & $26.6^{\circ} \mathrm{C}$
\end{tabular} \begin{tabular}{l|ll|l} 
Arch R & $26.0^{\circ} \mathrm{C}$ & Arch L & $26.6^{\circ} \mathrm{C}$ \\
Ankle Outter R & $27.3^{\circ} \mathrm{C}$ & Ankle Outter $\mathrm{L}$ & $26.8^{\circ} \mathrm{C}$
\end{tabular}

Anke Outer R $27.3{ }^{\circ} \mathrm{C}$

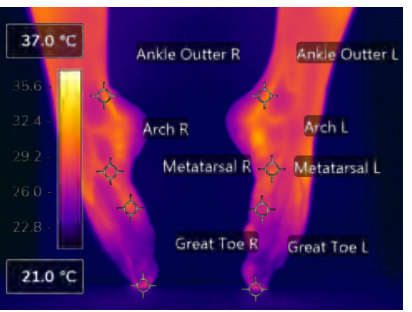

Measurements

\begin{tabular}{l|ll|l}
\hline Great Toe R & $27.4^{\circ} \mathrm{C}$ & Great Toe L & $26.4^{\circ} \mathrm{C}$ \\
\end{tabular} \begin{tabular}{l|lll} 
Metatarsal R & $28.9^{\circ} \mathrm{C}$ & Metatarsal L & $27.1^{\circ} \mathrm{C}$
\end{tabular}

$\begin{array}{llll}\text { Arch R } & 28.1^{\circ} \mathrm{C} & \text { Arch L } & 29.0^{\circ} \mathrm{C}\end{array}$

$\begin{array}{lll}\text { Ankle Outter R } & 30.2^{\circ} \mathrm{C}\end{array}$

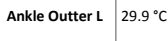

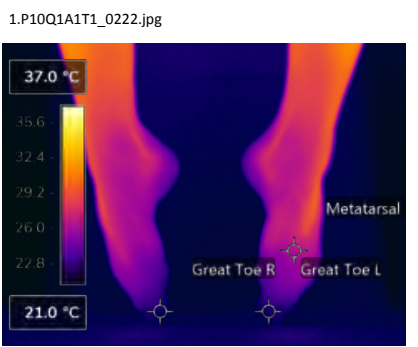

Measurements

\begin{tabular}{l|l} 
Great Toe R & $22.2^{\circ} \mathrm{C}$ \\
\end{tabular}

\begin{tabular}{lll} 
Great Toe $\mathrm{L}$ & $22.3^{\circ} \mathrm{C}$ \\
& & \\
\hline
\end{tabular}

Metatarsal L $\quad 26.3^{\circ} \mathrm{C}$

3.P10M2A3T3_0179.jpg

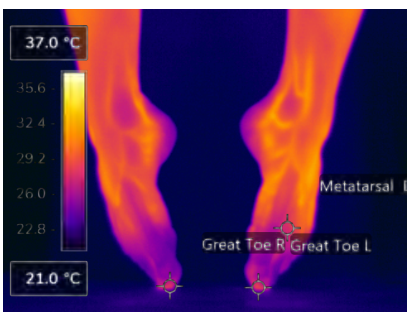

Measurements

\begin{tabular}{l|l|l|}
\hline Great Toe R & $28.1^{\circ} \mathrm{C}$ \\
\hline Get &
\end{tabular}

\begin{tabular}{l|l} 
Great Toe L & $28.4^{\circ} \mathrm{C}$ \\
&
\end{tabular}

$\begin{array}{ll}\text { Metatarsal L } & 27.8^{\circ} \mathrm{C}\end{array}$
1.P10Q1A1T1_0564.jpg

M1

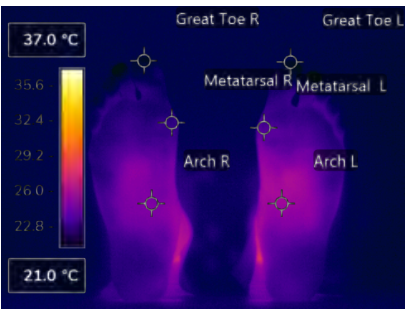

Measurements

\begin{tabular}{l|ll|l}
\hline Great Toe R & $21.3^{\circ} \mathrm{C}$ & Great Toe $\mathrm{L}$ & $21.3^{\circ} \mathrm{C}$
\end{tabular} $\begin{array}{llll}\text { Metatarsal R } & 22.9^{\circ} \mathrm{C} & \text { Metatarsal L } & 23.4^{\circ} \mathrm{C}\end{array}$ \begin{tabular}{l|ll|l} 
Arch R & $24.9^{\circ} \mathrm{C}$ & Arch L & $25.7^{\circ} \mathrm{C}$
\end{tabular}

2.P10M1A2T2_0652.jpg

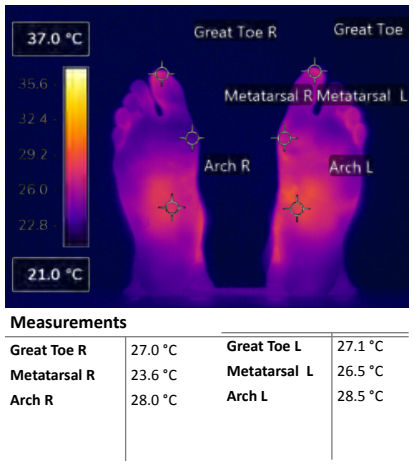

1.P10Q1A1T1_0564.jpg

M2

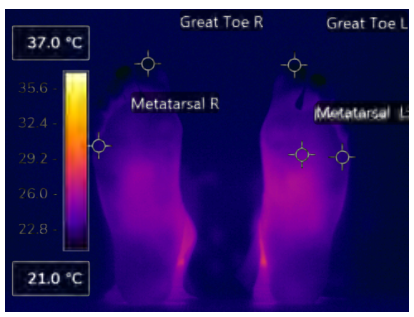

Measurements

\begin{tabular}{l|l}
\hline Great Toe R & $21.3^{\circ} \mathrm{C}$ \\
\hline
\end{tabular}

$\begin{array}{ll}\text { Metatarsal R } & 22.6^{\circ} \mathrm{C} \\ & \end{array}$

\begin{tabular}{ll} 
Great Toe L & $21.3^{\circ} \mathrm{C}$ \\
\hline
\end{tabular}

Metatarsal L1 $22.7^{\circ} \mathrm{C}$

$\begin{array}{ll}\text { Metatarsal L2 } & 24.4^{\circ} \mathrm{C}\end{array}$

3.P10M2A3T3_0510.jpg

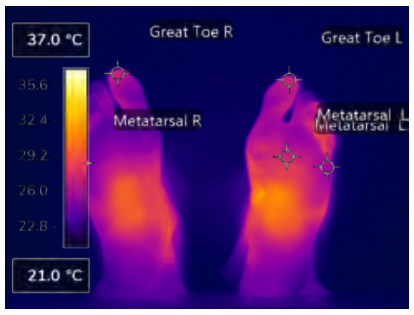

Measurements

\begin{tabular}{l|ll|l}
\hline Great Toe R & $27.3^{\circ} \mathrm{C}$ & Great Toe L & $27.4^{\circ} \mathrm{C}$
\end{tabular} \begin{tabular}{l|lll} 
Metatarsal R & $23.7^{\circ} \mathrm{C}$ & Metatarsal L1 & $25.9^{\circ} \mathrm{C}$
\end{tabular} 
1.P10Q1A1T1_0085.jpg

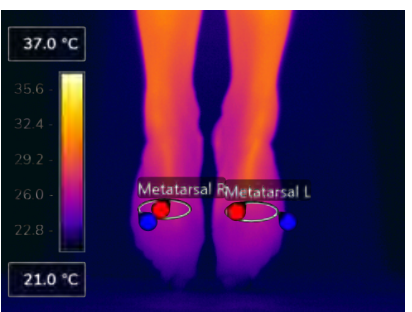

Measurements Metatarsal R

Avg

Metatarsa

Avg

4.P10M3A4TA.P10Q2A5T5_0089.jpg

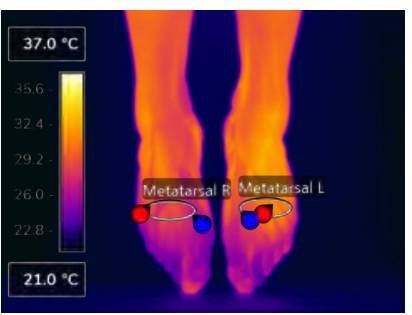

Measurements

Metatarsal R

Avs

Metatarsal

Avg
1.P10Q1A1T1_0222.jpg

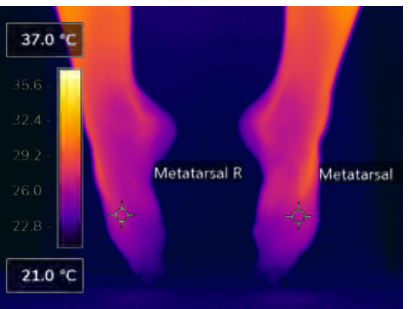

Measurements

\begin{tabular}{l|l}
\hline Metatarsal R & $26.7^{\circ} \mathrm{C}$ \\
& $26.4^{\circ} \mathrm{C}$
\end{tabular}

$26.4^{\circ} \mathrm{C}$

3.P10M2A3T3_0179.jpg

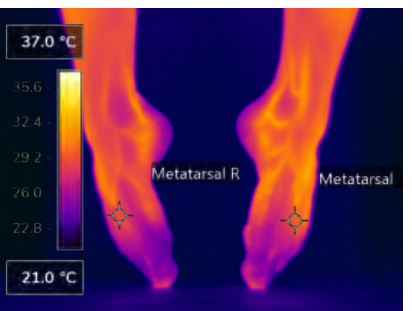

Measurements

\begin{tabular}{l|l}
\hline Metatarsal R & $29.2^{\circ} \mathrm{C}$ \\
Metatarsal L & $29.7^{\circ} \mathrm{C}$
\end{tabular}

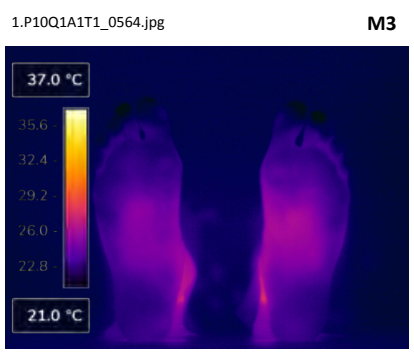

4.P10M3A4TA.P10Q2A5T5_0632.jpg

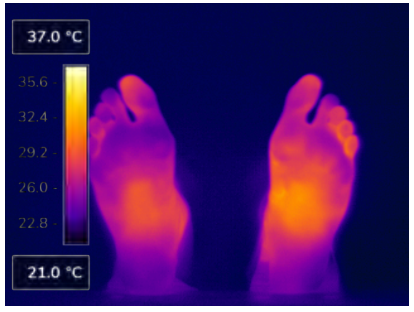




\section{H.5 Average Delta T and Average Discomfort Rating Results}

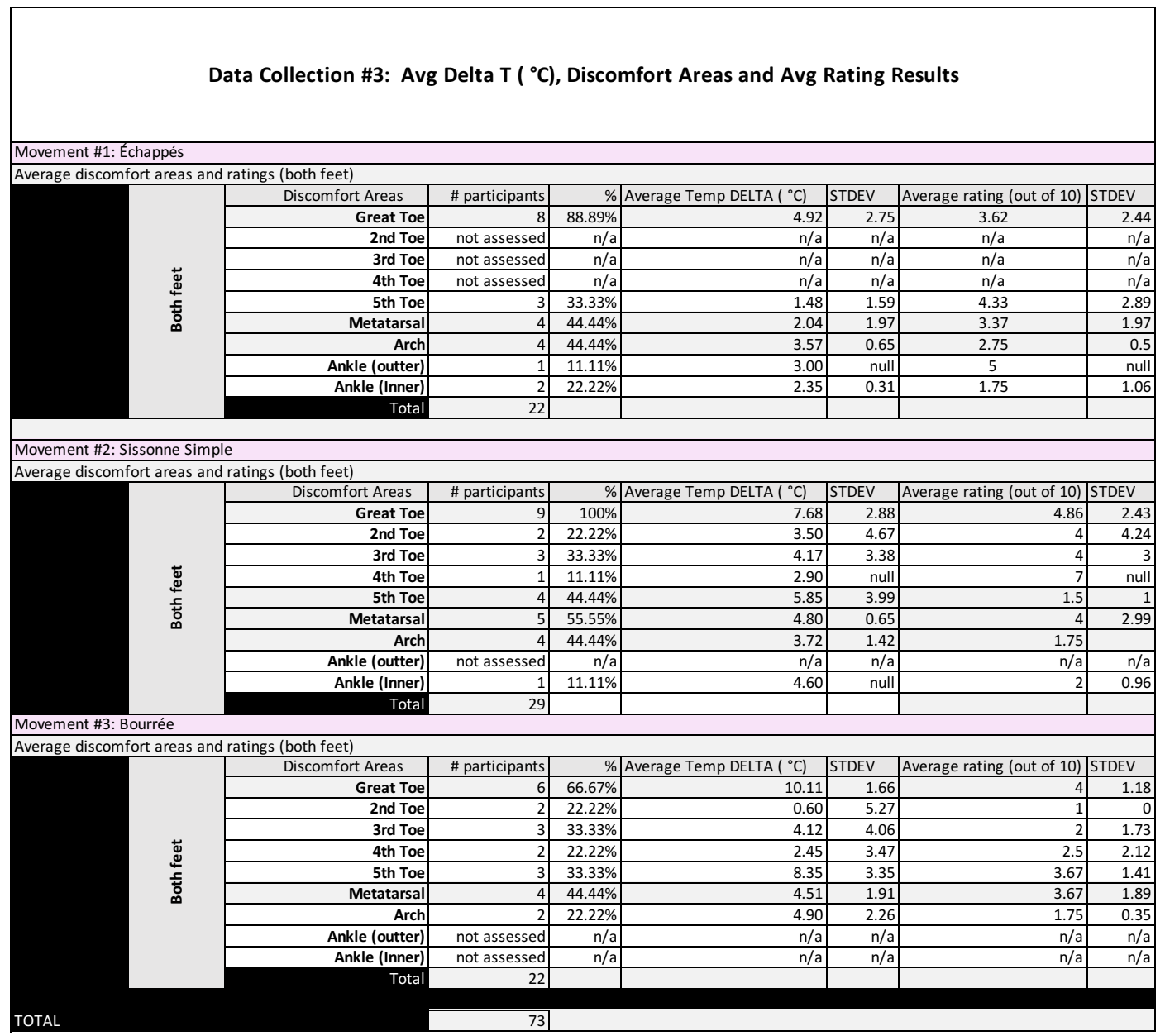


H.6 Pre-test Questionnaire Results

\begin{tabular}{|c|c|c|c|}
\hline \multicolumn{4}{|c|}{ Results \#1: Introductory Questionnaire } \\
\hline \multicolumn{4}{|c|}{ SECTION 1: BACKGOUND } \\
\hline \multirow{2}{*}{ Q1 Results } & Started ballet (Age) & Average & Standard Deviation \\
\hline & Started ballet (Age) & 4.78 age & 2.71 age difference \\
\hline \multirow{2}{*}{ Q2 Results } & Pointe Experience (Years) & Average & Standard Deviation \\
\hline & Pointe Experience (Years) & 7.44 years & 4.37 years difference \\
\hline \multirow[t]{6}{*}{ Q3 Results } & Current pointe class level & Totals & Percentage \\
\hline & Intermediate & 1 & $11.00 \%$ \\
\hline & Advanced & 6 & $66.00 \%$ \\
\hline & Pre-professional & 2 & $22.00 \%$ \\
\hline & Beginner & 0 & $0 \%$ \\
\hline & Professional & 0 & $0 \%$ \\
\hline \multirow[t]{5}{*}{ Q4 Results } & Current ballet technique & Totals & Percentage \\
\hline & Other & 1 & $11.00 \%$ \\
\hline & RAD & 4 & $44.00 \%$ \\
\hline & Vaganova & 4 & $44.00 \%$ \\
\hline & Cecchetti & 0 & $0 \%$ \\
\hline \multirow[t]{9}{*}{ Q5 Results } & Dance genres currently practicing & Totals & Percentage \\
\hline & None & 0 & $0 \%$ \\
\hline & Jazz & 9 & $100.00 \%$ \\
\hline & Tap Dance & 2 & $22.00 \%$ \\
\hline & Hip Hop & 4 & $44.00 \%$ \\
\hline & Modern & 5 & $55.00 \%$ \\
\hline & Contemporary & 7 & $77.00 \%$ \\
\hline & Breakdancing & 0 & $0 \%$ \\
\hline & Other & 2 & $22.00 \%$ \\
\hline \multicolumn{4}{|c|}{ SECTION 2: PRACTICE } \\
\hline \multirow[t]{5}{*}{ Q1 Results } & Pointe work readiness & Totals & Percentage \\
\hline & Was advised by my teacher & 8 & $78.00 \%$ \\
\hline & Tried it on my own & 0 & $0 \%$ \\
\hline & Professional screening by doctors & 1 & $11.00 \%$ \\
\hline & Other & 0 & $0 \%$ \\
\hline \multirow[t]{4}{*}{ Q2 Results } & Ways of practicing pointe work & Totals & Percentage \\
\hline & In class with a teacher & 9 & $100.00 \%$ \\
\hline & by myself & 4 & $44 \%$ \\
\hline & All of the above & 4 & $44 \%$ \\
\hline \multirow[t]{2}{*}{ Q3 Results } & Practice hours/week & Average & Standard Deviation \\
\hline & Practice hours/week & 5.55 hours & 5.85 hours difference \\
\hline \multirow[t]{2}{*}{ Q4 Results } & Practice hours alone & Average & Standard Deviation \\
\hline & Practice hours alone & 0.89 hours & 1.20 hours difference \\
\hline \multirow[t]{6}{*}{ Q5 Results } & Strongest foot en pointe & Totals & Percentage \\
\hline & Right foot & 4 & $44.00 \%$ \\
\hline & Left foot & 1 & $11.00 \%$ \\
\hline & Both & 2 & $22.00 \%$ \\
\hline & Uncertain & 2 & $22.00 \%$ \\
\hline & None & 0 & $0 \%$ \\
\hline
\end{tabular}


H.6 Pre-test Questionnaire Results

\begin{tabular}{|c|c|c|c|}
\hline \multicolumn{4}{|c|}{ SECTION 3: POINTE SHOES } \\
\hline \multirow{5}{*}{ Q1 Results } & Brand used in testing & Totals & Percentage \\
\hline & Gaynor Minden & 3 & $33.00 \%$ \\
\hline & Block & 3 & $33.00 \%$ \\
\hline & Other & 3 & $33.00 \%$ \\
\hline & Capezio, Sansha, Grishko,Freed & 0 & $0 \%$ \\
\hline \multirow[t]{5}{*}{ Q2 Results } & Condition & Totals & Percentage \\
\hline & Brand new & 0 & $0 \%$ \\
\hline & New & 0 & $0 \%$ \\
\hline & Used & 9 & $100.00 \%$ \\
\hline & Uncertain & 0 & $0 \%$ \\
\hline \multirow[t]{7}{*}{ Q3 Results } & Influencers on pointe shoes brand & Totals & Percentage \\
\hline & Myself & 3 & $33.00 \%$ \\
\hline & My teacher/The dance school & 1 & $11.00 \%$ \\
\hline & The pointe shoe fitter & 5 & $55.00 \%$ \\
\hline & My parents & 0 & $0 \%$ \\
\hline & My peers/My dancer friends & 0 & $0 \%$ \\
\hline & Other & 0 & $0 \%$ \\
\hline \multirow[t]{2}{*}{ Q4 Results } & \# pointe shoes used/last year & Average & Standard Deviation \\
\hline & \# pointe shoes used/last year & 4.55 shoes & 3.56 shoes difference \\
\hline \multirow[t]{2}{*}{ Q5 Results } & \# pointe shoes used for comfort en pointe & Average & Standard Deviation \\
\hline & $\#$ pointe shoes used for comfort en pointe & 2.89 shoes & 1.37 shoes difference \\
\hline \multirow[t]{7}{*}{ Q6 Results } & Knowing when to buy new pointe shoes & Totals & Percentage \\
\hline & When, my shoes loose structure and are soft & 9 & $100.00 \%$ \\
\hline & When, my shoes are dirty & 1 & $11.00 \%$ \\
\hline & When, I feel discomfort & 2 & $22.00 \%$ \\
\hline & When, my teacher tells me to & 0 & $0 \%$ \\
\hline & Uncertain & 0 & $0 \%$ \\
\hline & Other & 0 & $0 \%$ \\
\hline
\end{tabular}


H.6 Pre-test Questionnaire Results

\begin{tabular}{|c|c|c|c|}
\hline \multicolumn{4}{|c|}{ SECTION 4: USUAL Discomfort (When dancing en pointe) } \\
\hline \multirow[t]{5}{*}{ Q1 Results } & Feeling discomfort & Totals & Percentage \\
\hline & Yes & 4 & $44 \%$ \\
\hline & Maybe & 4 & $44 \%$ \\
\hline & Uncertain & 1 & $11.00 \%$ \\
\hline & No & 0 & $0 \%$ \\
\hline \multirow[t]{6}{*}{ Q2 Results } & Feet & Totals & Percentage \\
\hline & Left foot & 0 & $0 \%$ \\
\hline & Right foot & 0 & $0 \%$ \\
\hline & Both feet & 6 & $66.00 \%$ \\
\hline & Uncertain & 3 & $33 \%$ \\
\hline & No discomfort & 0 & $0 \%$ \\
\hline \multirow[t]{2}{*}{ Q3 Results } & Intensity (out of 10) & Average & Standard Deviation \\
\hline & $\begin{array}{l}0=\text { No Discomfort } \\
10=\text { Most discomfort imaginable }\end{array}$ & 2.7 & 1.00 difference \\
\hline \multirow{7}{*}{ Q4 Results } & Areas & Totals & Percentage \\
\hline & Toes & 9 & $100.00 \%$ \\
\hline & Ankle & 1 & $11.00 \%$ \\
\hline & Arch & 2 & $22.00 \%$ \\
\hline & Metatarsals & 2 & $22.00 \%$ \\
\hline & Other & 0 & $0 \%$ \\
\hline & Nowhere & 0 & $0 \%$ \\
\hline \multirow[t]{5}{*}{ Q5 Results } & Frequency & Totals & Percentage \\
\hline & Always & 1 & $11.00 \%$ \\
\hline & Often & 3 & $0 \%$ \\
\hline & Sometimes & 5 & $55.00 \%$ \\
\hline & Never & 0 & $0 \%$ \\
\hline \multirow[t]{9}{*}{ Q5 Results } & Coping styles & Totals & Percentage \\
\hline & Take a break & 2 & $22.00 \%$ \\
\hline & Remove my shoes & 1 & $11.00 \%$ \\
\hline & Massage my feet & 2 & $22.00 \%$ \\
\hline & Ignore it and continue dancing & 6 & $66.00 \%$ \\
\hline & Add more padding & 2 & $22.00 \%$ \\
\hline & Take medicine & 0 & $0 \%$ \\
\hline & Other & 0 & $0 \%$ \\
\hline & I do not usually experience discomfort & 0 & $0 \%$ \\
\hline
\end{tabular}


H.7 Post-test Questionnaire Results

\begin{tabular}{|c|c|c|c|}
\hline \multicolumn{4}{|c|}{ Results \#5: Closing Questionnaire } \\
\hline \multicolumn{4}{|c|}{ SECTION 1: Post- testing DISCOMFORT (wearing pointe shoes while completing questionnaire) } \\
\hline \multirow[t]{6}{*}{ Q1 Results } & Feet & Totals & Percentage \\
\hline & Left foot & 2 & $22 \%$ \\
\hline & Right foot & 1 & $11 \%$ \\
\hline & Both feet & 5 & $55.00 \%$ \\
\hline & Uncertain & 0 & $0 \%$ \\
\hline & No discomfort & 1 & $11 \%$ \\
\hline \multirow[t]{2}{*}{ Q2 Results } & Intensity (out of 10) & Average & Standard Deviation \\
\hline & $\begin{array}{l}0=\text { No Discomfort } \\
10=\text { Most discomfort imaginable }\end{array}$ & 2.11 & 1.52 difference \\
\hline \multirow[t]{7}{*}{ Q3 Results } & Areas & Totals & Percentage \\
\hline & Toes & 8 & $88.00 \%$ \\
\hline & Ankle & 1 & $11.00 \%$ \\
\hline & Arch & 3 & $33.00 \%$ \\
\hline & Metatarsals & 0 & $0.00 \%$ \\
\hline & Other & 1 & $11.00 \%$ \\
\hline & Nowhere & 1 & $11.00 \%$ \\
\hline \multirow[t]{5}{*}{ Q4 Results } & Frequency & Totals & Percentage \\
\hline & Always & 0 & $0 \%$ \\
\hline & Often & 6 & $67 \%$ \\
\hline & Sometimes & 3 & $33.00 \%$ \\
\hline & Never & 0 & $0 \%$ \\
\hline \multirow[t]{9}{*}{ Q5 Results } & Coping Styles & Totals & Percentage \\
\hline & Take a break & 1 & $11.11 \%$ \\
\hline & Remove my shoes & 0 & $0 \%$ \\
\hline & Massage my feet & 0 & $0 \%$ \\
\hline & Ignore it and continue dancing & 9 & $100.00 \%$ \\
\hline & Add more padding & 0 & $0 \%$ \\
\hline & Take medicine & 0 & $0 \%$ \\
\hline & Other & 0 & $0 \%$ \\
\hline & I do not usually experience discomfort & 0 & $0 \%$ \\
\hline
\end{tabular}


H.7 Post-test Questionnaire Results

\begin{tabular}{|c|c|c|c|}
\hline \multicolumn{4}{|c|}{ SECTION 2: PAST INJURIES (when dancing en pointe) } \\
\hline \multirow[t]{3}{*}{ Q6 Results } & injury in pointe class affected en pointe work & Totals & Percentage \\
\hline & $\begin{array}{rr} & \text { Yes } \\
\end{array}$ & 6 & $66.00 \%$ \\
\hline & No & 3 & $33 \%$ \\
\hline \multirow[t]{2}{*}{ Q7 Results } & $\#$ injury in pointe class & Average & Standard Deviation \\
\hline & \# injury in pointe class & 2.1 injuries & 2.31 injuries difference \\
\hline \multirow[t]{7}{*}{ Q8 Results } & Dancing en pointe even if injured & Totals & Percentage \\
\hline & Definitely yes & 2 & $33.00 \%$ \\
\hline & Probably yes & 1 & $11.00 \%$ \\
\hline & Might or might not & 2 & $22.00 \%$ \\
\hline & Probably not & 1 & $11.00 \%$ \\
\hline & Definetely not & 0 & $0 \%$ \\
\hline & N/A - not injured & 2 & $22.00 \%$ \\
\hline \multicolumn{4}{|c|}{ SECTION 3: OVERALL EXPERIENCE } \\
\hline \multirow[t]{2}{*}{ Q1 Results } & Years continuing pointe work & Average & Standard Deviation \\
\hline & Years continuing pointe work & 2.66 years & 4.24 years difference \\
\hline \multirow[t]{2}{*}{ Q2 Results } & Experience during testing (out of 10 ) & Average & Standard Deviation \\
\hline & $\begin{array}{l}0=\text { Extremely unsatisfied } \\
10=\text { Extremely satisfied }\end{array}$ & 9.55 & 0.83 difference \\
\hline \multirow[t]{6}{*}{ Q3 Results } & Willingness to participate again & Totals & Percentage \\
\hline & Definitely yes & 5 & $55.00 \%$ \\
\hline & Probably yes & 4 & $44.00 \%$ \\
\hline & Might or might not & 0 & $0 \%$ \\
\hline & Probably not & 0 & $0 \%$ \\
\hline & Definetely not & 0 & $0 \%$ \\
\hline
\end{tabular}




\section{H.8 Data Triangulation Convergence Results}

DT Data Triangulation for all discomfort assessments

(Pre-test Questionnaire, Movement 1,Movement 2, Movement 3,Post-test Questionnaire)

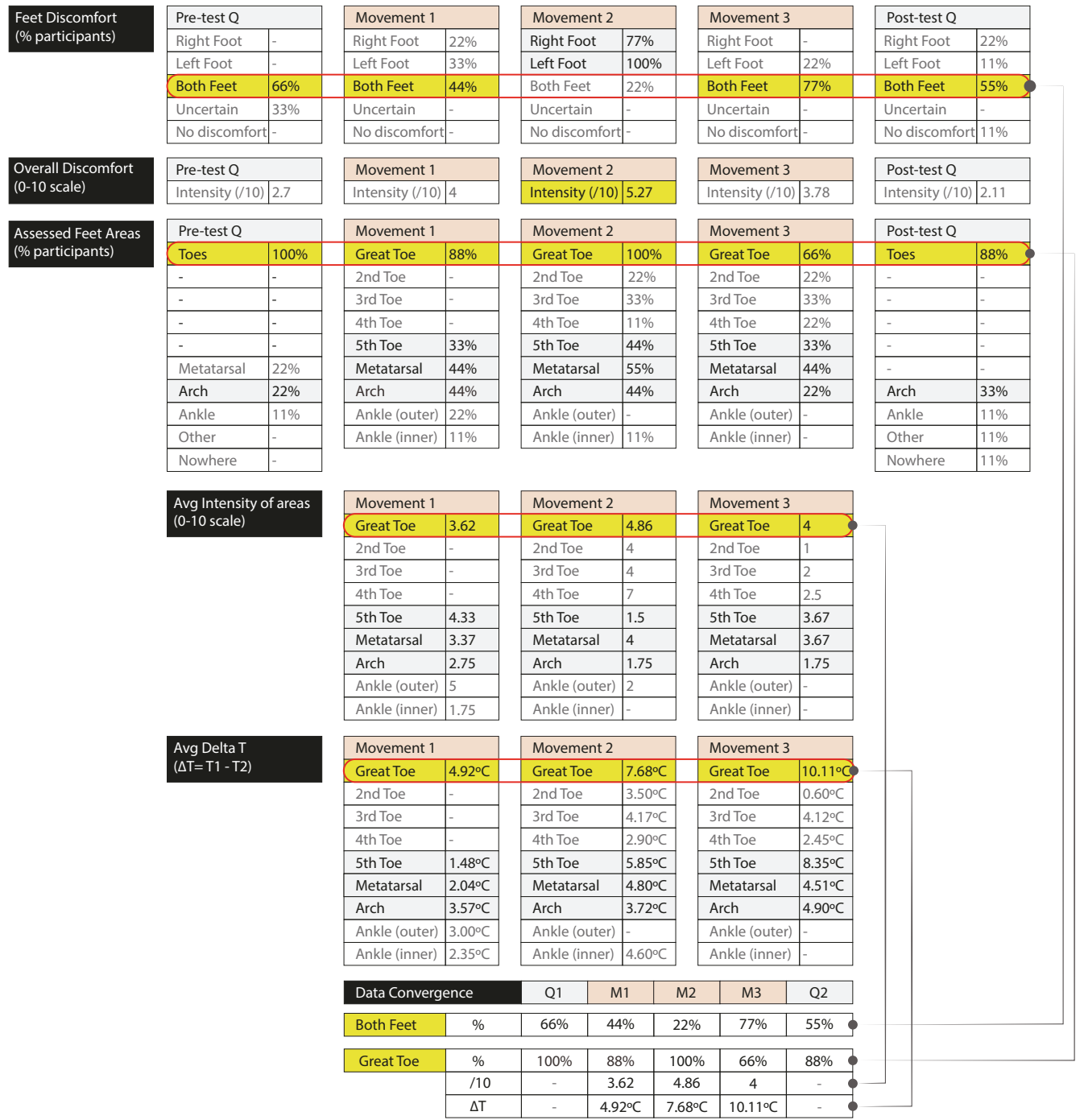

